\title{
A Comprehensive Review of Nanomaterials Developed Using Electrophoresis Process for High-Efficiency Energy Conversion and Storage Systems
}

\author{
Seok Hee Lee ${ }^{1,2,+}$, Sung Pil Woo ${ }^{3,+}$, Nitul Kakati $^{1} \oplus$, Dong-Joo Kim ${ }^{2} \oplus$ and Young Soo Yoon ${ }^{1, *}$ \\ 1 Department of Chemical and Biological Engineering, Gachon University, Seongnam-si 13120, Korea; \\ leesh@gachon.ac.kr (S.H.L.); nkakati@gachon.ac.kr (N.K.) \\ 2 Materials Research and Education Center, Auburn University, Auburn, AL 36849, USA; dkim@auburn.edu \\ 3 Department of Materials Science and Engineering, Yonsei University, Seoul 03722, Korea; \\ sungpil@yonsei.ac.kr \\ * Correspondence: benedicto@gachon.ac.kr; Tel.: +82-31-750-5596 \\ + These authors contributed equally to this work.
}

Received: 21 September 2018; Accepted: 2 November 2018; Published: 12 November 2018

check for updates

\begin{abstract}
Research carried out over the last few decades has shown that nanomaterials for energy storage and conversion require higher performance and greater stability. The nanomaterials synthesized by diverse techniques, such as sol-gel, hydrothermal, microwave, and co-precipitation methods, have brought energy storage and conversion systems to the center stage of practical application but they still cannot meet the capacity and mass production demands. Most reviews in the literature discuss in detail the issues related to nanomaterials with a range of structures synthesized using the above methods to enhance the performance. On the other hand, there have been few critical examinations of use of the electrophoresis process for the synthesis of nanomaterials for energy storage and conversion. The nanomaterials synthesized by electrophoresis processes related to colloidal interface science in the literature are compared according to the conditions to identify promising materials that are being or could be developed to satisfy the capacity and mass production demands. Therefore, a literature survey is of the use of electrophoresis deposition processes to synthesize nanomaterials for energy storage and conversion and the correlations of the electrophoresis conditions and properties of the resulting nanomaterials from a practical point of view.
\end{abstract}

Keywords: electrophoresis; colloidal interface; li-ion batteries; supercapacitor; solid oxide fuel cells; electrocatalysts

\section{Introduction}

Energy is essential in everyday life. In the future, sufficient and sustainable production of energy will be a prime issue. Currently, more than $80 \%$ of the energy used by society is supplied by fossil fuels, such as oil, coal and natural gas, none of which is renewable. Therefore, energy must be supplied by sustainable sources before fossil fuels are depleted. Although currently energy is produced from renewable natural sources, such as solar, wind, hydro, and geothermal heat, their energy sources are too limited in time and space to make a significant impact [1-4]. The use of electrochemical energy storage and conversion devices to allow the storage of surplus energy has attracted considerable attention. Currently electrochemical energy storage and conversion devices have been actively pursued for electric vehicle applications, but the devices still require durable and inexpensive sources to keep 
the maintenance cost low. On the other hand, it is almost impossible to find a device that fulfills all the requirements for practical application. The development of electrochemical energy storage and conversion devices of various types is a way to solve these problems and combine them in creative methods. The lithium ion battery is a type of rechargeable battery based on lithium ions moving between two electrodes [5-7]. During charging, lithium ions and electrons move from the cathode to the anode with the reverse process occurring during discharge. Because of their high energy density and efficiency, they are now used as a power supply for portable electronic devices. On the other hand, lithium ion batteries still require improvements of the energy density, durability, cost, and safety to be a practical power source for electric vehicles [8-10]. Supercapacitors are electrochemical capacitors that have much higher capacitance compared to conventional capacitors [11-14]. The supercapacitor is composed of two electrodes with a high specific surface area or redox active materials separated by an electrolyte. One type of supercapacitor, which is charged from ion adsorption and desorption, is known as an electric double layer capacitor. Another type of supercapacitor, which is charged by Faradic reactions, is called a pseudo-capacitor. Supercapacitors are appealing devices for power system applications but their energy density is much lower than that of lithium ion batteries. In contrast, a fuel cell is an electrochemical energy conversion device that supplies energy by fuel oxidation, hydrogen evolution reactions (HER), oxygen evolution reactions (OERs), and oxygen reduction reaction (ORRs) [15-18]. In addition, the activity and stability of the electrocatalysts in fuel cells need to be improved to increase their power density.

Over the past 20 years, considerable effort has been made to design advanced electrodes and electrocatalysts for electrochemical energy storage and conversion devices [19-24]. Recently, the application of electrophoresis techniques to design advanced electrodes for electrochemical energy storage and conversion devices has increased because it can form uniform deposits with control of the electrode thickness, nanostructured hybrid composites, and various 3D complex- and porous-structured electrodes [25-32]. In addition, electrophoresis techniques can be scaled-up to large product volumes and sizes. Electrophoresis is an important technology for colloidal processes [33,34]. Figure 1 presents a schematic diagram of the electrophoresis process.

(a)

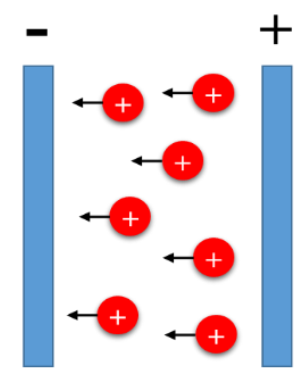

(b)

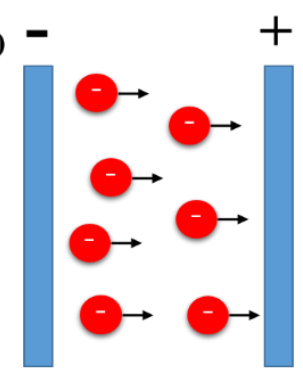

Figure 1. Schematic diagram of the electrophoresis process: (a) cathodic electrophoresis and (b) anodic electrophoresis.

Charged colloidal or larger particles suspended or dispersed in a medium migrate towards the electrode and deposit under an electric field. Two types of electrophoresis techniques can be defined depending on the surface charge of the suspended particles, as shown in Figure 1. If the particles are positively charged (Figure 1a), they will move towards the cathode, which is called cathodic electrophoresis. In contrast, if the charge particles are negatively charged, they will be attracted by the anode; this process is called anodic electrophoresis. Electrophoresis deposition (EPD) was developed by Ruess in 1808 [33] and it was first used in particle applications for deposition. EPD is largely used for the processing of traditional ceramics and restricted work was carried on the EPD of engineering ceramics [35]. In the last 10 years, however, the interest in EPD for advanced materials has increased significantly. In particular, the technique uses the fabrication of a coating, thin and thick films, the shaping of bulk ceramic materials, and the infiltration of porous substrates with nanostructured particles because of the many advantages, such as short formation time, simple 
apparatus, little restriction of the shape of substrates, and no requirement for a binder [36-39]. Recently, studies for the design of advanced electrodes to be used as the electrodes in electrochemical energy storage and conversion devices have increased significantly because of the excellent processing technique for high performance. Therefore, there is a general scientific view that additional R\&D research on electrochemical energy storage and conversion devices is needed [10,34]. Nevertheless, EPD has produced promising results for electrochemical energy storage and conversion devices. Such articles at this stage are believed to stimulate further research in this area. This manuscript provides a brief review of the mechanisms proposed to explain the principle of EPD as well as the more recent attempts to design electrodes for electrochemical energy storage and conversion devices. The advantages offered by EPD in not only developing the individual components, but also designing the entire electrochemical energy storage and conversion devices will summarized. A discussion will be attempted to correlate the various improvements achieved in the performance of the electrochemical energy storage and conversion devices with the mechanisms and factors influencing the EPD process. The review will conclude by summarizing the promising aspects of EPD and suggest further developments in electrochemical energy storage and conversion devices technology using EPD. The design approach will provide a new way of producing electrodes for high performance lithium ion batteries, supercapacitors, and electrocatalysts for fuel cells

\section{Mechanisms of Electrophoresis Process}

The basic mechanisms of electrophoresis deposition (EPD) were modeled on Derjaguin-Landau-Verwey-Overbeek (DLVO) theory and discussed by Sarkar and Nicolson as the important reference in the electrophoresis technique [33,36]. According to Zhitomirsky's analysis, the proposed mechanisms can be divided into four categories: (1) flocculation by particle accumulation, (2) particle charge neutralization, (3) electrochemical particle coagulation, and (4) an electrical double layer (EDL) distortion and thinning mechanism [33,34,36,40-42].

\subsection{Flocculation by Particle Accumulation}

Harmaker and Verwey reported similarities of sediment formation by electrophoresis and gravitation $[36,43,44]$. The main function of the application is to move the particles inside the electrolyte towards the electrode [34]. The particles accumulate due to the pressure exerted on the incoming layer and the outer layer, which is possible when deposition does not occur at the electrode [34]. This type of deposition can explain the deposition of a coating on a membrane that does not act as an electrode [36]. Vanderperre reported that when the solid loading is increased, the zeta potential of the particles moves towards the isoelectric point [45].

\subsection{Particle Charge Neutralization}

Grillon et al. suggested that charged particles are neutralized when they touch the electrode (or deposit) and then generate static electricity [46]. This mechanism can be explained for the single=particle and single later depositions and powder deposition by means of a chargeable salts by adding salts to the suspension (e.g., the experiments described by Brown and Salt [47]). On the other hand, this mechanism is invalid under the following conditions: (a) EPD for longer times; (b) when particle-electrode processes are prevented, the semi-permeable membrane induces deposition between the electrodes; and (c) when reactions occur at the electrode, which change the $\mathrm{pH}$ thereabout [34].

\subsection{Electrochemical Particle Coagulation}

This mechanism indicates the reduction of repulsive forces between the particles in suspension. Koelmans discussed the coagulation caused by increasing electrolyte concentration around the particles [48]. He suggested that the increase of ionic strength near the electrode is calculated when the potential difference was applied, and then proposed that its behavior was due to an increase in the electrolyte concentration around particles [36]. He confirmed that the ionic strength was similar to 
that needed to flocculate the suspension [36]. Therefore, Koelmans proposed that in this mechanism, an increase in the electrolyte concentration produces a decrease in repulsion between the depositing electrode and lowers the zeta potential, resulting in particle coagulation. Considering that it is essential with a finite time for the increasing the electrolyte concentration next to the electrode, a certain time must pass to achieve deposition. This time is reciprocally proportional to the square of the applied voltage $\left(t \infty 1 / E^{2}\right)$ in that a higher applied potential decreases the time required for deposition. This mechanism is possible when an $\mathrm{OH}^{-}$ions are generated by an electrode reaction in a suspension containing water. On the other hand, this mechanism is not suitable when the electrolyte concentration does not increase near the electrode.

\subsection{Electrical Double Layer (Edl) Distortion and Thinning}

Sarker and Nicholson explained that the distortion of the particle double layer is related to the invalidation of the electrochemical coagulation mechanism when the electrolyte concentration does not increase near the electrode $[33,36]$. When positively charged particles and their shells are moving towards the cathode electrode in the EPD cell, the double layer is distorted (thinner ahead and wider behind) because of the fluid dynamics and the applied electric field [34].

As a result, the counter ions in the extended tail can react easily with other cations moving towards the cathodic electrode due to the smaller coulombic force on the positively charged particles [36]. This process results in a reduction of the double layer thickness. Therefore, once the incoming particles come in with a thin double layer, the two particles come close sufficiently interact through London Van der Waal attractive forces and coagulation; this mechanism is shown in Figure 2. Considering the high concentration of particles near the electrodes or the high collision frequency, the distortion of the double layer leading to coagulation is fully appreciated. This mechanism is also applied to incoming particles with thin double layer heads which are already coagulated with particles in the deposit occurs [34]. Nicholson proposed a new theory that the model suggested by Sarkar and Nicholson [33] was incomplete and that the concentration of $\mathrm{H}^{+}$in the cathode was reduced due to particle discharge or other chemical reactions. As these particles move to the cathode, their zeta potential reduces due to the increasing $\mathrm{pH}$. Therefore, the particles are coagulated. This mechanism is general for all suspensions involving $\mathrm{H}^{+}\left(\right.$or $\left.\mathrm{H}_{3} \mathrm{O}^{+}\right)$
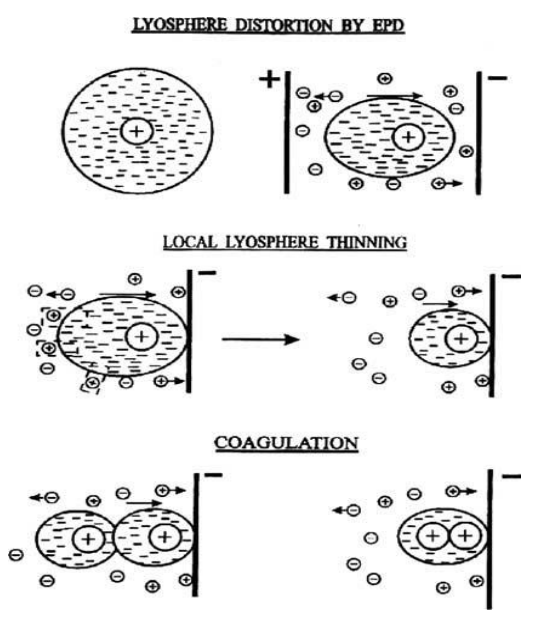

Figure 2. Schematic representation of the deposition mechanism due to electrical double layer distortion and thinning.

\section{Principals of Electrophoresis Process}

Charged particles in a suspension will migrate only in response to electrical signals. Ions representing opposite charge are attracted toward the surface of the charged particles while ions representing same charge are pushed out of the surface of the particles [35]. Charged particles in 
solution are surrounded by ions of an opposite charge, causing an electric double layer of particles [49]. This model of the particle double layer is called the Stern model [33]. Figure 3 shows a schematic representation of the double layer, showing the distribution of charged particles and potential drop across the double layer [50]. If the particle has a negative charge, the ions of opposite charge are attracted to the surface of the particle followed by the formation of a Stern layer and other ions, which are distributed more broadly, to form a diffuse double layer, as shown in Figure 3. The particle surface $\left(\psi_{0}\right)$ at the plane of shear between the Stern and diffuse layer $\left(\psi_{\delta}\right)$ is characterized by the zeta potential (C) that is contained in all electro kinetics [51].

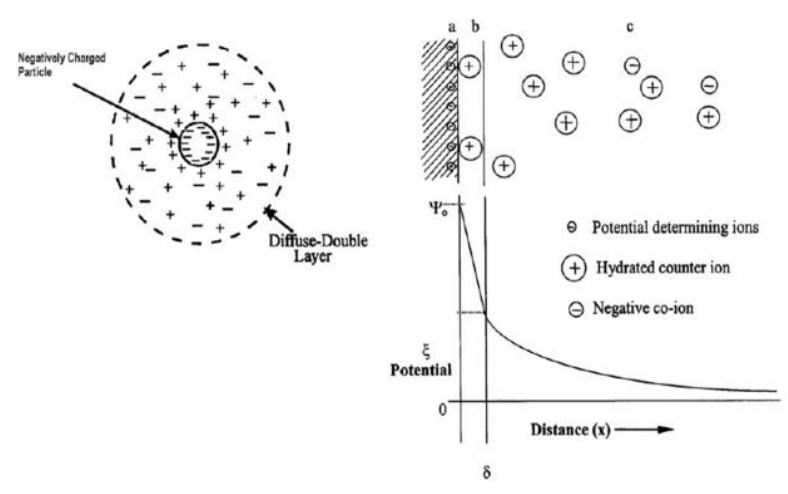

Figure 3. Schematic representation of the double layer and potential drop across the double layer: (a) surface charge; (b) Stern layer; (c) diffuse layers of counter-ions.

The potential $(\psi)$ at a distance $x$ from the Stern plane may be represented reasonably by the following linear form of the Poisson-Boltzmann Equation:

$$
\psi=\psi_{\delta} \exp (-k x)
$$

where $k$ is the Debye-Hückel parameter and has the unit of (length) ${ }^{-1} ; 1 / k$ is the distance at which the potential $(\psi)$ drops to $1 / e$ of its value at the Stern plane $\left(\psi_{\delta}\right)$ and this distance is called the double layer thickness or Debye length [34]. The Debye length thickness plays an important factor in the colloidal stability and for that matter in flocculation. The double layer thickness is controlled by the concentration and the number of charged ions in the medium. A high concentration of ions in solution generally decreases the thickness of the Debye length as well as the potential. The thickness of the Debye length is generally represented by the following equation:

$$
\frac{1}{k}=\left(\frac{\varepsilon \varepsilon_{0} k t}{e^{2} \sum i n_{i} z_{i}^{2}}\right)^{1 / 2}
$$

where $e$ is the electronic charge, $n_{i}$ is the concentration of ions with charge $z_{i}, \varepsilon$ is the relative dielectric constant of the solution, and $\varepsilon_{0}$ is the dielectric constant in a vacuum. For aqueous solutions at $25{ }^{\circ} \mathrm{C}$ [34], the $k$ is given in the following equation:

$$
k=2.3 \times 10^{9}\left(\sum n_{i} z_{i}^{2}\right)^{1 / 2}
$$

where $n_{i}$ is the molar concentration and $z_{i}$ is the charge of ion $I$ [34].

The main electrophoretic characteristic of the particle under the influence of an electric field is called the electrophoretic mobility, $\mu$, which can be determined as the coefficient of proportionality between the electric field strength, $E$, and the particle velocity, $v$ [50]:

$$
\mu=\frac{v}{E}
$$


The electrophoretic mobility increases with increasing particle zeta potential $(\zeta)$ and decreases with increasing viscosity $(\eta)$ of the media. Because $\mu$ and $\eta$ are dependent on the particle size, the electrophoretic mobility of small particles is determined by having a much smaller core radius $(r)$ of the particle than the Debye length of the counter ionic atmosphere $(r<1 / k)$, which is defined by the Hückel Equation [52]:

$$
\mu=\frac{2 \varepsilon \varepsilon_{0} \varsigma}{3_{\eta}}
$$

The electrophoretic mobility of particles of size much greater than the Debye length of the counter ionic layer $(r>1 / k)$ is defined by the Helmholtz-Smoluchowski Equation [53,54]:

$$
\mu=\frac{\varepsilon \varepsilon_{0} \varsigma}{\eta}
$$

The first model of EPD kinetics was proposed by Hamaker in 1940 for electrophoretic cells with planar geometry as shown in Equation (7) [55,56].

$$
m=C_{s} \mu S E_{t}
$$

It is related to the deposited mass per unit area, $m(\mathrm{~g})$, with slurry properties, such as suspension concentration, $C s\left(\mathrm{~g} \cdot \mathrm{cm}^{-3}\right)$, and electrophoretic mobility, $\mu\left(\mathrm{cm}^{2} \cdot \mathrm{s}^{-1} \cdot \mathrm{V}^{-1}\right)$, with physical and electrical conditions imposed on the system such as electric field, $E\left(\mathrm{~V} \cdot \mathrm{cm}^{-1}\right)$, deposition area, $S\left(\mathrm{~cm}^{2}\right)$, and deposition time, $t$ (s) [55]. The linear variation of deposited mass with deposition time is required to be kept constant parameters of Equation (7) without change with time. This fact limits the application of the Hamaker expression to short deposition times. The effectiveness of the microcrystalline deposition process with efficiency factor, $f \leq 1$, (i.e., if all the particles reaching the surface of electrode participate in the formation of the deposits, $f=1$ ) was quantified by Sarkar and Nicholson. The Hamaker equation was used to quantify the effect of changes in variation of particle concentration on EPD kinetics. Because the variation of bulk solid concentration in the suspension can be negligible in the early step of the process, only a small portion of the powder is deposited. Thus, the infinitesimal intervals of time in the Hamaker equation always holds. The equation can be expressed as:

$$
\frac{d m}{d t}=f \mu S E_{t}
$$

The amount of powder extracted from the bulk suspension at variation of particle concentrations increases for a longer period of time, and resulting in a decrease in Cs value. If the charged ions under the assumption that sedimentation does not occurs are the mass of the powder deposited by the EPD, the deposited mass is $m(0)=0$ during the initial time, $t=0$, which leads to the solution of Equation (3) [56].

$$
\begin{gathered}
m(t)=m_{0}\left(1-e^{-\frac{t}{\tau}}\right) \\
\tau=\frac{V}{f \mu S E} \text { (the volume of suspension }: V\left(\mathrm{~cm}^{-3}\right)
\end{gathered}
$$

This equation related to EPD kinetics has been widely applied by Sarkar and Nicholson [33] and completed the first description proposed by Zhang et al. [57] considering the incorporation of changes in particle concentration in EPD kinetics. Furthermore, the Sarkar and Nicholon model uses under constant-voltage conditions. However, the resistance of the deposit is higher than that of the resistance of suspension, and as a result the electric field strength is applied to the suspension. Thus, as shown in the Sarkar and Nicholson model, the charged particle velocity correspond only to the applied electric 
field strength, $v=E \mu$, and the effective electric field for a planar geometry was defined $a s=\Delta \psi / L$. The deposited mass considered these conditions be expressed as:

$$
m=\mu E S C_{d} \frac{\varnothing_{d}}{\varnothing_{d}-\varnothing_{s}} t
$$

where $v\left(\mathrm{~cm} \cdot \mathrm{s}^{-1}\right)$ is the electrophoretic rate of particles close to the electrode, $\varnothing_{d}$ is the volumetric fraction of the deposit, $C_{d}$ is the deposit concentration and $\varnothing_{s}$ is the volumetric fraction of the suspension [53,56]. In addition, Sarkar and Nicholson proposed working under galvanostatic or constant current conditions [33]. The voltage drop between the two electrodes increases over the time, however, the voltage/unit distance in the suspension remains constant. Ma and Cheng have defined the relationship between the kinetics parameter $(k)$ and the applied current intensity through experiments, as shown equation in the below.

$$
k=k_{o}\left(e^{\frac{i}{i^{0}}}-1\right)
$$

where $i\left(\mathrm{~mA} \cdot \mathrm{cm}^{-2}\right)$ is the current density, and $i^{0}\left(\mathrm{~mA} \cdot \mathrm{cm}^{-2}\right)$ and $k_{o}\left(\mathrm{~s}^{-1}\right)$ are considered the reference conditions from which the expression predicts the kinetics constant under other applied currents, facilitating more effective modelling and controlling of the process [56]. However, most of the experimental shown in the literature describing the EPD process were performed under potentiostatic or constant voltage conditions. On the few years ago, a mathematical description of the kinetics based on the Hamaker model and Bisesheuvel correction for suspensions with high solid loading should take into account changes in the suspension conductivity and the current density during EPD under constant voltage conditions by the Anne group [56]. The electric field considering the conductivity of the suspension can be expressed as shown equation in the below.

$$
E=\frac{I}{S Q_{s}}\left(\sigma_{s}\left(S \mathrm{~cm}^{-1}\right)\right.
$$

the suspension conductivity depends on the conductivity of the suspension liquid medium)

Considering Hamaker model (Equation (8)), the equation can be expressed as below

$$
\frac{d m}{d t}=f \mu \frac{I}{Q_{s}} C_{s} \frac{\varnothing_{d}}{\varnothing_{d}-\varnothing_{s}}
$$

This equation applied EPD results obtained from an alumina suspension prepared using ethanol as a dispersant in consideration of different additives. The proposed Equation (14) was verified by experimental data collected during the deposition. Finally, the Ferrari group has proposed the deposition kinetics that considering the relationship between colloidal parameters, and, for example, the deposition kinetics taking into account the suspension concentration and resistivity during the EPD process. This kinetics provides more accurate account of the experimental results obtained by the collected for longer deposition times and for suspensions in which resistivity change significantly during the deposition process. The kinetic equation describing this is as shown below

$$
M(t)=M_{o}\left(1-\frac{1}{1+\left(\rho_{s}, \frac{0}{\rho_{s}}, \infty\right)\left(e^{\frac{t}{\tau \infty}-1}\right)}\right)
$$

where $\rho s, 0$ is the initial resistivity of the suspension and $\rho s, \infty$ is the resistivity at infinite time, when $C s=0$. Finally, notice that if $\rho s, \infty=\rho s, 0$ (and hence $\rho s=\rho s, \infty$ constant) the solution of this last kinetics model (Equation (15)) reduces to the Sarkar and Nicholson model (Equation (9)). Furthermore, if $t<<\tau \infty$, this solution becomes that of the linear model proposed by Hamaker (Equation (7)). Thus, Equation (15) includes previous models of EPD kinetics. Table 1 summarizes various equations, corrections and experimental expressions proposed by different authors. The kinetic model of the 
theoretical electrophoresis demonstrate the particle motion generated near the electrode under various conditions. Recently, further research is underway, such as determining the role of particles-substrate interaction under an electric field, prediction of particle arrangement and design of micro and nanopattern materials.

Table 1. Summaries of different equations, corrections and experimental expressions proposed by different authors.

\begin{tabular}{|c|c|c|c|}
\hline Equation & Kinetics & Proposed Equation & Ref. \\
\hline (7) & Basic equation & $m=C_{S} \mu S E t$ & [55] \\
\hline (8) & $\begin{array}{l}\text { Quantification of the deposition behaviour: the } \\
\text { sticking factor }\end{array}$ & $d m / d t=f \mu S E C_{S}$ & [33] \\
\hline (9) & Considering the solid loading variation & $m(t)=m_{0}\left(1-e^{-t / \tau}\right)$ & [33] \\
\hline$(11)$ & Considering concentrated suspensions $\left(\Phi_{s}>0.2\right)$ & $m=C_{S} \mu \operatorname{SEt}\left(\Phi_{d} /\left(\Phi_{d}-\Phi_{S}\right)\right)$ & [58] \\
\hline$(12)$ & $\begin{array}{l}\text { Experimental expression determining the variation } \\
\text { of the kinetics parameter vs. the current applied }\end{array}$ & $k=k_{o}\left(e^{i / i o}-1\right)$ & [59] \\
\hline$(14)$ & Considering the suspension resistivity variation & $m=f \mu\left(I / \sigma_{\mathrm{S}}\right) C_{S}\left(\Phi_{d} /\left(\Phi_{d}-\Phi_{S}\right)\right)$ & {$[60]$} \\
\hline$(15)$ & $\begin{array}{l}\text { Considering the linear relationship of the } \\
\text { suspension resistivity and solid loading }\end{array}$ & $\begin{array}{c}m(t)=m_{0}(1-(1 / 1+ \\
\left.\left.\left(\rho_{s}, 0 / \rho_{s}, \infty\right)\left(e^{t / \tau}-1\right)\right)\right)\end{array}$ & [61] \\
\hline
\end{tabular}

\section{Factors Influencing Electrophoresis Deposition}

The mechanism of the EPD involves two steps. The first step is that the charged particles must moving to the electrodes under the influence of the electric field for deposition, and in the second step the transferred particles must coagulate and deposit on the electrode. A number of parameters are related to the suspension and physical characteristics, such as the electrical nature of the electrodes, the electrical conditions (voltage/intensity relationship, deposition time, and etc.) that influence the EPD process, and the quality of the deposited coating [53]. Some of the important ones are discussed below.

\subsection{Key Parameter Related to the Suspension}

\subsubsection{Zeta Potential}

The zeta potential of dispersed particles in a suspension is important factor for maintaining the stability in the suspension by enhancing and uniforming the surface charge. This plays helps stabilize the suspension by determining the intensity of the repulsive interaction among particles, the direction and migration velocity of the charged particle during the electrophoresis process, and the quality of the deposit. The overall system stability is determined by the interaction between the individual particles in the suspension. Two mechanisms by electrostatic and van der Waals forces influence this interaction. A high particle charge is needed to form high electrostatic repulsion to prevent agglomeration between particles. In contrast, a low particle charge leads to coagulation [62]. Various charging agents, such as acids, bases, and adsorbed ions or polyelectrolytes, can changed the zeta potential. Therefore, the various additives acting through different mechanisms affect the size of the charge magnitude and its polarity. The criteria for selection of charging agent is determined by the polarity and the deposition rate of charged particles. Therefore, it is important to control the particle loading and the concentration of solution and additives in the suspension to obtain the highest possible coating layer.

\subsubsection{Particle Size}

The particle size also is an important factor in the electrophoresis process. The dispersed particles should remain suspended in a stable suspension. For ceramic particles, particle size between 1-20 $\mu \mathrm{m}$ leads to good deposition [63]. The main problem is that the charged particles in the suspension tend to be deposited under the influence of gravity in a vertical system. In order to solve this problem, the electrophoresis process needs to be higher in the movement of particles than in the movement by gravity. In addition, the large particles dispersed in the suspension have a disadvantage that it is 
difficult to uniformly deposit the particles in the electric suspension. The electrophoresis process from the sedimentation suspension leas to a gradient in the deposition, so that a thin or thick deposition proceeds from the bottom when the electrode arranged in the vertical direction. In addition, when the large particles occur during the electrophoresis process, very strong surface charge must be generated or size of the electrical double layer region must increase. Although the gradient in deposition can be a problem, it also can be applied in a special field.

\subsubsection{Conductivity and Viscosity of the Suspension}

The conductivity of a suspension determined by the amount of the coexisting ions is an important factor in the electrophoresis process because the applied electric field in the electrophoresis process leads to charged particles but mostly by the free coexisting ions (electrolyte). When the conductivity of a suspension is too high, the particle mobility will be decreased by the amount of free ions in the suspension, leading to a decrease in zeta potential [64]. In contrast, when charge and ionic conductivity is low, the suspension acts as a resistor and causes a loss of stability [56]. In addition, the viscosity is an important factor in the electrophoresis process. The viscosity of the suspension depends on the amount, size and $\mathrm{pH}$ of the particles dispersed in the suspension. The suspension with low viscosity is essential for the electrophoresis process, and optimal suspension concentrations can be determined through experimentation.

\subsubsection{Stability of a Suspension}

The stability of a suspension is an important factor for a successful electrophoresis process. The tendency and rate which the aggregation of charged particles occurs or avoids determines the stability of the suspension. Therefore, the stability of a suspension varies depending on the charged particle size and size distribution, zeta potential, Debye length of the solution and the presence of adsorbed species. Particles less than $1 \mu \mathrm{m}$ in diameter try to keep the suspended state for a long time due to Brownian motion. In contrast, particles larger than $1 \mu \mathrm{m}$ require continuous hydrodynamic agitation to remain in suspension. Therefore, a stable suspension shows no flocculation or sedimentation of the particles. On the other hand, as the suspension is stabilized, the repulsion force between the particles is stronger than the electric field intensity, and deposition does not occur. The suspension stability is the most important characteristic in the electrophoresis process, however, this is changed by experiment and is not closely related to the fundamental parameters.

\subsection{Key Parameters Related to the Process}

\subsubsection{Deposition Time}

The yield of the thickness increases with increasing deposition time. Deposition is linear during the initial deposition time. On the other hand, when the time is increased continuously, the deposition rate is reduced and the plateau is reached through a very long deposition time. When a constant voltage is applied in an electric field affecting electrophoresis process, the layer formation by charged particles on the surface of electrode increases the deposition time and reduces the field strength. Despite this, there is generally a linear relationship between the deposition mass and time during the initial period of EPD [3]. Therefore, the optimal deposition time during EPD should be determined to obtain the desired coating layer.

\subsubsection{Applied Voltage}

Generally, the deposition yield is increased with increasing applied potential. The coating layer may receive distortion by rapid flow because a higher applied voltage may cause turbulence in the suspension. Therefore, the lateral movement of the deposited particles is limited when a higher voltage is applied. The limitation of this motion is due to particles already deposited on the surface by the higher voltages, which causes more pressures on particle flux and movement. Therefore, the applied 
voltage for electrophoresis process affects the deposition rate and structure on the surface deposition of charged particles.

\subsubsection{Concentration of the Solid in Suspension}

The concentration of solid in a suspension also plays an important role in multi-component EPD. In some cases, different particle species can be deposited at different rates with the same surface charge depending on the solids concentration of the suspension. Therefore, when the volume fraction of solids is high, the particles in the suspension are deposited at the same rate, however, when the volume fraction of solids is low, the deposition rate of the particles in the suspension is determined by the electrophoretic mobility for each particles. Multi-component EPD is largely used to design electrodes for the electrochemical energy storage and conversion devices, which will be discussed in more detail in later section.

\subsubsection{Conductivity of the Substrate}

The uniformity and conductivity of the electrode for a substrate is an important factor in the quality of film produced by EPD [53]. Generally, metal-based substrates are used to design electrochemical energy storage and conversion devices. On the other hand, the electrodes for SOFCs are ceramic films. Therefore, the deposition rate of charged particles in the EPD process is slow and a non-uniform film can be obtained because of the high resistance of the substrates leading to the binder additive. High quality films can be obtained by increasing the conductivity of the substrates substantially by removing the binder. The deposition of charged particles on non-conducting substrates will be discussed in more detail in the application of EPD for SOFC.

From the above discussion, the quality of the deposit and the kinetics of EPD are dependent on many parameters. These individual parameters need to be controlled carefully during EPD. In addition, their parameters are interrelated with each other. In particular, the quality of EPD depends heavily on the suspension conditions. For an easy EPD process, a well-dispersed stable suspension is required that is not an unstable suspension or agglomerated powder suspension. In general, a higher measured zeta potential also provides a better dispersion of particles in the suspension because it is closely related to the double layer thickness of the particles. Therefore, the parameters of the suspension need to be considered carefully to achieve a suitable suspension in the EPD process. Once the various parameters associated with suspension are determined, the parameters of EPD process can be easily changed for the desired deposition. In particular, the most important parameters affecting the EPD process are the voltage applied to the suspension, deposition rate and time and particle concentration in the suspension. Although a high applied voltage leads to a high deposition rate, a stable current density should be supplied to obtain a uniform film. In addition, increasing the particle concentration and deposition time can lead to a higher deposition rate. From the next section, the electrodes designed by considering the parameters related to the suspension and the process for the application of the electrochemical energy storage and conversion devices were investigated in detail and the properties in each of the areas for energy storage and conversion are reviewed.

\section{Applications of the Electrophoresis Deposition for Nanomaterials of Li-Ion Batteries}

Lithium-ion batteries have been used as energy storage materials since their invention in the 1970s, and are currently the most promising energy source for portable devices and vehicles [65-67]. The electrodes used in Li-ion batteries are manufactured through the following process: (1) mixing of an active, conducting, and binding material in an organic solvent to make a paste; (2) painting of the paste on a metal current collector, such as $\mathrm{Cu}$, stainless steel, and $\mathrm{Al}$; (3) evaporating the organic solvent; and (4) pressing the electrode. These processes should be optimized to obtain high-performance Li-ion batteries. In particular, the high discharge capacity at high-rate use is attained under optimized conditions to fabricate the electrodes for Li-ion batteries. Moreover, the cost of making the batteries also needs to be reduced. Thus far, considerable effort has been made to develop and produce new 
electrodes with higher performance for future Li-ion batteries [1]. The EPD technique is a new approach to prepare electrodes for $\mathrm{Li}$-ion batteries over traditional electrode materials containing active materials mixed with conducting carbon on a range of substrates because unlike other coating techniques, the material to be processed by EPD does not require defined properties; hence, there is wide variety of materials that can be coated and deposited [68-70]. Strongly coupled electrode materials form substrates with higher specific capacity, enhanced charging-discharging rate capability, and improved cycling stability due to the uniform distribution of active materials, appropriate density of electrodes, and enhanced electron transport resulting from the strong adhesion between the active and conductive materials and substrates.

\subsection{Cathode Materials}

Most cathode active materials are oxide-based materials that have lower electrical conductivity. To design electrodes with high electrical conductivity and performance, the multi-component EPD process is largely carried out with various parameters, such as the zeta-potential, conductivity of the substrate, and additives applied in suspensions for the EPD process. As shown in Figure $4 \mathrm{a}, \mathrm{LiCoO}_{2}$, which has a layered structure, is a typical cathode material of commercial Li-ion batteries. Although most of the Li can be extracted to give a theoretical capacity of $274 \mathrm{mAh} \cdot \mathrm{g}^{-1}$, a little over half of the capacity is practically reversible for insertion/deinsertion $\left(4.2 \mathrm{~V} \mathrm{vs} . \mathrm{Li} / \mathrm{Li}^{+}\right)$, which gives a specific capacity of $150 \mathrm{mAh} \cdot \mathrm{g}^{-1}$ [71-73].

(a)

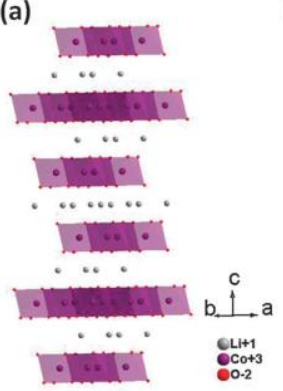

(b)

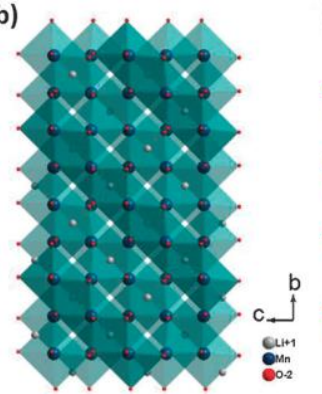

(c)

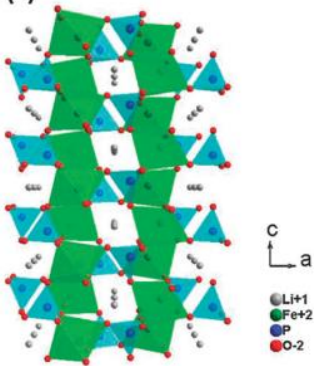

Figure 4. Schematic diagram of the crystal structures of three types of cathode materials for Li-ion batteries: (a) $\mathrm{LiCoO}_{2} ;$ (b) $\mathrm{LiMn}_{2} \mathrm{O}_{4} ;$ (c) $\mathrm{LiFePO}_{4}$.

Kanamura et al. fabricated $\mathrm{LiCoO}_{2}$ composite electrodes, where $\mathrm{I}_{2}$ was added to produce charged active materials in solution through the chemical reaction of $I_{2}$ with acetone $[30,74]$. The multi-component EPD process was conducted in an acetone solution containing various amounts of conducting materials, $\mathrm{I}_{2}, \mathrm{PTEF}$, and $\mathrm{LiCoO}_{2}$ at $100 \mathrm{~V}$ for $1 \mathrm{~min}$. The EPD process was repeated until the deposited mass was increased to $10 \mathrm{mg}$. They examined the effects of EPD with the amount of conductive material in the suspension and the size of the particles. The resulting $\mathrm{LiCoO}_{2} \mathrm{composite}$ electrode showed excellent rate performance. A specific capacity of $142 \mathrm{mAh} \cdot \mathrm{g}^{-1}$ was obtained at a rate of $0.1 \mathrm{C}$. The discharge capacity of the $\mathrm{LiCoO}_{2}$ composite electrode prepared by EPD was comparable to that of the electrode fabricated by a conventional process. The total fabrication time for the electrodes was $<5 \mathrm{~min}$. Compared to $\mathrm{LiCoO}_{2}, \mathrm{LiMn}_{2} \mathrm{O}_{4}$ (Figure $4 \mathrm{~b}$ ) is an attractive cathode material for Li-ion batteries because $\mathrm{Mn}$ is less expensive, more abundant, and environmentally benign than Co. In addition, $\mathrm{LiMn}_{2} \mathrm{O}_{4}$ exhibits higher rate capability and thermal stability than $\mathrm{LiCoO}_{2}$ [65-67]. Kanamura et al. also prepared $\mathrm{LiMn}_{2} \mathrm{O}_{4}$ composite electrodes by EPD [74]. A small $\mathrm{LiMn}_{2} \mathrm{O}_{4}$ particle size of $<1 \mu \mathrm{m}$ compared to that $(>10 \mu \mathrm{m})$ of $\mathrm{LiCoO}_{2}$ was used as the active material. EPD was conducted at $400 \mathrm{~V}$ for $1 \mathrm{~min}$ and the process was then repeated until the deposited mass was increased to $10 \mathrm{mg}$. The resulting $\mathrm{LiMn}_{2} \mathrm{O}_{4}$ composite electrode fabricated by EPD exhibited lower performance than that of the electrode prepared by the typical process due to the lower electronic conductivity of the active material, and because small $\mathrm{LiMn}_{2} \mathrm{O}_{4}$ particles in suspension for EPD deposits on the substrate more effectively than conductive powders. This suggests that larger active material sizes 
above $>10 \mu \mathrm{m}$ were suitable for the electrode of $\mathrm{LiMn}_{2} \mathrm{O}_{4}$ in the EPD process due to the connection for electrical conductivity inside the electrode matrix. Caballere et al. also fabricated $\mathrm{LiNi}_{0.5} \mathrm{Mn}_{1.5} \mathrm{O}_{4}$ electrodes as another spinel cathode material [75]. They reported the EPD kinetics to improve the reliability of the process, as shown in Figure 5a. The results showed that the substrate material itself played a critical role in the deposit formation, and the incorporation of carbon black helped stabilize the suspension and decrease the electrophoretic mobility. Moreover, citric acid as a dispersing agent not only played a key role in stabilizing particle surfaces by adsorption, but is also a major source of ions and hence is responsible for preserving the suspension conductivity.

(a)

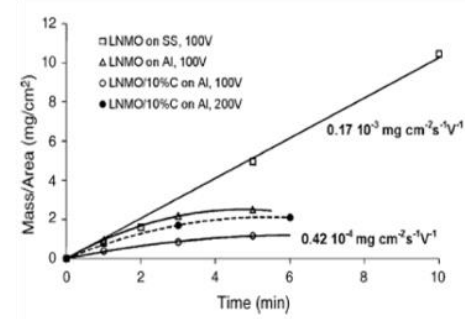

(c)

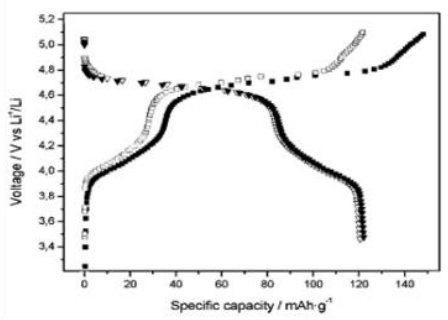

(b)

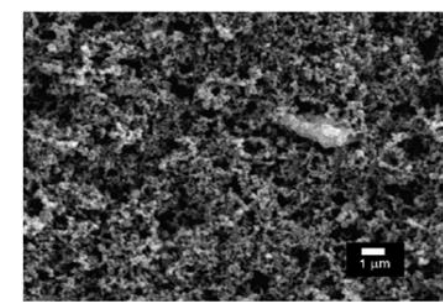

(d)

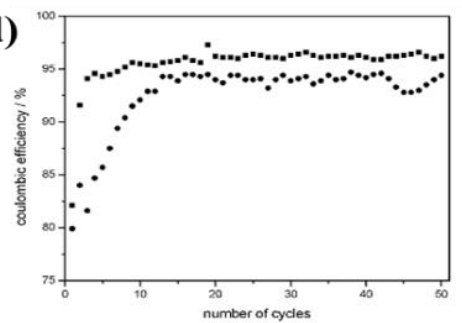

Figure 5. $\mathrm{LiNi}_{0.5} \mathrm{Mn}_{1.5} \mathrm{O}_{4} /$ carbon composite prepared by EPD as the cathode for Li-ion batteries: (a) EPD kinetics of the $\mathrm{LiNi}_{0.5} \mathrm{Mn}_{1.5} \mathrm{O}_{4}$ deposition on various substrates; (b) Top view of the $\mathrm{LiNi}_{0.5} \mathrm{Mn}_{1.5} \mathrm{O}_{4}$ / carbon composite electrode; (c) Charge-discharge curves for the EPD deposits cycled over the voltage range, 3.5-5.0 $\mathrm{V}$ at a $\mathrm{C} / 6$ rate; first charge and discharge (black), second charge and discharge (white); (d) Coulombic efficiency of $\mathrm{LiNi}_{0.5} \mathrm{Mn}_{1.5} \mathrm{O}_{4} /$ carbon composite electrode with the number of cycles. Standard electrode $(\bullet)$, electrode fabricated by EPD ( $\square)$ (charge/discharge rate C/6).

The electrodes optimized by the results of the formulation of EPD kinetics could further improve their electrochemical performance compared to the electrode by a typical process. In subsequent cycles, the coulombic efficiency of the electrode prepared by EPD remained at very high levels (95-97\%). Ferrari et al. also prepared a $\mathrm{LiNi}_{0.5} \mathrm{Mn}_{1.5} \mathrm{O}_{4}$ electrode by EPD. Citric acid and polyvinyl pyrrolidone (PVP) were used to stabilize the active and conductive materials in acetone, and polyvinyl butyral (PVB) was used as a binder to increase the film density [76]. In addition, the EPD kinetics of the suspension were optimized with the amounts of citric acid as a dispersing agent. The film density was increased with the connection between the active particles and addition of PVB as the binder. Prasanna et al. used $\mathrm{Li}\left[\mathrm{Ni}_{1 / 3} \mathrm{Co}_{1 / 3} \mathrm{Mn}_{1 / 3}\right] \mathrm{O}_{2}$ as the active material for the cathode electrode [77]. EPD was carried out at $100 \mathrm{~V}$ for $5 \mathrm{~min}$ to fabricate the thin electrode. The conditions of a suspension for EPD were optimized by varying three controllable input factors, namely the weight of the active material, conductive agent, and binder. The electrode prepared with the optimal parameters showed a discharge capacity of $147.18 \mathrm{mAh} \cdot \mathrm{g}^{-1}$ and a capacity retention ratio of $97.11 \%$. Applying EPD to prepare an electrode could improve its electrochemical performance further compared to the casting method as a typical process to make the electrode because its method increased the thickness compared to the EPD process. Typical casting methods increase the thickness due to the use of polymeric binders to bond the active material to the current collector. However, only the active material can be adhered to the current collector by the immigration of the ions in the suspension by the current applied from both electrodes using the EPD method, resulting in a thinner thickness than the typical process. An increase in electrode thickness will 
lead to an increase in internal resistance and stress accumulation by volume expansion and contraction during the lithiation and delithiation process. A thin EPD-prepared electrode could improve the capacity retention ratio [78,79]. The general formula, $\mathrm{LiMPO}_{4}(\mathrm{M}: \mathrm{Fe}, \mathrm{Co}, \mathrm{Mn}$, and Ni) (Figure 6c), has attracted considerable interest over the past fifteen years since it was first suggested as a cathode material for $\mathrm{Li}$ ion batteries [1]. $\mathrm{LiFePO}_{4}$ is widely used commercially for its various advantages such as excellent cycle life, high rate capability, high thermal and chemical stability, low over-potential, low cost, and environmental friendliness $[71-73,80,81]$. Nair et al. used $\mathrm{LiCoPO}_{4}$ with a nanosized $(200 \mathrm{~nm})$ flake-like structure as the active material for the cathode electrode [82]. The $\mathrm{LiCoPO}_{4}$ film without conductive agents was fabricated by EPD. The nanosized particles agglomerated to minimize the surface energy through EPD. The resulting $\mathrm{LiCoPO}_{4}$ film prepared by EPD showed a dense structure and a specific capacity of $103 \mathrm{mAh} \cdot \mathrm{g}^{-1}$ with a coulombic efficiency of $70 \%$ after 10 cycles. Recently, all-solid-state batteries have attracted significant attention around the world because of their high safety, reliability, and energy density [83-87]. Over the past 20 years, all-solid-state batteries fabricated using thin film techniques, such as physical vapor deposition and chemical vapor deposition, have been investigated thoroughly [83-87]. On the other hand, these techniques have disadvantages, such as high cost and long formation times. The EPD process to make thin and thick film electrodes has attracted increasing interest in recent years because of the short formation time, simple apparatus, and few restrictions on the shape of the substrates. Quan et al. used EPD and a hydrothermal reaction followed by a liquid state reaction to synthesize $\mathrm{LiCoO}_{2}$ thin films with nanosheet restacking, as shown Figure 6 [88].

(a)

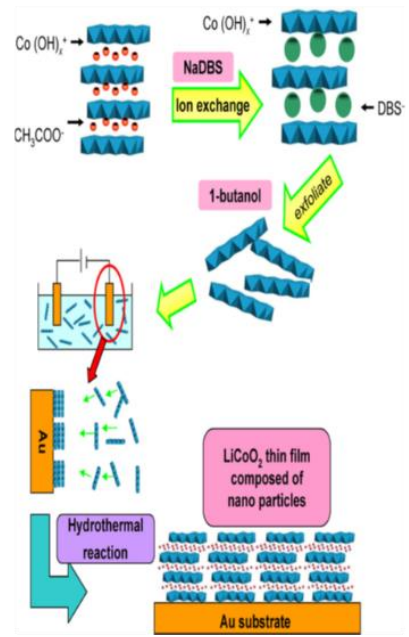

(b)

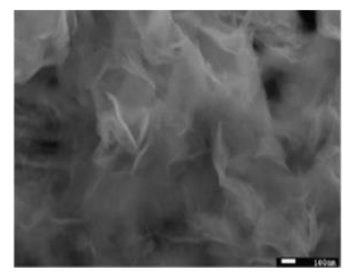

(c)

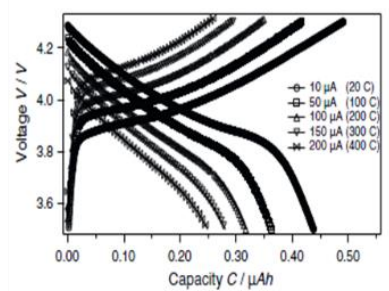

Figure 6. $\mathrm{LiCoO}_{2}$ thin film prepared by EPD as the cathode for Li ion batteries: (a) Synthesis of nanosized $\mathrm{LiCoO}_{2}$ by nanosheet restacking and subsequent hydrothermal method; (b) SEM image of the surface of the films with 5 min EPD; (c) Charge-discharge curves of 5 min deposited sample at various currents.

The resulting $\mathrm{LiCoO}_{2}$ thin film showed a higher specific capacity; $62 \%$ of the capacity was retained at a $400 \mathrm{C}$-rate compared to that at a $20 \mathrm{C}$-rate. Such high performance was attributed to the small size grain size and large surface area of the $\mathrm{LiCoO}_{2}$ thin film with nanosized particles. Mazor et al. used EPD to deposit the synthesized $\mathrm{LiFePO}_{4}$ nanoparticles directly on the surface of the 3D-substrate to fabricate 3D-microbatteries [89]. The disadvantages of $\mathrm{LiFePO}_{4}$ are its low electronic and ionic conductivity, which could impede electron transport and Li-ion diffusion within the active materials and limit the charging-discharging performance [71-73]. Copper sulfide-coated $\mathrm{LiFePO}_{4}$ nanoparticles were used because of their high electronic conductivity [90]. The EPD process was conducted in an acetone solution containing various amounts of conductive materials, PTEF, and CuS-coated $\mathrm{LiFePO}_{4}$ nanoparticles. The EPD of the 3D-substrate as a working electrode was carried out at $120 \mathrm{~V}$ for $1 \mathrm{~min}$. The $\mathrm{LiFePO}_{4}$ thin film coated on the 3D-substrate was observed by SEM, as shown in Figure 7a-d 
at high magnification. The 3D- $\mathrm{LiFePO}_{4}$ thin film as the cathode electrode prepared by EPD showed a peak-pulse-power capability of $200 \mathrm{~mW} \cdot \mathrm{cm}^{-2}$ and stable electrochemical behavior for more than 200 cycles (Figure 7f). These results were enhanced significantly compared to that of the $2 \mathrm{D}-\mathrm{LiFePO}_{4}$ thin film. The EPD process provided a uniform distribution, which resulted in lower polarization, shorter transport, and diffusion path lengths, leading to relatively high specific capacity. CuS assisted in the high electron conductivity and allowed better access of $\mathrm{Li}^{+}$to the active material sites.

(a)

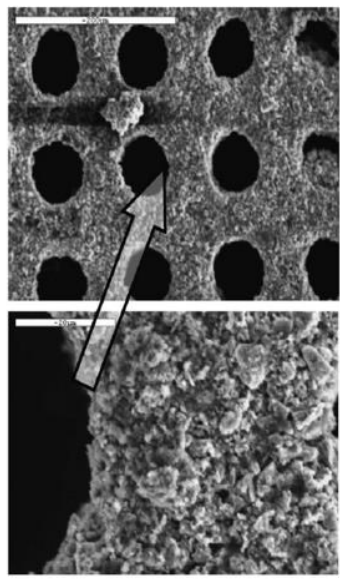

(b)

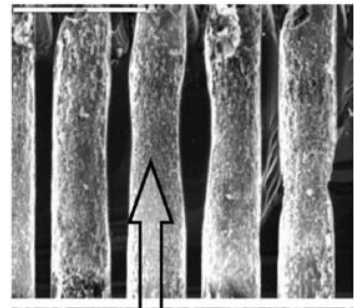

(d)

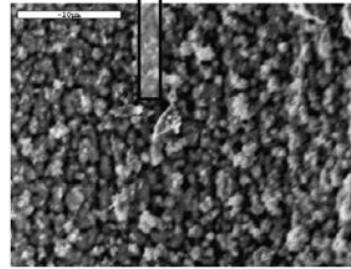

(e)

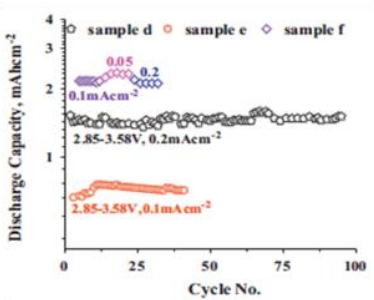

(f)

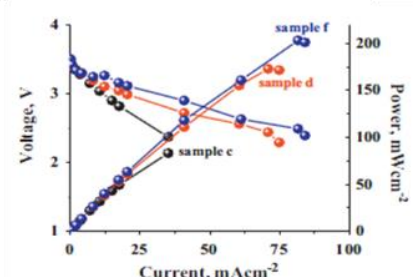

Figure 7. 3D-LiFePO 4 thin film prepared by EPD as the cathode for Li ion batteries: (a) Planar image of LiFePO ${ }_{4}$-coated 3D sample; (b) cross-section of the channels; (c) enlarged image of (a); (d) enlarged image of $(\mathbf{b}) ;(\mathbf{e})$ The electrochemical cycling performance of sample c (2D-LiFePO 4 thin film), sample d (3D-LiFePO 4 thin film), and sample f (CuS coated 3D-LiFePO 4 thin film) at various C-rates and voltage cutoffs; (f) Polarization curves of samples (c, d,f).

Huang et al. fabricated a binder-free and additive free $\mathrm{LiFePO}_{4} /$ reduced graphene oxide composite electrode by a one-step EPD process [91]. EPD was carried out in an IPA-based suspension containing graphene oxide and $\mathrm{Mn}\left(\mathrm{NO}_{3}\right)_{2} \cdot 6 \mathrm{H}_{2} \mathrm{O}$. Finally, the composite electrode was treated thermally to reduce graphene oxide under a $\mathrm{H}_{2} / \mathrm{Ar}$ atmosphere. The sample $(7.5 \mathrm{wt} . \%$ reduced graphene oxide, $91.5 \mathrm{wt} . \% \mathrm{LiFePO}_{4}$, and $\left.1 \mathrm{wt} . \% \mathrm{Mn}\left(\mathrm{NO}_{3}\right)_{2} \cdot 6 \mathrm{H}_{2} \mathrm{O}\right)$ exhibited high performance; the discharging capacity was $163.7 \mathrm{mAh} \cdot \mathrm{g}^{-1}$ at a low rate of $0.1 \mathrm{C}$ compared to the composite electrodes fabricated by the conventional method $\left(132.8 \mathrm{mAh} \cdot \mathrm{g}^{-1}\right)$. The results were attributed to the uniform and dense deposition with an intimate interface between the active materials and reduced graphene oxide due to the influence of an electric field. EPD contributed to the improved capacity and enhanced the rate performance and cyclability of the samples due to the additional advantage of generating composite electrodes free of binders and other additives.

\subsection{Anode Materials}

The interest in EPD is increasing, particularly in the field of nanotechnology, considering that nanoparticle suspensions can be manipulated by EPD to produce advanced nanostructured coatings and nanoscale films with enhanced properties suitable for anode electrodes of Li-ion batteries [53,92]. The goal is usually the development of mechanically robust nanocomposite coatings, and functional nanostructured films for the anode electrodes of Li-ion batteries. EPD can be considered to have contributed favorably to the enhanced electrochemical performance in the electrode by offering full realization of the active materials without conductive additives or a cohesive polymer binder.

\subsubsection{Carbon Based Anode Materials}

Commonly, graphite used as the anode material for the commercial Li-ion batteries has its own advantages such as high abundance, low cost, good stability, and high chemical stability. During the charging process of the lithium battery, Li-ions are intercalated into the graphite with a layered 
structure to form $\mathrm{LiC}_{6}$ [1]. The theoretical specific capacity is $372 \mathrm{mAh} \cdot \mathrm{g}^{-1}$ during this electrode reaction and the flat potential profile is only $0.2 \mathrm{~V}$ below that of lithium. When the same cathode material is used, graphite with a lower potential than lithium as an anode material can be used to have a wide voltage range and high capacity. First, binder-free graphite prepared by EPD is one of the most studied anode materials for Li-ion batteries [93-95]. Ui et al. used EPD to fabricate binder-free anode electrodes of four types of carbon materials, such as artificial graphite, natural graphite, soft carbon, and hard carbon [96]. EPD was carried out at various voltages. A small amount of soft carbon and hard carbon was observed at low deposition voltages, but it increased suddenly at voltages higher than $250 \mathrm{~V}$. The discharge capacities of these electrodes prepared by EPD were $296-395 \mathrm{mAh} \cdot \mathrm{g}^{-1}$ and the charge-discharge efficiencies were more than $90 \%$ for 30 cycles. This study also demonstrated that EPD can be applied successfully to the deposition of carbon materials with different particle shapes and grain sizes without any other binders [97]. In related studies, Lu et al. reported the preparation of binder-free graphite electrode by EPD [98]. The electrochemical properties of the electrodes prepared by EPD and conventional graphite electrode including PVDF as a binder were compared. EPD using $\mathrm{Cu}$ foil as a working electrode was conducted at $24 \mathrm{~V}$. The capacity of the binder-free graphite electrode was $220 \mathrm{mAh} \cdot \mathrm{g}^{-1}$, which is twice as large as the $100 \mathrm{mAh} \cdot \mathrm{g}^{-1}$ of the conventional graphite electrode at a 0.5 C-rate, as shown in Figure 8. XRD showed that copper-oxide was coated on the graphite particles during the EPD process. The copper-oxide coating on the graphite particles led to enhanced capacity because they changed to metallic $\mathrm{Cu}$, which forms a modified solid electrolyte interphase (SEI) layer during the charge/discharge process.

(a)

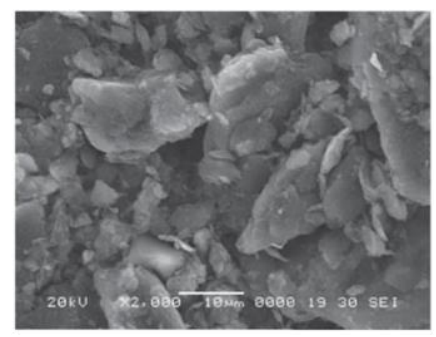

(c)

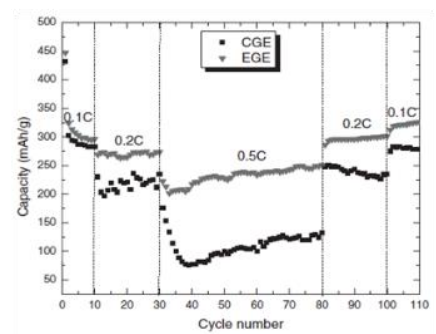

(b)

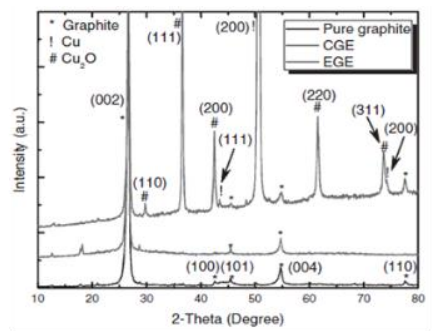

(d)

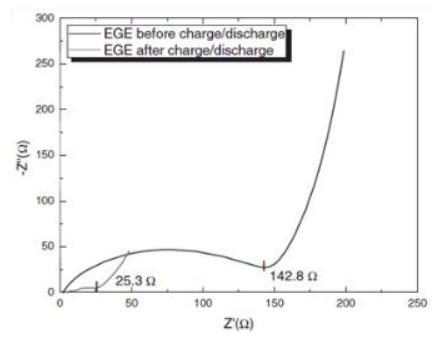

Figure 8. Binder-free graphite prepared by EPD as the anode for Li ion batteries: (a) Morphology of binder-free graphite; (b) XRD pattern of binder-free graphite; (c) C-rate performance of binder-free graphite; (d) Electrochemical impedance spectra of binder-free graphite before and after the electrochemical evaluation.

When the initial lithiation state, a solid electrolyte interphase (SEI), which is a stable passivating layer, can be formed at the interface between the anode and the electrolyte due to the electrochemical instability at the anode/electrolyte interface [99-105]. SEI formation is one of the most important and fundamental reactions of Li-ion batteries and is critical to the reversible cycling performance [105]. The characterization of SEI components is difficult with a conventional graphite electrode because the electrode contains a polymer binder material. The binder-free graphite electrode is required to achieve a better understanding of the SEI. Abraham et al. employed the EPD process to fabricate a binder-free graphite anode and elucidated the anode SEI in various electrolytes [105]. The binder-free graphite obtained an initial specific capacity of 400,360 , and $400 \mathrm{mAh} \cdot \mathrm{g}^{-1}$ in the $\mathrm{LiPF}_{6} / \mathrm{EC}, \mathrm{LIPF}_{6} / \mathrm{EMC}$, $\mathrm{LIPF}_{6} / \mathrm{EC} / \mathrm{EMC}(3: 7 v / v)$ electrolytes, respectively (Figure $\left.9 \mathrm{~b}\right)$. Transmission electron microscopy 
(TEM) with energy dispersive X-ray spectroscopy on the edge planes of binder-free graphite electrode during the first lithiation (Figure $9 \mathrm{c}-\mathrm{e}$ ). The results suggested that when an electrolyte composed of $\mathrm{LiPF}_{6} / \mathrm{EC}$ was utilized, the composition of the anode SEI was constant during the entire charging process, suggesting that the initially formed SEI close to the graphite surface is identical to the SEI at the electrolyte interface. Moreover, the SEI composition was also unchanged with increasing number of cycles up to at least five. All the extracted electrodes contained the same two components, lithium ethylene decarbonate (LEDC) and lithium fluoride (LiF) (Figure 9f). The SEI is located primarily on the edges of the graphite and was relatively thin at $\sim 50 \mathrm{~nm}$. Kang and Xiao et al. also used the EPD process to prepare a binder-free graphite anode, and the SEI layers formed on the graphite electrode in lithium cells containing $\mathrm{LiF}_{2} \mathrm{BC}_{2} \mathrm{O}_{4}, \mathrm{LiBF}_{4}$, and $\mathrm{LiB}\left(\mathrm{C}_{2} \mathrm{O}_{4}\right)$ electrolytes were examined [106,107].

(a)

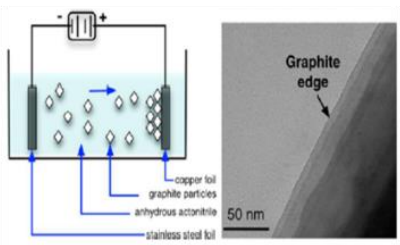

(c)

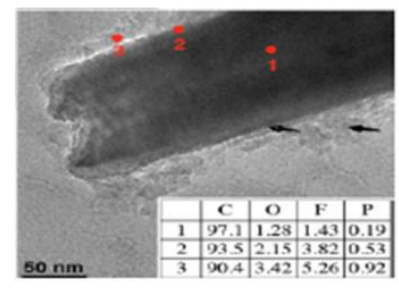

(e)

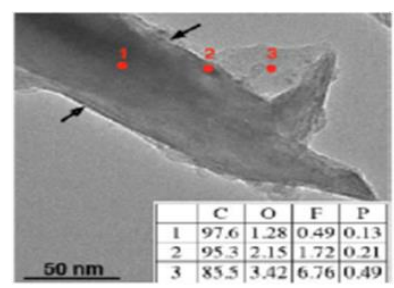

(b)

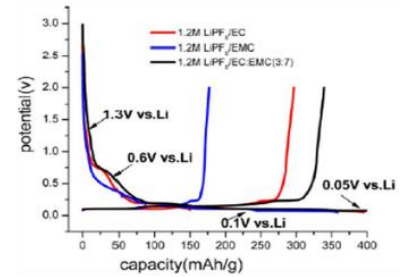

(d)

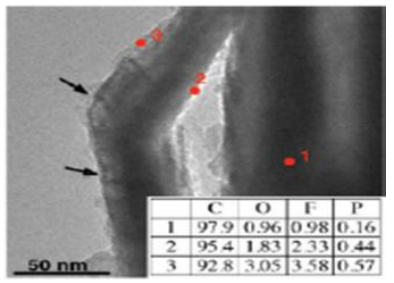

(f)

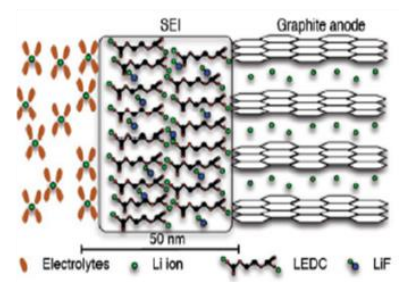

Figure 9. Binder-free graphite prepared by EPD as the anode for Li ion batteries: (a) Morphology of binder-free graphite; (b) Voltage versus capacity plots with $\mathrm{LiPF}_{6} / \mathrm{EC}, \mathrm{LIPF}_{6} / \mathrm{EMC}$, and $\mathrm{LIPF}_{6} / \mathrm{EC} / \mathrm{EMC}(3: 7 v / v)$ electrolytes. TEM images of binder-free graphite anode cycled to 0.05 V vs. $\mathrm{Li} / \mathrm{Li}^{+}$; (c) $\mathrm{LiPF}_{6} / \mathrm{EC}$; (d) $\mathrm{LiPF}_{6} / \mathrm{EMC}$; (e) $\mathrm{LiPF}_{6} / \mathrm{EC} / \mathrm{EMC}$, respectively. The red spots indicate the areas examined by EDX; (f) Schematic figure of SEI formed on graphite anodes during the first cycle.

Nie et al. also employed the EPD process to fabricate a binder-free graphite anode electrode to examine the graphite anode SEI in electrolytes including LiTFSI, LIFSI, and LiDFOB dissolved in ethylene carbonate (EC) [108]. The SEI layers on graphite during the entire charging process could be responsible for the electrochemical performance of the graphite anode. Graphene is a relatively new and promising material for use in energy storage applications because of its large surface area; good flexibility; good chemical and thermal stability; wide potential windows; rich surface chemistry; and extraordinary electrical, thermal and mechanical properties [109-114]. Lee et al. reported a graphene nanosheet electrode prepared by EPD. EPD was carried out in a suspension of IPA containing nickel nitrate salt [115]. The electric field was set to $100 \mathrm{~V} \cdot \mathrm{cm}^{-1}$ for $10 \mathrm{~min}$. The resulting electrophoretically deposited graphene nanosheet electrode showed a reversible specific capacity of $932 \mathrm{mAh} \cdot \mathrm{g}^{-1}$ at a rate of $0.2 \mathrm{C}$. Stable reversible capacities were reached at $200 \mathrm{mAh} \cdot \mathrm{g}^{-1}$ after 20 cycles. Seo et al. used EPD to deposit MWCNTs/graphene nanosheet composite directly on $\mathrm{Al}$ foil to fabricate an anode electrode, as shown in Figure 10a [116]. The suspension for EPD were prepared using $\mathrm{Ni}\left(\mathrm{NO}_{3}\right)_{2}$ in isopropyl alcohol (IPA). EPD was carried out at $100 \mathrm{~V}$ for $10 \mathrm{~min}$. The MWCNTs/graphene nanosheet (40:60 
$v / v$ ) anode showed an initial specific capacity of $2200 \mathrm{mAh} \cdot \mathrm{g}^{-1}$, which decreased to $458 \mathrm{mAh} \cdot \mathrm{g}^{-1}$ after 10 cycles (Figure 10b). In contrast, the capacity of the graphene nanosheet electrode without MWCNTs decreased from $1700 \mathrm{mAh} \cdot \mathrm{g}^{-1}$ to $282 \mathrm{mAh} \cdot \mathrm{g}^{-1}$, and the capacity of the MWCNTs without the graphene nanosheet decreased from $1000 \mathrm{mAh} \cdot \mathrm{g}^{-1}$ to $170 \mathrm{mAh} \cdot \mathrm{g}^{-1}$ within 10 cycles (Figure 10b). The results suggest that in the MWCNTs/graphene nanosheet composite electrode, the MWCNTs could serve as a spacer between the graphene nanosheet, providing a much higher porosity and efficient diffusion pathways for the electrolyte ions, as shown in Figure 10c.

(a)

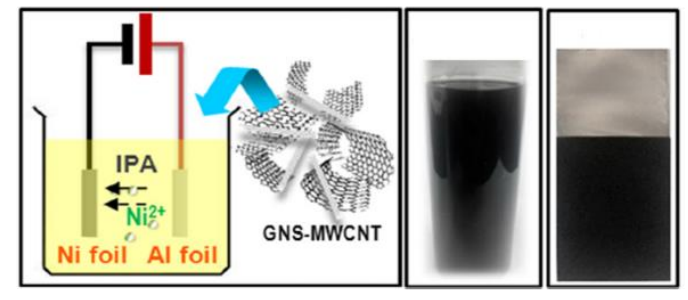

(b)

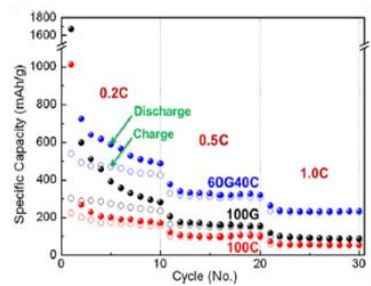

(c)

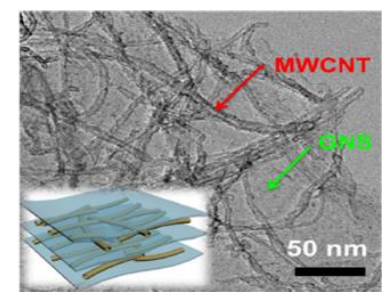

Figure 10. MWCNTs/graphene nanosheet composite prepared by EPD as the anode for Li-ion batteries: (a) Schematic representation of the electrophoretic deposition process, and MWCNTs/graphene nanosheet composite film deposited electrophoretically on Ni foil, respectively; (b) Cycling performance of the MWCNTs/graphene nanosheet composite electrodes at various current rates; (c) Typical HR-TEM image of 60G40C composites. The inset in the figure shows a schematic illustration of the MWCNTs/graphene nanosheet composites with uniform mixing.

\subsubsection{Metal Oxide-Based Anode Materials}

Replacing the carbon anode materials with higher-capacity anode materials could improve the specific capacity and energy of Li-ion batteries because this material has disadvantages, such as low stability and energy density. Metal oxides, which typically provide a capacity that is more than two times larger than that of carbon materials with higher potential, have attracted considerable interest [117-122]. Li-ion storage and release with these materials are based on the following conversion reaction:

$$
\mathrm{M}_{x} \mathrm{O}_{y}+2 y \mathrm{Li}^{+}+2 y \mathrm{e}^{-} \boxminus 2 \mathrm{M}+y \mathrm{Li}_{2} \mathrm{O},
$$

where $\mathrm{M}$ is a metal, such as $\mathrm{Sn}, \mathrm{Co}, \mathrm{Ni}, \mathrm{Fe}, \mathrm{Ti}, \mathrm{Cu}$, and $\mathrm{Mn}$, and the final product consists of a homogeneous distribution of metal nanoparticles embedded in $\mathrm{Li}_{2} \mathrm{O}$ matrix. Based on the conversion reaction, transition metal oxides have theoretical specific capacities, as high as $>1000 \mathrm{mAh} \cdot \mathrm{g}^{-1}$. On the other hand, their materials cause poor cyclic performance arising from the huge volume expansion and severe aggregation of metal oxides that decrease the reversible capacity during the charge-discharge cycles. Another drawback is the large voltage hysteresis between charge and discharge together with the poor energy efficiency. Nanoscale materials are attractive anode materials because they exhibit better adaptability to the strain arising from $\mathrm{Li}$ insertion/removal thereby improving the electrochemical cyclability. Moreover, the large surface area of nanomaterials allows for high charging/discharging rates because of the increased Li-ion flux through the liquid electrolyte/nanosized electrode material interface [123-125]. In particular, nanoscale transition metal oxides have been studied as alternative anode materials owing to their high capacity and excellent cycle reversibility. Various other transition metal oxides, such as $\mathrm{Fe}_{3} \mathrm{O}_{4}, \mathrm{Fe}_{2} \mathrm{O}_{3}, \mathrm{Co}_{3} \mathrm{O}_{4}, \mathrm{SnO}_{2}, \mathrm{TiO}_{2}$, and 
$\mathrm{Mn}_{3} \mathrm{O}_{4}$, produced improved energy densities and high power density beyond the bulk values [126-130]. A homogeneous composition and a monodisperse morphology is crucial for maximizing the nanoscale advantages. On the other, the size distribution and morphology of nanoparticles used in the electrode for Li-ion batteries cannot be controlled easily using conventional methods, such as casting or drop coating. Recently, EPD has attracted considerable attraction because the process can be applied to produce high-quality dense nanoparticle films with built-in charge transfer pathways without the need for binders that are free of conducting materials for anode electrodes. Importantly, the anode electrodes prepared by EPD with conducting additives or cohesive polymer binders allows an examination of the origins of the irreversible capacity loss during the whole battery operation [131-138]. Ha et al. prepared a nanoparticle film by the EPD of colloidally synthesized, monodisperse cobalt nanoparticles that were transformed to hollow $\mathrm{Co}_{3} \mathrm{O}_{4}$ through the nanoscale Kirkendall effect [139]. EPD was carried out for 10-30 min depending on the concentration and voltage. The $\mathrm{Co}_{3} \mathrm{O}_{4}$ nanoparticle films formed by EPD showed a higher density than that of the films prepared by conventional slurry and drop casting methods. The EPD film exhibited little or no de-adhesion of nanoparticles from the adhesion test compared to the films fabricated by conventional slurry and drop casting methods, as shown in Figure 11b. This excellent mechanical stability might provide a critical benefit for building a battery without additives. The resulting $\mathrm{Co}_{3} \mathrm{O}_{4}$ nanoparticle films formed by EPD showed a high reversible specific capacity of $1820 \mathrm{mAh} \cdot \mathrm{g}^{-1}$ at a rate of $0.05 \mathrm{C}$, and retained a capacity of $890 \mathrm{mAh} \cdot \mathrm{g}^{-1}$ after 50 cycles (Figure 11c). The EPD voltage did not influence the cycling performance significantly within the range from 150 to $600 \mathrm{~V}$, as shown in Figure 11d. On the other hand, the battery capacity depended strongly on the film thickness due to the limitation of the electrical conductivity of the oxide particles. TEM showed that after the first lithiation process, the hollow $\mathrm{Co}_{3} \mathrm{O}_{4}$ nanoparticles were no longer individual hollow nanoparticles. Moreover, after delithiation, the nanoparticles were even smaller than hollow nanoparticles. They suggested that these small nanoparticles can reversibly particles system, $5-10 \mathrm{~nm}$ may be a stable size for reversible lithiation and delithiation with pulverization. EPD is a critical solution-processing technique for achieving good battery performance for nanoparticles films.

Kim et al. employed EPD to examine the origins of the irreversible capacity loss by probing the changes in the electronic and structural properties of additive-free hollow structured $\mathrm{Co}_{3} \mathrm{O}_{4}$ nanoparticles [140]. The $\mathrm{Co}_{3} \mathrm{O}_{4}$ nanoparticles were assembled into monolayer scale and thick films up to $400 \mathrm{~nm}$ in thickness using EPD in a strong electric field. The nanoparticles film exhibited a specific capacity of $1300 \mathrm{mAh} \cdot \mathrm{g}^{-1}$ in the first discharge at a current density of $100 \mathrm{~mA} \cdot \mathrm{g}^{-1}$. A stabilized specific capacity of approximately $800 \mathrm{mAh} \cdot \mathrm{g}^{-1}$ was observed after three cycles. The $\mathrm{Co}_{3} \mathrm{O}_{4}$ nanoparticle film showed smaller capacity loss than the drop-cast film electrode. Wang et al. prepared a $\mathrm{V}_{2} \mathrm{O}_{5}$ nanoparticle film by EPD (Figure 12a) with a capacity of $300 \mathrm{mAh} \cdot \mathrm{g}^{-1}$ after 50 cycles when cycled between 0.4 and $1.6 \mathrm{~V}$ (Figure 12c) [134]. The porous structured $\mathrm{V}_{2} \mathrm{O}_{5}$ nanoparticle film prepared by EPD led to $\mathrm{Li}^{+}$intercalation capacity and enhanced cyclic stability. Wu's group reported the preparation of a monodisperse macroporous architecture of the $\mathrm{NiO}$ film as the anode electrode [138]. EPD was used to deposit the monolayer polystyrene sphere followed by the electrodeposition of $\mathrm{NiO}$ (Figure 12b). The film was immersed in a toluene solution to remove the PS template and annealed at $400{ }^{\circ} \mathrm{C}$. The macroporous $\mathrm{NiO}$ film as an anode electrode reached $1620 \mathrm{mAh} \cdot \mathrm{g}^{-1}$ at a rate of $1 \mathrm{C}$ and had a high capacity of $990 \mathrm{mAh} \cdot \mathrm{g}^{-1}$ at a rate of $15 \mathrm{C}$, which was approximately 2.7 times higher than that of the bare $\mathrm{NiO}$ film at the same rate (Figure 12d). A two-step process involving EPD and electrodeposition is a feasible technique for obtaining a monodispersed macroporous architecture electrode with enhanced capacity. 
(a)

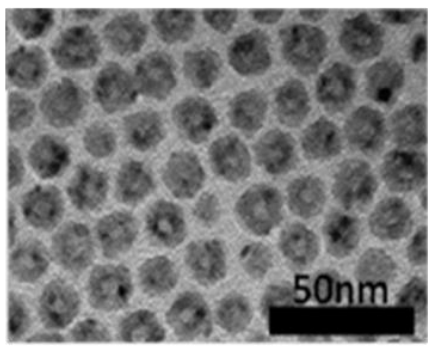

(c)

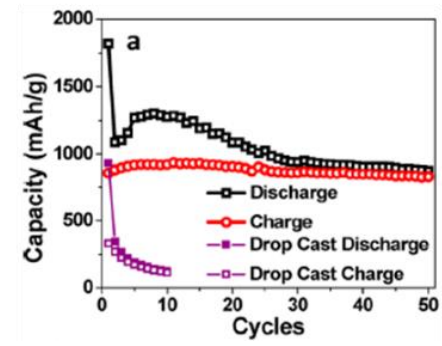

(b)

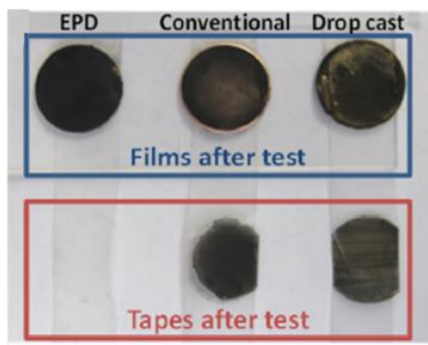

(d)

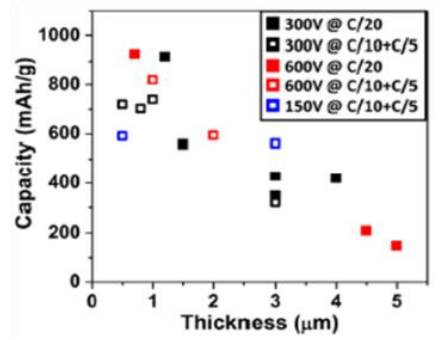

Figure 11. $\mathrm{Co}_{3} \mathrm{O}_{4}$ nanoparticle films prepared by EPD as the anode for Li-ion batteries: (a) TEM image of $\mathrm{Co}_{3} \mathrm{O}_{4}$ nanoparticles; $(\mathbf{b})$ Mechanical stability test of the $\mathrm{Co}_{3} \mathrm{O}_{4}$ nanoparticle films prepared by EPD, conventional slurry, and drop casting; (c) Capacity retention of $\mathrm{Co}_{3} \mathrm{O}_{4}$ nanoparticle films at a rate of $0.05 \mathrm{C}$ showing the charge (red circles) and discharge (black squares); (d) Relationship between the average film thickness and the charge capacity for different applied voltages during EPD.

(a)

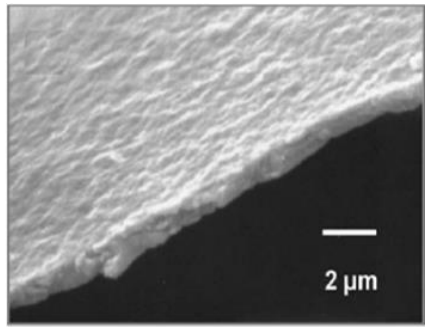

(c)

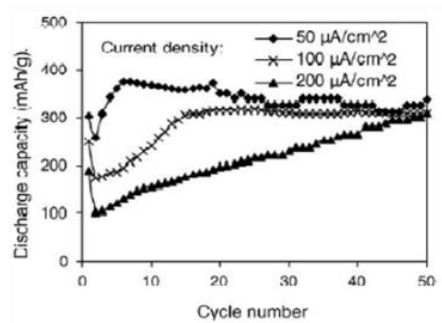

(b)

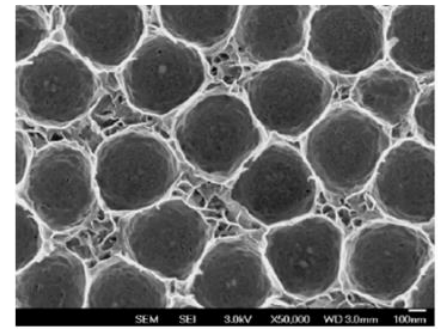

(d)

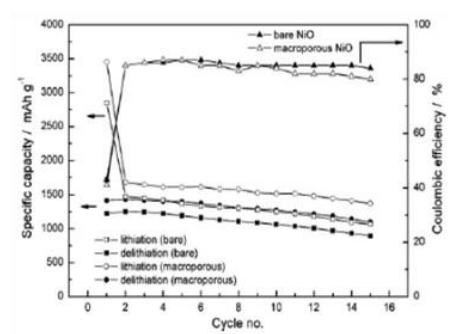

Figure 12. (a) SEM image of the $\mathrm{V}_{2} \mathrm{O}_{5}$ film prepared by EPD; (b) SEM image of a macroporous $\mathrm{NiO}$ film; (c) Cycling performance of $\mathrm{V}_{2} \mathrm{O}_{5}$ films prepared by EPD; (d) Cycling performance of a macroporous $\mathrm{NiO}$ film.

\subsubsection{Metal Oxide/Carbon Hybrid-Based Electrodes}

Although nanostructured transition metal oxides have been developed for use as anodes in Li-ion batteries, researchers have focused mainly on carbonaceous materials, such as graphite, carbon nanotubes, and graphene, as buffer carriers for effectively suppressing the pulverization and capacity fading of metal oxide anodes during the charge-discharge cycles [141-144]. Carbonaceous materials/metal oxide nanoparticles composites are expected to improve the stability over repeated charge-discharge cycling because carbon materials restrain the volume change in the active materials and enhance the conductivity of active materials. Generally, to fabricate an electrode for Li-ion batteries, a slurry containing a mixture of the active materials, conductive additives, and binder 
based on poly (vinylidene fluoride) (PVDF) is used. This means that an additional process is needed to combine the active materials with conducting additives and binders. In particular, the use of binders always degrades the performance of Li-ion batteries [145-147]. To solve this problem, EPD has attracted attention because it does not require extra binders or conductive additives for fabricating an electrode, and it can lead to a controllable and prominently improved energy density. The carbonaceous materials/metal oxide nanoparticles composite electrodes have been fabricated by EPD. Ui et al. used EPD to fabricate binder-free $\mathrm{SnO}_{2}$ nanoparticles/acetylene black (AB) electrodes [148]. EPD was carried out at $100 \mathrm{~V}$ for $10 \mathrm{~s}$ in acetone. The weight percentage of $\mathrm{AB}$ in the deposited film increased with increasing concentration of $\mathrm{AB}$ particles in acetone. The composition of the co-deposited film could be controlled easily by changing the concentration of $\mathrm{AB}$ particles. The resulting $\mathrm{SnO}_{2}$ nanoparticles / $\mathrm{AB}$ electrode showed an initial specific capacity of $887 \mathrm{mAh} \cdot \mathrm{g}^{-1}$ at a rate of $0.1 \mathrm{C}$ and a capacity after 50 cycles at $504 \mathrm{mAh} \cdot \mathrm{g}^{-1}$. Carbon nanotubes (CNTs) are used frequently as materials for composites with metal oxides. Metal oxide/CNTs can improve the electrochemical performance better than pure metal oxide nanoparticles due to the advantageous effects of the CNTs, such as a large surface area and high electrical conductivity. Xiao et al. used EPD to deposit directly $\mathrm{MnO}_{2}-\mathrm{MWCNTs}$ composites synthesized via a facile chemical bath deposition process. The resulting $\mathrm{MnO}_{2}-\mathrm{MWCNTs}$ composite film showed a specific discharge capacity of $741 \mathrm{mAh} \cdot \mathrm{g}^{-1}$ for the first cycle and $407 \mathrm{mAh} \cdot \mathrm{g}^{-1}$ for the 20th cycle [149]. EPD does not require the addition of binders and conductive additives, and leads to enhanced energy density of the electrode. Kim and co-workers developed two processing approaches involving the EPD of MWCNTs [150,151]. They used EPD to fabricate a binder-free MWCNTs film to synthesize metal oxide nanoparticles and nanorods by chemical vapor deposition (CVD), as shown in Figure 13a. $\mathrm{SnO}_{2}$ nanoparticles were deposited uniformly on the CNT surface by $\mathrm{CVD}$ (Figure 13b). The resulting binder-free $\mathrm{SnO}_{2}$-MWNCTs composite electrode showed a reversible capacity of $836 \mathrm{mAh} \cdot \mathrm{g}^{-1}$ in the first cycle and $470 \mathrm{mAh} \cdot \mathrm{g}^{-1}$ after 1000 cycles (Figure 13c) as well as a binder-free CoO-MWNCT composite with a reversible capacity of 600 and $550 \mathrm{mAh} \cdot \mathrm{g}^{-1}$ at a rate of $715 \mathrm{~mA} \cdot \mathrm{g}^{-1}$ after 50 and 100 cycles (Figure 13e), respectively, because the CNT film prepared by EPD provided several beneficial factors, such as facile electron transport, minimization of aggregation of the nanoparticles, and alleviation of huge volume expansion. EPD proved to be a more suitable technique for the production of MWCNTs films with better packing and alignment than spray or deep coating techniques without the addition of crosslinking molecules or binders.

(a)
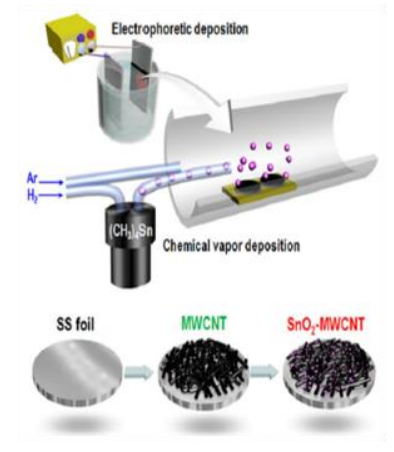

(b)

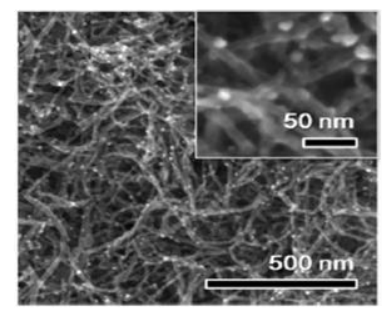

(c)

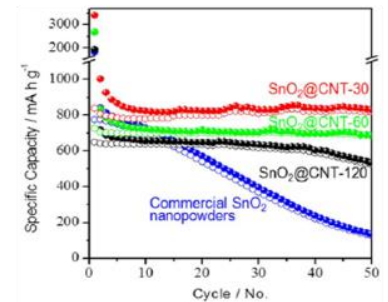

(d)

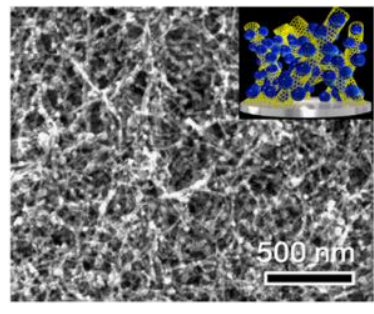

(e)

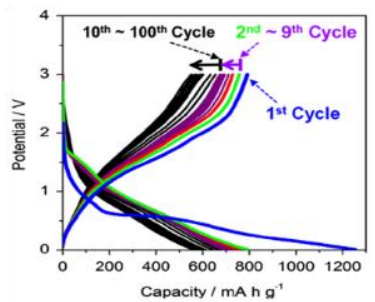

Figure 13. (a) Schematic illustration of the two-step process for the $\mathrm{SnO}_{2}-\mathrm{CNT}$ electrode; (b) SEM image of binder-free $\mathrm{SnO}_{2}$ nanoparticles-CNT electrode; (c) Cycling performance of binder-free $\mathrm{SnO}_{2}$ nanoparticle-CNT electrode; (d) SEM image of binder-free $\mathrm{CoO}$ nanoparticle-CNT electrode. (e) Charge-discharge curves of $\mathrm{CoO}$ nanoparticle-CNT electrode. 
Recently, EPD has been used successfully to deposit the binder-free graphene oxide-based graphene or graphene-based films, including nanosized metal oxides for use as the anode electrode [152-155]. Rangasamy et al. fabricated a binder-free, multi-layered Si-CuO quantum dot-wrapped graphene electrode by EPD [152]. In this work, well dispersed aqueous suspensions of graphene oxide were prepared (Figure 14a). The materials were deposited on $\mathrm{Cu}$ foil by EPD with a constant voltage of $10 \mathrm{~V}$ for $1 \mathrm{~min}$ and a second EPD was then carried out in suspensions of water and $\mathrm{HF}$, including Si quantum dots (QD) by applying voltage of $10 \mathrm{~V}$ for $1 \mathrm{~min}$. The multi-layered electrode was applied by annealing at $400{ }^{\circ} \mathrm{C}$ for $30 \mathrm{~min}$ under an $\mathrm{Ar}$ atmosphere for a further reduction process for graphene oxide. The annealed graphene/Si-CuO QD multi-layered film electrode exhibited an initial specific capacity of $2760 \mathrm{mAh} \cdot \mathrm{g}^{-1}$ at a rate of $0.5 \mathrm{C}$, which decreased gradually to $350 \mathrm{mAh} \cdot \mathrm{g}^{-1}$ at a rate of $5 \mathrm{C}$ with $12 \%$ retention, as shown in Figure 14b. The low-cost two-step process did not require the addition of binders and conductive additives, and led to reduced GO layers coupled to metal oxide layers to enhance the energy density of the electrode. Wang and co-workers proposed anchored nanosized metal oxide particles to the graphene surface using a facile one step EPD process and followed by thermal annealing $[153,154]$. This strategy avoided the use of harsh chemicals for reducing GO, and was free from binders or additives for fabricating Li-ion batteries. During EPD, the metal ions were reduced electrochemically to metal nanoparticles and then converted to metal oxide nanoparticles after annealing, producing a good final dispersion in the hybrid deposit, as shown in Figure 14c,e. The rate capability and cycling stability of their electrodes were improved significantly because highly conducting graphene offered conducting channels for nanoparticles and the nanoparticles allowed a large contact area between the electrode materials and the electrolyte. Thus, EPD is a convenient technique to obtain, in a single step, layers or composites of graphene and metal oxide nanoparticles with high capacity.

(a)

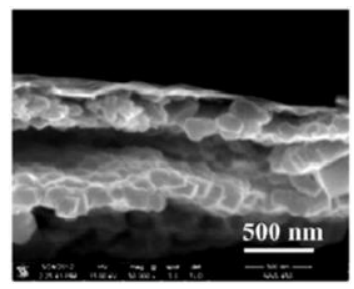

(b)

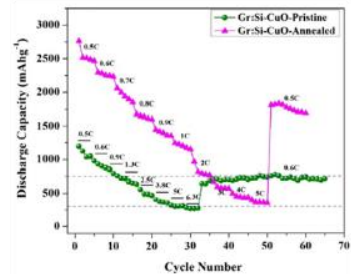

(c)

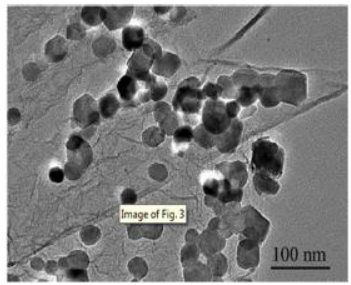

(d)

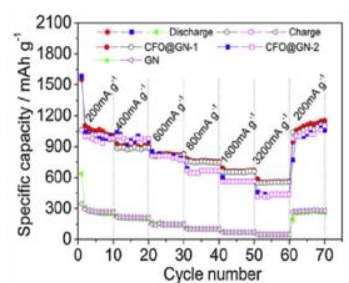

(e)

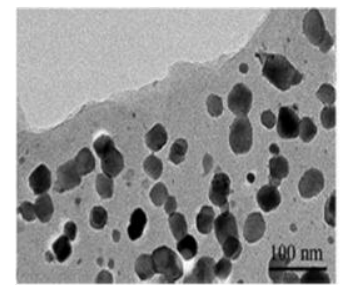

(f)

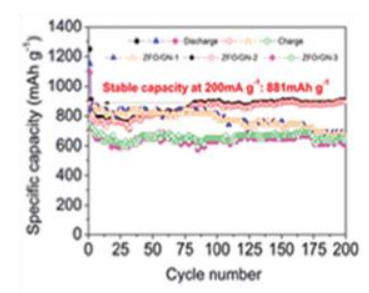

Figure 14. (a) SEM image of a graphene/Si-CuO QD multi-layered film electrode; (b) Cycling performance of a graphene/Si-CuO QD multi-layered film electrode; (c) SEM image of graphene/ $\mathrm{ZnFe}_{2} \mathrm{O}_{4}$ nanoparticle electrode; (d) Cycling performance of a graphene $/ \mathrm{ZnFe}_{2} \mathrm{O}_{4}$ nanoparticle electrode; (e) SEM image of a graphene/ $\mathrm{CoFe}_{2} \mathrm{O}_{4}$ nanoparticle electrode; (f) Cycling performance of a graphene $/ \mathrm{CoFe}_{2} \mathrm{O}_{4}$ nanoparticles electrode.

Lithium can react with metallic/semi-metallic elements and metal alloys, such as $\mathrm{Si}, \mathrm{Sn}, \mathrm{Ge}$, $\mathrm{Bi}, \mathrm{Cu}-\mathrm{Sn}$, and $\mathrm{Ni}-\mathrm{Sn}$, showing high capacity, while their applications face the same challenge of large volume changes during $\mathrm{Li}$ alloying/dealloying processes as metal oxides, which leads to severe capacity fading [156-160]. Carbonaceous materials/small metal nanoparticles composites are also expected to show improved stability over repeated charge-discharge cycling. EPD was used to fabricate binder-free metal-composite electrode films to enhance the performance [161-164]. Hwang et al. used EPD to prepare MWCNTs film electrodes followed by vapor-phase transport and nucleation of Ge nanoparticles on pre-deposited MWCNTs networks [161]. A uniform film was obtained when EPD 
was carried out at $100 \mathrm{~V}$ for $2 \mathrm{~min}$. The specific capacities and irreversibility between the discharge and charge capacities were stabilized after the first few cycles. A reversible capacity of more than $810 \mathrm{mAh} \cdot \mathrm{g}^{-1}$ was achieved, even after 200 cycles, which is approximately 2.2 times larger than that of a carbon-based anode electrode. Seo et al. developed Sn-MWCNTs nanocomposite anode films, in which the Sn nanoparticles were assembled on the MWCNTs film prepared directly by EPD [162]. The electrolytic deposition for Sn nanoparticles was conducted to synthesize Sn-MWCNTs nanocomposite anode film. The nanocomposite anode film showed better cycle performance and maintained higher reversible capacity. At the first discharge, the electrode showed a high specific capacity of $2100 \mathrm{mAh} \cdot \mathrm{g}^{-1}$ and was stabilized irreversibly around $700 \mathrm{mAh} \cdot \mathrm{g}^{-1}$ after 100 cycles. Interconnected MWCNTs nanoscale networks with large surface areas formed by EPD help to alleviate the effects of the huge volume change during the Li-alloying/de-alloying process. Recently, another approach to reduce the large volume expansion during charge/discharge cycling was suggested: the application of three-dimensional (3-D) porous structures [165-168]. EPD of a 3-D porous structure has been explored to simplify the synthetic approach and reduce the preparation time of composite anode electrodes [169-173]. This strategy integrates both the 3-D porous structure and composite coating. Carter et al. deposited single-walled carbon nanotubes (SWCNTs) directly on 3-D Ni foam by EPD [173]. The EPD for SWCNTs was carried out in polar NMP solvents without binders and surfactant-based dispersions. The 3-D SWCNTs anode electrode without the surfactant showed a higher specific capacity of $2210 \mathrm{mAh} \cdot \mathrm{g}^{-1}$ than that of 3-D SWCNTs anode electrode with the surfactant $\left(1840 \mathrm{mAh} \cdot \mathrm{g}^{-1}\right)$ after 200 cycles at a rate of $0.5 \mathrm{C}$. Such high performance was attributed to the morphology of the electrode and the absence of a surfactant led to higher average energies for electrolyte decomposition and metal storage and lower average energies for replenishing the electrolyte with Li metal. Cohn et al. developed two processing approaches to graphene-SWCNTs 3D-porous anode electrodes involving the EPD of SWCNTs [171]. The CVD process was used to deposit multi-layered graphene on 3D-Ni foam and EPD was then carried out in N-methylpyrrolidon (NMP) suspension to form a 3D-porous graphene-SWCNTs anode electrode (Figure 15a). The resulting 3D-porous graphene-SWCNTs anode electrode showed a high reversible specific capacity of $2640 \mathrm{mAh} \cdot \mathrm{g}^{-1}$ at a rate of $0.5 \mathrm{C}$, which retained $236 \mathrm{mAh} \cdot \mathrm{g}^{-1}$ at $75 \mathrm{C}$. In contrast, a lower specific capacity and cycling performance were observed for the 3D-porous electrodes of graphene because the irreversible capacity led to strong binding between the chemical species and $\mathrm{sp}^{3}$ carbon atoms. The results suggest that as SWCNTs enable reactivity with the electrolyte to chemisorb Li species, and graphene materials provide a surface topology capable of reaching high storage capacities, as shown in Figure 15d. Another type of 3-D porous graphene electrode containing Sn nanoparticles as active materials was obtained by EPD [160]. For EPD, a suspension including $\mathrm{GO}$ and $\mathrm{SnCl}_{2} \cdot 2 \mathrm{H}_{2} \mathrm{O}$ was used. The EPD conditions were $5 \mathrm{~V}$ and $30 \mathrm{~s}$, and graphene/Sn composites were deposited on 3-D Ni foam (Figure 15e). The 3D-porous graphene-Sn composite electrode exhibited a specific capacity of $964 \mathrm{mAh} \cdot \mathrm{g}^{-1}$ at a current density of $500 \mathrm{~mA} \cdot \mathrm{g}^{-1}$, which retained $520 \mathrm{mAh} \cdot \mathrm{g}^{-1}$ after 60 cycles compared to that of the 3D-porous Sn electrode (Figure 15f). The enhancement was attributed to graphene. EPD is a feasible technique for obtaining composite films on 3D-porous substrates with enhanced capacity. In addition, the time required for the preparation of the previously reported hybrid composite electrode was usually longer than $2 \mathrm{~h}$, which was shortened to $30 \mathrm{~s}$ in this work. Furthermore, the electrode is binder-free, whereas an extra conducting agent and binder are usually necessary for the fabrication of other electrodes [174-177]. 
(a)

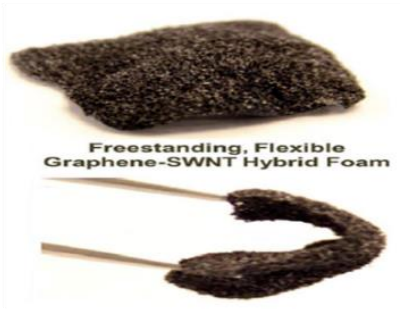

(c)

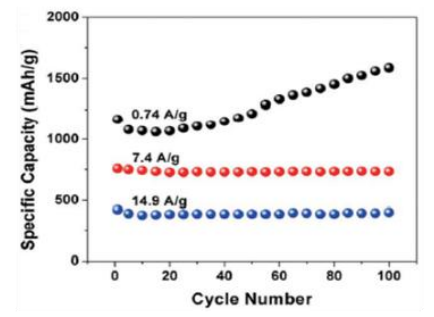

(e)

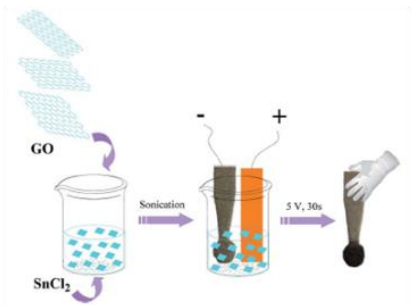

(b)

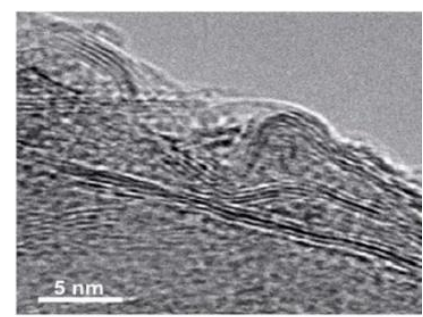

(d)

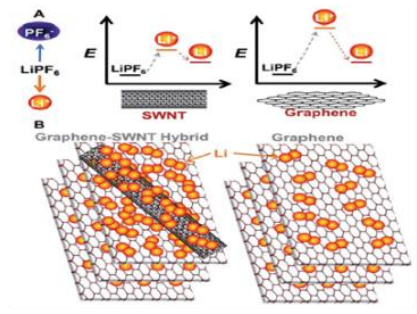

(f)

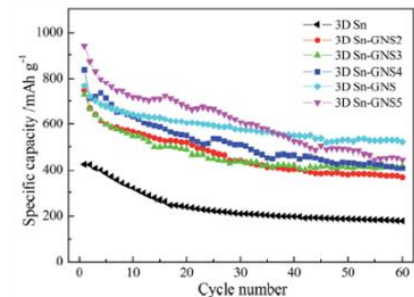

Figure 15. (a) Photograph of the 3D-porous graphene-SWCNTs electrode; (b) TEM image of the 3D-porous graphene-SWCNTs electrode; (c) Cycling performance of the 3D-porous graphene-SWCNTs electrode; (d) Schematic illustration of the improved capacity of the 3D-porous graphene-SWCNTs electrode; (e) Synthetic strategy illustration of the 3D-porous graphene/Sn composite electrode; (f) Cycling performance of the 3D-porous graphene/Sn composite electrode.

The details of the Li-ion electrode manufactured by applying the EPD process are summarized in Tables A1 and A2.

\section{Applications of the Electrophoresis Process for Nanomaterials of Supercapacitors}

Supercapacitors are an important type of energy storage device due to the high power performance and excellent cycling stability as a result of their high power density, fast charging-discharging rate, and excellent cycle stability [178-180]. Generally, there two types of supercapacitor materials with different energy storage mechanisms [181]. One is the electrical double layer capacitor (EDLC) based on the adsorption and desorption of ions. Therefore, it is strongly dependent on the surface area of the electrode materials that is accessible to the electrolyte ions. Another mechanism is a pseudo-capacitor based on the fast and reversible faradic processes that take place due to electro-active species [182,183]. Like batteries, supercapacitors are composed of two electrodes and an electrolyte. Although symmetrical supercapacitors have two identical electrodes made from the same materials, asymmetrical supercapacitors are comprised of two different electrodes including a positive electrode and a negative electrode. Binder materials are unavoidably used to fabricate the electrodes in those paste-coating methods, such as dipped, casted, and sprayed coatings, and they might cover the surface of the electrode materials or block the open porosity network. Recently, the EPD process was reported to be an attractive method for preparing electrodes because the process can be performed without binder materials. The following sections provide an overview of recent scientific and technological improvements of various configurations and electrodes prepared by EPD. 


\subsection{Carbon-Based Materials}

Carbon-based materials ranging from activated carbon to carbon nanotubes (CNTs) are the most widely considered EDLC electrode materials because of their high surface area and somewhat controllable pore size, depending on the method of activation (chemical or physical activation). As one of the most versatile electrode fabrication methods for carbon-based supercapacitors, EPD has been studied widely [184-186]. Nandhini et al. prepared nanoscale ball-milled activated carbon electrodes by EPD carried out at $100 \mathrm{~V}$ in an IPA suspension, including nickel nitrate, which afforded a nanoscale ball-milled activated carbon electrode in the sub-100 $\mathrm{nm}$ range with the highest specific capacitance of $1071 \mathrm{~F} \cdot \mathrm{g}^{-1}$ at a cyclic voltammetry $(\mathrm{CV})$ scan rate of $100 \mathrm{mV} \cdot \mathrm{s}^{-1}$ in $0.1 \mathrm{M} \mathrm{KOH}$ electrolyte [184]. The micro-supercapacitor by rational design of the device architecture and structure of the electrode showed that it could approach the power density of conventional electrolytic capacitors. Owing to restriction to form electrodes in micro-devices using conventional methods, Pech et al. employed EPD to fabricate the electrode for micro-supercapacitors [185]. Onion-like carbon (OLC) was used as the electrode material (Figure 16a). The micro-supercapacitor was fabricated by EPD carried out at $50 \mathrm{~V}$ on interdigital gold electrodes patterned on a Si wafer (Figure 16b). The OLC-based micro-supercapacitors showed ultra-high power handling capability and could be cycled at very high scan rates (Figure 16c), offering a specific capacitance of $0.9 \mathrm{mF} \cdot \mathrm{cm}^{-2}$ at $100 \mathrm{~V} \cdot \mathrm{s}^{-1}$, which is comparable to the values reported in the literature at much lower scan rates $\left(1-100 \mathrm{mV} \cdot \mathrm{s}^{-1}\right)$ for electrochemical double-layer micro-capacitors $\left(0.4-2 \mathrm{mF} \cdot \mathrm{cm}^{-2}\right)[187,188]$. The structure of the OLCs and the binder-fee electrode fabrication by EPD play an important role in the high performance of the micro-supercapacitor. In addition, the short distance between the micro-electrodes results in a decrease in the mean ionic diffusion path between the electrodes. Carbon nanotubes have attracted attention for supercapacitor electrode applications because of their unique pore structure, superior electrical properties, and good mechanical and thermal stability [189-192]. CNTs are usually considered to be the ideal high-power electrode material because of their good electrical conductivity and readily accessible surface area. Moreover, their high mechanical resilience and open tubular network make them a good support for active materials.

(a)

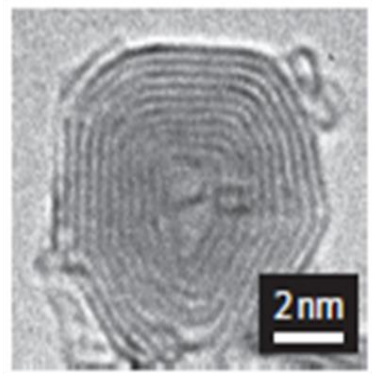

(b)

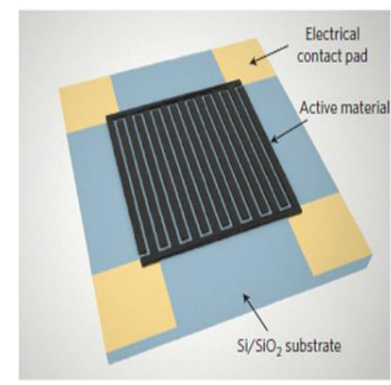

(c)
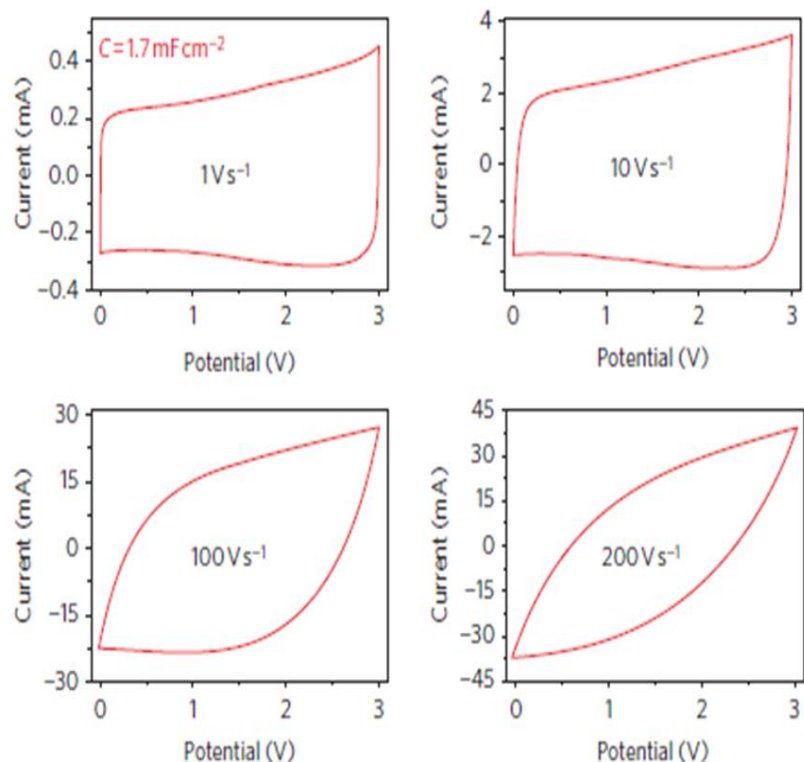

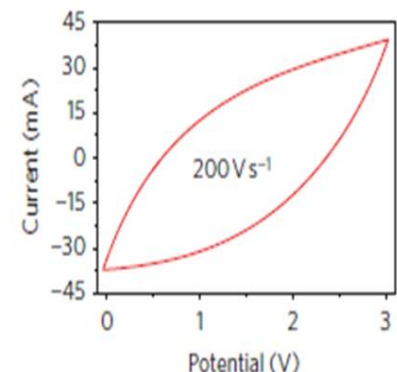

Figure 16. (a) TEM image of OLC produced at $1800{ }^{\circ} \mathrm{C}$; (b) Schematic diagram of the micro-supercapacitor $\left(25 \mathrm{~mm}^{2}\right)$; (c) CV scans at different scan rates for a micro-supercapacitor with 16 interdigital electrodes and tested in $1 \mathrm{M} \mathrm{NEt}_{4} \mathrm{BF}_{4}$ in propylene carbonate (PC). 
The EPD of CNTs has been expanded continuously due to the effective manipulation of CNTs (both single-walled and multi-walled) for applications to supercapacitors [193-196]. Du et al. used EPD to prepare MWCNTs electrodes for supercapacitor applications [193]. The resulting MWCNTs electrode fabricated by EPD showed a pore network MWCNTs film with a high specific surface area. Therefore, the capacitance of $21 \mathrm{~F} \cdot \mathrm{g}^{-1}$ and power density of $20 \mathrm{~kW} \cdot \mathrm{kg}^{-1}$ showed no degradation after 100 cycles at $500 \mathrm{mV} \cdot \mathrm{s}^{-1}$ in a $\mathrm{KOH}$ electrolyte. In particular, hydrogen treatment of the MWCNTs electrode prepared by EPD decreased the resistance of electrode remarkably compared to an argon treatment. Clearly, a considerable amount of oxygen-containing species on the nanotubes were removed by the hydrogen treatment. The resulting hydrogen treatment showed a very low equivalent series resistance (ESR). Moore et al. examined SWCNTs electrodes deposited electrophoretically on stainless steel and compared them with the electrodes prepared by drop coating and high voltage electro-sprayed (HVES) [195]. The electrodes prepared by EPD had higher specific surface areas than that by the other coating processes because EPD suggested a unique pore network SWCNTs film. The SWCNTs electrode prepared at $30 \mathrm{~V}$ for $60 \mathrm{~min}$ showed a high specific capacitance of $26.50 \mathrm{mF} \cdot \mathrm{cm}^{-2}$ at $20 \mathrm{mV} \cdot \mathrm{s}^{-1}$. Dinh et al. fabricated a MWCNTs electrode by EPD for an all-solid-state micro-supercapacitor [196]. The MWCNTs electrode showed a specific capacitance of $1.8 \mathrm{mF} \cdot \mathrm{cm}^{-2}$ in a PVA- $\mathrm{H}_{3} \mathrm{PO}_{4}-\mathrm{SiWA}$ solid electrolyte. The MWCNTs electrode prepared by EPD showed good capacitance in a solid electrolyte. Various carbon materials, including graphene have been used to form an EDL capacitive material owing to its high surface area and electrical conductivity [197-199]. Wang et al. reported the preparation of reduced graphene and MWCNTs composite electrodes for capacitors [200]. The graphene oxide and MWCNTs composite was deposited electrophoretically on carbon cloth and then treated by hydrogen thermal reduction to obtain reduced graphene. Compared to pristine graphene coated on carbon cloth, including polymeric binders, the reduced graphene/MWCNTs deposited on the carbon cloth by EPD showed significantly enhanced specific capacitance, improved rate capability, lower device resistance, and higher power densities due to their porous structure and the synergetic effect between graphene and MWCNTs. EPD proved to be a suitable process for the production of graphene/MWCNTs composite electrodes compared to casting and sprayed methods, while avoiding the addition of polymeric binders. Nam et al. developed another reduced graphene/carbon black spacer composite, in which a binder-free composite was deposited electrophoretically [201]. The relative amount of reduced graphene oxide and carbon black in the deposit was adjusted by the zeta potential with a suspension concentration and $\mathrm{pH}$ for the EPD process. EPD was carried out at $6 \mathrm{~V}$ for $10 \mathrm{~min}$ at $\mathrm{pH} 9$ in a suspension containing a reduced graphene oxide/carbon black weight ratio of 9:1. The composite electrode showed a specific capacitance of $138.4 \mathrm{~F} \cdot \mathrm{g}^{-1}$ at a CV scan rate of $10 \mathrm{mV} \cdot \mathrm{s}^{-1}$ and $133.3 \mathrm{~F} \cdot \mathrm{g}^{-1}$ at a galvanostatic current density of $2 \mathrm{~A} \cdot \mathrm{g}^{-1}$ in a TEA $\mathrm{BF}_{4}$ electrolyte because the electrode incorporates carbon black particles inside the reduced graphene oxide sheets as spacers, meaning that the interlayer distance of reduced graphene/carbon black can adequately accommodate the electrolyte ions. Recently, 3D-architecture electrodes for supercapacitors have been fabricated because the structure effectively prevents the aggregation of graphene and maintains their high specific surface area, resulting in good capacitive performance [202,203]. Because EPD can deposit graphene materials on complicated 3D-porous electrodes without aggregation, Zhang et al. deposited graphene oxide directly on 3D-porous Ni form by EPD [203] and reduced the prepared electrode by a hydrogen treatment (Figure 17a,b). The EPD process was conducted at $50 \mathrm{~V}$ for $13 \mathrm{~min}$ in a water suspension. 
(a)

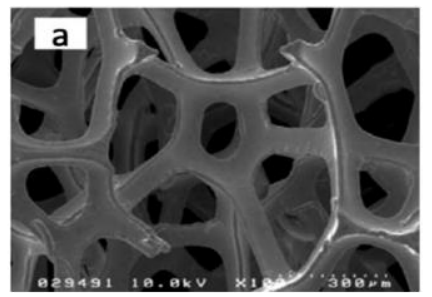

(c)

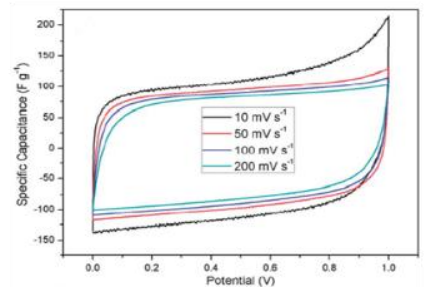

(b)

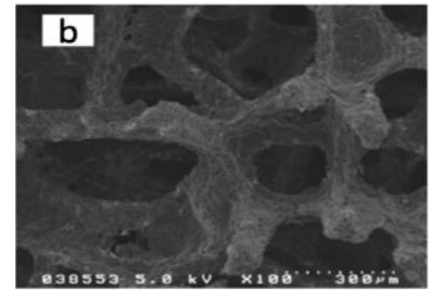

(d)

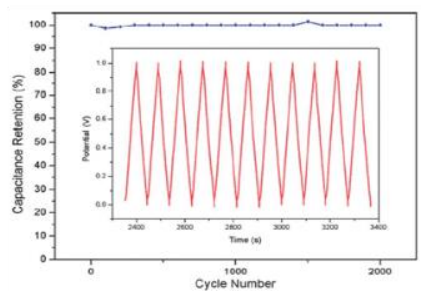

Figure 17. (a) SEM image of bare nickel foam; (b) SEM image of 3D porous graphene electrode prepared by EPD; (c) CV curves at various scan rates of 3D porous graphene electrode prepared by EPD; (d) Cycle performance of 3D porous graphene electrode prepared by EPD at a current density of $1 \mathrm{~A} \cdot \mathrm{g}^{-1}$.

This 3D-porous reduced graphene electrode exhibited a maximum specific capacitance of $110 \mathrm{~F} \cdot \mathrm{g}^{-1}$ at a lower scan rate of $10 \mathrm{~m} \cdot \mathrm{V}^{-1}$ (Figure 18c) as well as no decrease in the initial specific capacitance after 2000 cycles at a galvanostatic current density of $1 \mathrm{~A} \cdot \mathrm{g}^{-1}$ in $6 \mathrm{M} \mathrm{KOH}$ electrolyte (Figure 17d). Thus, EPD provided 3D-porous graphene films suitable for supercapacitor electrodes. Graphene oxide is used widely as an electrode material. On the other hand, it needs to be treated further by chemical, electrochemical, or thermal reduction to regain conductivity. Despite this, post-reduction treatment would destroy the film structure due to the decomposition of oxygen-containing functional groups. To solve this problem, Liu et al. deposited reduced graphene oxide directly by AC-EPD to produce a binder-free electrode for flexible supercapacitors (Figure 18a) [204]. AC-EPD was carried out using positive and negative pulse signals, whose frequency and peak-to-peak voltage $\left(V_{p p}\right)$ at $5 \mathrm{~Hz}$ and $60 \mathrm{~V}$. As a result, the process led to synchronization of the formation and reduction of graphene oxide film (Figure 18b). The reduced-graphene oxide electrodes were prepared at different duty ratios and reactive times $(1,2$, and $3 \mathrm{~h}$ ). XPS showed that the $\mathrm{O} 1$ s peak intensity in an electrode with a $60 \%$ duty ratio and $3 \mathrm{~h}$ reaction time decreased significantly compared to that in graphene oxide (Figure 18c,d). After the reaction, the intensities of all C 1s peaks of carbon binding to oxygen decreased gradually with time or decreasing duty ratio. This can be explained by the fact that a smaller duty ratio means a longer negative pulse time for reducing graphene oxide and restoring the structure within the graphene nanosheets. The capacitor assembled at a $60 \%$ duty ratio and $3 \mathrm{~h}$ reaction time showed a specific capacitance of electrode of $157 \mathrm{~F} \cdot \mathrm{g}^{-1}$, which was larger than the $145 \mathrm{~F} \cdot \mathrm{g}^{-1}$ obtained for an $80 \%$ duty ratio and $3 \mathrm{~h}$ reaction time at a scan rate of $10 \mathrm{mV} \cdot \mathrm{s}^{-1}$ as well as a long cyclic life with approximately $91.3 \%$ specific capacitance retention after 2000 cycles at a scan rate of $100 \mathrm{mV} \cdot \mathrm{s}^{-1}$ (Figure 18f). AC-EPD is a promising method for the environmentally friendly production of graphene electrodes for supercapacitors. 
(a)

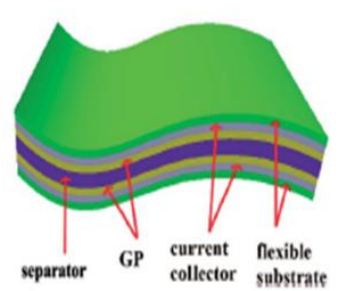

(d)

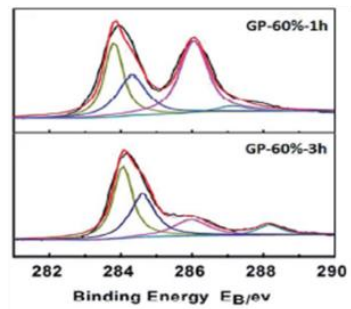

(b)

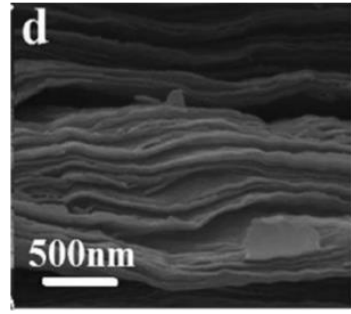

(e)

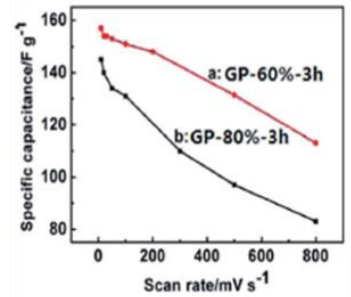

(c)

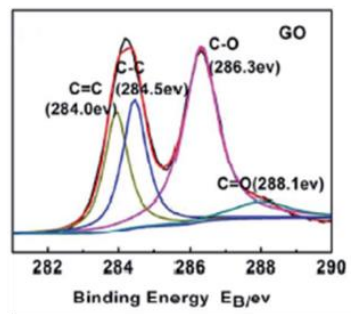

(f)

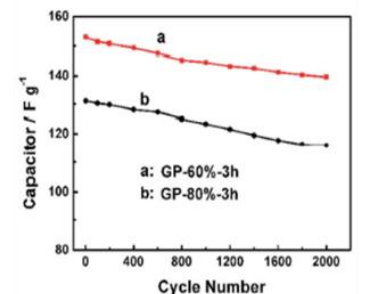

Figure 18. (a) Flexible graphene paper supercapacitor; (b) SEM image of a graphene electrode prepared at a $60 \%$ duty ratio for $3 \mathrm{~h}$; (c) XP spectra of graphene oxide; (d) XP spectra of graphene electrode prepared at a $60 \%$ duty ratio for $3 \mathrm{~h}$; (e) Specific capacitance of graphene electrode prepared at a $60 \%$ duty ratio for $3 \mathrm{~h}$ at $10 \mathrm{mV} \cdot \mathrm{s}^{-1}$; (f) Cycle performance of the graphene electrode prepared at a $60 \%$ duty ratio for $3 \mathrm{~h}$ at $100 \mathrm{mV} \cdot \mathrm{s}^{-1}$.

\subsection{Metal Oxide-Based Materials}

Pseudo-capacitive materials are faradic in origin, involving fast and reversible electrochemical redox reactions between the electrolyte and electro-active species on the electrode surface $[205,206]$. While the pseudo-capacitance can be higher than the EDL capacitance, it suffers from the drawbacks of a low power density due to poor electrical conductivity, leading to a lack of stability during cycling. Although the lack of stability can be improved by adding carbon materials, the metal oxide-based supercapacitors that have a nanostructure were fabricated by EPD without carbon and binder additives for pore and particle networks (high power), and mechanical stability (long cycle life). The most commonly known electrode materials include ruthenium oxide, manganese oxide, nickel oxide, and vanadium nitride as well as electrically conducting polymers, such as polyaniline, and oxygen or nitrogen containing surface functional groups [207-211]. In particular, amorphous hydrous ruthenium oxide $\left(\mathrm{RuO}_{2} \cdot x \mathrm{H}_{2} \mathrm{O}\right)$ exhibited a much higher specific capacitance $\left(720 \mathrm{~F} \cdot \mathrm{g}^{-1}\right)$ due to the mixed proton-electron conductivity in $\mathrm{RuO}_{2} \cdot x \mathrm{H}_{2} \mathrm{O}[207,212,213]$. Jang et al. prepared a $\mathrm{RuO}_{2} \cdot x \mathrm{H}_{2} \mathrm{O}$ electrode by EPD without a binder and conducting additive [213]. EPD was carried out at $50 \mathrm{~V}$, followed by annealing at $250{ }^{\circ} \mathrm{C}$. The highest specific capacitance was $734 \mathrm{~F} \cdot \mathrm{g}^{-1}$ at a cyclic voltammetry (CV) scan rate of $1 \mathrm{mV} \cdot \mathrm{s}^{-1}$ in an aqueous sulfuric acid solution [213]. This study suggests that particle contact was improved significantly by heat-treatment at $250{ }^{\circ} \mathrm{C}$, providing high electronic conductivity between the contact of particles and good mechanical strength. In addition, this group examined the effects of PTEF during EPD [207]. EPD was carried out in 2\% PTEF and 10\% water in ethanol using $50 \mathrm{~V}$ for $1 \mathrm{~min}$. The specific capacitance of the electrode without PTEF decreased rapidly, showing only $5 \%$ of the initial capacitance after 50 cycles due to the poor mechanical stability of the electrode. On the other hand, with PTEF addition, the cyclability was improved by up to $43 \%$ after 200 cycles because PTEF acted as a binder to maintain the electrode layers without heat treatment in a $1.0 \mathrm{M}$ sulfuric acid electrolyte. $\mathrm{MnO}_{2}$ is another attractive pseudo-capacitive material due to its reversible redox capability, low cost, high abundance, and environmental compatibility compared to the other transition metal oxide systems. Various structured $\mathrm{MnO}_{2}$ electrodes prepared by EPD have been developed to enhance the electrochemical performance [208-211,214-217]. Chen et al. synthesized $\mathrm{MnO}_{2}$ powders by spray pyrolysis $[208,209]$. The spray pyrolyzed $\mathrm{MnO}_{2}$ powders exhibiting hollow spherical structures were deposited electrophoretically at $100 \mathrm{~V}$ for $10 \mathrm{~min}$ in a water-based suspension. The electrode prepared by EPD showed reversible electrochemical behavior 
in a $1.0 \mathrm{M} \mathrm{Na}_{2} \mathrm{SO}_{4}$ electrolyte with a high specific capacitance of $275 \mathrm{~F} \cdot \mathrm{g}^{-1}$ at a scan rate of $25 \mathrm{mV} \cdot \mathrm{s}^{-1}$ with a cycling efficiency of $85 \%$ after 300 cycles due to the relatively high surface area of the electrode fabricated by EPD. The specific surface area for the reaction in the electrodes can be controlled by EPD under the conditions of suspensions, substrates with various structures, applied times, and voltages. In addition, EPD has been used to fabricate electrodes for pseudo-capacitors using nanostructures, such as nanofibers [210], nanoneedles [211], nanowires [214], nanorods [215], and nanostars [216]. Ranjusha et al. reported the preparation of a thin film electrode of $\alpha-\mathrm{MnO}_{2}$ nanowires by EPD [214]. The $\alpha-\mathrm{MnO}_{2}$ nanowires were first synthesized by a hydrothermal method, as shown in Figure 19a, and EPD was then carried out to fabricate a thin film electrode at $40 \mathrm{~V}$ for $1 \mathrm{~h}$.

(a)

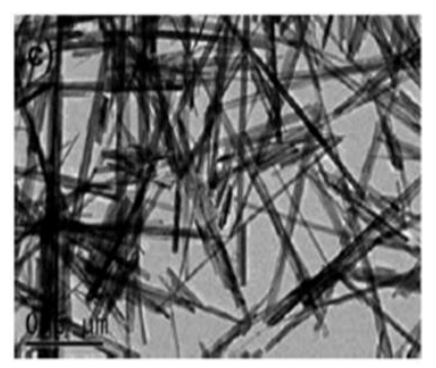

(c)

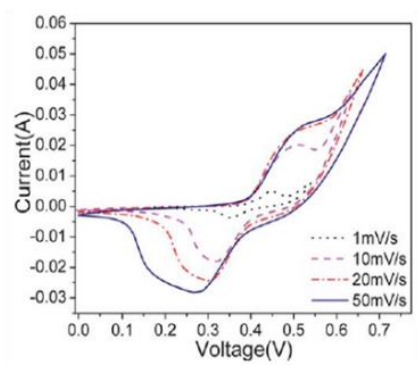

(b)

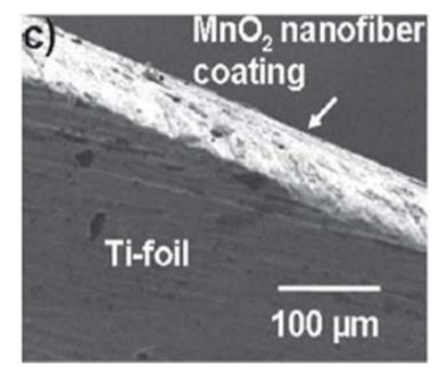

(d)

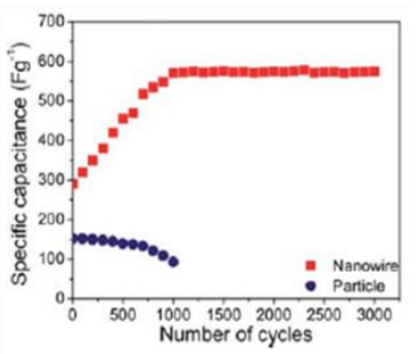

Figure 19. (a) TEM image of $\alpha-\mathrm{MnO}_{2}$ nanowires synthesized by hydrothermal method for $24 \mathrm{~h}$; (b) SEM image of the electrophoretically deposited layer of $\alpha-\mathrm{MnO}_{2}$ nanowires; (c) Cycle performance of $\alpha-\mathrm{MnO}_{2}$ nanowires-based electrode in $0.1 \mathrm{M} \mathrm{KOH}$ electrolyte at different scan rates; (d) Specific capacitance variation with respect to the number of cycles for $\alpha-\mathrm{MnO}_{2}$ nanowires and particles-based electrodes.

The prepared thin film electrode had a coating thickness of $\sim 20 \mu \mathrm{m}$ and showed a specific capacitance of 1050 and $347 \mathrm{~F} \cdot \mathrm{g}^{-1}$ at a scan rate of 1 and $50 \mathrm{mV} \cdot \mathrm{s}^{-1}$, respectively, as shown in Figure 19c. The nanowire-based electrode prepared by EPD showed an increase in capacitance at the end of the 3000th CV cycle, as shown in Figure 19d. This results indicate that the porous microstructure with a high specific area was electrochemically advantageous. Because the porous microstructure produced by the EPD process can provide a substantially larger spatial clearance for electrode expansion and contraction during cycling. Santhanagopalan et al. employed high voltage electrophoretic deposition (HVEPD) to align and deposit the $\alpha-\mathrm{MnO}_{2}$ nanorods synthesized by a hydrothermal method [215]. Moreover, they reported the approach of HVEPD to prepare electrodes that might be scalable or applicable to flexible substrates, such as rod coating and pasting nanomaterials, as shown in Figure 20a. The $\alpha-\mathrm{MnO}_{2}$ nanorods were dispersed in IPA solution containing the Mg salt to prevent bundle formation during HVEPD, and the Ni salt was used to improve the electrical contact between the nanorods and the stainless steel substrate. The amount of ions coated on the nanorod surface, ionic mobility, and the optimum ionic mass in the dispersion solution vary depending on the type of precursor salts. It is necessary to adjust the salt concentration in order to provide sufficient charge on the nanorods and to deposit an appropriately thick coating layer on the substrate. On the other hand, because of the excessively added Ni content, excess of charging agent and precursor result in unstable dispersion of the suspension, deteriorated alignment, and reduced specific capacitance. The deposition voltage, time, and amounts of precursors were optimized for the optimal alignment of 
the $\alpha-\mathrm{MnO}_{2}$ nanorods. HVEPD was carried out with various holding layers on the substrate surface at $800 \mathrm{~V}$ for $30 \mathrm{~s}$. In particular, the aligned $\alpha-\mathrm{MnO}_{2}$ nanorods electrode with the Ni holding layer showed a specific capacitance of $8501 \mu \mathrm{F} \cdot \mathrm{cm}^{-2}$ and a specific capacitance retention of $92 \%$ after 2000 cycles at a current density of $0.25 \mathrm{~mA} \cdot \mathrm{cm}^{-2}$.
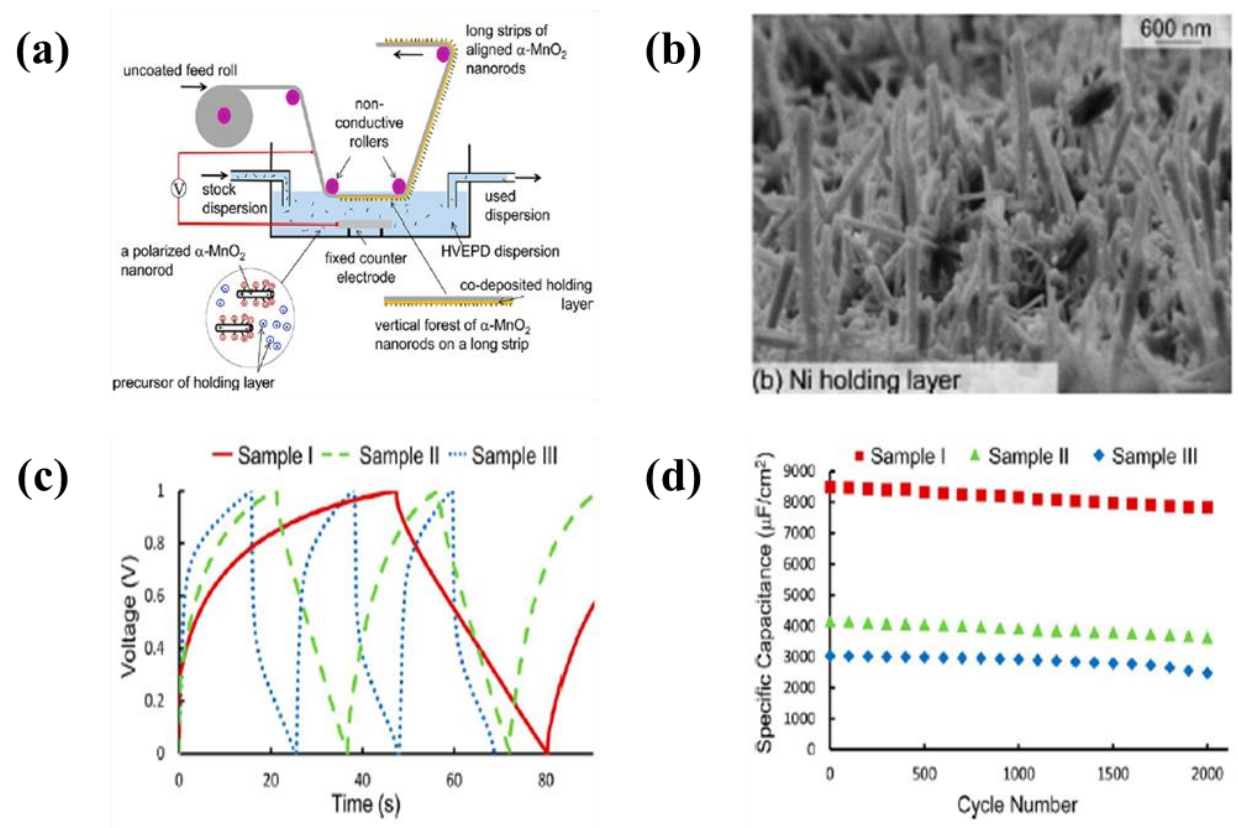

Figure 20. (a) Schematic and working mechanism of continuous HVEPD setup; (b) FE-SEM image of aligned nanoforests of $\alpha-\mathrm{MnO}_{2}$ nanorods with Ni holding layers; (c) Galvanostatic charge discharge curves at $0.25 \mathrm{~mA} \cdot \mathrm{cm}^{-2}$ current for the three types of samples; (d) Decrease in the device capacitance over 2000 cycles for the three types of samples.

These results were attributed to adhesion between the nanorods and substrate by HVEPD with a holding layer. The aligned $\alpha-\mathrm{MnO}_{2}$ nanorods electrode with a Ni holding layer prepared by a continuous HVEPD for scaling up the electrodes showed galvanostatic charge-discharge curves for parts of the long strip with a similar area to a small rigid sample. EPD proved to be suitable process for the mass-production of the electrode with better packing and alignment. In addition to $\mathrm{RuO}_{2}$ and $\mathrm{MnO}_{2}, \mathrm{NiO}$ is another attractive pseudo-capacitive material for use as an electrode material in alkaline electrochemical capacitors. $\mathrm{NiO}$ [218,219], $\mathrm{NiO}$ nanowire [220], nickel hydroxide [221], and $\mathrm{NiMoO}_{4}$ [222] electrodes were prepared by EPD to enhance the electrochemical performance of pseudo-capacitors.

\subsection{Polymer/Carbon Composite Based Materials}

Conducting polymers, such as polyaniline (PANI), polypyrrole (PPy), 1-pyrenebuturic acid $(\mathrm{PBH})$, and polyethylenedioxythiophene (PEDOT), are important materials in pseudo-capacitors. The incorporation of carbonaceous materials, such as MWCNTs and graphene sheets into these polymers could form hybrid materials with enhanced specific capacitance, rate capability, and cycling stability. EPD has been expanded to prepare conducting polymer-based hybrid electrodes for supercapacitor applications [222-230]. Li et al. prepared MWCNTs films by EPD and coated them with PPy by an in-situ electropolymerization method [223]. EPD was carried out $20 \mathrm{~V}$ to fabricate MWCNTs films. The PPY-MWCNTs hybrid electrode recorded a specific capacitance of $224 \mathrm{~F} \cdot \mathrm{g}^{-1}$ at a scan rate of $2 \mathrm{mV} \cdot \mathrm{s}^{-1}$ in a $0.5 \mathrm{M} \mathrm{Na}_{2} \mathrm{SO}_{4}$ electrolyte. Su et al. employed EPD to prepare a PBH-MnO $2-\mathrm{MWCNTs}$ hybrid electrode [224]. EPD was performed from aqueous MWCNTs, $\mathrm{MnO}_{2}$, and $\mathrm{PBH}$ suspension at $10 \mathrm{~V}$. The film mass was $0.3 \mathrm{mg} \cdot \mathrm{cm}^{-2}$. The deposit prepared from a $2 \mathrm{~g} \cdot \mathrm{L}^{-1} \mathrm{MnO}_{2}$ suspension, containing $0.5 \mathrm{~g} \cdot \mathrm{L}^{-1}$ and $0.1 \mathrm{~g} \cdot \mathrm{L}^{-1} \mathrm{PBH}$, showed a specific capacitance of 250 and $90 \mathrm{~F} \cdot \mathrm{g}^{-1}$ at scan 
rates of 2 and $100 \mathrm{mV} \cdot \mathrm{s}^{-1}$, respectively, and was higher than that of the electrode without MWCNTs ( $40 \mathrm{~F} \cdot \mathrm{g}^{-1}$ at a scan rate of $2 \mathrm{mV} \cdot \mathrm{s}^{-1}$ ) in a $0.5 \mathrm{M} \mathrm{Na}_{2} \mathrm{SO}_{4}$ electrolyte. Shi et al. used EPD to prepare a PPy nanofiber/MWCNTs hybrid electrode [225]. EPD was performed from an aqueous MWCNTs and PPy nanofiber suspension containing malachite green oxalate salt (MG). In a $0.5 \mathrm{M} \mathrm{Na}_{2} \mathrm{SO}_{4}$ electrolyte, the resulting PPy-MWCNTs hybrid electrode containing MG as a dispersant exhibited a higher specific capacitance than the PPy-MWCNTs hybrid electrode without MG, as shown in Figure 21a,b. In particular, The PPy-MWCNTs (10 wt.\%) hybrid electrode prepared by EPD in suspension including $30 \mathrm{mg} \cdot \mathrm{cm}^{-2}$ of MG showed a maximum capacitance of $4.62 \mathrm{~F} \cdot \mathrm{cm}^{-2}$ at a scan rate $2 \mathrm{mV} \cdot \mathrm{s}^{-1}$ as well as high capacitance retention after 1000 cycles (Figure 21c,d. The results suggest that the adsorption of MG on the surface of the MWCNTs and PPy nanofiber during EPD allowed the efficient dispersion of both materials and the fabrication of a hybrid electrode.

(a)

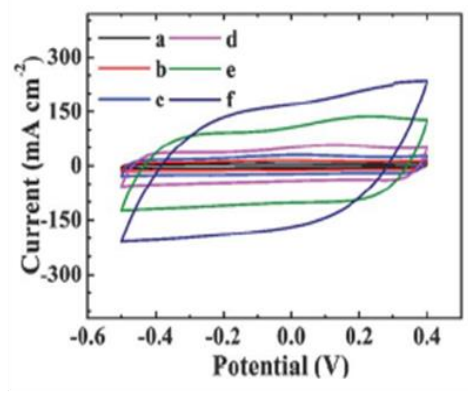

(c)

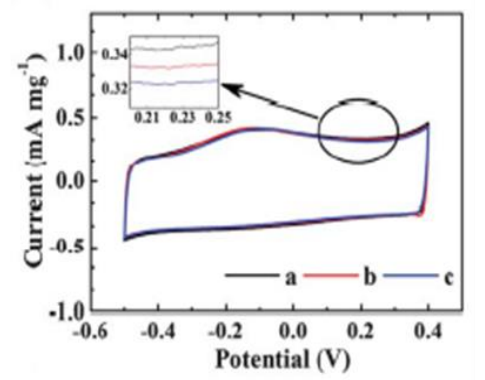

(b)

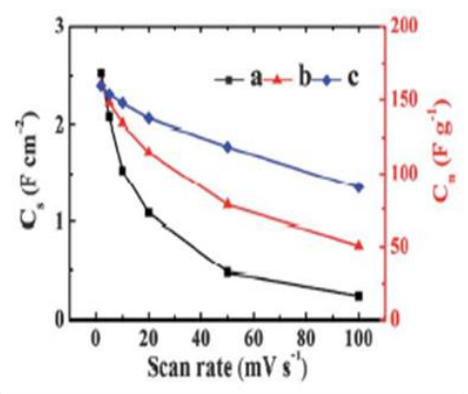

(d)

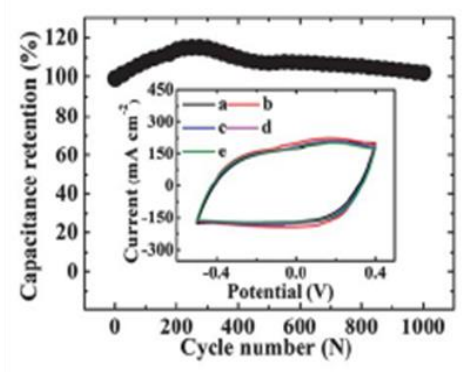

Figure 21. (a) Cycle performance of PPy-MWCNTs (10 wt.\%) hybrid electrode dispersed using MG at various scan rates (a: 2, b: 5, c: 10, d: 20, e: 50, and f: $100 \mathrm{mV} \cdot \mathrm{s}^{-1}$ ); (b) Corresponding $\mathrm{C}_{\mathrm{s}}$ (area) and $\mathrm{C}_{\mathrm{m}}$ (mass) values obtained from the CV data versus scan rate; (c) Cycle performance of the PPy-MWCNTs (10 wt.\%) hybrid electrode dispersed using MG at a scan rate of $2 \mathrm{mV} \cdot \mathrm{s}^{-1}$ (mass loading of MG of a: 20, b: 25 , and c: $\left.30 \mathrm{mg} \cdot \mathrm{cm}^{-1}\right)$; (d) Capacitance retention versus cycle numbers of PPy-MWCNTs (10 wt.\%) hybrid electrode dispersed using MG of $30 \mathrm{mg} \cdot \mathrm{cm}^{-1}$ (inset shows CVs. at a scan rate of $50 \mathrm{mV} \cdot \mathrm{s}^{-1}$ ).

Subramanian et al. fabricated a hybrid electrode of graphene/PPy by EPD. The graphene sheets were deposited electrophoretically on the surface of the Ti plate at $20 \mathrm{~V}$ for $30 \mathrm{~min}$ and PPy was then deposited by an in situ polymerization method, affording a hybrid supercapacitor electrode with a specific capacitance as high as $1510 \mathrm{~F} \cdot \mathrm{g}^{-1}$ at a scan rate of $10 \mathrm{mV} \cdot \mathrm{s}^{-1}$ in a $\mathrm{LiClO}_{4}$ electrolyte [227]. Shi et al. prepared a PPy-graphene hybrid electrode by EPD in a suspension of PPy-graphene containing safranin (SAF) at $30 \mathrm{~V}$ for $15 \mathrm{~min}$ [228]. In a $0.5 \mathrm{M} \mathrm{Na}_{2} \mathrm{SO}_{4}$ electrolyte, the resulting PPy-graphene hybrid electrode exhibited higher specific capacitance and lower capacitance reduction at a high scan rate than the graphene-MWCNTs hybrid electrode prepared by EPD. Tong et al. prepared a binder-free layered graphene/PANI hybrid electrode by EPD in an aqueous suspension containing PANI/graphene nanosheets [230]. EPD was carried out at a voltage of -20 V for $20 \mathrm{~min}$, as shown in Figure 22a,b. The PANI/graphene nanosheets were fabricated with the amount of graphene from 300 (PG300) to 30 (PG30). The layered graphene/PANI hybrid electrode (PG300) showed a high gravimetric capacitance of $384 \mathrm{~F} \cdot \mathrm{g}^{-1}$ at a constant current density of $0.5 \mathrm{~A} \cdot \mathrm{g}^{-1}$ and maintained up to $84 \%$ of its capacity over 1000 cycles at a constant current density of $2 \mathrm{~A} \cdot \mathrm{g}^{-1}$ in a $1 \mathrm{M}$ 
$\mathrm{H}_{2} \mathrm{SO}_{4}$ electrolyte. The layered graphene/PANI hybrid electrode (PG300) recorded a higher specific capacitance than PG30, pure PANI, and graphene, as shown in Figure 22c,d. Overall, EPD appears to be an effective method for the deposition of organic molecules and composites and has applications for supercapacitors.

(a)

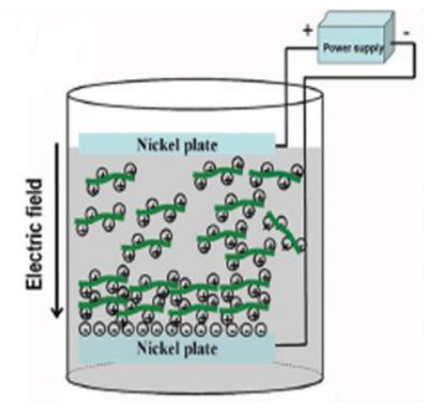

(c)

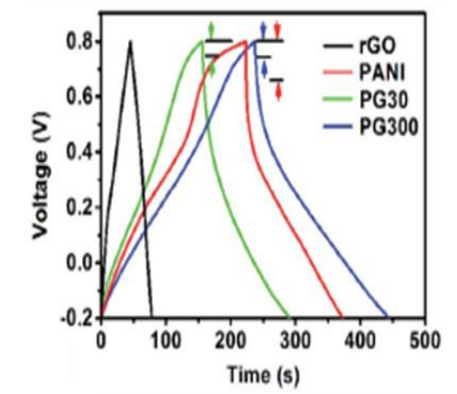

(b)

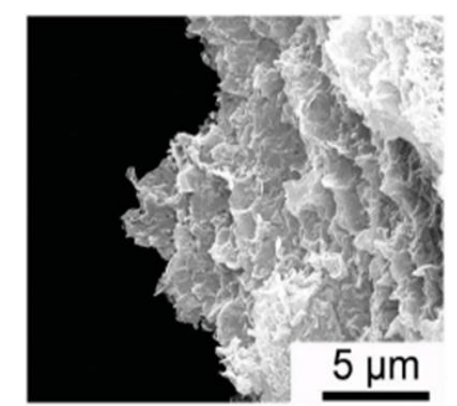

(d)

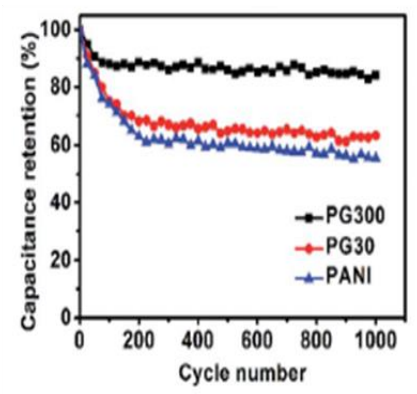

Figure 22. (a) Sketch of the electrophoretic deposition for the preparation of the layered polyaniline/graphene electrode; (b) SEM image of the fracture surface of the layered polyaniline/graphene hybrid electrode prepared by EPD; (c) Galvanostatic charge/discharge curves at a current density of $0.5 \mathrm{~A} \cdot \mathrm{g}^{-1} ;$ (d) Cycle stability at a current density of $2 \mathrm{~A} \cdot \mathrm{g}^{-1}$.

\subsection{Metal Oxide/Carbon Composite Based Materials}

Pseudo-capacitive materials include, but are not limited, to metal oxides, metal hydroxides, and conducting polymers. As the pseudo-capacitance arises from reversible redox reactions, it is desirable to increase the surface area of the active materials to reduce the diffusion length of the electrons and allow a higher flux of electrons and ions. Hybrid materials with CNTs and graphene sheets are useful pseudo-capacitive materials because most metal hydroxides, metal oxides, and conducting polymers have low electrical conductivity. Capacitance decay could be due to the agglomeration of active materials or fractions of the active materials losing electrical contact with the current collectors. Recently, EPD has been applied to prepare composites and functional nanostructured electrodes for supercapacitors because they can provide well-dispersed pseudo-capacitive materials that lead to electrodes with high specific surface areas, a three dimensional network, and high contact with the current collectors. $\mathrm{MnO}_{2}$-based-electrodes are attractive pseudo-capacitive materials because of their reversible redox capability, low cost, high abundance, and environmental compatibility. Various hybrid electrodes of $\mathrm{MnO}_{2}$-carbonaceous materials have been developed by the EPD process to enhance the electrochemical performance [149,231-242]. $\mathrm{MnO}_{2}-\mathrm{MWCNTs}$ hybrid electrodes were prepared by EPD in a suspension of $\mathrm{MnO}_{2}$ nanoparticles containing MWCNTs. The hybrid electrodes prepared by EPD showed higher specific capacitance compared to the electrodes without MWCNTs in a $\mathrm{Na}_{2} \mathrm{SO}_{4}$ electrolyte [232,233]. Fang et al. synthesized a MWCNTs $/ \alpha-\mathrm{MnOOH}$ coaxial nanocable hybrid electrode by EPD [238], which was carried out in an ethanol based-MWCNTs suspension including an aqueous $\mathrm{Mn}\left(\mathrm{NO}_{3}\right)_{2}$ solution at $50 \mathrm{~V}$ for $150 \mathrm{~s}$. The film electrode was treated thermally at $200{ }^{\circ} \mathrm{C}$. The specific capacitance of the MWCNTs $/ \alpha-\mathrm{MnOOH}$ coaxial nanocable hybrid electrode reached 202 $\mathrm{F} \cdot \mathrm{g}^{-1}$ at a constant current density of $0.65 \mathrm{~A} \cdot \mathrm{g}^{-1}$, which was much higher than that of bulk $\mathrm{MnO}_{2}$ and comparable to that of the MWCNTs film electrode. After 1200 galvanostatic cycles, the specific 
capacitance retained $205 \mathrm{~F} \cdot \mathrm{g}^{-1}$, exhibiting excellent long cycle life stability in a $0.1 \mathrm{M} \mathrm{Na}_{2} \mathrm{SO}_{4}$ electrolyte. Ranjusha et al. employed EPD to prepare a $\mathrm{MnO}_{2}$ nanowire/carbon nanobead hybrid electrode [239]. The hybrid electrode was deposited electrophoretically at $40 \mathrm{~V}$ for $15 \mathrm{~min}$ in a $\mathrm{MnO}_{2}$ nanowire/carbon nanobead uniformly dispersed suspension. The hybrid electrode was deposited electrophoretically in the suspension containing $10 \mathrm{wt}$.\% carbon nanobeads recorded a specific capacitance of $625 \mathrm{~F} \cdot \mathrm{g}^{-1}$ at a $50 \mathrm{mV} \cdot \mathrm{s}^{-1} \mathrm{CV}$ scan in a $0.1 \mathrm{M} \mathrm{KOH}$ electrolyte. The hybrid electrode prepared by EPD showed no such peeling or disintegration of the electrode in the electrolyte at the end of the 10,000 cycles due to the presence of carbon nanobeads that could be beneficial because it could increase the elastic modulus of the electrode overlay to prevent peeling or delamination under cycling. ICP-AES showed that only 0.01 and 0.02 ppm Mn was present in the electrolyte at the 1st and 10,000th cycle, respectively, which reflects the structural stability of these film electrodes prepared by EPD. Zhitomirsky et al. examined the effects of charging additives for the EPD process in ethanol or water-based suspension containing $\mathrm{MnO}_{2}$ and MWCNTs. Dopamine (DA) [232], calconcarboxylic acid (CCA) [237], chromotrope FB (CFB) [237], pyrocatechol violet (PV) [240], m-crexol purple (CP) [240], and celestine blue dye [241] were used as charging additives. In the case of dopamine, the addition of dopamine to the suspension resulted in the adsorption of protonated DA on the $\mathrm{MnO}_{2}$ surface, which led to improved particle stability and increased particle charge. As a result, an increase in deposition yield and the effective dispersion of $\mathrm{MnO}_{2}$ and MWCNTs for EPD were observed [232]. The highest specific capacitance of the $\mathrm{MnO}_{2}$-MWCNTs hybrid electrode (material loading of $2 \mathrm{mg} \cdot \mathrm{cm}^{-2}$ ) was $650 \mathrm{~F} \cdot \mathrm{g}^{-1}$ at a scan rate of $2 \mathrm{mV} \cdot \mathrm{s}^{-1}$ in a $0.5 \mathrm{M} \mathrm{Na}_{2} \mathrm{SO}_{4}$ electrolyte. In the case of CCA and CFB, CCA as a charging additive was more efficient than CFB because the salicylate type of bonding involving $\mathrm{COOH}$ and $\mathrm{OH}$ groups played an important role in the adsorption of CCA molecules on the surface of $\mathrm{MnO}_{2}$ particles and $\pi-\pi$ interactions on the surface of the MWCNTs. The results revealed higher deposition in a suspension containing CCA compared to that with CFB during EPD at a deposition voltage of $60 \mathrm{~V}$. The maximum specific capacitance of the $\mathrm{MnO}_{2}-\mathrm{MWCNTs}$ hybrid electrode (material loading of $0.15 \mathrm{mg} \cdot \mathrm{cm}^{-2}$ ) was $290 \mathrm{~F} \cdot \mathrm{g}^{-1}$ at a scan rate of $2 \mathrm{mV} \cdot \mathrm{s}^{-1}$ in a $0.5 \mathrm{M} \mathrm{Na}_{2} \mathrm{SO}_{4}$ electrolyte. In the case of PV, the additive as a charging agent of PV was attributed to the $\pi-\pi$ interaction and catecholate type bonding of the surface of $\mathrm{MnO}_{2}$ and MWCNTs, respectively [240]. The use of PV as a charging additive has the advantages of a uniform distribution of individual components and a low binder content in the composite in the EPD process. A high specific capacitance of the hybrid electrode (material loading of $40 \mathrm{mg} \cdot \mathrm{cm}^{-2}$ ) prepared by the EPD process (at $100 \mathrm{~V}$ for $2 \mathrm{~min}$ ) in a suspension, including PV as the charging additive, showed $148 \mathrm{~F} \cdot \mathrm{g}^{-1}$ at a scan rate of $2 \mathrm{mV} \cdot \mathrm{s}^{-1}$ in a $0.5 \mathrm{M} \mathrm{Na}_{2} \mathrm{SO}_{4}$ electrolyte. A hybrid capacitor electrode, combining redox-active pseudo-capacitive oxides of $\mathrm{MnO}_{2}$ [234,242] and $\mathrm{Mn} / \mathrm{Mo}$ mixed oxides [235] with the MWCNTs framework was prepared by EPD. The electrodes were based on the deposition of MWCNTs films by EPD in a suspension containing water-based MWCNTs, followed by electrochemical deposition [235,242] and redox deposition [234]. Their hybrid electrodes showed high specific capacitances of 869 [234], 408 [235], and 540.7 [242] F.g ${ }^{-1}$ in $0.65 \mathrm{M} \mathrm{K}_{2} \mathrm{SO}_{4}$ or $0.5 \mathrm{M} \mathrm{Na}_{2} \mathrm{SO}_{4}$ electrolytes, respectively. Soumya et al. fabricated a $\mathrm{PbO}_{2}$ nanoparticles-CNTs/graphene asymmetric hybrid electrode by EPD with a specific capacitance of $250 \mathrm{~F} \cdot \mathrm{g}^{-1}$ at a scan rate of $5 \mathrm{mV} \cdot \mathrm{s}^{-1}$, which was much higher than that of the $\mathrm{PbO}_{2}$ /graphene asymmetric electrode by EPD [242]. In addition to $\mathrm{MnO}_{2}$-carbonaceous materials, $\mathrm{NiO}$ or Ni metal-carbonaceous materials have been fabricated by EPD and assessed as electrodes for pseudo-capacitors [243-247]. Wu et al. prepared a NiO-carbon nanofiber hybrid electrode by EPD at $10 \mathrm{~V}$ for $30 \mathrm{~s}$ in an IPA-based suspension containing vapor-grown carbon nanofibers and $\mathrm{Ni}\left(\mathrm{NO}_{3}\right)_{2}$ followed by a thermal treated to form a NiO-carbon nanofiber composite electrode at $300{ }^{\circ} \mathrm{C}$ for $3 \mathrm{~h}$ in air [243]. The NiO-carbon nanofiber hybrid electrode showed much higher cycling stability (approximately 91\% capacitance retention) than pure $\mathrm{NiO}$ because of the interactions between $\mathrm{NiO}$ and the carbon nanofibers that stabilized the active materials and the high conductivity of carbon nanofibers in the composite electrode. Lin et al. prepared Ni-decorated activated-carbon electrodes by one-step EPD [245]. The EPD of the composite electrodes were carried out at $15 \mathrm{~V}$ for various periods of time to obtain the required weight. The suspension including activated-carbon was 
used with various concentrations of nickel nitrate. The effective specific capacitance of the composite electrode deposited using $0.4 \mathrm{mM}$ nickel nitrate measured using a supercapacitor device (Figure 23b) was $142 \mathrm{~F} \cdot \mathrm{g}^{-1}$ at a scan rate of $50 \mathrm{mV} \cdot \mathrm{s}^{-1}$ and the value decreased moderately to $110 \mathrm{~F} \cdot \mathrm{g}^{-1}(78 \%$ capacitance of $50 \mathrm{mV} \cdot \mathrm{s}^{-1}$ ) in a $\mathrm{KOH}$ electrolyte (Figure 23c). The Ni-decorated activated-carbon electrode by one-step EPD exhibited stable capacitance during cycling with very little degradation occurring over 200 test cycles, as shown in Figure 23d.

(a)

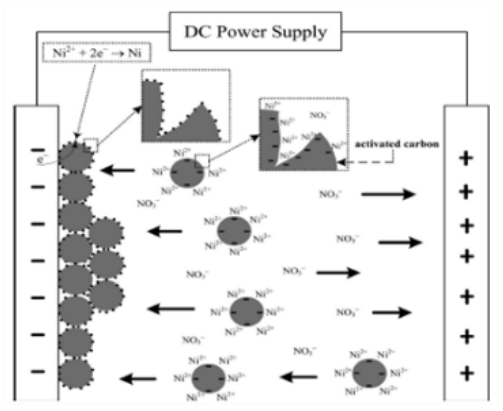

(c)

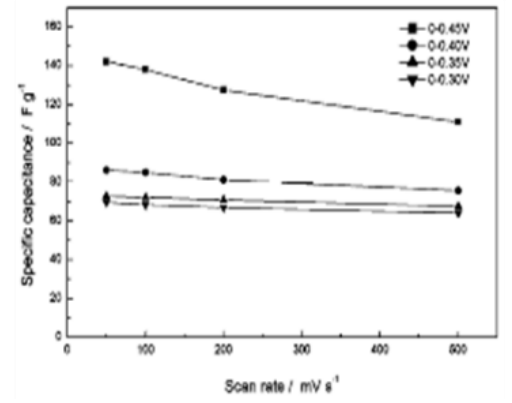

(b)

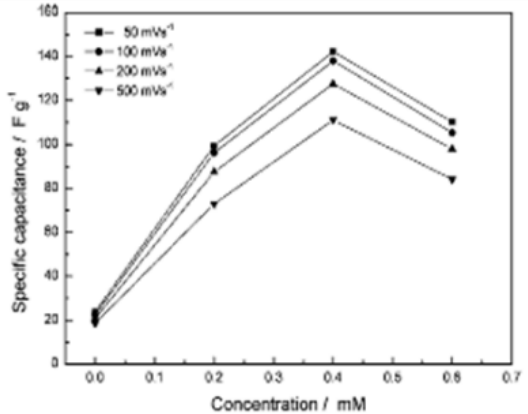

(d)

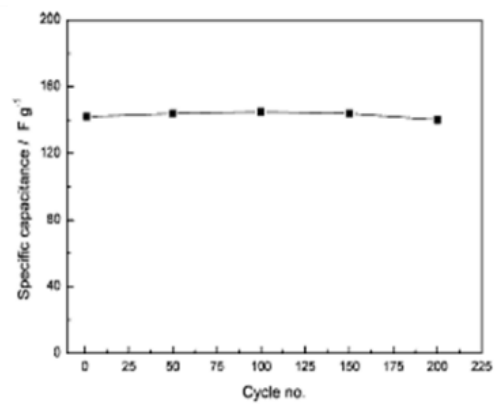

Figure 23. (a) Schematic diagram of the proposed Ni-decorated activated-carbon deposition in the EPD process; (b) Specific capacitance of Ni-decorated activated-carbon electrodes deposited with various concentrations of nickel nitrate; (c) Specific capacitance of a Ni-decorated activated-carbon electrode deposited at a concentration of $0.4 \mathrm{mM}$ nickel nitrate; (d) Variation of the specific capacitance with the cycle number for the Ni-decorated activated-carbon electrode deposited using $0.4 \mathrm{mM}$ nickel nitrate.

Wu et al. reported the hybrid electrode of $\mathrm{Ni} / 1$,4-bezenedicarboxylic (BDC) powder carbonized at various temperatures prepared by EPD [247]. EPD was carried out at $-60 \mathrm{~V}$ for $10 \mathrm{~s}$ in a suspension containing Ni-BDC powder carbonized at $800{ }^{\circ} \mathrm{C}$ and IPA. The hybrid electrode reached as much as $886 \mathrm{~F} \cdot \mathrm{g}^{-1}$ at a discharge current density of $1 \mathrm{~A} \cdot \mathrm{g}^{-1}$ that only decreased slightly to $746 \mathrm{~F} \cdot \mathrm{g}^{-1}$ at $30 \mathrm{~A} \cdot \mathrm{g}^{-1}$ in a $1 \mathrm{M} \mathrm{KOH}$ electrolyte. Lin et al. proposed a novel electrode structure of 3D-porous CNT network by an EPD-supported nickel oxide nanonet, as shown in Figure 24a [246]. They developed two processing approaches involving EPD of MWCNTs. In the first step, a 3D porous CNT film was deposited electrophoretically up to a mass loading of $0.22 \mathrm{mg}$ at $-60 \mathrm{~V}$ and nickel oxide nanonet was then formed between the adjacent CNTs by hydrothermal synthesis. The well-dispersed nickel oxide nanonet provided a large faradaic capacitance of $1511 \mathrm{~F} \cdot \mathrm{g}^{-1}$ at a high current density of $50 \mathrm{~A} \cdot \mathrm{g}^{-1}$ as well as high capacitance retention of $92.4 \%$, which was superior to that of the $\mathrm{NiO}$ electrode with the CNTs network (59\%), as shown in Figure 23d. 
(a)

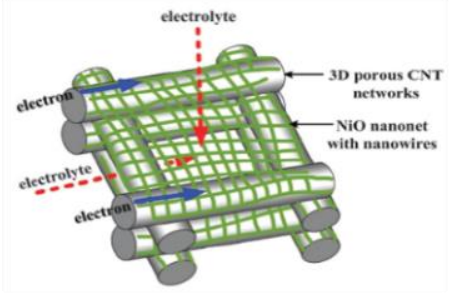

(c)

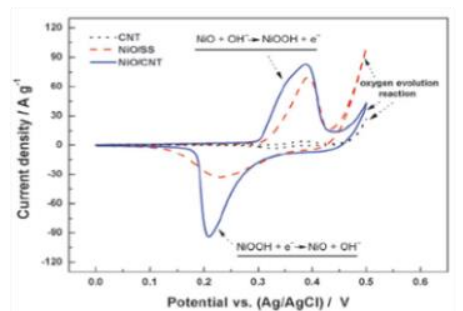

(b)

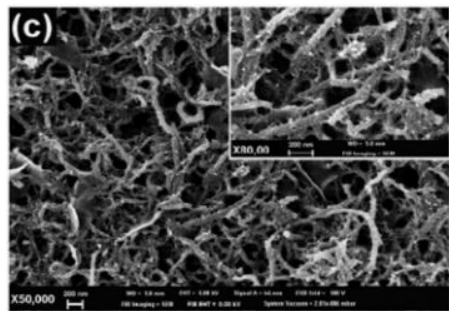

(d)

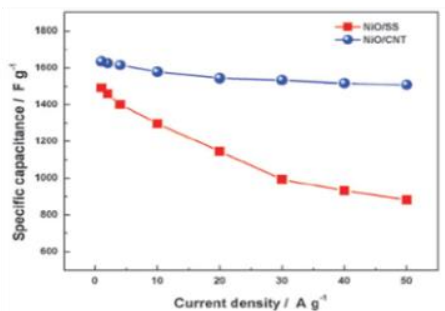

Figure 24. (a) Schematic diagram of a novel electrode structure of 3D porous CNT networks with an attached nickel oxide nanonet for supercapacitor applications; (b) SEM image of the CNT film with the attached $\mathrm{NiO}$ nanonet; (c) CV scans of the $\mathrm{NiO}$ without CNTs, NiO/CNTs, and bare CNTs electrodes at a scan rate of $10 \mathrm{mV} \cdot \mathrm{s}^{-1} ;$ (d) Relationship between the specific capacitance and discharge current density of the $\mathrm{NiO}$ without CNTs and $\mathrm{NiO} / \mathrm{CNT}$ electrodes.

In addition, the hybrid materials with the graphene nanosheets also are useful pseudo-capacitive materials. EPD is a useful technique for depositing hybrid materials with graphene nanosheets. A number of variants of EPD have been used to form deposits suitable for electrodes, including graphene oxide deposition, direct deposition of a graphene sheet, exfoliated graphene oxide reduced before deposition, graphene oxide platelets reduced by the EDP conditions, as well as graphene oxide layers modified by transition metal oxide interfaces, such as $\mathrm{MnO}_{2}, \mathrm{NiO}$, and $\mathrm{Ni}(\mathrm{OH})_{2}$. As a typical example, a two-step process, which involved the EPD of graphene oxide and the subsequent deposition of metal oxide by in situ electrochemical deposition [248-252]. Xia et al. developed a two-step process including EPD [248]. In this study, a well-dispersed graphene oxide suspension was prepared in isopropyl alcohol. The material was deposited on a nickel foam substrate using a constant voltage of $100 \mathrm{~V}$ for $20 \mathrm{~s}$. Subsequently, the highly porous $\mathrm{NiO}$ films were deposited by chemical bath deposition (CBD) in an electrolyte containing nickel sulfate, potassium persulfate, and aqueous ammonia and then annealed at $300{ }^{\circ} \mathrm{C}$ for $1 \mathrm{~h}$ in argon. The graphene sheet/porous $\mathrm{NiO}$ hybrid electrode exhibited excellent capacitance of 400 and $324 \mathrm{~F} \cdot \mathrm{g}^{-1}$ at constant current densities of 2 and $40 \mathrm{~A} \cdot \mathrm{g}^{-1}$, respectively, which is higher than those of the porous $\mathrm{NiO}$ electrode $\left(279\right.$ and $188 \mathrm{~F} \cdot \mathrm{g}^{-1}$ at 2 and $\left.40 \mathrm{~A} \cdot \mathrm{g}^{-1}\right)$ in $1 \mathrm{M}$ $\mathrm{KOH}$ electrolyte. Wu et al. prepared a multilayered graphene nanosheet and $\mathrm{MnO}_{2}$ nanowire hybrid electrode by a 2 step process with EPD [249]. The graphene nanosheets were deposited on the substrate by EPD and $\mathrm{MnO}_{2}$ nanowires were then fabricated on the graphene nanosheets films by anodic deposition. The capacitance of the multilayered graphene nanosheets and $\mathrm{MnO}_{2}$ nanowires hybrid electrode reached as high as $252 \mathrm{~F} \cdot \mathrm{g}^{-1}$ at a low current density of $2 \mathrm{~A} \cdot \mathrm{g}^{-1}$, which decreased slightly to $179 \mathrm{~F} \cdot \mathrm{g}^{-1}$ at a very high current density of $100 \mathrm{~A} \cdot \mathrm{g}^{-1}$ in a $1 \mathrm{M} \mathrm{Na}_{2} \mathrm{SO}_{4}$ electrolyte. In addition, they prepared the tubular graphene nanoribbons film by EPD and $\mathrm{MnO}_{2}$ nanoparticles was then attached to the film by electrochemical deposition [250]. The specific capacitance of the tubular graphene nanoribbons with the attached $\mathrm{MnO}_{2}$ hybrid electrode reached $266 \mathrm{~F} \cdot \mathrm{g}^{-1}$, which is much higher than that of the graphene nanoribbons material $\left(88 \mathrm{~F} \cdot \mathrm{g}^{-1}\right)$ at a discharge current density of $1 \mathrm{~A} \cdot \mathrm{g}^{-1}$. The specific capacitance of the hybrid electrode prepared by a 2 step process with EPD is comparable to that of the hybrid material by electrostatic layer-by-layer self-assembly $\left(263 \mathrm{~F} \cdot \mathrm{g}^{-1}\right)$ [253] and higher than that of the $\mathrm{Mn}_{3} \mathrm{O}_{4}$ /graphene nanocomposite hybrid material (175 F.g ${ }^{-1}$ ) [254]. Ghasemi et al. deposited $\mathrm{MnO}_{2}$ nanoparticles [251] and nickel-cobalt hexacyanoferrate nanostructure [252] on the surface of graphene nanosheets by EPD. Their hybrid electrodes had a higher specific capacitance than the graphene nanosheet electrode. A range of hybrid electrodes of metal oxide-graphene nanosheets 
was developed by EPD in a single step to enhance the electrochemical performance and reduce the time needed for synthesis [253-256]. Wu et al. prepared a NiO-attached graphene oxide nanosheet hybrid electrode by single step EPD [253]. EPD was carried out in a graphene oxide suspension consisting of IPA and the nickel nitrate additive to obtain the nickel attached graphene oxide hybrid electrode. The EPD of nickel-attached graphene oxide was performed in the presence of nickel nitrate. When the graphene oxide sheet arrives at the substrate, the nickel ions adsorbed at the surface of the graphene oxide sheet can be reduced electrochemically to metallic nickel because the graphene sheet has high electrical conductivity, which allows electrons to flow from the substrate to the outer layer of the graphene sheet, as shown in Figure 25a. As a result, the nickel-attached graphene oxide sheet continues to deposit layer-by-layer (Figure 25b). Subsequently, the hybrid electrode was treated thermally at $300{ }^{\circ} \mathrm{C}$ for $1 \mathrm{~h}$ in air, resulting in the conversion of deposited nickel nanoparticles to nickel oxide nanoparticles. The specific capacitance of the $\mathrm{NiO}$ attached graphene oxide hybrid electrode $\left(460 \mathrm{~F} \cdot \mathrm{g}^{-1}\right)$ was much higher than those of the bare graphene oxide electrode $\left(13 \mathrm{~F} \cdot \mathrm{g}^{-1}\right)$ and $\mathrm{NiO}$ $\left(40 \mathrm{~F} \cdot \mathrm{g}^{-1}\right)$ electrode at a constant current density of $10 \mathrm{~A} \cdot \mathrm{g}^{-1}$, as shown in Figure $25 \mathrm{c}$. The capacitance retention of the hybrid electrode after 3000 cycles remained almost unchanged, whereas that of the bare graphene oxide decreased with increasing number of cycles (Figure 25d).

(a)

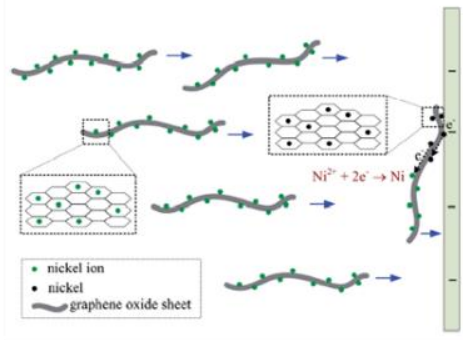

(c)

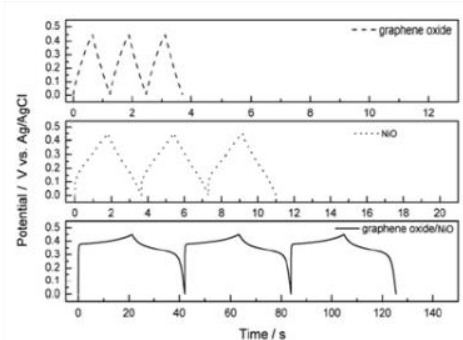

(b)

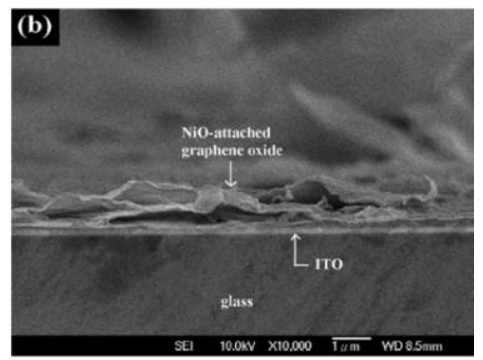

(d)

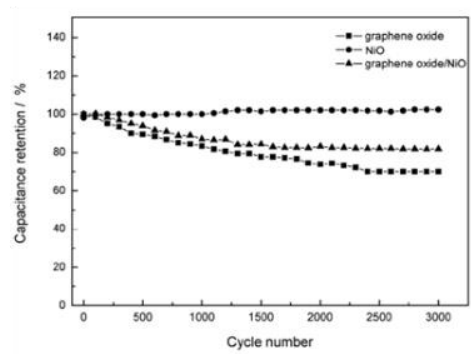

Figure 25. (a) Schematic formation of nickel-attached graphene oxide in the EPD process; (b) SEM image of NiO-attached graphene oxide hybrid electrode after heat treatment; (c) Galvanostatic charge/discharge curves of graphene oxide, $\mathrm{NiO}$, and $\mathrm{NiO}$-attached graphene oxide hybrid electrodes at a current density of $10 \mathrm{~A} \cdot \mathrm{g}^{-1}$ in $0.5 \mathrm{M} \mathrm{KOH}$ electrolyte; (d) Relationship between the capacitance retention and the cycle number of graphene oxide, $\mathrm{NiO}$, and $\mathrm{NiO}$-attached graphene oxide hybrid electrodes at $10 \mathrm{~A} \cdot \mathrm{g}^{-1}$.

Graphene nanosheets and metal nanoparticles have been used as nano-building blocks for assembly into hybrid structures with promising performance in supercapacitors. On the other hand, in most graphene and metal nanoparticles hybrid structures, the graphene sheets and metal nanoparticles do not enable control of the reaction process, orientation of the building blocks, and organization on the nanoscale. The EPD build-up has been used to prepare multilayered reduced graphene oxide/metal nanoparticle hybrid electrodes because this assembly strategy can effectively control the orientation of graphene nanosheets and metal nanoparticles and the organization at the nanoscale [254]. Niu et al. used electrophoretic layer-by-layer assembly to construct a multilayered reduced graphene oxide/ $\mathrm{Au}$ nanoparticles hybrid electrode [254]. First, graphene oxide was deposited electrophoretically at $30 \mathrm{~V}$ for $8 \mathrm{~min}$ in a DMF suspension with graphene oxide and a second EPD was carried out in a DMF suspension with $\mathrm{Au}$ nanoparticles at $30 \mathrm{~V}$ for various times. The process was repeated to fabricate the 
multilayered graphene oxide-based hybrid electrode, as shown Figure 26a,b. The specific capacitance was related strongly to the Au nanoparticles deposition time in the EPD process (Figure 26c). When the Au nanoparticles deposition time was more than $120 \mathrm{~s}$, the specific capacitance of the hybrid electrode decreased with increasing deposition time because the Au nanoparticle layers provided support to the reduced graphene oxide layers to avoid the self-aggregation of reduced graphene oxide, which increased the active electrochemical surface area further (Figure 26d). They attributed the reduced specific capacitance of the hybrid electrode when the density of Au nanoparticles was too large to the slightly supportive effect of Au nanoparticles on the reduced graphene oxide layers, which led to a reduction of the active electrochemical surfaced area.

(a)

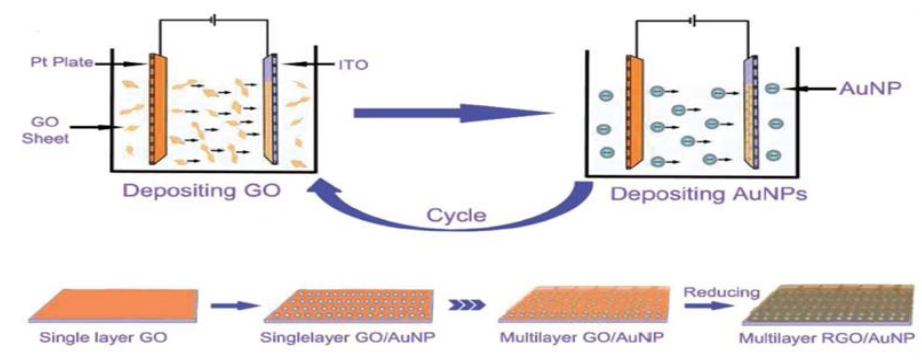

(b)

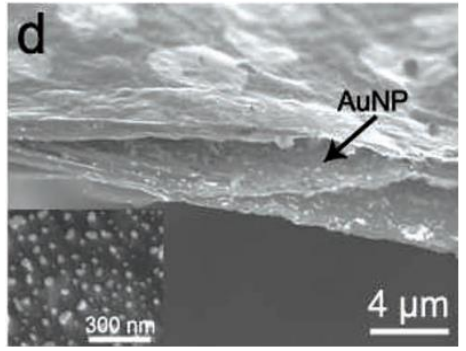

(d)

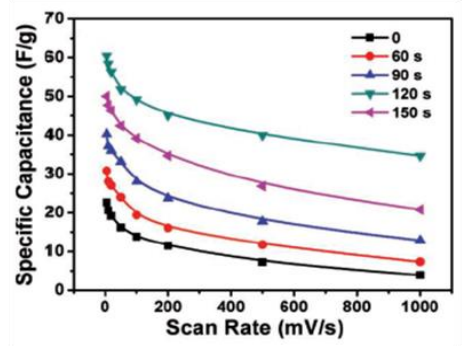

(c)

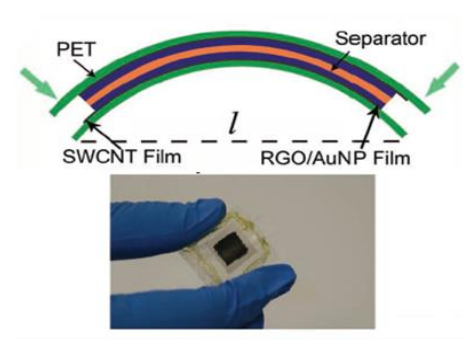

(e)

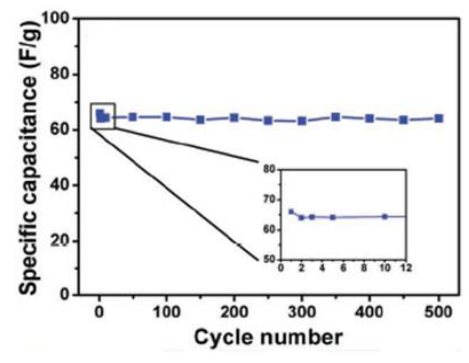

Figure 26. (a) Schematic diagram of the process for producing multilayered reduced graphene oxide/Au nanoparticles hybrid electrode; (b) Cross-section SEM image of multilayered reduced graphene oxide/Au nanoparticles hybrid electrode; (c) Schematic diagram of the optical image and multilayered reduced graphene oxide/Au nanoparticles hybrid electrode supercapacitor; (d) Specific capacitance of multilayered reduced graphene oxide/Au nanoparticles hybrid electrode supercapacitors with different Au nanoparticles deposition times at different scan rates; (e) Variation of the capacitance stability of the hybrid electrode supercapacitor with the number of cycles.

The specific capacitance of the supercapacitor applying the hybrid electrodes was approximately $65 \mathrm{~F} \cdot \mathrm{g}^{-1}$ at a constant current density of $1 \mathrm{~A} \cdot \mathrm{g}^{-1}$ in an organic electrolyte. As shown in Figure 26e, after the first cycle, there was a slight decrease in the specific capacitance and the specific capacitance was stable up to 500 cycles. Zhang et al. fabricated a reduced graphene oxide $/ \mathrm{Ni}(\mathrm{OH})_{2}$ hybrid electrode using a one-step EPD process [254]. EPD was carried out in a graphene oxide-based suspension containing $\mathrm{Ni}\left(\mathrm{NO}_{3}\right)_{2}$ for various voltages and times. Nickel ions decorated the graphene oxide deposits on the electrode under an applied potential and the nickel ions transform to $\mathrm{Ni}(\mathrm{OH})_{2}$ through the EPD process. They suggested that the reduced graphene oxide $/ \mathrm{Ni}(\mathrm{OH})_{2}$ hybrid electrode could be produced and their electrochemical properties were dependent on the EPD conditions. In particular, 
a suitable applied potential, stable colloidal suspension, higher concentration of $\mathrm{Ni}\left(\mathrm{NO}_{3}\right)_{2}$, and the appropriate deposition time were the key parameters for the high-quality electrode and high electrochemical performance. Therefore, the conditions suggested for the EPD process are $5 \mathrm{~V}$ for $1 \mathrm{~min}$ in $50 \mathrm{~mL}$ of a water-based suspension containing $20 \mathrm{mg}$ of graphene oxide and $20 \mathrm{mg} \mathrm{Ni}\left(\mathrm{NO}_{3}\right)_{2}$. The hybrid electrode fabricated by the optimized EPD process exhibited a specific capacitance of $1404 \mathrm{~F} \cdot \mathrm{g}^{-1}$ at a constant current density of $2 \mathrm{~A} \cdot \mathrm{g}^{-1}$ and retained $1004 \mathrm{~F} \cdot \mathrm{g}^{-1}$ at $20 \mathrm{~A} \cdot \mathrm{g}^{-1}$. The details of the supercapacitors manufactured by applying the EPD process are summarized in Table A3.

\section{Applications of the Electrophoresis Deposition for Solid Oxide Fuel Cells}

Solid oxide fuel cells (SOFCs) have attracted considerable attention as new electric power generation systems because of their high-energy conversion efficiency, clean power generation, and versatile nature of the technology for the direct conversion of chemical energy to electrical energy [257]. Commonly, a SOFC consists of a solid electrolyte layer containing an oxidizer electrode (cathode) and a fuel electrode (anode). The electrodes need to be porous, at least permeable to the oxidizer at the cathode and fuel at the anode, while the electrolyte layer must be dense to prevent the leakage of gas across the layer. Almost all SOFCs currently being developed employ an yttria stabilized zirconia (YSZ) electrolyte, with a strontium doped lanthanum manganite $\left(\mathrm{La}_{0.8} \mathrm{Sr}_{0.2} \mathrm{MnO}_{3}(\mathrm{LSM})\right.$ ) cathode and a mixed nickel/YSZ cermet anode, and use doped lanthanum chromite $\left(\mathrm{LaCrO}_{3}\right)$ as the interconnect. The motivation for the reduced operating temperature SOFCs to $800^{\circ} \mathrm{C}$ or less includes a decrease in the degradation of the cell components $[258,259]$. On the other hand, the conductivity of the electrolyte and the electrode kinetics will be decreased significantly with a lower operating temperature. This problem can be overcome by lowering the electrolyte resistance, the electrolyte thickness, or using alternative materials with higher ionic conductivity at lower temperatures. Although a previous study showed that $\mathrm{LaGaO}_{3}$-based oxides [260] and cerium oxide doped with gadolinium (GDC) [261,262] exhibits high oxide ion conductivity and are useful as electrolytes in intermediate temperature SOFCs, the thickness of the electrolyte is still an important key to develop technology of SOFCs. To fabricate more efficient and less expensive thin film SOFCs, an enhanced method to fabricate a porous electrode and non-porous electrolyte is needed. The EPD process can be used fabricate thin, dense and gas tight electrolytes as well as porous electrodes for SOFC applications. To fabricate dense and gas tight electrolytes as well as porous electrodes, the EPD process was carried out with various parameters, such as zeta-potential, conductivity of the substrate, and additives applied to suspensions for EPD process. Ishihara et al. published the first account of EPD for the production of zirconia electrolytes for SOFCs [263-265]. In these studies, a yttria-stabilized zirconia (YSZ) electrolyte film was deposited on a porous $\mathrm{La}_{0.85} \mathrm{Sr}_{0.15} \mathrm{MnO}_{3}(\mathrm{LSM})$ cathode in an acetylacetone suspension using at least six deposition steps, each followed by a sintering step. Will et al. reported the EPD processing of thin YSZ on porous substrates (NiO/YSZ), which were prepared by tape casting. In this study, emphasis was placed on the kinetics of the deposition process (including a direct determination of the deposited layer thickness during the EPD process) and not on achieving the optimal values of the SOFC for maximum performance [266]. Because the substrates for EPD are restricted to conductive materials, $\mathrm{NiO}$ was reduced to metallic Ni by heat treatment in $10 \% \mathrm{H}_{2}$ and $90 \% \mathrm{Ar}$ at $700{ }^{\circ} \mathrm{C}$ before the EPD experiments. Besra and Liu et al. demonstrated that dense YSZ thin films could be fabricated on a porous NiO-YSZ substrate in an acetylacetone suspension by EPD, followed by sintering [264,267]. The deposition conditions with time and voltage for EPD were optimized, as shown in Figure 27a,b. The SOFC cell constructed on these sintered bi-layers of TSZ/NiO-YSZ exhibited a maximum power density of $611 \mathrm{~mW} \cdot \mathrm{cm}^{2}$ at $850^{\circ} \mathrm{C}$ (Figure $27 \mathrm{~d}$ ). In addition, the deposition of $\mathrm{YSZ}$ on a non-conducting porous $\mathrm{NiO}-\mathrm{YSZ}$ substrate showed that when saturated with the solvent, the porous substrate can allow the development of a conductive path between the electrical contact and the particles in suspension, as shown in Figure 27c. 
(a)

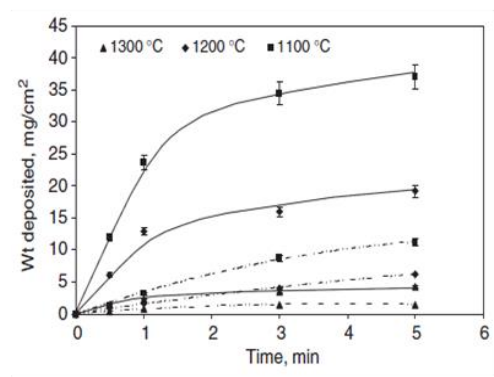

(c)

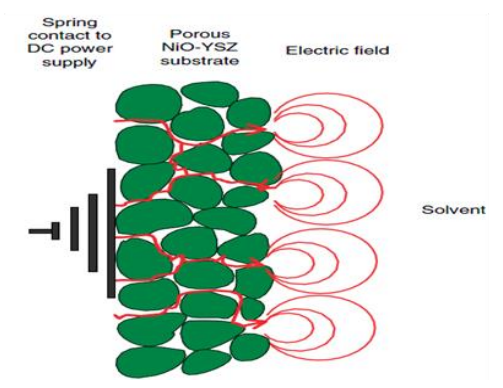

(b)

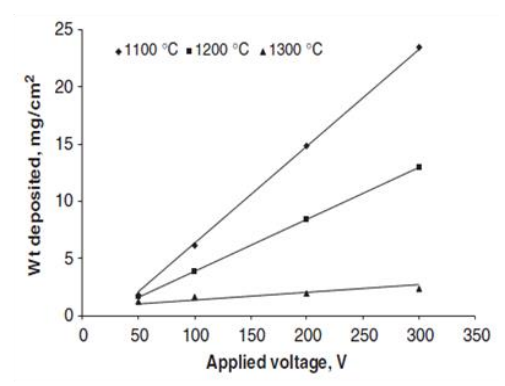

(d)

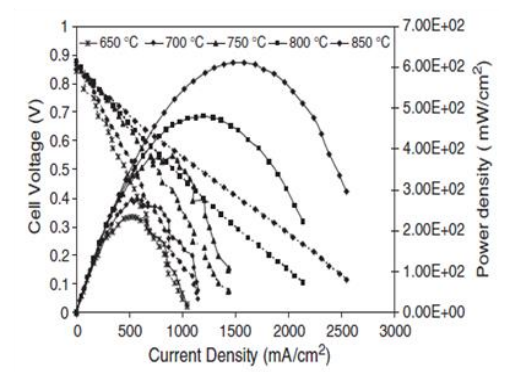

Figure 27. (a) Deposition characteristics of yttria-stabilized zirconia (YSZ) on porous NiO-YSZ as a function of the deposition time for a constant applied voltage of $300 \mathrm{~V}$ (solid lines) and $50 \mathrm{~V}$ (dashed lines); (b) Amount of yttria-stabilized zirconia (YSZ) deposited after $1 \mathrm{~min}$ as a function of the applied potential on NiO-YSZ substrates sintered at different temperatures; (c) Conceptual representation of the possible electrophoretic deposition mechanism on non-conducting substrates; (d) Performance characteristics of a solid oxide fuel cell with the configuration, NiO-YSZ/YSZ/LSM-YSZ, as a function of the operating current density.

Basu et al. [268] and Hosomi et al. [269] applied EPD to deposit a dense YSZ electrolyte on non-conducting porous doped $\mathrm{LaMnO}_{3}$ and NiO-YSZ substrates. They used a carbon interlayer on the ceramic substrates prior to the deposition of YSZ by EPD, followed by sintering. The lower surface roughness and better packing density of the coatings produced using the graphite interlayers were attributed to the more controlled deposition and equipotential electric-field distribution formed on the porous substrate when the interlayer is present. In particular, the SOFC cell constructed on these sintered YSZ/NiO-YSZ bi-layers exhibited a maximum power density of $2.01 \mathrm{~W} \cdot \mathrm{cm}^{2}$ at $800{ }^{\circ} \mathrm{C}$ [269]. Ji et al. confirmed the packing mechanism of the YSZ particles in the acetylacetone suspension after adding $I_{2}$ [270]. The results showed that the packing density of YSZ particles was increased further when the deposit was immersed in pure acetylacetone with the application of a constant electric field because the suspension containing iodine increased the charge density of $\mathrm{H}^{+}$ions, resulting in a decrease in the zeta-potential. Majhi et al. fabricated dense YSZ thin films on a porous scratched NiO-YSZ substrate in an acetylacetone suspension by EPD, followed by sintering at $1200{ }^{\circ} \mathrm{C}$ for $2 \mathrm{~h}$ [271]. The SOFC cell constructed on these sintered bi-layers exhibited an open circuit voltage (OCV) of $1.03 \mathrm{~V}$ and a maximum power density of $624 \mathrm{~mW} \cdot \mathrm{cm}^{2}$ at $800{ }^{\circ} \mathrm{C}$. Ji et al. prepared a dense YSZ thin film on a porous NiO-YSZ substrate in an isopropanol suspension containing iodine by EPD at $10 \mathrm{~V}$ for $60 \mathrm{~min}$ [272]. When the concentration of $\mathrm{I}_{2}$ was $0.5 \mathrm{~g} \cdot \mathrm{L}^{-1}$, the weight of YSZ deposited on the substrate reached the maximum. The SOFC cell constructed on these sintered bi-layers exhibited an open circuit voltage (OCV) of $1.0 \mathrm{~V}$ and a maximum power density of $440 \mathrm{~mW} \cdot \mathrm{cm}^{2}$ at $900{ }^{\circ} \mathrm{C}$. Dense YSZ thin films on porous LSM-YSZ and NiO-YSZ substrates were deposited electrophoretically in ethanol-based suspensions [273-275]. The optimal solvent rate (3:1 and 2:2 (acetone:ethanol)) by adding $I_{2}$ was required to achieve smooth, homogeneous, crack-free YSZ coatings by EPD. Zou et al. prepared a dense YSZ film on a porous NiO-YSZ substrate by EPD, followed by sintering [276]. EPD was carried out at $30 \mathrm{~V}$ for $90 \mathrm{~s}$ in a suspension of ethanol containing polyethylene glycol (PEG). The SOFC cell constructed on these sintered bi-layers exhibited a maximum power density of $850 \mathrm{~mW} \cdot \mathrm{cm}^{2}$ at $900{ }^{\circ} \mathrm{C}$. Dense YSZ films were fabricated by EPD in 
various suspensions, such as $n$-propanol, $n$-butanol, ethylene glycol $[277,278]$, tetramethylammonium hydroxide [279], isopropanol [280], and water-based ammonium polyacrylate [281]. On the other hand, despite both economic and environmental disadvantages, instead of water-based suspensions, organic suspensions were used as the carrier to avoid the detrimental effects of the electrolysis of water on the quality of the deposited film $[277,278]$. Cherng et al. suggested aqueous EPD to fabricate dense YSZ films [281]. EPD carried out in water-based suspensions containing ammonium polyacrylate (PPA-NH 4$)$. The added dispersant, PAA- $\mathrm{NH}_{4}$, dissociates into $\mathrm{PAA}^{-}$and $\mathrm{NH}_{4}{ }^{+}$in water, with the former adsorbed onto the surface of YSZ particles, resulting in a negative zeta-potential. Therefore, the particles remain suspended electrostatically and can move and deposit onto the substrate under a DC electric field. The deposition rate increased with increasing current density and decreasing PPA-NH ${ }_{4}$ concentration. With increasing concentration of PPA-NH${ }_{4}$ and dissociated $\mathrm{PAA}^{-}$and $\mathrm{NH}_{4}{ }^{+}$in suspension, the electrical resistance of the suspension decreased, resulting in the potential drop across the electrodes and an increase in the electric field strength for EPD. This lowered the driving force for electrophoresis and lowered the deposition rate. Zhitomirsky and Petric reported the EPD of $\mathrm{La}_{0.85} \mathrm{Sr}_{0.2} \mathrm{Ga}_{0.875} \mathrm{Mg}_{0.125} \mathrm{O}_{3-x}$ (LSGM) and $\mathrm{La}_{0.8} \mathrm{Sr}_{0.2} \mathrm{Co}_{0.2} \mathrm{Fe}_{0.8} \mathrm{O}_{3-\delta}$ (LSCF) on the substrate of $\left(\mathrm{Ce}_{0.8} \mathrm{Gd}_{0.2}\right) \mathrm{O}_{1.9}$ (CGO) on Ni foils and a porous Ni-YSZ substrate prepared by tape casting [282,283]. The aim of the work involved finding a common solvent/binder/dispersant system for EPD of these materials. The ethyl alcohol, phosphate ester (PE) and polyvinyl butyral (PVB) were identified as a suitable solvent, dispersant, and binder, respectively, for EPD. In addition, self-supported dense films, EPD process was used to fabrication of thickness of $40-80 \mu \mathrm{m}$ on a graphite substrate from LSGM and then sintered at high temperature [284]. The SOFC cell constructed on these sintered anode and cathode-layers exhibited a maximum power density of $0.5 \mathrm{~W} \cdot \mathrm{cm}^{2}$ at $700{ }^{\circ} \mathrm{C}$. Boccaccini et al. deposited LSCF electrophoretically on a porous CGO substrate [285]. To obtain a porous LSCF film, the best results were achieved at an applied voltage of $20 \mathrm{~V}$ for $2 \mathrm{~min}$ with a suspension containing acetylacetone, iodine, and starch. EPD was demonstrated to be a simple and useful method for fabricating a porous LSCF electrode on a CGO substrate. Bozza et al. used EPD to fabricate dense LSGM films on the substrate of the $\mathrm{La}_{0.4} \mathrm{Ce}_{0.6} \mathrm{O}_{2-x}$ (LDC) electrode followed by sintering at high temperatures [286,287]. The conditions for EPD were optimized in a common acetone/water $/ I_{2}$ system for the EPD of these materials. The SOFC cell constructed on these sintered by-layered LDC/LSGM recorded a power density of $780 \mathrm{~mW} \cdot \mathrm{cm}^{2}$ at $700{ }^{\circ} \mathrm{C}$ [287]. Moreover, the $\mathrm{La}_{0.8} \mathrm{Sr}_{0.2} \mathrm{Ga}_{0.8} \mathrm{Mg}_{0.115} \mathrm{Co}_{0.085} \mathrm{O}_{3-\delta}$ (LSGCM) electrolyte was deposited by EPD in the acetone/water/ $\mathrm{I}_{2}$ system [288]. EPD was carried out at $60 \mathrm{~V}$ for $2 \mathrm{~min}$. The LSGCM/LDC bi-layer obtained by EPD was co-fired at $1400{ }^{\circ} \mathrm{C}$ for $2 \mathrm{~h}$. A dense and crack-free $8 \mu \mathrm{m}$ film supported on a porous skeleton of LDC was obtained. Bi-layered films, such as $\mathrm{NiO}-\mathrm{YSZ} / \mathrm{YSZ}, \mathrm{YSZ} / \mathrm{Sm}_{0.2} \mathrm{Ce}_{0.8} \mathrm{O}_{1.9}$ (SDC), and LSM/LSM-YSZ, were also fabricated by a 2 step EPD process to minimize the ohmic losses of SOFC cells [289-291]. Liu et al. reported the best NiO:YSZ ratio in acetylacetone-based suspension for EPD as well as the condition to fabricate dense YSZ films by EPD, which were subsequently co-fired. It was confirmed that the sample cracking occurred when the high $\mathrm{NiO}$ content was significantly reduced as the $\mathrm{NiO}$ content to $60 \%$ in the suspension. When the $\mathrm{NiO}$ content is reduced to $50 \%$, some crack-free samples can be obtained, however, the film composition was not desirable for SOFC applications [289]. The best results were achieved in the suspension with a $\mathrm{NiO} / \mathrm{YSZ}$ ratio of 40:60 at a short deposition time and applied voltage (200 V for $3 \mathrm{~min}$ ). The SOFC cell constructed NiO/YSZ (40:60)-supported dense YSZ displayed a peak power density of $434 \mathrm{~mW} \cdot \mathrm{cm}^{-1}$ at $800{ }^{\circ} \mathrm{C}$ [289]. Matsuda deposited a bi-layered YSZ/SDC electrolyte film electrophoretically. YSZ was deposited directly on a porous NiO-YSZ substrate. After EPD of YSZ, SDC was deposited on the as-deposited YSZ film on the porous substrate at $600 \mathrm{~V}$ in an ethanol-based suspension. The SOFC cell was constructed on the bi-layered electrolyte films composed of $4 \mu \mathrm{m}$ YSZ and $1 \mu \mathrm{m}$ SDC films. A maximum power density of $0.6 \mathrm{~W} \cdot \mathrm{cm}^{-2}$ was obtained at $700{ }^{\circ} \mathrm{C}$ [290]. Reducing the operating temperature of the SOFCs to below $800^{\circ} \mathrm{C}$ is important to reduce degradation of the cell components. On the other hand, the electrolyte conductivity decreased significantly with decreasing operating temperature. To solved these problem, it is only necessary to reduce the thickness 
of the electrolyte or to lower the electrolyte resistance with an alternative material with a high ionic conductivity at a low temperature. Following these reports, Cheng attempted to use the EPD method on dense SDC deposited on a porous NiO-SDC substrate [292]. Highly dense SDC films were obtained at $60 \mathrm{~V}$ for $1 \mathrm{~min}$ in a mixed suspension of acetone and ethanol. The SOFC cell constructed on these sintered recorded a maximum power density of $155 \mathrm{~mW} \cdot \mathrm{cm}^{2}$ at $500{ }^{\circ} \mathrm{C}$ as well as an open circuit potential of $0.92 \mathrm{~V}$. Zunic et al. employed EPD to deposit a dense proton conducting electrolyte of $\mathrm{BaCe}_{0.9} \mathrm{Y}_{0.1} \mathrm{O}_{3-x}$ (BCY10) on a NiO-BCY10 substrate to use intermediate temperature SOFCs [293,294]. A highly dense BCY10 film on the NiO-BCY10 substrate was deposited at $60 \mathrm{~V}$ compared to at 10 to $50 \mathrm{~V}$ for $1 \mathrm{~min}$. The SOFC cell constructed from NiO-BCY10/BCY10/LSCF-BCY10 displayed a maximum power density of $208 \mathrm{~mW} \cdot \mathrm{cm}^{-1}$ at $650{ }^{\circ} \mathrm{C}$ [295]. Although EPD could produce various thin and gas-tight electrolyte or electrode films, this method is not suitable for mass production due to complicated multi-deposition and sintering steps, time-consuming, and excessive high cost. In addition, it was confirmed that an electrolyte or electrode and acceptable fuel cell performance could not be obtained without the multiple deposition steps. Therefore, Cherng et al. used consecutive EPD to deposit a porous NiO-YSZ, dense YSZ, and a porous LSM onto a thin wire electrode, followed by stripping, drying, and a single co-sintering [295-297]. The effects of the three major EPD process variables, such as the current density, solid loading, and surfactant concentration were investigated. The deposition rate increased with increasing current density and solid loading but decreased with increasing surfactant $\mathrm{PAA}-\mathrm{NH}_{4}$ concentration, and the porosity decreased with increasing deposition rate [297]. As shown in Figure 28a, a tubular SOFC was made by consecutive EPD and co-sintering at $1250{ }^{\circ} \mathrm{C}$. The optimal power density at $800{ }^{\circ} \mathrm{C}$ reached $368.8 \mathrm{~mW} \cdot \mathrm{cm}^{-2}$ for the anode with $70 \mathrm{wt} . \%$ and degraded to lower values at higher $\mathrm{NiO}$ contents (Figure 28b).

(a)

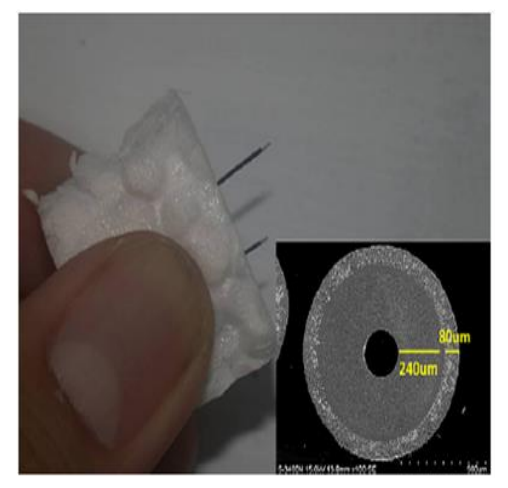

(b)

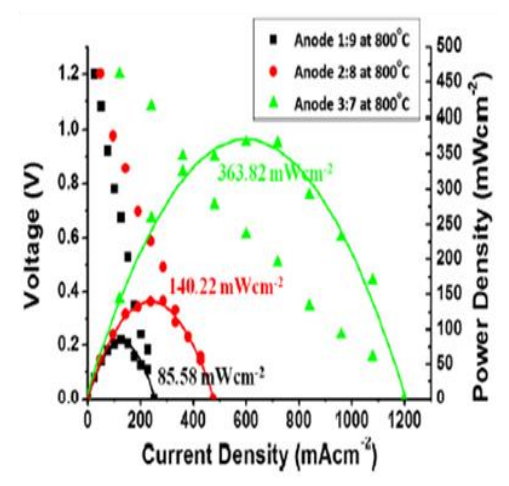

Figure 28. (a) Photograph (with an inset for close-up) of typical micro-tubular SOFCs made by consecutive EPD and single-step co-sintering; (b) Electrochemical performance of such micro-tubular SOFCs with various anode compositions.

Subsequently, Droushiotis et al. used EPD to fabricate dense YSZ on the un-sintered NiO-YSZ hollow fibers in an ethanol-based suspension. The YSZ-coated NiO-YSZ fibers were co-fired at high temperatures. The SOFC cell prepared using the YSZ-coated NiO-YSZ fibers delivered a peak power density of $0.2 \mathrm{~W} \cdot \mathrm{cm}^{-2}$ at $800{ }^{\circ} \mathrm{C}$ [298]. As shown in the literature, there still remains a need to be addressed until the commercial utilization for SOFC using the EPD process is feasible. Optimization of process parameters such as a suitable solvent and development of a suitable EPD chemistry remains an important topic [34]. Through optimization, it is possible to manufacture homogeneous, uniform, and crack-free films. In addition, oxidation-resistant metallic alloys, such as Crofer22 APU, E-Brite, and SS430 are used as interconnect materials because of the easy fabrication, low material cost, significantly better mechanical properties, and higher electrical and thermal conductivity. On the other hand, the evaporation of volatile $\mathrm{Cr}$ species $\left(\mathrm{Cr}_{3}\right.$ or $\mathrm{Cr}_{2}(\mathrm{OH})_{2}$ is a serious problem associated with these chromia-forming alloys, which leads to rapid performance degradation. Recently, EPD has been used to produce the desired $(\mathrm{Mn}, \mathrm{Co})_{3} \mathrm{O}_{4}$ spinel coatings on SOFC interconnects because of its deposition 
efficiency, cost-effectiveness, and ease of operation compared to other coating methods [299-301]. Smeacetto et al. deposited a $(\mathrm{Mn}, \mathrm{Co})_{3} \mathrm{O}_{4}$ spinel coating layer by $\mathrm{EPD}$ at $50 \mathrm{~V}$ and various deposition times in a suspension of ethanol and water (a volume ratio of $60 / 40\left(\mathrm{EtOH} / \mathrm{H}_{2} \mathrm{O}\right)$, followed by sintering at $1000{ }^{\circ} \mathrm{C}$ for $2 \mathrm{~h}$. The inner and central layer of the $(\mathrm{Mn}, \mathrm{Co})_{3} \mathrm{O}_{4}$ spinel coating were obtained after a $20 \mathrm{~s}$ deposition time in the suspension, as shown in Figure 29a. The area specific resistance (ASR) of the $(\mathrm{Mn}, \mathrm{Co})_{3} \mathrm{O}_{4}$ spinel coating layer fabricated by EPD was measured in real SOFC stacks. The results showed that the increase rates of the spinel coating layer prepared by EPD are $0.53 \mathrm{~m} \Omega \cdot \mathrm{cm}^{2}$ per $1000 \mathrm{~h}$. Therefore, the ASR value after $40,000 \mathrm{~h}$ operation would be $\sim 40 \mathrm{~m} \Omega \cdot \mathrm{cm}^{2}$ by making a simple assumption of increased ASR values. Generally, the target for ASR of each single SOFC component was estimated to be $\sim 100 \mathrm{~m} \Omega \cdot \mathrm{cm}^{2}$ so that the prepared coating fulfills the criteria of the sufficient protective nature of the coating.

(a)

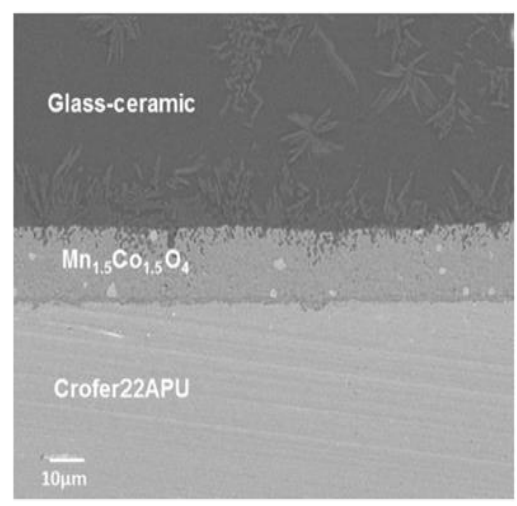

(b)

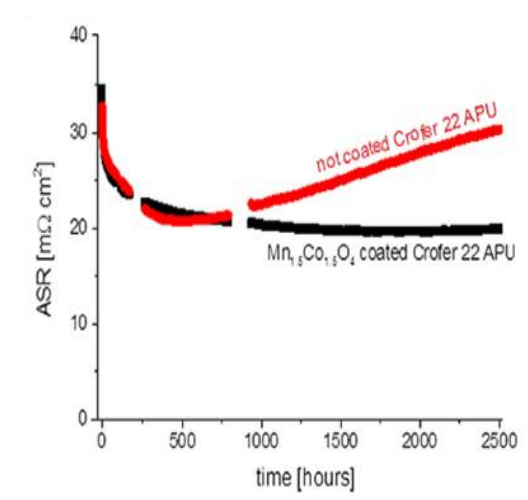

Figure 29. (a) SEM cross section image of the $\mathrm{Mn}_{1.5} \mathrm{Co}_{1.5} \mathrm{O}_{4}$ coated Crofer22APU obtained at $50 \mathrm{~V}$ and $20 \mathrm{~s}$ and sintered at $1000{ }^{\circ} \mathrm{C}$ for $2 \mathrm{~h}$ in air; (b) Area Specific Resistance of uncoated and $\mathrm{Mn}_{1.5} \mathrm{Co}_{1.5} \mathrm{O}_{4}$ coated Crofer22APU alloy tested at $800{ }^{\circ} \mathrm{C}$ under a $500 \mathrm{~mA} \cdot \mathrm{cm}^{-2}$ load.

The details of the SOFCs manufactured by applying the EPD process are summarized in Table A4.

\section{Applications of EPD for Nanomaterials of Electrocatalysis}

Electrocatalysis is important for reducing the overpotential for a number of reactions vital to renewable energy applications, including fuel cells, metal-air batteries, and water splitting cells [302-307]. Significant efforts have been devoted to the development of electrocatalysts for fuel oxidation, hydrogen evolution reactions (HER), oxygen evolution reactions (OER), and oxygen reduction reaction (ORR). The goal of their electrocatalysts was to obtain high activity and stability at low cost. The controlling size and surface structures of the electrocatalysts particles are important for achieving the optimal catalytic effects. Unlike other liquid state synthesis processes that could take a long time and poison the active sites on the catalyst surface by the surfactant or other capping agents, the EPD process could be used to tune the morphology and size of the catalyst particles on various carbonaceous materials, such as carbon black, carbon nanotubes, and graphene as well as impart higher porosity and better catalyst particle distribution on the substrates by depositing electrocatalysts to enhance the catalytic effects by controlling the applied voltage and time, $\mathrm{pH}$ of the suspension, and the kinds of the suspensions. In addition, the high interfacial stability for electrical conductivity between the electrocatalysts and substrates could increase charge transport in electrocatalysis. Noble metals, including $\mathrm{Pt}, \mathrm{Au}, \mathrm{Pd}$, and $\mathrm{Ru}$, are well-known catalysts for oxidation reactions of methanol, ethanol, and formic acid. Electrocatalysts of these metals formed by EPD on various materials and substrates have shown higher activity than commercially available metal/carbon catalysts or electrodes prepared by conventional processes, such as screen printing and decal process in fuel oxidation reactions. Typically, Pt/carbon catalysts were deposited electrophoretically on a carbon electrode or Nafion membrane for the oxidation reactions of methanol and hydrogen [308-316]. The performance of the electrocatalyst depends on the composition of the suspension and the conditions of the EPD process. 
Morikawa et al. deposited Pt/C catalysts on the both surfaces of Nafion membranes using HVEPD for different deposition times. An ethanol-based suspension was used due to the high voltage of EPD used (a constant voltage: $1000 \mathrm{~V}$ ) [309]. The performance of a membrane electrode assembly (MEA) prepared by HVEPD was higher than that fabricated by a conventional hot-press method. These results were attributed to the higher uniformity of the electrocatalyst on the surface of Nafion prepared by the EPD process compared to the conventional process. Jeng et al. employed EPD to deposit uniform $\mathrm{Pt}-\mathrm{Ru}$ electrocatalysts synthesized by a modified polyol process on carbon paper. The EPD operations were performed at an applied DC voltage of $5 \mathrm{~V}$ for $30 \mathrm{~min}$ in a $\mathrm{HClO}_{4}$-based suspension with a Nafion solution and electrocatalyst. The electrode fabricated by EPD exhibited a higher methanol oxidation reaction than the electrode prepared by the conventional process. Girishkumar and Louh et al. used a 2 step EPD process to enhance the catalytic effects [310,311]. The first step EPD was used to form a porous layer of SWCNTs of carbon black to enhance the distribution of electrocatalysts, which led to high catalytic effects. Subsequently, the electrocatalysts were deposited electrophoretically on a porous layer prepared by first-step EPD. The resulting MEA applied multilayer electrodes showed significantly higher catalytic activity towards the hydrogen oxidation reaction and oxygen reduction reaction than that of the applied a commercial Pt/C catalyst. Therefore, EPD could be a simple and versatile technique to design the MEA-applied electrocatalysts for fuel cells. In more recent studies, Felix et al. deposited an electrocatalyst on carbon paper by EPD. They examined the catalyst suspension and the conditions for the EPD process [314]. The optimal suspension conditions were obtained when the catalyst particles were deposited in a suspension with a Nafion solution, a $\mathrm{pH}$ of 8-10 and an applied voltage was $100 \mathrm{~V}$. The resulting MEA prepared by EPD showed superior performance with a peak power increase of approximately $73 \%$ at similar platinum $(\mathrm{Pt})$ loadings as well as lower charge transfer resistance for the MEA compared to the MEA fabricated by conventional hot-press process. The results indicated that the EPD process supplied a high pore area and a better dispersion of $\mathrm{Pt}$ particles within the catalyst layer on the carbon electrode. In addition, they studied suspensions containing the $\mathrm{Pt} / \mathrm{C}$ catalyst, polytetrafluoroethylene (PTEF) and $\mathrm{NaCl}$ for EPD to fabricate MEA for use at high temperatures [316]. Stable catalyst suspensions were obtained at $\mathrm{NaCl}$ concentrations $0.1 \mathrm{mM}$ and an applied voltage of $100 \mathrm{~V}$. The carbon paper electrode deposited electrophoretically in the suspension showed a $\sim 12 \%$ increase in peak power at a slightly lower Pt catalyst loading of $\sim 4 \mathrm{wt} . \%$ as well as lower charge transfer resistance compared to the electrode prepared by an ultrasonic spray because the electrode fabricated by EPD had higher porosity than that the electrode obtained by the ultrasonic spray method. A comparison of the PTFE and Nafion solution in the catalyst layer of the electrodes fabricated by EPD revealed PTEF to have better performance and be more suitable for use at high temperatures $\left(160^{\circ} \mathrm{C}\right)$. A nano-architectured Pt catalyst layer was prepared by the pulsed electrophoretic deposition (PED) [317-319]. Yu et al. synthesized branched Pt nanoparticles on a carbon black electrode by PED [317]. PED was carried out in a suspension at various $\mathrm{pH}$ containing Pt nanoparticles colloid at a duty cycle $\left\{\mathrm{t}_{o n} /\left(\mathrm{t}_{o n}+\mathrm{t}_{o f f}\right)\right\}$ of $25 \%$ and a $\mathrm{t}_{c y c l e}\left(\mathrm{t}_{o n}+\mathrm{t}_{\text {off }}\right)$ time fixed to $1 \mathrm{~s}$. The Pt-carbon black electrode showed higher mass activity and specific activity for the methanol oxidation reaction than a commercial Pt/C catalyst. Recently, Adibish et al. employed PED to synthesize Pt/C catalyst electrodes at different deposition times and duty cycles [318]. The electrochemical active surface area (ECSA) of the Pt/C electrode synthesized by PED showed the highest value when the deposition time was $10 \mathrm{~min}$ and the duty cycle $\left\{\mathrm{t}_{o n} /\left(\mathrm{t}_{o n}+\mathrm{t}_{\text {off }}\right)\right\}$ was $25 \%$. With increasing deposition time, the ECSA was decreased because of the relatively low active surface area of the Pt catalyst caused by the coagulation of Pt nanoparticles. Carbonaceous materials, such as carbon nanotube [319], $\mathrm{C}_{60}$ [319], carbon nanofibers [320], and graphene nanosheets [321-325], which have a high specific surface area, have been used as the supports for loading $\mathrm{Pt}$ nanoparticles because their materials can supply high catalytic activity by enhancing the catalytic surface area. The EPD process was employed to deposit their materials on the electrode and synthesize Pt nanoparticles. Kamat et al. synthesized branched Pt nanoparticles on $\mathrm{C}_{60}$ and single-walled carbon nanotubes (SWCNTs) as supports by EPD and electrochemical deposition (ECD) $[324,325]$. The amounts of SWCNTs and $\mathrm{C}_{60}$ on the electrodes 
were optimized according to the EPD conditions for methanol oxidation. The higher catalytic activity was attributed to the larger surface area provided by the supporting architecture and the decreased overpotential for the methanol oxidation reaction. Qin produced Pd nanoparticles deposited carbon nanofibers by PED for ethanol oxidation in alkaline media [320]. The carbon nanofibers were deposited electrophoretically to form a 3D network structure, which led to a large number of available Pd active sites for ethanol oxidation and the Pd nanoparticles were then deposited on the electrode that had a 3D network structure of carbon nanofibers by PED. The Pd nanoparticles decorating the carbon nanofiber electrode showed good electrocatalytic activity toward ethanol oxidation in a $\mathrm{KOH}$ electrolyte. In addition, the Pt nanoparticles formed on graphene nanosheets showed higher activity than commercially available metal/carbon catalysts in fuel oxidation reactions. Seger et al. synthesized branched Pt nanowires on graphene oxide (GO) by a solution phase reaction, in which $\mathrm{NaBH}_{4}$ was used to reduce the Pt precursor and GO nanosheets [321]. The Pt-reduced graphene electrocatalysts were deposited electrophoretically on carbon paper with a constant voltage for various deposition times. The Pt-reduced graphene electrocatalyst-based fuel cell delivered a maximum power of $161 \mathrm{~mW} \cdot \mathrm{cm}^{-2}$ compared to $96 \mathrm{~mW} \cdot \mathrm{cm}^{-2}$ for the unsupported Pt-based fuel cell. The electrocatalyst on the graphene nanosheets was useful to achieve relatively better performance in fuel cell applications. Liu employed EPD and ELD to synthesize uniform Pt nanoparticles on reduced GO nanosheets, affording an electrocatalyst with a 2 times higher peak current density for the methanol oxidation reaction than a Pt catalyst without reduced GO supports [322]. Wallace et al. fabricated novel electrocatalytic electrodes by the EPD of graphene and Pt nanoparticles sequentially or via a single-step EPD of graphene: Pt composite nanoparticles onto the electrode [323]. Through fabrication optimization, the process time of the single-step EPD of graphene:Pt composite was shorter than that of the layer-by-layer approach (seconds compared to minutes). The electrocatalytic electrode by the single-step EPD showed an almost 10 times higher Pt electrochemically active surface area for electrocatalysis. The oxygen reduction reaction at the cathode is vital for fuel cells. The sluggish kinetics of the ORR at the cathode seriously limits the power output and efficiency of fuel cells. Thus far, $\mathrm{Pt}$ and its alloys have been the most active ORR catalysts, despite their high cost. EPD has been used to fabricate the electrode for Pt-based ORR catalysts [310,312,319,325]. Seger et al. reported a higher ORR activity than the electrode-applied commercial catalyst when $\mathrm{Pt}_{-} \mathrm{SiO}_{2}$ nanoparticles were assembled onto a carbon paper electrode by EPD [312]. Zheng et al. synthesized branched Pt nanoparticles on carbon nanofibers by EPD [319]. The Pt-carbon nanofiber nanocomposite electrocatalyst showed higher mass activity and specific activity for the oxygen reduction reaction than a commercial $\mathrm{Pt} / \mathrm{C}$ catalyst. Kamat et al. reported a fuel cell with a Pt supported on a SWCNTs film as the cathode catalyst outperforming that with an unsupported Pt cathode catalyst [325]. Non-precious metal ORR catalysts have been pursued actively because of the scarcity and prohibitive price of noble metals for the large scale application of fuel cells [326-328]. Chi et al. employed EPD to deposit $\mathrm{ZnCo}_{2} \mathrm{O}_{4}$ on a nickel substrate [329]. EPD was conducted at a voltages of 10 and $30 \mathrm{~V}$ for $1-5 \mathrm{~min}$. The effects of the electrophoresis variables, including the deposition time and applied voltages, were discussed. A longer deposition time resulted in compact and homogeneous surfaces at low applied voltages. The electrode deposited at $10 \mathrm{~V}$ for $5 \mathrm{~min}$ showed the best electrocatalytic properties compared to the other electrodes and the overpotential for OER at a given current density of $100 \mathrm{~mA} \cdot \mathrm{cm}^{-2}$ was $0.203 \mathrm{~V}$. The effects of nanoparticle deposition on the catalytic activity of $\mathrm{Co}_{3} \mathrm{O}_{4}$ nanoparticles for the oxygen reduction reaction (ORR) and oxygen evolution reaction (OER) were evaluated for two deposition methods: dropcasting and EPD [330]. EPD of Co nanoparticles was conducted by immersing the glass carbon electrode into a $1 \mathrm{mg} \cdot \mathrm{mL}^{-1}$ suspension of Co nanoparticles in hexane at $300 \mathrm{~V}$ for $30 \mathrm{~s}$, followed by an annealing process to complete the conversion of $\mathrm{Co}_{0} \mathrm{Co}_{3} \mathrm{O}_{4}$ at $230{ }^{\circ} \mathrm{C}$ for $2 \mathrm{~h}$. The kinetic characteristics of the electrode prepared by EPD was enhanced significantly compared to the dropcast electrode. The electrode prepared by EPD showed a smaller slope of $96 \mathrm{mV}$ per decade compared to $109 \mathrm{mV}$ per decade for the drop-cast electrode, as shown in Figure 30b. A smaller slope is indicative of more favorable kinetic characteristics. 
(a)

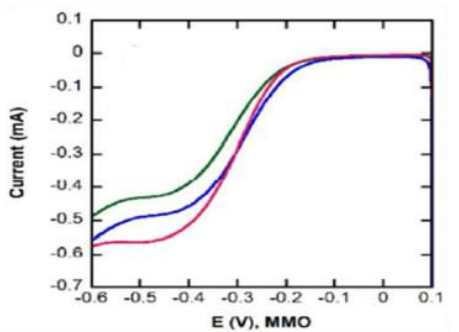

(c)

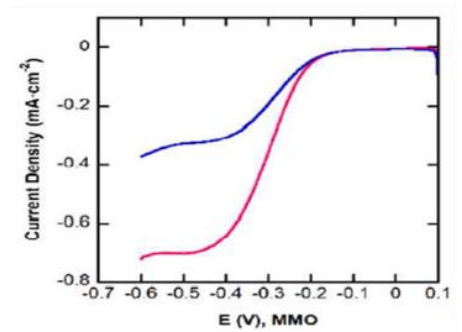

(b)

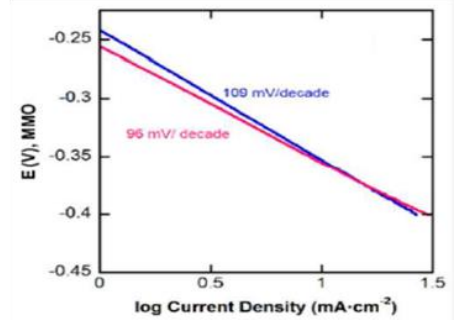

(d)

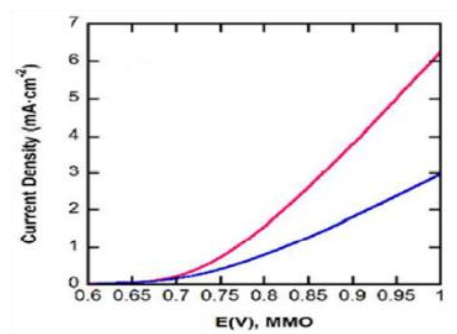

Figure 30. (a) ORR polarization curves for the $\mathrm{Co}_{3} \mathrm{O}_{4}$ nanoparticle thin film electrode deposited by EPD (pink) and dropcast (blue and green); (b) Tafel plots of the dropcast and EPD thin film electrodes derived by the mass-transport correction of corresponding RDE data (Rotation speed: 1600 RPM); (c) ORR polarization curves for $\mathrm{Co}_{3} \mathrm{O}_{4}$ nanoparticle thin film electrode deposited by EPD (pink) and dropcast (blue) after adjusting for the surface area; (d) OER polarization curves for the $\mathrm{Co}_{3} \mathrm{O}_{4}$ nanoparticle thin film electrode deposited by EPD (pink) and dropcast (blue) after adjusting for the surface area.

These Tafel slopes were related to the geometrical area of the electrode. Considering the ORR and OER comparisons, as shown in Figure 30c,d, the electrode fabricated EPD was $\sim 2$ times more active than the drop-cast electrode for the ORR and OER because the electrode produced by EPD exhibited better current conduction and was denser. Bryan et al. used EPD to deposit graphene thin films before the deposition of a thin layer of $\mathrm{CO}_{3} \mathrm{O}_{4}$ nanoparticles by chemical bath deposition (Figure 31a) [331]. The by-layer composite electrode showed a higher catalytic current than $\mathrm{Co}_{3} \mathrm{O}_{4}$ layers without graphene layers, with an OER onset potential of $0.82 \mathrm{~V}$ (NHE), while the graphene electrode did not exhibited any catalytic activity towards the OER, as shown Figure 31b. In addition, The OER occurred at a lower overpotential when the number of bi-layers increased, which was attributed to the larger catalytic surface area of the graphene layer fabricated by EPD (Figure 31c). The ORR current density of the by-layer composite electrode obtained at $-0.3 \mathrm{~V}\left(0.2 \mathrm{~mA} \cdot \mathrm{cm}^{-2}\right)$ was one order of magnitude higher than that of the graphene electrode $\left(0.02 \mathrm{~mA} \cdot \mathrm{cm}^{-2}\right)$. Therefore, the by-layer composite electrode fabricated by a 2 step process including EPD can be used as a bi-functional catalyst for both the OER and ORR, which can be applied potentially as an electrocatalyst for both water electrolysis and fuel cells for energy conversion and storage systems. 
(a)

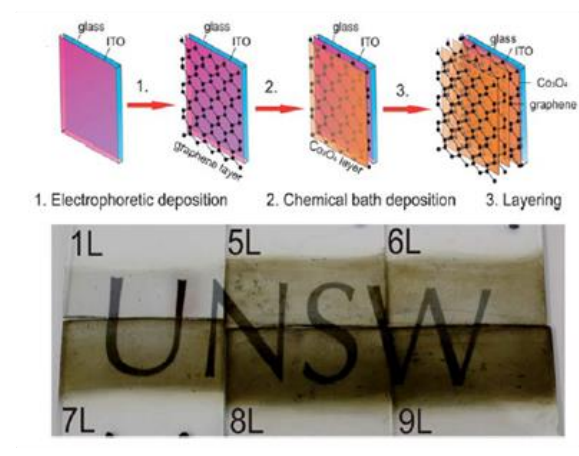

(c)

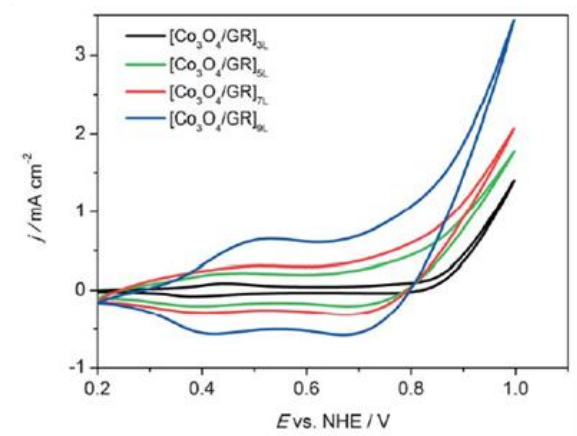

(b)

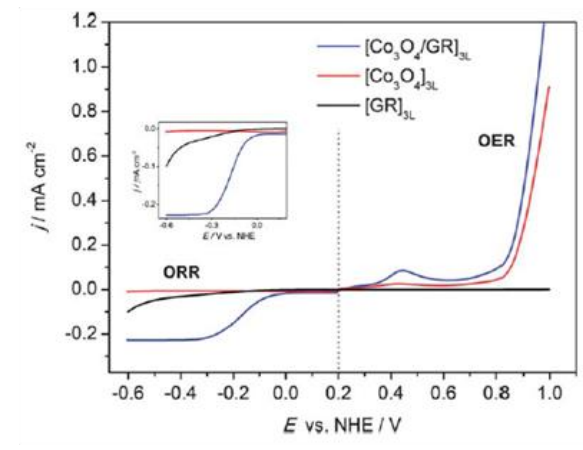

(d)

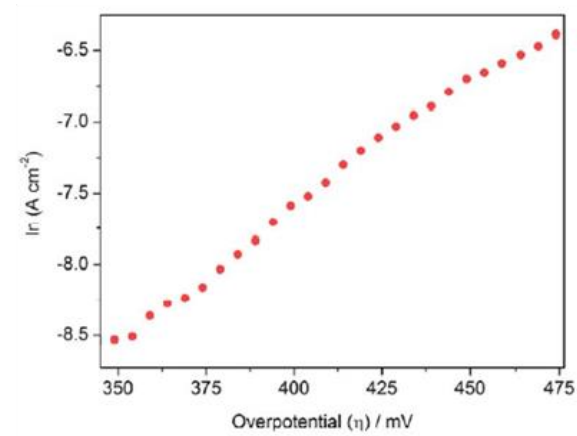

Figure 31. (a) Fabrication scheme of a bi-layer composite electrode; (b) Linear sweep voltammograms of by-layer composite electrode (red), $\mathrm{Co}_{3} \mathrm{O}_{4}$ nanoparticles electrode (blue), graphene electrode (black). The inset shows the magnified ORR region; (c) Cyclic voltammograms obtained at a scan rate of $10 \mathrm{mV} \cdot \mathrm{s}^{-1}$ with different numbers of bi-layers in a bi-layer composite electrode; (d) Tafel plot generated from water oxidation using the bi-layer composite electrode of 9 layers.

The details of the electrocatalysts manufactured by applying the EPD process are summarized in Table A5.

\section{Summary}

Systematic efforts have been made to design and synthesize advanced nanomaterials for electrochemical energy storage and conversion by EPD [32,139,185,215,240,331]. The electrodes for electrochemical energy storage and conversion devices have been studied to enhance the stability and efficiency, which are the prime issues in electrochemical energy storage and conversion devices. An application of EPD for such electrodes can be found in advanced ceramic materials, coatings for thin and thick films, multilayered composites, functionally graded materials, hybrid materials, self-supported components, micro-patterned assemblies, and nanotechnology. Because EPD is an automated process, a variety of parameters, such as applied voltage, frequency, concentration of the dispersed species, and deposition time can be controlled to yield a better response under the optimized conditions $[33,34,40,59]$. Accordingly, advanced nanomaterials with improved characteristics have recently been designed and manufactured by EPD. Moreover, EPD process is simple to install and can be used to deposit a variety of areas and thicknesses by adjusting a variety of parameters. Especially, it is possible to deposit various electrode materials in nanometer thickness which is more cost effective compared to other processes. From this review, it is clear that EPD can yield better performance for practical applications in electrochemical energy storage and conversion devices. The following are some of the possible future directions of research for the development of nanomaterials designed and manufactured by EPD for electrochemical energy storage and conversion devices. 
1. EPD was assessed to produce nanomaterials in energy storage devices. Oxide-based active materials are used comprehensively for the cathode electrode but their active materials have low electrical conductivity. Therefore, hybrid materials containing active and carbon materials without a binder material led to a degradation of the performance of the nanomaterials synthesized by well controlled EPD process. The hybrid materials were deposited on substrates with various structures because EPD does not influence the form of the substrates. EPD can used to deposit thin and thick films for all-solid-state-based cathode electrodes without organic additives to improve safety.

2. When designing anode materials by EPD, the aim should be to minimize the volume expansion, which leads to performance degradation during lithium intercalation, and enhance the activated sites. In this regard, studies of EPD have been conducted to design uniform coatings for thin and thick films, multilayered composites, and hybrid materials. Such electrodes designed by EPD can be increased without sacrificing the performance. A study of the high performance and stability of the nanomaterials designed by EPD appears to be very promising for finding new nanomaterials with the optimal activity towards practical applications.

3. An enhancement of the specific surface area or activated sites of nanomaterials for supercapacitor applications is the main concern. Recent studies found that the use of EPD to design and manufacture electrodes enhances the specific capacitance for supercapacitors. The uniform thin and thick films, multilayered composites, and hybrid materials have been designed by EPD to increase the specific capacitance. In particular, the specific surface area and activated sites for high specific capacitance can be improved using graphene nanosheets and carbon nanotubes during the EPD process. A high electrical conductivity can lead to enhanced specific capacitance.

4. The electrodes for solid oxide fuel cells generally need to be porous to permeate the fuel, while the electrolyte layer must be dense to prevent the leakage of gas across the layer. Electrodes have been designed with a variety of parameters, such as applied voltage, concentration of the dispersed species, and deposition time, to form highly porous and dense electrodes. The use of EPD can raise the energy density more than when a conventional process is used. Recently, EPD has been used to produce laminated ceramics because of its deposition efficiency, cost-effectiveness and ease of operation compared to other coating methods, such as lithography, self-assembly, dip coating and screen printing, and spin coating.

5. Nanostructured electrocatalysts based on noble metals have been studied comprehensively for the oxidation reactions of methanol, ethanol and formic acid, and the oxygen reduction reaction. The use of EPD to design electrocatalysts or electrodes is another cost effective way to achieve fuel cell commercialization. Recently, non-precious metal electrocatalysts for the oxygen reduction reaction have been pursued actively to reduce the prohibitive price of noble metals. The nanostructured electrocatalysts fabricated by EPD for catalytic activity could be an effective way to use fuel cells.

\section{Outlook}

The application of EPD for electrochemical energy storage and conversion devices has increased rapidly and improved the performance of existing electrochemical electrodes significantly. Further efforts will be needed to fully investigate the mechanism and properties of the EPD process. In particular, a better understanding of electrophoresis in colloidal systems and the effects of parameters, such as applied voltage, time, and suspension during the EPD process, is needed. Such understanding will allow better control of the morphology and structure of the nano-materials and could lead to new materials. In addition, EPD should be studied under modulated electric fields, such as pulsed direct current and alternating current to design electrodes with various structures for electrochemical energy storage and conversion devices because EPD under modulated electric fields can impart improved characteristics compared to those obtained by classical EPD, including well-oriented microstructures [50,332]. In addition, it leads to high reproducibility because EPD under 
modulated fields can be automated. Accordingly, attention should be paid to the design and fabrication of 2D and 3D structures for the novel generation of future advanced applications in electrochemical energy storage and conversion devices. Finally, future efforts should be devoted to the development of currently unknown nano-materials and their applied electrodes designed by a range of EPD processes to potentially revolutionize batteries, supercapacitors, and fuel cells.

Author Contributions: Conceptualization, S.H.L. and S.P.W.; methodology, S.H.L. and S.P.W.; formal analysis, N.K.; investigation, S.H.L., S.P.W. and N.K.; data curation, N.K.; writing-original draft preparation, S.H.L. and S.P.W.; writing-review and editing, D.J.K. and Y.S.Y.; visualization, S.H.L., S.P.W. and N.K.; supervision, D.J.K. and Y.S.Y.; project administration, Y.S.Y.; funding acquisition, Y.S.Y.

Acknowledgments: This work was supported by the International Collaborative Energy Technology R\&D Program of the Korea Institute of Energy Technology Evaluation and Planning (KETEP), granted financial resource from the Ministry of Trade, Industry \& Energy, Republic of Korea (20158520000210). Futhermore, this work was supported by the Gachon University research fund of 2016 (GCU-2016-0218).

Conflicts of Interest: The authors declare no conflict of interest. 


\section{Appendix A}

Table A1. Overview of cathode electrodes designed by EPD showing the nanomaterials for Li-ion batteries and EPD conditions investigated.

\begin{tabular}{|c|c|c|c|c|c|c|c|}
\hline \multirow{2}{*}{ No. } & \multicolumn{2}{|c|}{ Materials } & \multirow{2}{*}{ Suspension Medium } & \multicolumn{2}{|c|}{ EPD Conditions } & \multirow{2}{*}{$\begin{array}{c}\text { Specification } \\
\text { (Charge/Discharge Capacity) }\end{array}$} & \multirow{2}{*}{ Ref } \\
\hline & Coating & Substrate & & Voltage & Time & & \\
\hline 1 & $\mathrm{LiCoO}_{2}$ & $\mathrm{Al}$ foil & $\begin{array}{l}\text { Acetone, } \mathrm{I}_{2}, \text { PTEF, and ketjen } \\
\text { black }(\mathrm{C} \cdot \mathrm{A})\end{array}$ & 100 & $1 \mathrm{~min}$ & $\begin{array}{l}\text { A specific capacity of } 142 \mathrm{mAh} \cdot \mathrm{g}^{-1} \\
\text { maintained a capacity of } 120 \mathrm{mAh} \cdot \mathrm{g}^{-1} \\
\text { after } 20 \text { cycles }\end{array}$ & [30] \\
\hline 2 & $\mathrm{LiMn}_{2} \mathrm{O}_{4}$ & $\mathrm{Al}$ foil & $\begin{array}{l}\text { Acetone, } \mathrm{I}_{2}, \mathrm{PTEF} \text {, and ketjen } \\
\text { black }(\mathrm{C} \cdot \mathrm{A})\end{array}$ & 400 & $1 \mathrm{~min}$ & $\begin{array}{l}\text { A specific capacity of } 110 \mathrm{mAh} \cdot \mathrm{g}^{-1} \\
\text { maintained a capacity of } 75 \mathrm{mAh} \cdot \mathrm{g}^{-1} \\
\text { after } 20 \text { cycles }\end{array}$ & [74] \\
\hline 3 & $\mathrm{LiNi}_{0.5} \mathrm{Mn}_{1.5} \mathrm{O}_{4}$ & $\mathrm{Al}$ foil and SS & $\begin{array}{l}\text { Acetone or ethanol, } \\
\text { polyethyleneimine (PEI), citric } \\
\text { acid, and ketjen black (C.A) }\end{array}$ & $0.15-4 \mu \mathrm{A} \cdot \mathrm{cm}^{-1}$ & $10 \mathrm{~min}$ & $\begin{array}{l}\text { A specific capacity of } 122 \mathrm{mAh} \cdot \mathrm{g}^{-1} \text { with } \\
\text { coulombic efficiency of } 95-97 \% \text { after } \\
50 \text { cycles }\end{array}$ & {$[75]$} \\
\hline 4 & $\mathrm{LiNi}_{0.5} \mathrm{Mn}_{1.5} \mathrm{O}_{4}$ & Al disk & $\begin{array}{l}\text { Aceton, PVP, citric acid, PVB, and } \\
\text { carbon black }(\mathrm{C} \cdot \mathrm{A})\end{array}$ & 100 & $5 \mathrm{~min}$ & $\begin{array}{l}\text { A specific capacity of } 130 \mathrm{mAh} \cdot \mathrm{g}^{-1} \\
\text { maintained the capacity after } 20 \text { cycles }\end{array}$ & {$[76]$} \\
\hline 5 & $\mathrm{Li}\left[\mathrm{Ni}_{1 / 3} \mathrm{Co}_{1 / 3} \mathrm{Mn}_{1 / 3}\right] \mathrm{O}_{2}$ & $\mathrm{Al}$ foil & $\begin{array}{l}\text { Aceton, PVDF, and } I_{2} \text {, denka } \\
\text { black (C.A) }\end{array}$ & $60 \mathrm{~V}$ & $1 \mathrm{~min}$ & $\begin{array}{l}\text { A specific capacity of } 147.18 \mathrm{mAh} \cdot \mathrm{g}^{-1}, \\
97.11 \% \text { capacity retention after } 50 \text { cycles } \\
\text { at } 0.2 \mathrm{C} \text {-rate. }\end{array}$ & {$[77]$} \\
\hline 6 & $\mathrm{LiCoPO}_{4}$ & Ti plate & IPA and $\mathrm{LiCl}$ & $60 \mathrm{~V}$ & $30 \mathrm{~min}$ & $\begin{array}{l}\text { A specific capacity of } 103 \mathrm{mAh} \cdot \mathrm{g}^{-1} \text { with } \\
\text { coulombic efficiency of } 55 \% \text { after } \\
10 \text { cycles }\end{array}$ & [82] \\
\hline 7 & $\mathrm{LiCoO}_{2}$ & $\mathrm{Au}$ & $\begin{array}{l}\text { 1-butanol and cobalt hydroxide } \\
\text { nanosheet }\end{array}$ & $20 \mu \mathrm{A} \cdot \mathrm{cm}^{-1}$ & $5-40 \mathrm{~min}$ & $\begin{array}{l}\text { A utilization efficiency of the discharge } \\
\text { capacity sustained } 74 \% \text { efficiency over } \\
\text { 200 C-rate }\end{array}$ & [88] \\
\hline 8 & $\mathrm{LiFePO}_{4}$ & 3D-Ni disk & $\begin{array}{l}\text { Acetone, } \mathrm{I}_{2}, \mathrm{PVDF} \text {, non-ionic } \\
\text { surfactant triton } \mathrm{X}-100 \text { and ketjen } \\
\text { black }(\mathrm{C} \cdot \mathrm{A})\end{array}$ & $60-100 \mathrm{~V}$ & $1-2 \mathrm{~min}$ & $\begin{array}{l}\text { A peak-pulse-power capability of } 200 \\
\mathrm{~mW} \cdot \mathrm{cm}^{-2} \text { and an energy density of } \\
6-10 \mathrm{mWh} \cdot \mathrm{cm}^{-2}\end{array}$ & [89] \\
\hline 9 & $\mathrm{LiMnPO}_{4}$ & $\mathrm{Al}$ foil & Isopropanol and nickel nitrate & $50 \mathrm{~V}$ & $60 \mathrm{~min}$ & $\begin{array}{l}\text { A specific capacity of } 83 \mathrm{mAh} \cdot \mathrm{g}^{-1}, 86 \% \\
\text { capacity retention after } 30 \mathrm{cycles} \text { at } 1 \mathrm{C} \\
\text { rate }\end{array}$ & [90] \\
\hline 10 & $\begin{array}{l}\mathrm{LiFePO}_{4} / \text { reduced } \\
\text { graphene oxide }\end{array}$ & Carbon cloth & IPA, $\mathrm{Mg}\left(\mathrm{NO}_{3}\right)_{2} \cdot 6 \mathrm{H}_{2} \mathrm{O}$ & $90 \mathrm{~V}$ & - & $\begin{array}{l}\text { A specific capacity of } 174.7 \mathrm{mAh} \cdot \mathrm{g}^{-1} \text { at } \\
0.2 \mathrm{C}\end{array}$ & [91] \\
\hline
\end{tabular}


Table A2. Overview of the anode electrodes fabricated by EPD showing the nanomaterials for Li-ion batteries and EPD conditions investigated.

\begin{tabular}{|c|c|c|c|c|c|c|c|}
\hline \multirow{2}{*}{ No. } & \multicolumn{2}{|c|}{ Materials } & \multirow{2}{*}{ Suspension Medium } & \multicolumn{2}{|c|}{ EPD Conditions } & \multirow{2}{*}{$\begin{array}{c}\text { Specification } \\
\text { (Charge/Discharge Capacity) }\end{array}$} & \multirow{2}{*}{ No. } \\
\hline & Coating & Substrate & & Voltage & Time & & \\
\hline 1 & Si nanoparticles / AB & $\mathrm{Cu}$ foil & Citric acid monohydrate, acetone & $120 \mathrm{~V}$ & $5-60 \mathrm{~s}$ & $\begin{array}{l}\text { An initial capacity of } 3150 \mathrm{mAh} \cdot \mathrm{g}^{-1} \text { and } \\
\text { remained the capacity of } 2175 \mathrm{mAh} \cdot \mathrm{g}^{-1} \text { after } \\
50 \text { cycles at } 0.1 \mathrm{C} \text {-rate }\end{array}$ & [92] \\
\hline 2 & $\begin{array}{l}\text { Artificial graphite, natural } \\
\text { graphite, soft carbon, and } \\
\text { hard carbon }\end{array}$ & Mo foil & $\begin{array}{l}\text { Acetonitrile, triethylamine (TEA), } \\
\text { tetramethylguanidine (TMG), and } \\
\text { pyridine (Py). }\end{array}$ & $0-500 \mathrm{~V}$ & $10-60 \mathrm{~s}$ & $\begin{array}{l}\text { A reversible capacities of } 296-395 \mathrm{mAh} \cdot \mathrm{g}^{-1} \text { with } \\
\text { a coulombic efficiency of } 90 \% \text { after } 30 \text { cycles }\end{array}$ & [96] \\
\hline 3 & Graphite & $\mathrm{Cu}$ foil & $\begin{array}{l}\text { Acetonitrile, triethylamine (TEA), } \\
\text { tetramethylguanidine (TMG), and } \\
\text { pyridine (Py). }\end{array}$ & $24 \mathrm{~V}$ & $15 \mathrm{~min}$ & $\begin{array}{l}\text { A reversible capacities of } 330 \mathrm{mAh} \cdot \mathrm{g}^{-1} \text { at } 0.2 \mathrm{C} \text {, } \\
\text { maintained the capacity after } 30 \text { cycles }\end{array}$ & [98] \\
\hline 4 & Graphite & $\mathrm{Cu}$ foil & Acetonitrile and triethylamine (TEA) & $50 \mathrm{~V}$ & $2 \mathrm{~min}$ & $\begin{array}{l}\text { An initial capacities were } 400,360 \text {, and } \\
400 \mathrm{mAh} \cdot \mathrm{g}^{-1} \text { at } \mathrm{LiPF}_{6} / \mathrm{EC}, \mathrm{LIPF}_{6} / \mathrm{EMC} \text {, } \\
\mathrm{LIPF}_{6} / \mathrm{EC} / \mathrm{EMC}(3: 7 \mathrm{v} / \mathrm{v}) \text {, respectively }\end{array}$ & [105] \\
\hline 5 & Graphite & $\mathrm{Cu}$ foil & Acetonitrile and triethylamine (TEA) & $32 \mathrm{~V}$ & $1 \mathrm{~min}$ & $\begin{array}{l}\text { An initial capacities were } 450 \text { and } 550 \mathrm{mAh} \cdot \mathrm{g}^{-1} \\
\text { at } \mathrm{LiPF}_{6} \text { and } \mathrm{LiF}_{2} \mathrm{BC}_{2} \mathrm{O}_{4} \text {, respectively }\end{array}$ & [106] \\
\hline 6 & Graphite & $\mathrm{Cu}$ foil & Acetonitrile and triethylamine (TEA) & $32 \mathrm{~V}$ & $1 \mathrm{~min}$ & $\begin{array}{l}\text { An initial capacities were } 450,520,620 \text {, and } \\
620 \mathrm{mAh} \cdot \mathrm{g}^{-1} \text { at } \mathrm{LiPF}_{6}, \mathrm{LiBOB}_{2} \mathrm{LiBF}_{4} \text {, and } \\
\mathrm{LiF}_{2} \mathrm{BC}_{2} \mathrm{O}_{4} \text {, respectively }\end{array}$ & [107] \\
\hline 7 & Graphite & $\mathrm{Cu}$ foil & Acetonitrile and triethylamine (TEA) & $32 \mathrm{~V}$ & $1 \mathrm{~min}$ & $\begin{array}{l}\text { An initial capacities were } 375,370 \text {, and } \\
320 \mathrm{mAh} \cdot \mathrm{g}^{-1} \text { at LiTFSI, LIFSI, and LiDFOB } \\
\text { dissolved in EC, respectively }\end{array}$ & [108] \\
\hline 8 & Graphene nanosheet & Stainless steel & $\mathrm{Ni}\left(\mathrm{NO}_{3}\right)_{2}$ in isopropyl alcohol (IPA) & $100 \mathrm{~V}$ & $10 \min$ & $\begin{array}{l}\text { A reversible discharge capacity of } 392 \mathrm{mAh} \cdot \mathrm{g}^{-1} \\
\text { in initial cycle and stabilized the capacity of } \\
200 \mathrm{mAh} \cdot \mathrm{g}^{-1} \text { after } 20 \text { cycles at } 0.2 \mathrm{C} \text {. }\end{array}$ & [115] \\
\hline 9 & $\begin{array}{l}\text { MWCNTs/Graphene } \\
\text { nanosheet }\end{array}$ & Al foil & $\mathrm{Ni}\left(\mathrm{NO}_{3}\right)_{2}$ in isopropyl alcohol (IPA) & $100 \mathrm{~V}$ & $10 \mathrm{~min}$ & $\begin{array}{l}\text { A specific discharge capacity of } 2200 \mathrm{mAh} \cdot \mathrm{g}^{-1} \\
\text { in initial cycle and stabilized } 458 \mathrm{mAh} \cdot \mathrm{g}^{-1} \text { after } \\
10 \text { cycles at } 0.2 \mathrm{C}\end{array}$ & [117] \\
\hline 10 & $\mathrm{MoO}_{\mathrm{x}}$ nanoparticles & Stainless steel & Methanol & $300 \mathrm{~V}$ & $1-2 \min$ & $\begin{array}{l}\text { A reversible capacity of } 630 \mathrm{mAh} \cdot \mathrm{g}^{-1} \text { and } 93 \% \\
\text { capacity retention after } 150 \text { cycles at } 0.5 \mathrm{C} \text { rate }\end{array}$ & [131-133] \\
\hline 11 & $\mathrm{~V}_{2} \mathrm{O}_{5}$ nanoparticles & ITO & Water & $5 \mathrm{~V}$ & - & $\begin{array}{l}\text { A specific capacity of } 300 \mathrm{mAh} \cdot \mathrm{g}^{-1} \text { of } \\
50 \mu \mathrm{Ah} \cdot \mathrm{cm}^{2} \text { and maintained the good capacity } \\
\text { after } 50 \mathrm{cycles}\end{array}$ & [134] \\
\hline 12 & $\mathrm{TiO}_{2}$ nanosheet & Pt coated Si wafer & Water & $5 \mathrm{~V}$ & - & $\begin{array}{l}\text { A specific capacity of } 190 \mathrm{mAh} \cdot \mathrm{g}^{-1} \text { at } \\
3.85 \mu \mathrm{Ah} \cdot \mathrm{cm}^{2}\end{array}$ & {$[135]$} \\
\hline
\end{tabular}


Table A2. Cont.

\begin{tabular}{|c|c|c|c|c|c|c|c|}
\hline \multirow{2}{*}{ No. } & \multicolumn{2}{|c|}{ Materials } & \multirow{2}{*}{ Suspension Medium } & \multicolumn{2}{|c|}{ EPD Conditions } & \multirow{2}{*}{$\begin{array}{c}\text { Specification } \\
\text { (Charge/Discharge Capacity) }\end{array}$} & \multirow{2}{*}{ No. } \\
\hline & Coating & Substrate & & Voltage & Time & & \\
\hline 13 & $\mathrm{TiO}_{2}$ nanosheet & Pt coated Si wafer & Water & $5 \mathrm{~V}$ & - & $\begin{array}{l}\text { A reversible capacity of } 170 \mathrm{mAh} \cdot \mathrm{g}^{-1} \text { when } \\
\text { cycled between } 0.8 \text { and } 3.2 \mathrm{~V}\end{array}$ & {$[136]$} \\
\hline 14 & $\mathrm{TiO}_{2}$ nanoparticles & 3D-Al & Ethanol, PE169, and Butvar & $50 \mathrm{~V}$ & $1-2 \mathrm{~min}$ & - & {$[137]$} \\
\hline 15 & Polystyrene sphere/ $\mathrm{NiO}_{2}$ & Stainless steel & water & $60 \mathrm{~V}$ & $2 \min$ & $\begin{array}{l}\text { A specific capacity of } 1620 \mathrm{mAh} \cdot \mathrm{g}^{-1} \text { at } 1 \mathrm{C} \text {-rate } \\
\text { and } 990 \mathrm{mAh} \cdot \mathrm{g}^{-1} \text { at } 15 \mathrm{C} \text {-rate }\end{array}$ & {$[138]$} \\
\hline 16 & $\begin{array}{l}\text { Hollow structured } \mathrm{Co}_{3} \mathrm{O}_{4} \\
\text { nanoparticles }\end{array}$ & $\mathrm{Cu}$ foil & Hexane & $150-600 \mathrm{~V}$ & $\begin{array}{c}10-30 \\
\min \end{array}$ & $\begin{array}{l}\text { A reversible specific capacity of } 1820 \mathrm{mAh} \cdot \mathrm{g}^{-1} \\
\text { remained the capacity of } 890 \mathrm{mAh} \cdot \mathrm{g}^{-1} \text { after } \\
50 \text { cycles at } 0.05 \text { C-rate }\end{array}$ & [139] \\
\hline 17 & $\begin{array}{l}\text { Hollow structured } \mathrm{Co}_{3} \mathrm{O}_{4} \\
\text { nanoparticles }\end{array}$ & $\mathrm{SiO}_{2} / \mathrm{Si}$ & Hexane & $1500 \mathrm{~V}$ & - & $\begin{array}{l}\text { A specific capacity of } 1300 \mathrm{mAh} \cdot \mathrm{g}^{-1} \text { in the first } \\
\text { discharge as a current density of } 100 \mathrm{~mA} \cdot \mathrm{g}^{-1} \\
\text { and stabilized } 800 \mathrm{mAh} \cdot \mathrm{g}^{-1} \text { after } 3 \text { cycles }\end{array}$ & {$[140]$} \\
\hline 18 & $\mathrm{SnO}_{2}$ nanoparticles- $\mathrm{AB}$ & $\mathrm{Cu}$ foil & Aceton and Acetylene Black & $100 \mathrm{~V}$ & $10 \mathrm{~s}$ & $\begin{array}{l}\text { A initial capacities were } 887 \mathrm{mAh} \cdot \mathrm{g}^{-1} \text { at } 0.1 \\
\text { C-rate and remained the capacity of } 504 \\
\mathrm{mAh} \cdot \mathrm{g}^{-1} \text { after } 50 \text { cycles }\end{array}$ & {$[140]$} \\
\hline 19 & $\mathrm{MnO}_{2}$-MWCNTs & Ni foil & Ethanol and sulfuric acid & $50 \mathrm{~V}$ & $5 \mathrm{~min}$ & $\begin{array}{l}\text { A specific capacity of } 741 \mathrm{mAh} \cdot \mathrm{g}^{-1} \text { for first cycle } \\
\text { and } 407 \mathrm{mAh} \cdot \mathrm{g}^{-1} \text { after } 20 \text { cycle at } 120 \mathrm{~mA} \cdot \mathrm{g}^{-1} \\
\text { current density }\end{array}$ & {$[149]$} \\
\hline 20 & $\mathrm{SnO}_{2}-\mathrm{MWCNTs}$ & Stainless steel & Isopropyl alcohol (IPA) and Ni salt & $100 \mathrm{~V}$ & $10 \mathrm{~min}$ & $\begin{array}{l}\text { A reversible capacity of } 780,510 \text {, and } 470 \\
\mathrm{mAh} \cdot \mathrm{g}^{-1} \text { at } 1 \text { C-rate after } 100,500 \text {, and } \\
1000 \text { cycles, respectively }\end{array}$ & {$[150]$} \\
\hline 21 & CoO-MWCNTs & Stainless steel & Isopropyl alcohol (IPA) and Ni salt & $100 \mathrm{~V}$ & $2 \mathrm{~min}$ & $\begin{array}{l}\text { A reversible capacity of } 600 \text { and } 550 \mathrm{mAh} \cdot \mathrm{g}^{-1} \text { at } \\
\text { the rate of } 715 \mathrm{~mA} \cdot \mathrm{g}^{-1} \text { after } 50 \text { and } 100 \text { cycles, } \\
\text { respectively }\end{array}$ & {$[151]$} \\
\hline 22 & $\begin{array}{l}\text { Multi layered } \\
\text { Graphene-Si-CuO }\end{array}$ & $\mathrm{Cu}$ foil & $\begin{array}{l}1 \text { step: water } \\
2 \text { step: water and HF }\end{array}$ & $10 \mathrm{~V}$ & $1 \mathrm{~min}$ & $\begin{array}{l}\text { A initial capacity of } 2869 \mathrm{mAh} \cdot \mathrm{g}^{-1} \text { at } 0.5 \mathrm{C} \text {-rate } \\
\text { and the capacity retention of } 71 \% \text { after } \\
100 \text { cycles at } 1 \mathrm{C} \text {-rate }\end{array}$ & {$[152]$} \\
\hline 23 & $\begin{array}{l}\text { Graphene- } \mathrm{ZnFe}_{2} \mathrm{O}_{4} \\
\text { nanoparticles }\end{array}$ & $\mathrm{Cu}$ foil & $\begin{array}{l}\mathrm{Fe}\left(\mathrm{NO}_{3}\right)_{3} \cdot 9 \mathrm{H}_{2} \mathrm{O} \text { and } \mathrm{Zn}\left(\mathrm{NO}_{3}\right)_{2} \cdot 6 \mathrm{H}_{2} \mathrm{O} \\
\text { suspension }\end{array}$ & $60 \mathrm{~V}$ & $5 \mathrm{~min}$ & $\begin{array}{l}\text { A initial capacities were } 910 \mathrm{mAh} \cdot \mathrm{g}^{-1} \text { at } \\
200 \mathrm{~mA} \cdot \mathrm{g}^{-1} \text { and remained the capacity of } \\
881 \mathrm{mAh} \cdot \mathrm{g}^{-1} \text { after } 200 \text { cycles }\end{array}$ & [153] \\
\hline 24 & $\begin{array}{l}\text { Graphene- } \mathrm{CoFe}_{2} \mathrm{O}_{4} \\
\text { nanoparticles }\end{array}$ & $\mathrm{Cu}$ foil & $\begin{array}{l}\mathrm{Fe}\left(\mathrm{NO}_{3}\right)_{3} \cdot 9 \mathrm{H}_{2} \mathrm{O} \text { and } \\
\mathrm{Co}\left(\mathrm{NO}_{3}\right)_{2} \cdot 6 \mathrm{H}_{2} \mathrm{O} \text { suspension }\end{array}$ & $60 \mathrm{~V}$ & $400 \mathrm{~s}$ & $\begin{array}{l}\text { A specific capacity of } 865 \mathrm{mAh} \cdot \mathrm{g}^{-1} \text { at } \\
1000 \mathrm{~mA} \cdot \mathrm{g}^{-1} \text { and remained the capacity after } \\
200 \text { cycles }\end{array}$ & {$[154]$} \\
\hline 25 & Graphene- $\mathrm{TiO}_{2}$ nanotubes & $\mathrm{TiO}_{2}$ nanotubes & - & $4 \mathrm{~V}$ & $30 \mathrm{~min}$ & $\begin{array}{l}\text { An initial capacity of } 1100 \mathrm{mAh} \cdot \mathrm{g}^{-1} \text { when } \\
\text { cycled between } 0.01 \text { and } 3 \mathrm{~V} \text { at } 0.1 \mathrm{~mA} \cdot \mathrm{g}^{-1}\end{array}$ & {$[155]$} \\
\hline
\end{tabular}


Table A2. Cont.

\begin{tabular}{|c|c|c|c|c|c|c|c|}
\hline \multirow{2}{*}{ No. } & \multicolumn{2}{|c|}{ Materials } & \multirow{2}{*}{ Suspension Medium } & \multicolumn{2}{|c|}{ EPD Conditions } & \multirow{2}{*}{$\begin{array}{c}\text { Specification } \\
\text { (Charge/Discharge Capacity) }\end{array}$} & \multirow{2}{*}{ No } \\
\hline & Coating & Substrate & & Voltage & Time & & \\
\hline 26 & Ge-MWCNTs & Stainless steel & Isopropyl alcohol (IPA) and Ni salt & $100 \mathrm{~V}$ & $2 \mathrm{~min}$ & $\begin{array}{l}\text { A reversible capacity of } 1240,960,810,620 \text { and } \\
490 \mathrm{mAh}^{-1} \text { at } 0.5,1,2,3 \text {, and } 5 \text { C-rates, } \\
\text { respectively }\end{array}$ & [161] \\
\hline 27 & Sn-MWCNTs & Stainless steel & Isopropyl alcohol (IPA) and Ni salt & $100 \mathrm{~V}$ & $2 \mathrm{~min}$ & $\begin{array}{l}\text { A specific capacity of } 2100 \mathrm{mAh} \cdot \mathrm{g}^{-1} \text { and } \\
\text { irreversibility stabilized around } 700 \mathrm{mAh} \cdot \mathrm{g}^{-1} \\
\text { after } 100 \text { cycles }\end{array}$ & [162] \\
\hline 28 & Graphene-Sn nanoparticles & $\mathrm{Cu}$ foil & $\begin{array}{l}\text { Isopropyl alcohol (IPA) and } \\
\mathrm{Mg}\left(\mathrm{NO}_{3}\right)_{2} \cdot \mathrm{H}_{2} \mathrm{O}\end{array}$ & $300 \mathrm{~V}$ & $30 \mathrm{~min}$ & $\begin{array}{l}\text { A specific capacity of } 733,535,466,417 \text {, and } \\
417 \mathrm{mAh} \cdot \mathrm{g}^{-1} \text { at } 100,200,500, \text { and } 1000 \mathrm{~mA} \cdot \mathrm{g}^{-1} \text {, } \\
\text { respectively }\end{array}$ & [163] \\
\hline 29 & Si nanoparticles & $\mathrm{Cu}$ foil & Acetonitrile and triethylamine (TEA) & $32 \mathrm{~V}$ & $1 \mathrm{~min}$ & $\begin{array}{l}\text { An initial capacities of } 1800 \text { and } 1700 \mathrm{mAh} \cdot \mathrm{g}^{-1} \\
\text { at } \mathrm{LiPF}_{6} / \mathrm{EC} \text { and } \mathrm{LiPF}_{6} / \mathrm{FEC} \text {, respectively }\end{array}$ & [164] \\
\hline 30 & Carbon nanoparticles & $\begin{array}{l}\text { Dendritic Sn } \\
\text { foams }\end{array}$ & Ethanol and sulfuric acid & $70 \mathrm{~V}$ & $10 \mathrm{~s}$ & $\begin{array}{l}\text { A reversible capacities of about } \\
600-300 \mathrm{mAh} \cdot \mathrm{g}^{-1} \text { at } 99.1 \mathrm{~mA} \cdot \mathrm{g}^{-1} \text { with a } \\
\text { coulombic efficiency of } 90 \% \text { after } 30 \text { cycles }\end{array}$ & [169] \\
\hline 31 & Sn-garphene & Ni form & $\mathrm{HCl}, \mathrm{SnCl}_{2} \cdot \mathrm{H}_{2} \mathrm{O}$ & $5 \mathrm{~V}$ & $30 \mathrm{~s}$ & $\begin{array}{l}\text { An initial capacity of } 964 \mathrm{mAh} \cdot \mathrm{g}^{-1} \text { and } \\
\text { remained the capacity of } 520 \mathrm{mAh} \cdot \mathrm{g}^{-1} \text { after } \\
60 \text { cycles }\end{array}$ & [170] \\
\hline 32 & Graphene-SWCNTs & Ni form & NMP & $40 \mathrm{~V}$ & - & $\begin{array}{l}\text { A reversible capacity of } 2640 \mathrm{mAh} \cdot \mathrm{g}^{-1} \text { and } \\
236 \mathrm{mAh} \cdot \mathrm{g}^{-1} \text { at } 0.5 \text { and } 75 \mathrm{C} \text {, respectively }\end{array}$ & [171] \\
\hline 33 & SWCNTs & Ni form & NMP & $30 \mathrm{~V}$ & - & $\begin{array}{l}\text { A reversible capacity of } 2210 \mathrm{mAh} \cdot \mathrm{g}^{-1} \text { with } \\
\text { energy efficiencies up } \sim 50 \% \text { and cycling } \\
\text { behavior greater than } 500 \text { cycles }\end{array}$ & [173] \\
\hline 34 & Ge-acetylene black & $\mathrm{Ni}$ form & $\begin{array}{l}\text { Isopropyl alcohol (IPA) } \\
\mathrm{GeCl}_{4}\end{array}$ & $100 \mathrm{~V}$ & $2 \mathrm{~min}$ & $\begin{array}{l}\text { A specific capacity of } 924 \mathrm{mAh} \cdot \mathrm{g}^{-1} \text { after } \\
100 \text { cycles at } 0.1 \mathrm{C} \text {-rate }\end{array}$ & [177] \\
\hline 35 & Reduced graphene oxide & Stainless steel & Water & $30 \mathrm{~V}$ & - & $\begin{array}{l}\text { A specific discharge capacity of } 1120 \mathrm{mAh} \cdot \mathrm{g}^{-1} \\
\text { as a constant current density of } 1 \mathrm{~mA} \cdot \mathrm{cm}^{-2} \text { and } \\
85 \% \text { capacity retention after } 50 \text { cycles }\end{array}$ & [333] \\
\hline 36 & $\mathrm{Li}_{4} \mathrm{Ti}_{5} \mathrm{O}_{12}$ & $\mathrm{Cu}$ foil & $\begin{array}{l}\text { Acetonitrile, Ketjen Black, } \mathrm{I}_{2} \text {, and } \\
\text { polyethyleneoxide }\end{array}$ & $100 \mathrm{~V}$ & $2 \mathrm{~min}$ & $\begin{array}{l}\text { A specific capacity of } 149 \mathrm{mAh} \cdot \mathrm{g}^{-1} \text { at } 0.1 \mathrm{C} \text {-rate } \\
\text { and } 85 \% \text { of its theoretical capacity }\end{array}$ & [334] \\
\hline 37 & $\mathrm{~A}-\mathrm{Fe}_{2} \mathrm{O}_{3}$-carbon nanofiber & Stainless steel & $\begin{array}{l}\mathrm{Ni}\left(\mathrm{NO}_{3}\right)_{2} \text { and isopropyl alcohol } \\
\text { (IPA) }\end{array}$ & $40 \mathrm{~V}$ & $30 \mathrm{~s}$ & $\begin{array}{l}\text { A specific capacity of } 1850 \text { and } 970 \mathrm{mAh} \cdot \mathrm{g}^{-1} \text { at } 1 \\
\text { and } 10 \mathrm{C} \text {-rate, respectively }\end{array}$ & [335] \\
\hline
\end{tabular}


Table A2. Cont.

\begin{tabular}{|c|c|c|c|c|c|c|c|}
\hline \multirow{2}{*}{ No. } & \multicolumn{2}{|c|}{ Materials } & \multirow{2}{*}{ Suspension Medium } & \multicolumn{2}{|c|}{ EPD Conditions } & \multirow{2}{*}{$\begin{array}{c}\text { Specification } \\
\text { (Charge/Discharge Capacity) }\end{array}$} & \multirow{2}{*}{ No. } \\
\hline & Coating & Substrate & & Voltage & Time & & \\
\hline 38 & $\beta-\mathrm{Ni}(\mathrm{OH})_{2}$ & $\mathrm{Cu}$ foil & $\begin{array}{l}\mathrm{Ni}(\mathrm{OH})_{2} \text {, carbon black, and } \\
\text { ethylic }\end{array}$ & $5 \mathrm{~mA} \cdot \mathrm{cm}^{-2}$ & $\begin{array}{c}10-30 \\
\min \end{array}$ & $\begin{array}{l}\text { An initial capacity of } 1400 \mathrm{mAh} \cdot \mathrm{g}^{-1} \text { and remained the capacity } \\
\text { of } 600 \mathrm{mAh} \cdot \mathrm{g}^{-1} \text { after } 30 \text { cycles }\end{array}$ & [336] \\
\hline 39 & $\begin{array}{l}\text { Carbon nanofiber } / \mathrm{Mn}_{3} \mathrm{O}_{4} \\
\text { coaxial nanocalbles }\end{array}$ & Carbon nanofiber & $\mathrm{Mg}\left(\mathrm{NO}_{3}\right)_{2} \cdot 6 \mathrm{H}_{2} \mathrm{O}$ & $10 \mathrm{~V}$ & $120 \mathrm{~min}$ & $\begin{array}{l}\text { An initial capacity of } 1690 \mathrm{mAh} \cdot \mathrm{g}^{-1} \text { at a current density of } \\
100 \mathrm{~mA} \cdot \mathrm{g}^{-1} \text { and remained the capacity of } 760 \mathrm{mAh} \cdot \mathrm{g}^{-1} \text { after } \\
50 \text { cycles }\end{array}$ & [337] \\
\hline 40 & $\begin{array}{l}\text { Carbon Carbon } \\
\text { nanofiber/NiO core-shell } \\
\text { nanocables }\end{array}$ & Carbon nanofiber & $\mathrm{Ni}\left(\mathrm{NO}_{3}\right)_{2} \cdot 6 \mathrm{H}_{2} \mathrm{O}$ & $10 \mathrm{~V}$ & $120 \mathrm{~min}$ & $\begin{array}{l}\text { An initial capacity of } 1400 \mathrm{mAh} \cdot \mathrm{g}^{-1} \text { and remained the capacity of } \\
825 \mathrm{mAh} \cdot \mathrm{g}^{-1} \text { after } 50 \text { cycles at a current density of } 200 \mathrm{~mA} \cdot \mathrm{g}^{-1}\end{array}$ & [338] \\
\hline 41 & $\begin{array}{l}\text { Flower-like } \mathrm{Co}_{3} \mathrm{O}_{4} / \text { carbon } \\
\text { nanofiber core shell }\end{array}$ & Carbon nanofiber & $\mathrm{Co}\left(\mathrm{NO}_{3}\right)_{2} \cdot 6 \mathrm{H}_{2} \mathrm{O}$ & $10 \mathrm{~V}$ & $120 \mathrm{~min}$ & $\begin{array}{l}\text { An initial capacity of } 1446 \mathrm{mAh} \cdot \mathrm{g}^{-1} \text { and remained the capacity of } \\
911 \mathrm{mAh} \cdot \mathrm{g}^{-1} \text { after } 50 \text { cycles at a current density of } 200 \mathrm{~mA} \cdot \mathrm{g}^{-1}\end{array}$ & [339] \\
\hline \multirow{2}{*}{42} & \multirow{2}{*}{$\mathrm{Ge} / \mathrm{CNTs}$} & \multirow{2}{*}{$\mathrm{Cu}$ foil } & $\mathrm{Ni}\left(\mathrm{NO}_{3}\right)_{2} \cdot 6 \mathrm{H}_{2} \mathrm{O}$ and IPA & $100 \mathrm{~V}$ & $2 \mathrm{~min}$ & \multirow{2}{*}{$\begin{array}{l}\text { An initial capacity of } 1442 \mathrm{mAh} \cdot \mathrm{g}^{-1} \text { and remained the capacity } \\
\text { of } 810 \mathrm{mAh} \cdot \mathrm{g}^{-1} \text { after } 100 \text { cycles at a current density of } 0.2 \mathrm{C} \text {-rate }\end{array}$} & \multirow{2}{*}{ [340] } \\
\hline & & & $\mathrm{GeCl}_{4}$ including ionic liquid & - & - & & \\
\hline 43 & $\mathrm{Fe}_{3} \mathrm{O}_{4} / \mathrm{CNTs} / \mathrm{rGO}$ & $\mathrm{Cu}$ foil & Acetone and $\mathrm{I}_{2}$ & $100 \mathrm{~V}$ & $15 \mathrm{~s}$ & $\begin{array}{l}\text { A specific capacity of } 540 \mathrm{mAh} \cdot \mathrm{g}^{-1} \text { at a very high current density } \\
\text { of } 10 \mathrm{~A} \cdot \mathrm{g}^{-1}\end{array}$ & [341] \\
\hline
\end{tabular}

Table A3. Overview of the electrodes fabricated by EPD showing the nanomaterials for supercapacitors and EPD conditions investigated.

\begin{tabular}{|c|c|c|c|c|c|c|c|}
\hline \multirow{2}{*}{ No. } & \multicolumn{2}{|c|}{ Materials } & \multirow{2}{*}{ Suspension Medium } & \multicolumn{2}{|c|}{ EPD Conditions } & \multirow{2}{*}{$\begin{array}{c}\text { Specification } \\
\text { (A specific Capacitnace) }\end{array}$} & \multirow{2}{*}{ Ref. } \\
\hline & Coating & Substrate & & Voltage & Time & & \\
\hline 1 & $\begin{array}{l}\text { Nanoscale activate } \\
\text { carbon }\end{array}$ & Ti foil & $\begin{array}{l}\text { Isopropyl alcohol (IPA) and } \mathrm{Ni} \\
\text { salt }\end{array}$ & $100 \mathrm{~V}$ & - & $\begin{array}{l}\text { A specific capacitance of } 1071 \mathrm{~F} \cdot \mathrm{g}^{-1} \text { at } 100 \mathrm{mV} \cdot \mathrm{s}^{-1} \text { and area } \\
\text { capacitance of } 0.48 \mathrm{~F} \cdot \mathrm{cm}^{-2}\end{array}$ & [184] \\
\hline 3 & Onion like carbon & Au coated Si wafer & Ethanol, water, and $\mathrm{MgCl}_{2}$ & $50 \mathrm{~V}$ & - & $\begin{array}{l}\text { A specific capacitances of } 1.1 \mathrm{mF} \cdot \mathrm{cm}^{-2} \text { and } 0.84 \mathrm{mF} \cdot \mathrm{cm}^{-2} \text { at } \\
20 \text { and }-50^{\circ} \mathrm{C} \text { at } 10 \mathrm{mV} \cdot \mathrm{s}^{-1} \text {, respectively }\end{array}$ & [186] \\
\hline 4 & SWCNTs & $\mathrm{Ni}$ form & NMP & $40 \mathrm{~V}$ & - & $\begin{array}{l}\text { A specific capacitance of } 83 \mathrm{~F} \cdot \mathrm{g}^{-1} \text { at } 0.1 \mathrm{~A} \cdot \mathrm{g}^{-1} \text { with energy } \\
\text { density of } \sim 25 \mathrm{Wh} \cdot \mathrm{kg}^{-1}\end{array}$ & {$[171]$} \\
\hline 5 & MWCNTs & Ni foil & Ethanol and $\mathrm{Mg}\left(\mathrm{NO}_{3}\right)_{2} \cdot 6 \mathrm{H}_{2} \mathrm{O}$ & $40-50 \mathrm{~V}$ & - & $\begin{array}{l}\text { A maximum specific capacitance } 21 \mathrm{~F} \cdot \mathrm{g}^{-1} \text { at a scan rate of } \\
500 \mathrm{mV} \cdot \mathrm{s}^{-1} \text { and no degradation after } 100 \text { cycles }\end{array}$ & [192] \\
\hline 6 & MWCNTs & Ni foil & Ethanol and $\mathrm{Mg}\left(\mathrm{NO}_{3}\right)_{2} \cdot 6 \mathrm{H}_{2} \mathrm{O}$ & $40-50 \mathrm{~V}$ & - & $\begin{array}{l}\text { A maximum specific capacitance } 21 \mathrm{~F} \cdot \mathrm{g}^{-1} \text { at a scan rate of } \\
0.78 \mathrm{~mA} \cdot \mathrm{cm}^{-1} \text { and no IR drop due to the hydrogen treatment }\end{array}$ & [194] \\
\hline
\end{tabular}


Table A3. Cont.

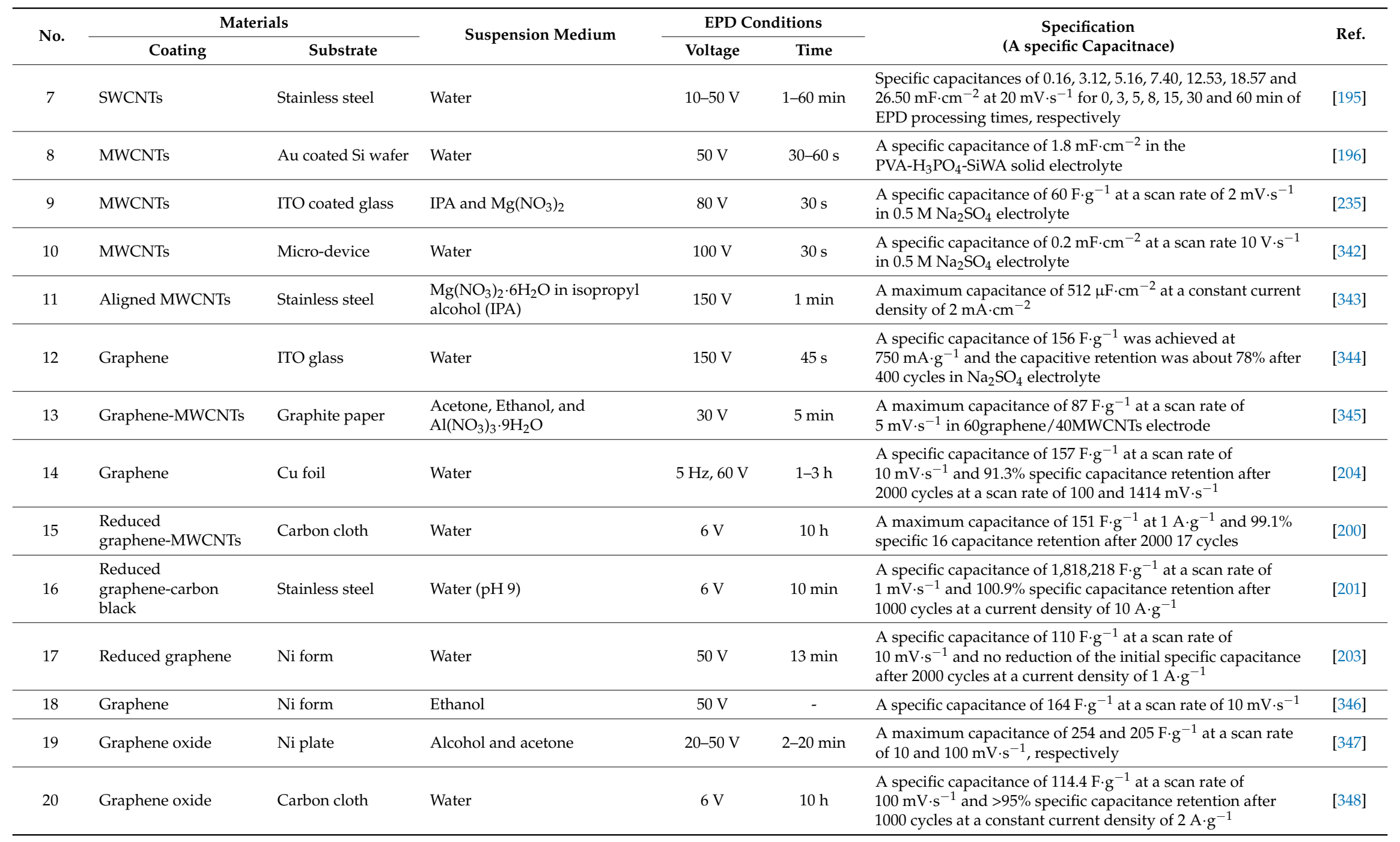


Table A3. Cont.

\begin{tabular}{|c|c|c|c|c|c|c|c|}
\hline \multirow{2}{*}{ No. } & \multicolumn{2}{|c|}{ Materials } & \multirow{2}{*}{ Suspension Medium } & \multicolumn{2}{|c|}{ EPD Conditions } & \multirow{2}{*}{$\begin{array}{c}\text { Specification } \\
\text { (A specific Capacitnace) }\end{array}$} & \multirow{2}{*}{ Ref. } \\
\hline & Coating & Substrate & & Voltage & Time & & \\
\hline 21 & Graphene-MWNCTs & Ti plate & Water and safranin (SAF) & $30 \mathrm{~V}$ & $15 \mathrm{~min}$ & $\begin{array}{l}\text { A specific capacitance of } 141.2 \text { and } 52.8 \mathrm{~F} \cdot \mathrm{g}^{-1} \text { at scan rates of } 2 \\
\text { and } 100 \mathrm{mV} \cdot \mathrm{s}^{-1} \text {, respectively }\end{array}$ & [228] \\
\hline 22 & Graphene nansheets & Ni foam & Ethanol & $50 \mathrm{~V}$ & - & $\begin{array}{l}\text { A specific capacitance of } 139 \text { and } 100 \mathrm{~F} \cdot \mathrm{g}^{-1} \text { at a constant } \\
\text { current densities of } 3 \text { and } 6 \mathrm{~A} \cdot \mathrm{g}^{-1} \text {, respectively }\end{array}$ & [349] \\
\hline 23 & Graphene oxide & SS & Anhydrous alcohol & $10 \mathrm{~V}$ & $60 \mathrm{~min}$ & A specific capacitance of $117 \mathrm{~F} \cdot \mathrm{g}^{-1}$ at a scan rate of $100 \mathrm{mV} \cdot \mathrm{s}^{-1}$ & [350] \\
\hline 24 & $\mathrm{RuO}_{2} \cdot x \mathrm{H}_{2} \mathrm{O}$ & Ti plate & Ethanol & $50-200 \mathrm{~V}$ & $10-600 \mathrm{~s}$ & $\begin{array}{l}\text { A specific capacitance of } 734 \text { and } 608 \mathrm{~F} \cdot \mathrm{g}^{-1} \text { at a scan rate of } 1 \\
\text { and } 50 \mathrm{mV} \cdot \mathrm{s}^{-1} \text {, respectively }\end{array}$ & [213] \\
\hline 25 & $\mathrm{RuO}_{2} \cdot x \mathrm{H}_{2} \mathrm{O}$ & Ti plate & Ethanol, water, and PTEF & $50 \mathrm{~V}$ & $1 \mathrm{~min}$ & $\begin{array}{l}\text { A specific capacitance of electrode prepared } 2 \% \mathrm{PTEF} \text { and } 10 \% \\
\text { water is } 599 \mathrm{~F} \cdot \mathrm{g}^{-1} \text { at a scan rate of } 10 \mathrm{mV} \cdot \mathrm{s}^{-1}\end{array}$ & [207] \\
\hline 26 & $\begin{array}{l}\text { Ruthenic acid } \\
\text { nanosheets }\end{array}$ & ITO coated PET & $\begin{array}{l}\text { DMF, methanol, ethanol, or } \\
\text { acetonitrile }\end{array}$ & $5 \mathrm{~V}$ & $2-60 \mathrm{~min}$ & $\begin{array}{l}\text { A specific capacitance of } 620 \mathrm{~F} \cdot \mathrm{g}^{-1} \text { at a scan rate of } 2 \mathrm{mV} \cdot \mathrm{s}^{-1} \text { in } \\
0.5 \mathrm{M} \mathrm{H}_{2} \mathrm{SO}_{4} \text { electrolyte }\end{array}$ & [351] \\
\hline 24 & $\begin{array}{l}\text { Spray pyrolyzed } \\
\mathrm{MnO}_{2} \text { powders }\end{array}$ & Graphite & Water & $100 \mathrm{~V}$ & $10-20 \mathrm{~min}$ & $\begin{array}{l}\text { A maximum capacitance of } 275 \mathrm{~F} \cdot \mathrm{g}^{-1} \text { at a scan rate of } \\
25 \mathrm{mV} \cdot \mathrm{s}^{-1} \text { and } 234 \mathrm{~F} \cdot \mathrm{g}^{-1} \text { after } 100 \text { cycles }\end{array}$ & [208] \\
\hline 28 & $\begin{array}{l}\text { Spray pyrolyzed iron } \\
\text { added } \mathrm{MnO}_{2}\end{array}$ & Graphite & Water & $100 \mathrm{~V}$ & $10-20 \mathrm{~min}$ & $\begin{array}{l}\text { A specific capacitance of } 232 \mathrm{~F} \cdot \mathrm{g}^{-1} \text { at a scan rate of } 25 \mathrm{mV} \cdot \mathrm{s}^{-1} \\
\text { and } 78 \% \text { specific capacitance retention after } 1200 \text { cycles at a } \\
\text { scan rate of } 10029 \mathrm{mV} \cdot \mathrm{s}^{-1}\end{array}$ & [209] \\
\hline 29 & $\mathrm{MnO}_{2}$ nanofibes & SS foil & Water and Sodium alginate & $5-50 \mathrm{~V}$ & $1-10 \mathrm{~min}$ & $\begin{array}{l}\text { A maximum capacitance of } 412 \mathrm{~F} \cdot \mathrm{g}^{-1} \text { at a scan rate of } 2 \mathrm{mV} \cdot \mathrm{s}^{-1} \\
\text { and no reduction of the initial specific capacitance after } \\
1000 \text { cycles }\end{array}$ & [210] \\
\hline 30 & $\mathrm{MnO}_{2}$ nano particles & Graphite & Ethanol and $\mathrm{H}_{2} \mathrm{SO}_{4}$ & $100 \mathrm{~V}$ & $20 \mathrm{~min}$ & $\begin{array}{l}\text { A maximum capacitance of } 236 \mathrm{~F} \cdot \mathrm{g}^{-1} \text { at a scan rate of } \\
25 \mathrm{mV} \cdot \mathrm{s}^{-1} \text { and } 70 \% \text { specific capacitance retention after } \\
275 \text { cycles }\end{array}$ & [211] \\
\hline 31 & $\mathrm{MnO}_{2}$ nanowire & Ti foil & IPA & $40 \mathrm{~V}$ & $1 \mathrm{~h}$ & $\begin{array}{l}\text { A maximum capacitance of } 1050 \mathrm{~F} \cdot \mathrm{g}^{-1} \text { at a scan rate of } \\
1 \mathrm{mV} \cdot \mathrm{s}^{-1} \text { and } 750 \mathrm{~F} \cdot \mathrm{g}^{-1} \text { of the specific capacitance at a current } \\
\text { density of } 1 \mathrm{~mA} \cdot \mathrm{g}^{-1}\end{array}$ & [214] \\
\hline 32 & $\alpha-\mathrm{MnO}_{2}$ nanorod & SS foil & $\begin{array}{l}\text { IPA, } \mathrm{Mg}\left(\mathrm{NO}_{3}\right)_{2} \cdot 6 \mathrm{H}_{2} \mathrm{O} \text {, and } \\
\mathrm{NiCl}_{2} \cdot 6 \mathrm{H}_{2} \mathrm{O}\end{array}$ & $800 \mathrm{~V}$ & $30 \mathrm{~s}$ & $\begin{array}{l}\text { A maximum capacitance of } 8500 \mu \mathrm{F} \mathrm{cm} \mathrm{cm}^{2} \text { and } 92 \% \text { specific } \\
\text { capacitance retention after } 2000 \text { cycles at a current density of } \\
0.25 \mathrm{~mA} \cdot \mathrm{cm}^{-2}\end{array}$ & [215] \\
\hline 33 & $\begin{array}{l}\mathrm{MnO}_{2} \mathrm{Nano} / \text { Micro } \\
\text { hybrids }\end{array}$ & Ti foil & IPA & $40 \mathrm{~V}$ & $15 \mathrm{~min}$ & $\begin{array}{l}\text { A specific capacitance of } 1100 \mathrm{~F} \cdot \mathrm{g}^{-1} \text { at a scan rate of } 5 \mathrm{mV} \cdot \mathrm{s}^{-1} \\
\text { and no reduction of the initial specific capacitance after } \\
10000 \text { cycles at a scan rate of } 200 \mathrm{mV} \cdot \mathrm{s}^{-1}\end{array}$ & [216] \\
\hline
\end{tabular}


Table A3. Cont.

\begin{tabular}{|c|c|c|c|c|c|c|c|}
\hline \multirow{2}{*}{ No. } & \multicolumn{2}{|c|}{ Materials } & \multirow{2}{*}{ Suspension Medium } & \multicolumn{2}{|c|}{ EPD Conditions } & \multirow{2}{*}{$\begin{array}{c}\text { Specification } \\
\text { (A specific Capacitnace) }\end{array}$} & \multirow{2}{*}{ Ref. } \\
\hline & Coating & Substrate & & Voltage & Time & & \\
\hline 34 & $\mathrm{MnO}_{2}$ & SS Graphite & Ethanol and PE & $10-100 \mathrm{~V}$ & $1-15 \mathrm{~min}$ & $\begin{array}{l}\text { A maximum capacitance of } 377 \mathrm{~F} \cdot \mathrm{g}^{-1} \text { at a scan rate of } 2 \mathrm{mV}^{-1} \\
\text { (loading amount: } 50 \mu \mathrm{g} \cdot \mathrm{cm}^{-2} \text { ) in } 0.1 \mathrm{M} \mathrm{Na}_{2} \mathrm{SO}_{4} \text { electrolyte }\end{array}$ & [352] \\
\hline 35 & Aligned $\beta-\mathrm{MnO}_{2}$ nanorod & Stainless steel & $\begin{array}{l}\mathrm{Mg}\left(\mathrm{NO}_{3}\right)_{2} \cdot 6 \mathrm{H}_{2} \mathrm{O} \text { in isopropyl } \\
\text { alcohol (IPA) }\end{array}$ & $150 \mathrm{~V}$ & $1 \mathrm{~min}$ & $\begin{array}{l}\text { A maximum capacitance of } 689 \mu \mathrm{F} \cdot \mathrm{cm}^{-2} \text { at a constant current } \\
\text { density of } 2 \mathrm{~mA} \cdot \mathrm{cm}^{-2}\end{array}$ & [245] \\
\hline 36 & $\mathrm{NiO}$ & SS foil & $\begin{array}{l}\text { IPA and iodine, nickel nitrate or } \\
\text { cobalt nitrate }\end{array}$ & $10 \mathrm{~V}$ & $30 \mathrm{~s}$ & $\begin{array}{l}\text { A specific capacitance of } 180 \mathrm{~F} \cdot \mathrm{g}^{-1} \text { at a scan rate of } \\
10 \mathrm{mV} \cdot \mathrm{s}^{-1} \text { and no change of specific capacitance retention } \\
\text { after } 4000 \text { cycles at a constant current density of } 8 \mathrm{~A} \cdot \mathrm{g}^{-1} \text { in } \\
0.5 \mathrm{M} \mathrm{KOH} \text { electrolyte }\end{array}$ & [218] \\
\hline 37 & $\mathrm{NiO}$ & SS foil & IPA, Iodine, and water & $10 \mathrm{~V}$ & $30 \mathrm{~s}$ & $\begin{array}{l}\text { A specific capacitance of } 112 \mathrm{~F} \cdot \mathrm{g}^{-1} \text { at a scan rate of } 10 \mathrm{mV} \cdot \mathrm{s}^{-1} \\
\text { and } 90 \% \text { specific capacitance retention after } 5000 \text { cycles at a } \\
\text { constant current of } 4 \mathrm{~A} \cdot \mathrm{g}^{-1} \text { in } 0.5 \mathrm{M} \mathrm{KOH} \text { electrolyte }\end{array}$ & [219] \\
\hline 38 & $\mathrm{NiO}$ nanowires & Ti foil & IPA and nickel nitrate & $40 \mathrm{~V}$ & $60 \mathrm{~min}$ & $\begin{array}{l}\text { A specific capacitance of } 750 \mathrm{~F} \cdot \mathrm{g}^{-1} \text { at a scan rate of } 1 \mathrm{mV} \cdot \mathrm{s}^{-1} \\
\text { and } 12 \% \text { capacitance fades after } 1000 \text { cycles in } 0.1 \mathrm{M} \mathrm{NaOH} \\
\text { electrolyte }\end{array}$ & [220] \\
\hline 39 & $\begin{array}{l}\mathrm{MnO}_{2} \\
\text { nanoparticles-cationic } \\
\text { celestine blue dye }\end{array}$ & Ni plaques & Ethanol & $20 \mathrm{~V}$ & $1-8 \min$ & $\begin{array}{l}\text { A specific capacitance of } 0.34 \mathrm{~F} \cdot \mathrm{cm}^{-2} \text { at a scan rate of } \\
2 \mathrm{mV} \cdot \mathrm{s}^{-1} \text { and high capacitance retention of } 88.5 \% \text { in the scan } \\
\text { rate of } 2-100 \mathrm{mV} \cdot \mathrm{s}^{-1} \text { in } 0.5 \mathrm{M} \mathrm{Na}_{2} \mathrm{SO}_{4} \text { electrolyte }\end{array}$ & [241] \\
\hline 40 & $\begin{array}{l}\text { Polystyrene sphere/nickel } \\
\text { hydroxide }\end{array}$ & SS foil & IPA & $60 \mathrm{~V}$ & $30 \mathrm{~s}$ & $\begin{array}{l}\text { A specific capacitance of } 800 \mathrm{~F} \cdot \mathrm{g}^{-1} \text { at a discharge current } \\
\text { density of } 10 \mathrm{~A} \cdot \mathrm{g}^{-1} \text { in } 0.5 \mathrm{M} \mathrm{KOH} \text { electrolyte }\end{array}$ & [211] \\
\hline 41 & $\mathrm{NiMoO}_{4}$ & Ni foil & IPA & $40 \mathrm{~V}$ & $15 \mathrm{~min}$ & $\begin{array}{l}\text { A specific capacitance of } 972 \mathrm{~F} \cdot \mathrm{g}^{-1} \text { at a scan rate of } 1 \mathrm{mV} \cdot \mathrm{s}^{-1} \\
\text { in } 1 \mathrm{M} \mathrm{NaOH} \text { electrolyte }\end{array}$ & [222] \\
\hline 42 & Hybrid materials & SS foil & Water & $\begin{array}{l}30 \mathrm{~Hz} \\
200 \mathrm{~V}\end{array}$ & $30 \mathrm{~s}$ & $\begin{array}{l}\text { A specific capacitance of } 172 \mathrm{~F} \cdot \mathrm{g}^{-1} \text { and good cyclability at } \\
7 \mathrm{~mA} \cdot \mathrm{cm}^{-2} \text { over } 1100 \text { cycles }\end{array}$ & [353] \\
\hline 43 & PPY-MWCNTs & SS foil & Water & $1 \mathrm{~mA} \cdot \mathrm{cm}^{-2}$ & - & $\begin{array}{l}\text { A specific capacitance of } 224 \mathrm{~F} \cdot \mathrm{g}^{-1} \text { at a scan rate of } 2 \mathrm{mV} \cdot \mathrm{s}^{-1} \\
\text { in } 0.5 \mathrm{M} \mathrm{Na}_{2} \mathrm{SO}_{4} \text { electrolyte (Pulsed electrophoretic } \\
\text { deposition) }\end{array}$ & [223] \\
\hline 44 & PBS-MnO 2 -MWCNTs & $\begin{array}{l}\text { SS foil Pt coated } \\
\text { wafer }\end{array}$ & Water & $1-10 \mathrm{~V}$ & $1-10 \mathrm{~min}$ & $\begin{array}{l}\text { A specific capacitance of } 250 \text { and } 90 \mathrm{~F} \cdot \mathrm{g}^{-1} \text { at a scan rate of } 2 \\
\text { and } 100 \mathrm{mV} \cdot \mathrm{s}^{-1} \text { in } 0.5 \mathrm{M} \mathrm{Na}_{2} \mathrm{SO}_{4} \text { electrolyte, respectively }\end{array}$ & [224] \\
\hline 45 & $\begin{array}{l}\text { PPy } \\
\text { nanofiber-MWCNTs-MG }\end{array}$ & SS & Water & $30 \mathrm{~V}$ & - & $\begin{array}{l}\text { A maximum capacitance of } 4.62 \mathrm{~F} \cdot \mathrm{cm}^{-2} \text { at a scan rate of } \\
2 \mathrm{mV} \cdot \mathrm{s}^{-1} \text { in } 0.5 \mathrm{M} \mathrm{Na}_{2} \mathrm{SO}_{4} \text { electrolyte (a material loading of } \\
30 \mathrm{mg} \mathrm{cm} \text { ) }\end{array}$ & [225] \\
\hline
\end{tabular}


Table A3. Cont.

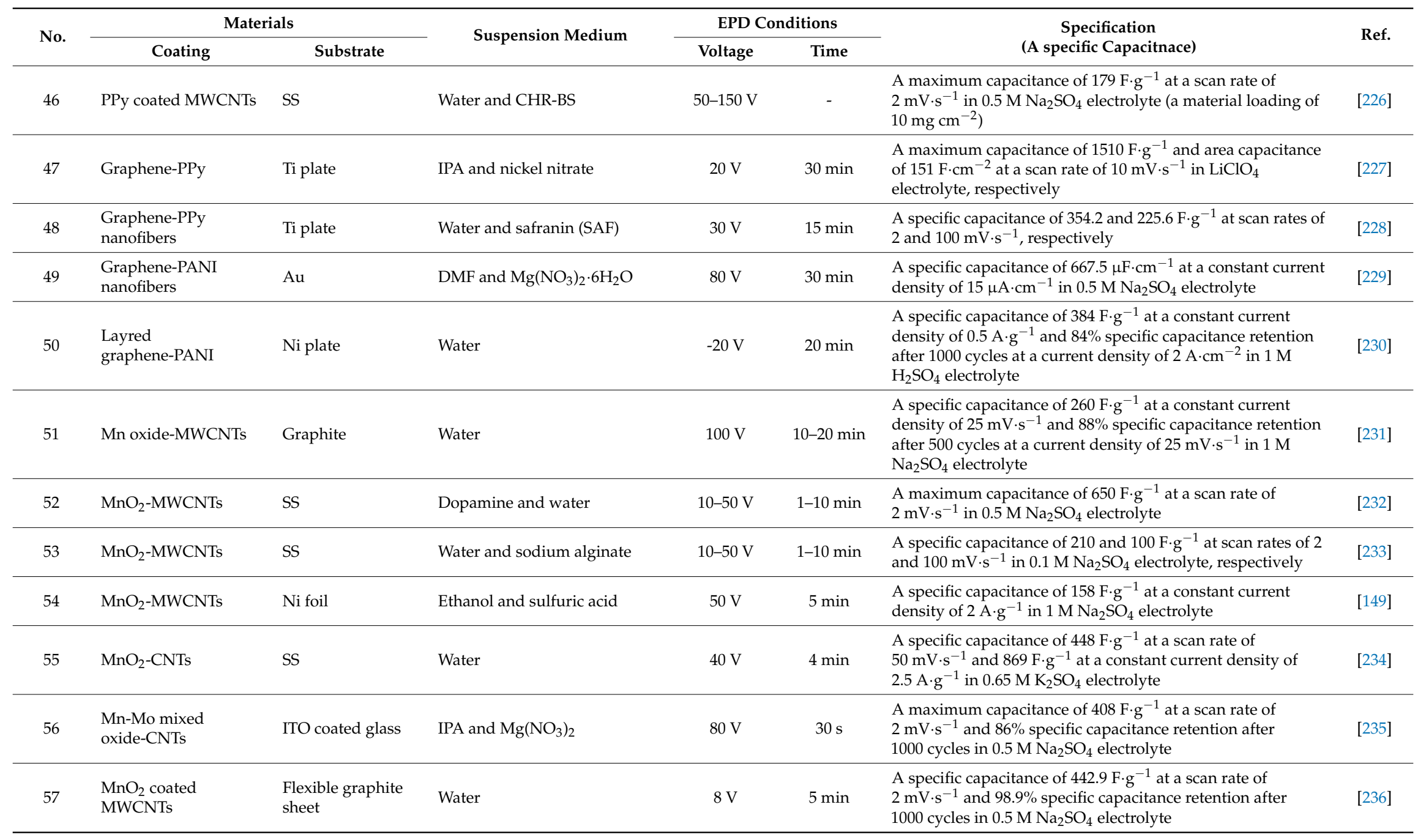


Table A3. Cont.

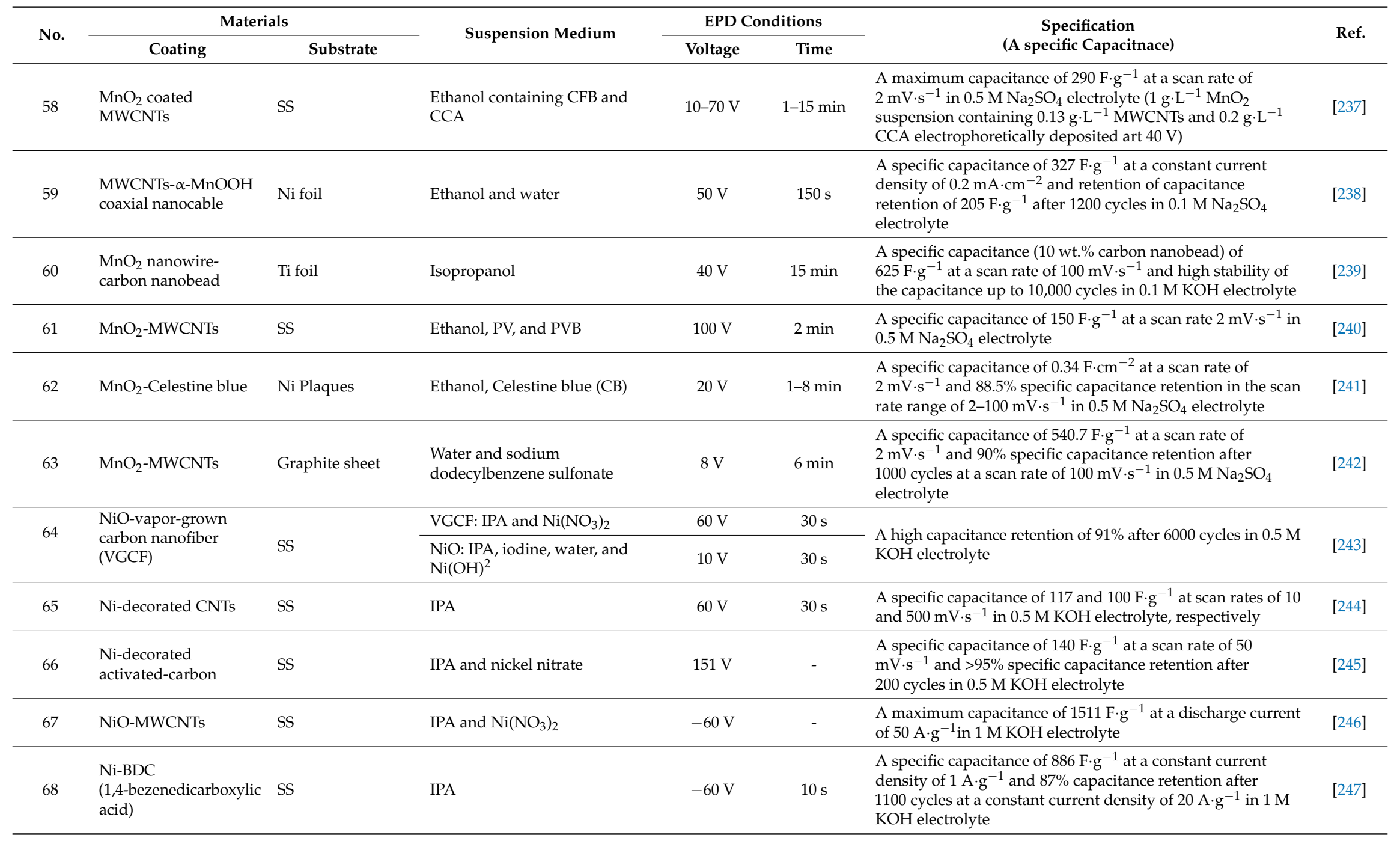


Table A3. Cont.

\begin{tabular}{|c|c|c|c|c|c|c|c|}
\hline \multirow{2}{*}{ No. } & \multicolumn{2}{|c|}{ Materials } & \multirow{2}{*}{ Suspension Medium } & \multicolumn{2}{|c|}{ EPD Conditions } & \multirow{2}{*}{$\begin{array}{c}\text { Specification } \\
\text { (A specific Capacitnace) }\end{array}$} & \multirow{2}{*}{ Ref. } \\
\hline & Coating & Substrate & & Voltage & Time & & \\
\hline 69 & $\begin{array}{l}\text { Graphene } \\
\text { nanosheet/porous } \\
\mathrm{NiO}\end{array}$ & Ni form & IPA and $\mathrm{Mg}\left(\mathrm{NO}_{3}\right)_{2} \cdot 6 \mathrm{H}_{2} \mathrm{O}$ & $100 \mathrm{~V}$ & $20 \mathrm{~s}$ & $\begin{array}{l}\text { A specific capacitance of } 400 \text { and } 324 \mathrm{~F} \cdot \mathrm{g}^{-1} \text { at a constant } \\
\text { current densities of } 2 \text { and } 40 \mathrm{~A} \cdot \mathrm{g}^{-1} \text {, respectively in } 1 \mathrm{M} \mathrm{KOH} \\
\text { electrolyte }\end{array}$ & [248] \\
\hline 70 & $\begin{array}{l}\text { Graphene } \\
\text { nanosheets } / \mathrm{MnO}_{2} \\
\text { nanowires }\end{array}$ & SS & $\begin{array}{l}1 \text { step: IPA } \\
2 \text { step: Manganous acetate, } \\
\text { sodium sulfate }\end{array}$ & $\begin{array}{c}60 \mathrm{~V} \\
0.125 \\
\mathrm{~mA} \cdot \mathrm{cm}^{-2}\end{array}$ & - & $\begin{array}{l}\text { A specific capacitance of } 252 \mathrm{~F} \cdot \mathrm{g}^{-1} \text { at a constant current } \\
\text { density of } 2 \mathrm{~A} \cdot \mathrm{g}^{-1} \text { and } 96 \% \text { capacitance retention after } \\
6000 \text { cycles at a constant current density of } 40 \mathrm{~A} \cdot \mathrm{g}^{-1} \text { in } 1 \mathrm{M} \\
\mathrm{Na}_{2} \mathrm{SO}_{4} \text { electrolyte }\end{array}$ & [249] \\
\hline 71 & $\begin{array}{l}\mathrm{NiO} / \text { graphene oxide } \\
\text { nanosheets }\end{array}$ & SS & IPA and nickel nitrate & $60 \mathrm{~V}$ & - & $\begin{array}{l}\text { A specific capacitance of } 569 \mathrm{~F} \cdot \mathrm{g}^{-1} \text { at a constant current } \\
\text { density of } 5 \mathrm{~A} \cdot \mathrm{g}^{-1}\left(\mathrm{NiO}: 28 \mathrm{~F} \cdot \mathrm{g}^{-1} \text {, graphene oxide: } 11 \mathrm{~F} \cdot \mathrm{g}^{-1}\right) \\
\text { in } 0.5 \mathrm{M} \mathrm{KOH} \text { electrolyte }\end{array}$ & [253] \\
\hline 72 & $\begin{array}{l}\text { Multilayered } \\
\text { graphene sheet/Au } \\
\text { nanoparticles }\end{array}$ & ITO coated glass & DMF & $30 \mathrm{~V}$ & $8 \mathrm{~min}$ & $\begin{array}{l}\text { A specific capacitance of } 65 \mathrm{~F} \cdot \mathrm{g}^{-1} \text { at a constant current } \\
\text { density of } 1 \mathrm{~F} \cdot \mathrm{g}^{-1} \text { in organic electrolyte }\end{array}$ & [254] \\
\hline 73 & $\begin{array}{l}\text { Graphene } \\
\text { nanoribbons } / \mathrm{MnO}_{2}\end{array}$ & SS & $\mathrm{IPA} \mathrm{Mn}\left(\mathrm{NO}_{3}\right)_{2} \cdot 4 \mathrm{H}_{2} \mathrm{O}$ & $\begin{array}{l}60 \mathrm{~V} \\
-30 \mathrm{~V}\end{array}$ & - & $\begin{array}{l}\text { A specific capacitance of } 266 \mathrm{~F} \cdot \mathrm{g}^{-1} \text { at a constant current } \\
\text { density of } 1 \mathrm{~A} \cdot \mathrm{g}^{-1} \text { and } 98 \% \text { capacitance retention after } \\
3000 \text { cycles at a constant current density of } 10 \mathrm{~A} \cdot \mathrm{g}^{-1} \text { in } 1 \mathrm{M} \\
\mathrm{Na}_{2} \mathrm{SO}_{4} \text { electrolyte }\end{array}$ & [250] \\
\hline 74 & $\begin{array}{l}\mathrm{Ni}-\mathrm{CO} \\
\text { hexacyanoferrate } \\
\text { nanostructure/graphene }\end{array}$ & SS & Water & $5 \mathrm{~V}$ & $7 \mathrm{~min}$ & $\begin{array}{l}\text { A maximum capacitance of } 411 \mathrm{~F} \cdot \mathrm{g}^{-1} \text { a constant current } \\
\text { density of } 0.2 \mathrm{~A} \cdot \mathrm{g}^{-1} \text { and } 83 \% \text { capacitance retention after } \\
800 \text { cycles at a scan rate of } 25 \mathrm{mV} \cdot \mathrm{s}^{-1} \text { in } 1 \mathrm{MNO}_{3} \text { electrolyte }\end{array}$ & [251] \\
\hline 75 & $\begin{array}{l}\mathrm{MnO}_{2} \\
\text { nanoparticles/graphene } \\
\text { nanosheets }\end{array}$ & SS & Water & $4 \mathrm{~V}$ & $5 \mathrm{~min}$ & $\begin{array}{l}\text { A specific capacitance of } 392 \mathrm{~F} \cdot \mathrm{g}^{-1} \text { at a constant current } \\
\text { density of } 1 \mathrm{~A} \cdot \mathrm{g}^{-1} \text { and }>90 \% \text { capacitance retention after } \\
1200 \text { cycles at a constant current density of } 6 \mathrm{~A} \cdot \mathrm{g}^{-1} \text { in } 0.5 \mathrm{M} \\
\mathrm{Na}_{2} \mathrm{SO}_{4} \text { electrolyte }\end{array}$ & [252] \\
\hline 76 & Graphene $/ \mathrm{MnO}_{2} / \mathrm{CNT}$ & Ni plate & Hydrochloric acid and IPA & $50 \mathrm{~V}$ & $2 \mathrm{~min}$ & $\begin{array}{l}\text { A maximum capacitance of } 416 \mathrm{~F} \cdot \mathrm{g}^{-1} \text { at a constant current } \\
\text { density of } 3 \mathrm{~A} \cdot \mathrm{g}^{-1} \text { and } 83.3 \% \text { capacitance retention after } \\
15,000 \text { cycles at a constant current density of } 3 \mathrm{~A} \cdot \mathrm{g}^{-1} \text { in } 0.1 \mathrm{M} \\
\mathrm{Na}_{2} \mathrm{SO}_{4} \text { electrolyte }\end{array}$ & [255] \\
\hline 77 & $\begin{array}{l}\text { Reduced graphene } \\
\text { oxide } / \mathrm{Ni}(\mathrm{OH})_{2}\end{array}$ & $\begin{array}{l}\text { Ni form SS ITO } \\
\text { coated glass }\end{array}$ & Water and $\mathrm{Ni}\left(\mathrm{NO}_{3}\right)_{2}$ & $2-10 \mathrm{~V}$ & $30-600 \mathrm{~s}$ & $\begin{array}{l}\text { Maximum capacitances of } 1404 \text { and } 1004 \mathrm{~F} \cdot \mathrm{g}^{-1} \text { at constant } \\
\text { current densities of } 2 \text { and } 20 \mathrm{~A} \cdot \mathrm{g}^{-1} \text {, respectively in } 6 \mathrm{M} \mathrm{KOH} \\
\text { electrolyte }\end{array}$ & [256] \\
\hline
\end{tabular}


Table A3. Cont.

\begin{tabular}{|c|c|c|c|c|c|c|c|}
\hline \multirow{2}{*}{ No. } & \multicolumn{2}{|c|}{ Materials } & \multirow{2}{*}{ Suspension Medium } & \multicolumn{2}{|c|}{ EPD Conditions } & \multirow{2}{*}{$\begin{array}{c}\text { Specification } \\
\text { (A specific Capacitnace) }\end{array}$} & \multirow{2}{*}{ Ref } \\
\hline & Coating & Substrate & & Voltage & Time & & \\
\hline 78 & $\begin{array}{l}\mathrm{PbO}_{2}-\mathrm{CNTs} / \text { graphene } \\
\text { asymmetric electrode }\end{array}$ & Ti plate & Acetonitrile & $20 \mathrm{~V}$ & $60 \mathrm{~min}$ & $\begin{array}{l}\text { A specific capacitance of } 250 \mathrm{~F} \cdot \mathrm{g}^{-1} \text { at a scan rate of } 5 \mathrm{mV} \cdot \mathrm{s}^{-1} \\
\text { and } 87 \% \text { capacitance retention after } 3000 \text { cycles at a scan rate } \\
\text { of } 100 \mathrm{mV} \cdot \mathrm{s}^{-1} \text { in } 0.1 \mathrm{M} \mathrm{KOH} \text { electrolyte }\end{array}$ & [260] \\
\hline 79 & $\begin{array}{l}\text { Graphene/carbon } \\
\text { nanotube } / \mathrm{MnO}_{2}\end{array}$ & Ni plate & Hydrochloric acid and IPA & $50 \mathrm{~V}$ & $2 \min$ & $\begin{array}{l}\text { A specific capacitance of } 964 \mathrm{~F} \cdot \mathrm{g}^{-1} \text { at a constant current } \\
\text { density of } 1 \mathrm{~A} \cdot \mathrm{g}^{-1} \text { and } 67 \% \text { capacitance retention at constant } \\
\text { current densities from } 1 \text { to } 10 \mathrm{~A} \cdot \mathrm{g}^{-1} \text { in } 0.1 \mathrm{M} \mathrm{Na}_{2} \mathrm{SO}_{4} \\
\text { electrolyte }\end{array}$ & [354] \\
\hline \multirow{2}{*}{80} & \multirow{2}{*}{$\begin{array}{l}\text { Graphene/Ni-Fe-HCF } \\
\text { (hexacyanoferrate) }\end{array}$} & \multirow{2}{*}{ SS } & Water & $5 \mathrm{~V}$ & $10 \mathrm{~min}$ & \multirow{2}{*}{$\begin{array}{l}\text { A specific capacitance of } 67.77 \mathrm{mAh} \cdot \mathrm{g}^{-1} \text { at a constant current } \\
\text { density of } 0.5 \mathrm{Ag}^{-1} \text { and }>95 \% \text { capacitance retention at a scan } \\
\text { rate of } 0.02 \mathrm{~V} \cdot \mathrm{s}^{-1} \text { in } 0.5 \mathrm{KNO}_{3} \text { electrolyte }\end{array}$} & \multirow{2}{*}{355} \\
\hline & & & $\begin{array}{l}\mathrm{NiCl}_{2} \cdot 6 \mathrm{H}_{2} \mathrm{O}, \mathrm{FeCl}_{3} \cdot 6 \mathrm{H}_{2} \mathrm{O} \\
\mathrm{K} 3 \mathrm{Fe}(\mathrm{CN})_{6}\end{array}$ & $0.35 \mathrm{~V}$ & $300 \mathrm{~s}$ & & \\
\hline 81 & $\mathrm{RuO}_{2}$-graphene-CNT & Carbon fiber cloth & $\mathrm{CNT}, \mathrm{CNS}$ & $20 \mathrm{~V}$ & $5 \mathrm{~min}$ & $\begin{array}{l}\text { A high specific capacitance up to } 480.3 \mathrm{~F} \cdot \mathrm{g}^{-1} \text { and remarkable } \\
\text { cycling stability ( } 89.4 \% \text { capacitance retention after } \\
10,000 \text { cycles) }\end{array}$ & [356] \\
\hline
\end{tabular}

Table A4. Overview of the SOFCs fabricated by EPD showing the materials for SOFCs and EPD conditions investigated.

\begin{tabular}{|c|c|c|c|c|c|c|c|}
\hline \multirow{2}{*}{ No. } & \multirow{2}{*}{ Support Materials } & \multirow{2}{*}{ Materials for EPD } & \multirow{2}{*}{ Suspension Medium } & \multicolumn{2}{|c|}{ EPD Conditions } & \multirow{2}{*}{$\begin{array}{c}\text { Specification } \\
\text { (An optimized Condition and a Power Density) }\end{array}$} & \multirow{2}{*}{ Ref. } \\
\hline & & & & Voltage & Time & & \\
\hline 1 & LSM & YSZ & Acetylacetone and $\mathrm{I}_{2}$ & $10 \mathrm{~V}$ & $3 \mathrm{~min}$ & $\begin{array}{l}\text { A maximum power density of } 1.5 \mathrm{~W} \cdot \mathrm{cm}^{-2} \text { and } \\
\text { open circuit voltage of } 1.0 \mathrm{~V} \text {, respectively }\end{array}$ & [263] \\
\hline 2 & LSM & YSZ & Ketone and $\mathrm{I}_{2}$ & $10 \mathrm{~V}$ & $3 \mathrm{~min}$ & $\begin{array}{l}\text { A maximum power density of } 1.84 \mathrm{~W} \cdot \mathrm{cm}^{-2} \text { and } \\
\text { open circuit voltage of } 1.03 \mathrm{~V} \text {, respectively }\end{array}$ & [264] \\
\hline 3 & LSM & YSZ & - & - & - & $\begin{array}{l}\text { A maximum power density of } 1.87 \mathrm{~W} \cdot \mathrm{cm}^{-2} \text { and } \\
\text { open circuit voltage of } 1.03 \mathrm{~V} \text {, respectively }\end{array}$ & [265] \\
\hline 4 & LSM & $\begin{array}{l}\mathrm{LM} / \mathrm{YSZ} / \mathrm{NiO}-\mathrm{YSZ} \\
\text { multilayer }\end{array}$ & isopropanol & $20-600 \mathrm{~V}$ & $1-60 \mathrm{~min}$ & $\begin{array}{l}\text { YSZ: at } 40 \mathrm{~V} \text { for } 10 \mathrm{~min} \text { in isopropanol NiO-YSZ: at } \\
40 \mathrm{~V} \text { for } 10 \mathrm{~min} \text { in isopropanol }\end{array}$ & [280] \\
\hline 5 & $\begin{array}{l}\text { Carbon interlayer } \\
\text { coated LDM tube }\end{array}$ & YSZ & Glacial acetic acid & $50 \mathrm{~V}$ & $5 \mathrm{~min}$ & $\begin{array}{l}\text { A density of } 98.5 \% \text { of YSZ with interlayer ( } 94 \% \text { of } \\
\text { YSZ without interlayer) }\end{array}$ & [268] \\
\hline 6 & LSM-YSZ & YSZ & $\begin{array}{l}\text { Acetone including ethanol with } \\
\text { amount of } I_{2}\end{array}$ & $5-40 \mathrm{~V}$ & $3-30 \mathrm{~min}$ & $\begin{array}{l}\text { A high density of YSZ at } 20 \mathrm{~V} \text { for } 8 \mathrm{~min} \text { in } \\
\text { suspension of } \mathrm{I}_{2} \text { concentration of } 0.6 \mathrm{~g} / \mathrm{L}, \mathrm{YSZ} \\
\text { concentration of } 9.0 \mathrm{~g} / \mathrm{L} \text {, and a mixture of } \\
\text { acetone/ethanol (volume ratio } 3 / 1 \text { ) }\end{array}$ & [273] \\
\hline
\end{tabular}


Table A4. Cont.

\begin{tabular}{|c|c|c|c|c|c|c|c|}
\hline \multirow{2}{*}{ No. } & \multirow{2}{*}{ Support Materials } & \multirow{2}{*}{ Materials for EPD } & \multirow{2}{*}{ Suspension Medium } & \multicolumn{2}{|c|}{ EPD Conditions } & \multirow{2}{*}{$\begin{array}{l}\text { Specification } \\
\text { (An optimized Condition and a Power Density) }\end{array}$} & \multirow{2}{*}{ Ref. } \\
\hline & & & & Voltage & Time & & \\
\hline 7 & Stainless steel & $3 \mathrm{YSZ}, 6 \mathrm{YSZ}$, and 8YSZ & $\begin{array}{l}n \text {-propanol, methanol, ethanol, } \\
\text { iso-propanol, } n \text {-butanol, ethylene } \\
\text { glycol, acetone, and acetylacetone }\end{array}$ & $20-300 \mathrm{~V}$ & $1-30 \mathrm{~min}$ & $\begin{array}{l}\text { A high dispersion of } 8 \mathrm{YSZ} \text { in } n \text {-propanol suspension } \\
\text { and dense uniform coating at less than } 100 \mathrm{~V} \text { for } 10 \mathrm{~min}\end{array}$ & [277] \\
\hline 8 & $\mathrm{NiO}-\mathrm{ScSZ}$ & YSZ & $n$-propanol & $50 \mathrm{~V}$ & $1-30 \mathrm{~min}$ & $\begin{array}{l}\text { A dense uniform coating at } 50 \mathrm{~V} \text { for } 10 \mathrm{~min} \text { and an OCV } \\
\text { of } 1.165 \mathrm{~V} \text { at } 928 \mathrm{~K} \text { in anode-supported YSZ electrolyte } \\
\text { deposited by EPD }\end{array}$ & [278] \\
\hline 9 & NiO-YSZ & $\begin{array}{l}\text { NiO-YSZ/YSZ } \\
\text { bi-layers }\end{array}$ & Acetylacetone & $25-500 \mathrm{~V}$ & $1-3 \mathrm{~min}$ & $\begin{array}{l}\text { A maximum power density of } 434 \mathrm{~mW} \cdot \mathrm{cm}^{-2} \text { and open } \\
\text { circuit voltage of } 0.99 \mathrm{~V} \text { at } 800{ }^{\circ} \mathrm{C}\end{array}$ & [289] \\
\hline 10 & NiO-YSZ & YSZ & Acetylacetone & $50-300 \mathrm{~V}$ & $1-5 \min$ & $\begin{array}{l}\text { A maximum power density of } 611 \mathrm{~mW} \cdot \mathrm{cm}^{-2} \text { and open } \\
\text { circuit voltage of } 0.88 \mathrm{~V} \text { at } 850^{\circ} \mathrm{C} \text { (at } 50 \mathrm{~V} \text { for } 1 \mathrm{~min} \text { ) }\end{array}$ & [264] \\
\hline 11 & NiO-YSZ & YSZ & $\mathrm{I}_{2}$ with isopropanol & $10 \mathrm{~V}$ & $60 \mathrm{~min}$ & $\begin{array}{l}\text { A maximum power density of } 440 \mathrm{~mW} \cdot \mathrm{cm}^{-2} \text { and open } \\
\text { circuit voltage of } 1.0 \mathrm{~V} \text { at } 900{ }^{\circ} \mathrm{C}\end{array}$ & [272] \\
\hline 12 & Graphite & $\mathrm{Ni}-\mathrm{YSZ}$ & $\begin{array}{l}\text { Tetramethylammonium } \\
\text { hydroxide (TMAH)adding } \\
\text { 13polyacrylic acid based } \\
\text { pol14yelectrolyte (PPA) 15and } \\
\text { carboxymet16hylcellulose } \\
(\mathrm{CM} 17 \mathrm{C})\end{array}$ & $2 \mathrm{~mA} \cdot \mathrm{cm}^{-2}$ & $5-10 \mathrm{~min}$ & $\begin{array}{l}\text { A higher electrophoretic mobility of powder in pH } 9 \\
\text { and } 10 \text { adding } 1.5 \mathrm{wt} . \% \text { of PAA and } 0.5 \mathrm{wt} . \% \text { of CMC }\end{array}$ & [279] \\
\hline 13 & NiO-YSZ & YSZ/SDC bi-layers & Ethanol & $600 \mathrm{~V}$ & - & $\begin{array}{l}\text { A maximum power density of } 0.6 \mathrm{~W} \cdot \mathrm{cm}^{-2} \text { at } 700{ }^{\circ} \mathrm{C} \text { of } \\
\text { bi-layered electrolyte consisting of } 4 \mu \mathrm{m} \text {-thick } \mathrm{YSZ} \text { and } \\
1 \mu \mathrm{m} \text {-thick SEC films }\end{array}$ & [290] \\
\hline 14 & $\begin{array}{l}\text { Graphite coated } \\
\text { NiO-YSZ }\end{array}$ & YSZ & Acetone & $400 \mathrm{~V}$ & - & $\begin{array}{l}\text { A maximum power density of } 2.01 \mathrm{~W} \cdot \mathrm{cm}^{-2} \text { at } 800{ }^{\circ} \mathrm{C} \\
\text { (YSZ of } 5 \mu \mathrm{m} \text {-thick) }\end{array}$ & [269] \\
\hline 15 & NiO-YSZ & YSZ & Acetylacetone & $25-100 \mathrm{~V}$ & $1-3 \min$ & $\begin{array}{l}\text { A maximum power density of } 263.8 \mathrm{~mW} \cdot \mathrm{cm}^{-2} \text { and } \\
\text { open circuit voltage of } 0.97 \mathrm{~V} \text { at } 650^{\circ} \mathrm{C}(100 \mathrm{~V} \text { for } 3 \mathrm{~min})\end{array}$ & [267] \\
\hline 16 & NiO-YSZ & YSZ & 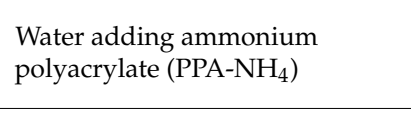 & $2.2 \mathrm{~mA} \cdot \mathrm{cm}^{-2}$ & 30 and $75 \mathrm{~s}$ & $\begin{array}{l}\text { A dense and uniform YSZ electrolyte film of } 6 \mu \mathrm{m} \text {-thick } \\
\text { and increase of deposition rate with increasing current } \\
\text { density and with decreasing PAA-NH } \mathrm{P}_{4} \text { concentration }\end{array}$ & [281] \\
\hline 17 & Fecralloy & YSZ & Acetylacetone adding $I_{2}$ & $\begin{array}{l}15-480 \mathrm{~V} \\
0-250 \mathrm{~V}\end{array}$ & $1-20 \mathrm{~min}$ & $\begin{array}{l}\text { A reduction of deposit porosity of electrolyte after a first } \\
\text { step of a } 240 \mathrm{~s} \text { EPD in an electric field of } 60 \mathrm{~V} \text { and then } \\
240 \mathrm{~s} \text { EPD in an electric field of } 240 \mathrm{~V} \text { as a second step }\end{array}$ & [270] \\
\hline
\end{tabular}


Table A4. Cont.

\begin{tabular}{|c|c|c|c|c|c|c|c|}
\hline \multirow{2}{*}{ No. } & \multirow{2}{*}{ Support Materials } & \multirow{2}{*}{ Materials for EPD } & \multirow{2}{*}{ Suspension Medium } & \multicolumn{2}{|c|}{ EPD Conditions } & \multirow{2}{*}{$\begin{array}{c}\text { Specification } \\
\text { (An optimized Condition and a Power Density) }\end{array}$} & \multirow{2}{*}{ Ref. } \\
\hline & & & & Voltage & Time & & \\
\hline 18 & LSM/YSZ & YSZ & $\begin{array}{l}\text { Mixture of acetone/ethanol } \\
\text { adding } \mathrm{I}_{2}\end{array}$ & $10-40 \mathrm{~V}$ & 4-8 min & $\begin{array}{l}\text { An uniform film without cracks in suspension of } \\
\text { acetone/ethanol (rate: } 50 / 50 \mathrm{~mL} \text { ) at } 30 \mathrm{~V} \text { for } 6 \mathrm{~min}\end{array}$ & [274] \\
\hline 19 & NiO-YSZ & YSZ & acetone/ethanol (50:50) & $20 \mathrm{~V}$ & $1-4 \min$ & $\begin{array}{l}\text { A dense thick film without crack at } 20 \mathrm{~V} \text { for } 1 \mathrm{~min} \\
\text { leaded to a better result in EIS analysis }\end{array}$ & [275] \\
\hline 20 & NiO-YSZ & YSZ & $\begin{array}{l}\text { Ethanol adding polyethylene } \\
\text { glycol (PEG) }\end{array}$ & $30 \mathrm{~V}$ & $1.5 \mathrm{~min}$ & $\begin{array}{l}\text { A maximum power density of } 850 \mathrm{~mW} \cdot \mathrm{cm}^{-2} \text { at } 850^{\circ} \mathrm{C} \\
\text { (YSZ of } 10 \mu \mathrm{m} \text {-thick) }\end{array}$ & [276] \\
\hline 21 & NiO-YSZ & YSZ & Acetylacetone & $50-300 \mathrm{~V}$ & $1-5 \min$ & $\begin{array}{l}\text { A maximum power density of } 624 \mathrm{~mW} \cdot \mathrm{cm}^{-2} \text { and open } \\
\text { circuit voltage of } 1.03 \mathrm{~V} \text { at } 800{ }^{\circ} \mathrm{C}(\mathrm{EPD} \text { conditions: at } \\
100 \mathrm{~V} \text { for } 3 \mathrm{~min} \text { ) }\end{array}$ & [271] \\
\hline 22 & $\mathrm{Cu}$ wire & $\begin{array}{l}\text { NiO-YSZ, YSZ, and } \\
\text { LSM }\end{array}$ & $\begin{array}{l}\text { Water adding ammonium } \\
\text { polyacrylate }\left(\mathrm{PPA}-\mathrm{NH}_{4}\right)\end{array}$ & $\begin{array}{l}1,5, \text { and } 10 \\
\mathrm{~mA} \cdot \mathrm{cm}^{-2}\end{array}$ & - & $\begin{array}{l}\text { A maximum power density of } 3.5 \mathrm{~mW} \cdot \mathrm{cm}^{-2} \text { at } 800{ }^{\circ} \mathrm{C} \\
(\text { YSZ of } 6 \mu \mathrm{m} \text {-thick) }\end{array}$ & [295] \\
\hline 23 & Carbon coated YSZ & $\begin{array}{l}\text { LSM-YSZ/LSM } \\
\text { bi-layers }\end{array}$ & Acetylacetone adding $\mathrm{I}_{2}$ & $15 \mathrm{~V}$ & - & $\begin{array}{l}\text { A minimal polarization resistance of LSM/YSZ (10:4 } \\
(v: v)) \text { bi-layered film at } 600{ }^{\circ} \mathrm{C}(4 \mu \mathrm{m} \text {-thick })\end{array}$ & [292] \\
\hline 24 & $\mathrm{Cu}$ wire & $\begin{array}{l}\text { NiO-YSZ, YSZ, and } \\
\text { LSM }\end{array}$ & $\begin{array}{l}\text { Water adding ammonium } \\
\text { polyacrylate }\left(\mathrm{PPA}^{-N_{4}}\right)\end{array}$ & $\begin{array}{l}2,5, \text { and } 10 \\
\mathrm{~mA} \cdot \mathrm{cm}^{-2}\end{array}$ & - & $\begin{array}{l}\text { A maximum power density of } 363.8 \mathrm{~mW} \cdot \mathrm{cm}^{-2} \text { at } \\
800{ }^{\circ} \mathrm{C} \text { (YSZ of } 35 \mu \mathrm{m} \text {-thick) }\end{array}$ & [296] \\
\hline 25 & $\mathrm{Cu}$ wire & $\begin{array}{l}\text { NiO-YSZ, YSZ, and } \\
\text { LSM }\end{array}$ & 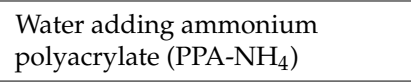 & $100 \mathrm{~mA} \cdot \mathrm{cm}^{-2}$ & - & $\begin{array}{l}\text { A maximum power density of } 363.8 \mathrm{~mW} \cdot \mathrm{cm}^{-2} \text { at } \\
800{ }^{\circ} \mathrm{C} \text { (the anode with } 70 \mathrm{wt} . \% \mathrm{NiO} \text { ) }\end{array}$ & [297] \\
\hline 26 & Stainless steel & NiO-YSZ & $\begin{array}{l}\text { Ethanol, acetone, methanol, } \\
\text { isopropanol, acetyl acetone, and } \\
n \text {-butanol adding } \mathrm{I}_{2}\end{array}$ & $50-300 \mathrm{~V}$ & $30-420 \mathrm{~s}$ & $\begin{array}{l}\text { A high deposition rate of } 60 \mathrm{NiO}-40 \mathrm{YSZ}(\mathrm{wt} . \%) \text { in } \\
\text { isopropanol-suspension adding } 0.5 \mathrm{mM} \mathrm{I}_{2} \text { (EPD } \\
\text { conditions: at } 200 \mathrm{~V} \text { for } 3 \mathrm{~min} \text { ) }\end{array}$ & [357] \\
\hline 27 & NiO-YSZ & YSZ & $\begin{array}{l}\text { Acetylacetone and acetone with } \\
\text { ethanol }\end{array}$ & $110 \mathrm{~V}$ & $2.5 \mathrm{~min}$ & $\begin{array}{l}\text { A maximum power density of } 200 \mathrm{~mW} \cdot \mathrm{cm}^{-2} \text { at } 800^{\circ} \mathrm{C} \\
\text { (YSZ of } 40 \mu \mathrm{m} \text {-thick) }\end{array}$ & [298] \\
\hline 28 & Ni fole & LSGM, LSCF, and YSG & $\begin{array}{l}\text { Ethanol adding phosphate ester } \\
\text { and polyvinyl butyral }\end{array}$ & $\begin{array}{c}0.05-1 \\
\mathrm{~mA} \cdot \mathrm{cm}^{-2}\end{array}$ & $1-10 \mathrm{~min}$ & $\begin{array}{l}\text { A good dispersion and charging of ceramic particles in } \\
\text { phosphate ester as well as improvement of adhesion of } \\
\text { the deposits without cracking by using polyvinyl } \\
\text { bytyral in ethanol-based suspension }\end{array}$ & [282] \\
\hline 29 & Ni fole & LSGM, CGO, and YSG & $\begin{array}{l}\text { Ethanol and isopropanol adding } \\
\text { phosphate ester and polyvinyl } \\
\text { butyral }\end{array}$ & $50-200 \mathrm{~V}$ & $1-6 \mathrm{~min}$ & $\begin{array}{l}\text { A high deposition rate of LSGM and YSG in ethanol } \\
\text { and CGO in isopropanol (adding polyvinyl butyral) }\end{array}$ & [283] \\
\hline 30 & Graphite & LSGM & Acetylacetone adding $\mathrm{I}_{2}$ & $20 \mathrm{~mA} \cdot \mathrm{cm}^{-2}$ & $50-200 \mathrm{~s}$ & $\begin{array}{l}\text { A maximum power density of } 0.5 \mathrm{~W} \cdot \mathrm{cm}^{-2} \text { at } 700^{\circ} \mathrm{C} \\
\text { (LSGM of } 40 \mu \mathrm{m} \text {-thick) }\end{array}$ & [284] \\
\hline 31 & LDC & LSGM & Acetone and water adding $\mathrm{I}_{2}$ & $20-80 \mathrm{~V}$ & - & $\begin{array}{l}\text { A good degree of packing of LSGM particles in } \\
\text { suspension }\left(\mathrm{I}_{2}: 0.1 \mathrm{~g} \cdot \mathrm{L}^{-1}, \mathrm{H}_{2} \mathrm{O}: 45 \mathrm{~mL} \cdot \mathrm{L}^{-1}\right)\end{array}$ & [286] \\
\hline
\end{tabular}


Table A4. Cont.

\begin{tabular}{|c|c|c|c|c|c|c|c|}
\hline \multirow{2}{*}{ No. } & \multirow{2}{*}{ Support Materials } & \multirow{2}{*}{ Materials for EPD } & \multirow{2}{*}{ Suspension Medium } & \multicolumn{2}{|c|}{ EPD Conditions } & \multirow{2}{*}{$\begin{array}{c}\text { Specification } \\
\text { (An optimized Condition and a Power Density) }\end{array}$} & \multirow{2}{*}{ Ref. } \\
\hline & & & & Voltage & Time & & \\
\hline 32 & LDC & LSGM & Acetone and water adding $I_{2}$ & - & - & $\begin{array}{l}\text { A maximum power density of } 780 \mathrm{~mW} \cdot \mathrm{cm}^{-2} \text { at } 700^{\circ} \mathrm{C} \\
\text { (LSGM of } 30 \mu \mathrm{m} \text {-thick) }\end{array}$ & [287] \\
\hline 33 & LDC & LSGCM & Acetone and water adding $I_{2}$ & $80 \mathrm{~V}$ & $2 \min$ & $\begin{array}{l}\text { A good degree of packing of LSGM particles in } \\
\text { suspension }\left(\mathrm{I}_{2}: 0.1 \mathrm{~g} \cdot \mathrm{L}^{-1} \text { in acetone, } \mathrm{H}_{2} \mathrm{O}: 60 \mathrm{~mL} \cdot \mathrm{L}^{-1} \text {, }\right. \\
\left.\text { powder: } 0.9 \mathrm{~g} \cdot \mathrm{L}^{-1}\right)\end{array}$ & [288] \\
\hline 34 & YSZ-BCYO & BCY10 & Acetylacetone adding $\mathrm{I}_{2}$ & $40 \mathrm{~V}$ & $5 \mathrm{~min}$ & $\begin{array}{l}\text { A maximum power density of } 174 \mathrm{~mW} \cdot \mathrm{cm}^{-2} \text { at } 650^{\circ} \mathrm{C} \\
\text { (BCYO of } 12 \mu \mathrm{m} \text {-thick) }\end{array}$ & [293] \\
\hline 35 & YSZ-BCYO & BCY10 & Acetylacetone adding $\mathrm{I}_{2}$ & $30-60 \mathrm{~V}$ & $1 \mathrm{~min}$ & $\begin{array}{l}\text { A maximum power density of } 296 \mathrm{~mW} \cdot \mathrm{cm}^{-2} \text { at } 700^{\circ} \mathrm{C} \\
(\text { EPD at } 60 \mathrm{~V} \text { for } 1 \mathrm{~min} \text { ) }\end{array}$ & [294] \\
\hline 36 & NiO-SSZ & SSZ & Acetylacetone adding $\mathrm{I}_{2}$ & $10-50 \mathrm{~V}$ & $5-50 \mathrm{~min}$ & $\begin{array}{l}\text { A maximum power density of } 1.8,1.2,0.4 \text {, and } \\
0.1 \mathrm{~W} \cdot \mathrm{cm}^{-2} \text { at } 900,800,700 \text {, and } 600^{\circ} \mathrm{C} \text {, respectively } \\
(\mathrm{BCYO} \text { of } 12 \mu \mathrm{m} \text {-thick) }\end{array}$ & [358] \\
\hline 37 & $\mathrm{NiO}-\mathrm{SDC}$ & SDC & $\begin{array}{l}\text { Mixture of acetone and ethanol } \\
(3: 1 / v: v) \text { adding } I_{2}\end{array}$ & $60 \mathrm{~V}$ & $1-3 \mathrm{~min}$ & $\begin{array}{l}\text { A maximum power density of } 155 \mathrm{~mW} \cdot \mathrm{cm}^{-2} \text { and open } \\
\text { circuit voltage of } 0.92 \mathrm{~V} \text { at } 600^{\circ} \mathrm{C}(\mathrm{EPD} \text { conditions: at } \\
60 \mathrm{~V} \text { for } 1 \mathrm{~min})\end{array}$ & [292] \\
\hline 38 & $\mathrm{NiO}-\mathrm{LCN}$ & $\mathrm{LCN}$ & $\begin{array}{l}\text { Water and acetylacetone adding } \\
\mathrm{I}_{2}\end{array}$ & $25 \mathrm{~V}$ & $2 \mathrm{~min}$ & $\begin{array}{l}\text { An electrolyte specific resistance of } 1.3 \Omega \cdot \mathrm{cm}^{2} \text { at } 800^{\circ} \mathrm{C} \\
\text { (LNC of } 10 \mu \mathrm{m} \text {-thick) }\end{array}$ & [359] \\
\hline 39 & NiO-LCN & $\mathrm{NiO}-\mathrm{LCN}$ & $\begin{array}{l}\text { Water and acetylacetone adding } \\
\mathrm{I}_{2}\end{array}$ & $25 \mathrm{~V}$ & $3 \mathrm{~min}$ & An electrolyte specific resistance of $0.16 \Omega \cdot \mathrm{cm}^{2}$ at $800^{\circ} \mathrm{C}$ & [290] \\
\hline 40 & CGO & LSCF & $\begin{array}{l}\text { Acetylacetone, ethyl alcohol, and } \\
\text { acetone adding } \\
\text { pol(vinlbutyral-co-vinyl } \\
\text { alcohol-co-vinyl acetate), and } \\
\text { phosphate ester, starch }\end{array}$ & $10-40 \mathrm{~V}$ & $1-5 \min$ & $\begin{array}{l}\text { A high uniform LSCF film at } 20 \mathrm{~V} \text { for } 2 \mathrm{~min} \text { in } \\
\text { suspension containing acetylacetone, } \mathrm{I}_{2} \text {, and starch }\end{array}$ & [285] \\
\hline 41 & T441 stainless steel & $(\mathrm{Mn}, \mathrm{Co})_{3} \mathrm{O}_{4}$ & Ethanol & $200-500 \mathrm{~V}$ & $1 \mathrm{~min}$ & $\begin{array}{l}\text { An ASR of } 17.2 \mathrm{~m} \Omega \cdot \mathrm{cm}^{2} \text { in film deposited with } 400 \mathrm{~V} \\
\text { for } 1 \mathrm{~min}\end{array}$ & [299] \\
\hline 42 & Crofer22APU & $(\mathrm{Mn}, \mathrm{Co})_{3} \mathrm{O}_{4}$ & $\begin{array}{l}\text { Mixture of ethanol and water } \\
\text { (volume ratio: } 60 / 40 \text { ) }\end{array}$ & $50 \mathrm{~V}$ & $20 \mathrm{~s}$ & An ASR of $20 \mathrm{~m} \Omega \cdot \mathrm{cm}^{2}$ at $800{ }^{\circ} \mathrm{C}$ for $1000 \mathrm{~h}$ under air & [300] \\
\hline 43 & Crofer22APU & $(\mathrm{Mn}, \mathrm{Co})_{3} \mathrm{O}_{4}$ & Acetone & $20 \mathrm{~V}$ & $1 \mathrm{~min}$ & An ASR of $17 \mathrm{~m} \Omega \cdot \mathrm{cm}^{2}$ at $800^{\circ} \mathrm{C}$ for $50 \mathrm{~h}$ under air & [301] \\
\hline 44 & PPY-coated NiO-YSZ & YSZ & $\begin{array}{l}\text { Isopropanol medium using } \\
\text { iodine, acetylacetone, and water }\end{array}$ & $15-40 \mathrm{~V}$ & $1-4 \min$ & $\begin{array}{l}\text { A maximum power density of } 0.91 \mathrm{~W} \cdot \mathrm{cm}^{-2} \text { at } 0.7 \mathrm{~V} \\
\text { (EPD conditions: at } 15 \mathrm{~V} \text { for } 1 \mathrm{~min} \text { ) }\end{array}$ & {$[55]$} \\
\hline
\end{tabular}

Yttria-stabilized zirconia (YSZ); $\mathrm{La}_{0.6} \mathrm{Sr}_{0.4} \mathrm{MnO}_{3}(\mathrm{LSM}) ; \mathrm{La}_{0.2} \mathrm{MnO}_{3 \pm d} ; \mathrm{LaMnO}_{3}(\mathrm{LDM}) ; \mathrm{La}_{0.8} \mathrm{Sr}_{0.2} \mathrm{Ga}_{0.875} \mathrm{Mg}_{0.125} \mathrm{O}_{3-x}\left(\mathrm{LSGM}_{2}\right) \mathrm{La}_{0.8} \mathrm{Sr}_{02} \mathrm{Co}_{0.2} \mathrm{Fe}_{0.8} \mathrm{O}_{3-\delta}\left(\mathrm{LSCF}_{2}\right) ;\left(\mathrm{Ce}_{0.8} \mathrm{Gd}_{0.2}\right) \mathrm{O}_{1.9}(\mathrm{CGO}) ;$

$\mathrm{La}_{0.4} \mathrm{Ce}_{0.6} \mathrm{O}_{2-x}(\mathrm{LDC}) ; \mathrm{La}_{0.8} \mathrm{Sr}_{0.2} \mathrm{Ga}_{0.8} \mathrm{Mg}_{0.115} \mathrm{Co}_{0.085} \mathrm{O}_{3-\delta}$ (LSGCM); $\mathrm{BaCe}_{0.9} \mathrm{Y}_{0.1} \mathrm{O}_{3-x}(\mathrm{BCY} 10) ; \mathrm{Zr}(\mathrm{Sc}) \mathrm{O}_{2}$ (SSZ); $\mathrm{Sm}_{0.2} \mathrm{Ce}_{0.8} \mathrm{O}_{1.9}(\mathrm{SDC}) ; \mathrm{La}_{0.995} \mathrm{Ca}_{0.005} \mathrm{NbO}_{4}(\mathrm{LCN})$. 
Table A5. Overview of the electrocatalysts fabricated by EPD showing the nanomaterials for electrocatalysis and EPD conditions investigated.

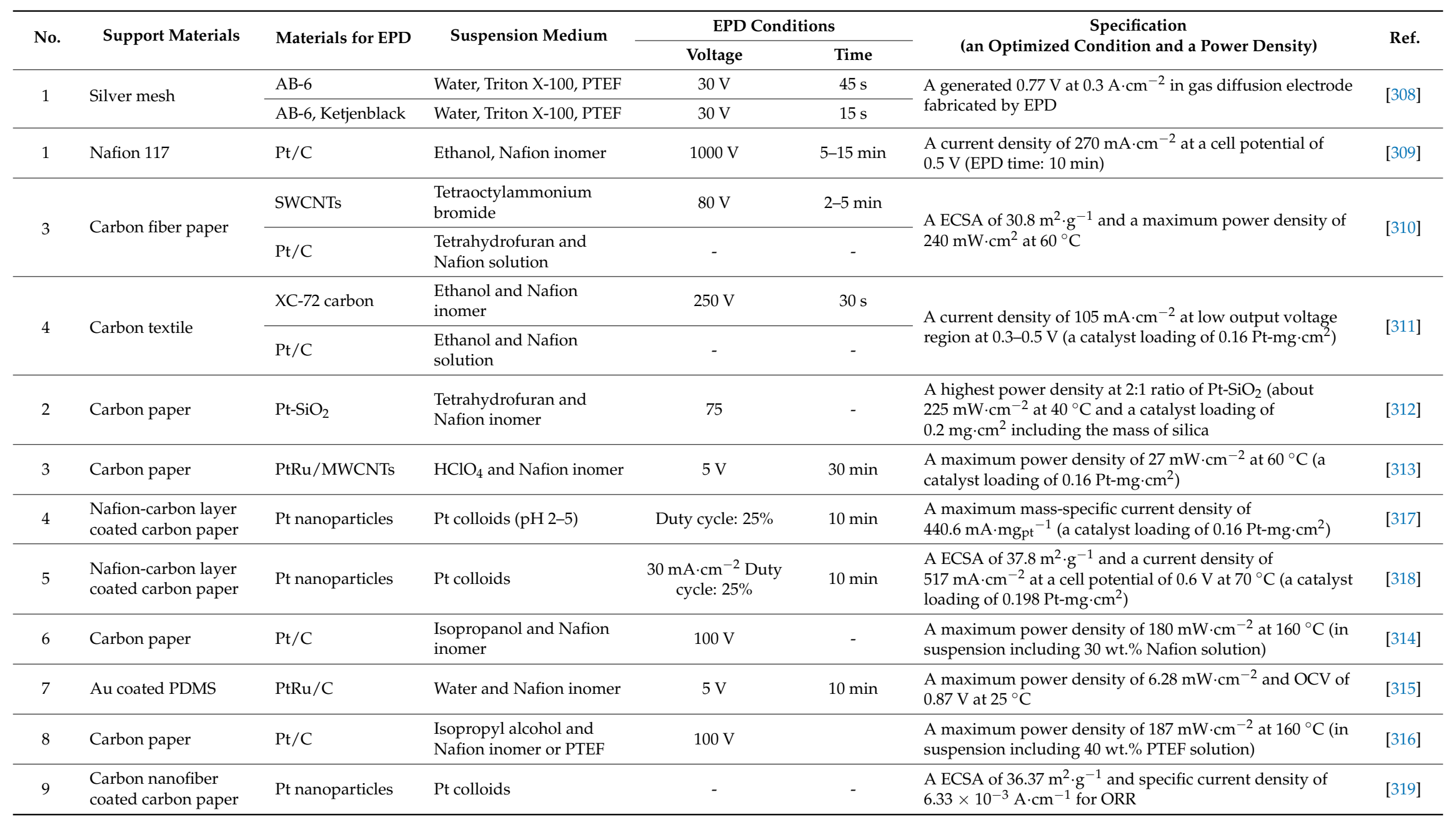


Table A5. Cont.

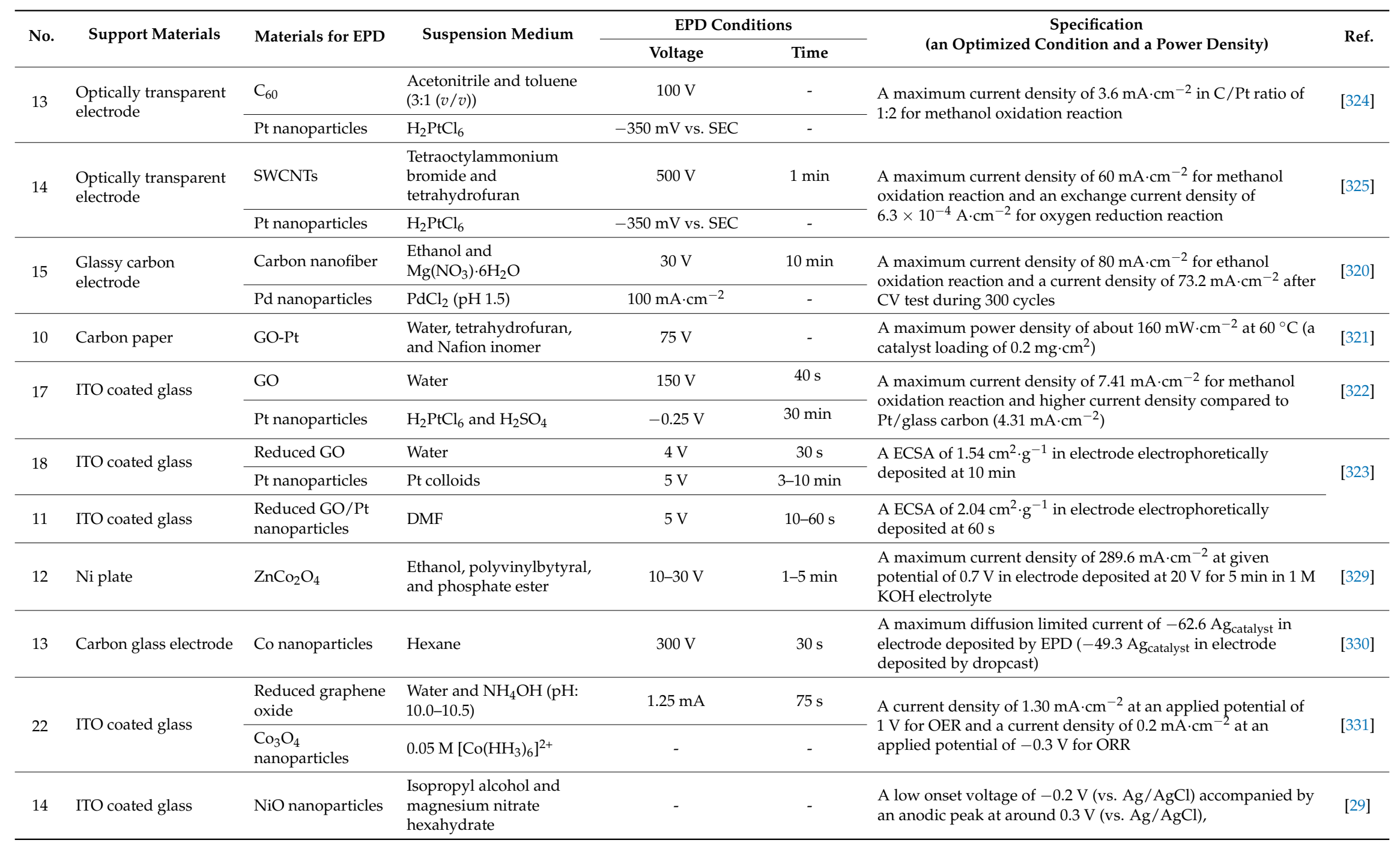




\section{References}

1. Dunn, B.; Kamath, H.; Tarascon, J.-M. Electrical Energy Storage for the Grid: A Battery of Choices. Science 2011, 334, 928-935. [CrossRef] [PubMed]

2. Armand, M.; Tarascon, J.-M. Building better batteries. Nature 2008, 451, 652-657. [CrossRef] [PubMed]

3. Bruce, P.G.; Freunberger, S.A.; Hardwick, L.J.; Tarascon, J.-M. Li-O $\mathrm{O}_{2}$ and Li-S batteries with high energy storage. Nat. Mater. 2012, 11, 19-29. [CrossRef] [PubMed]

4. Larcher, D.; Tarascon, J.-M. Towards greener and more sustainable batteries for electrical energy storage. Nat. Chem. 2015, 7, 19-29. [CrossRef] [PubMed]

5. Bruce, P.G.; Scrosati, B.; Tarascon, J.-M. Nanomaterials for Rechargeable Lithium Batteries. Angezw. Chem. Int. Ed. 2008, 47, 2930-2946. [CrossRef] [PubMed]

6. Tarascon, J.M.; Armand, M. Issues and challenges facing rechargeable lithium batteries. Nature 2011, 414, 359-367. [CrossRef] [PubMed]

7. Goodenough, J.B.; Kim, Y.S. Challenges for Rechargeable Li Batteries. Chem. Mater. 2010, 22, 587-603. [CrossRef]

8. Scrosati, B.; Hassoun, J.; Sun, Y.-K. Lithium-ion batteries. A look into the future. Energy Environ. Sci. 2011, 4, 3287-3295. [CrossRef]

9. Etacheri, V.; Marom, R.; Elazari, R.; Salitra, G.; Aurbach, D. Challenges in the development of advanced Li-ion batteries: A review. Energy Environ. Sci. 2011, 4, 3243-3262. [CrossRef]

10. Wang, H.; Dai, H. Strongly coupled inorganic-nano-carbon hybrid materials for energy storage. Chem. Soc. Rev. 2013, 42, 3088-3113. [CrossRef] [PubMed]

11. Simon, P.; Gogotsi, Y. Materials for electrochemical capacitors. Nat. Mater. 2008, 7, 845-854. [CrossRef] [PubMed]

12. Wang, G.; Zhang, L.; Zhang, J. A review of electrode materials for electrochemical supercapacitors. Chem. Soc. Rev. 2012, 41, 797-828. [CrossRef] [PubMed]

13. Cao, X.; Yin, Z.; Zhang, H. Three-dimensional graphene materials: Preparation, structures and application in supercapacitors. Energy Environ. Sci. 2014, 7, 1850-1865. [CrossRef]

14. Yu, Z.; Tetard, L.; Zhai, L.; Thomas, J. Supercapacitor electrode materials: Nanostructures from 0 to 3 dimensions. Energy Environ. Sci. 2015, 8, 702-730. [CrossRef]

15. Kou, R.; Shao, Y.; Mei, D.; Nie, Z.; Wang, D.; Wang, C.; Viswanathan, V.V.; Park, S.H.; Aksay, I.A.; Lin, Y.; et al. Stabilization of Electrocatalytic Metal Nanoparticles at Metal-Metal Oxide-Graphene Triple Junction Points. J. Am. Chem. Soc. 2011, 133, 2541-2547. [CrossRef] [PubMed]

16. Lin, J.; Peng, Z.; Wang, G.; Zakhidov, D.; Larios, E.; Yacaman, M.J.; Tour, J.M. Enhanced Electrocatalysis for Hydrogen Evolution Reactions from $\mathrm{WS}_{2}$ Nanoribbons. Adv. Energy Mater. 2014, 4, 1301875. [CrossRef]

17. Mengmeng, Z.; Rong, L.; Xiaoxuan, C.; Chao, X.; Xinglong, G. Hybrid of porous cobalt oxide nanospheres and nitrogen-doped graphene for applications in lithium-ion batteries and oxygen reduction reaction. J. Power Sources 2015, 290, 25-34.

18. Gnana kumar, G.; Christy, M.; Jang, H.S.; Nahm, K.S. Cobaltite oxide nanosheets anchored graphene nanocomposite as an efficient oxygen reduction reaction (ORR) catalyst for the application of lithium-air batteries. J. Power Sources 2015, 288, 451-460. [CrossRef]

19. Liu, N.; Lu, Z.; Zhao, J.; McDowell, M.T.; Lee, H.W.; Zhao, W.; Cui, Y. A pomegranate-inspired nanoscale design for large-volume-change lithium battery anodes. Nat. Nanotechnol. 2014, 9, 187-192. [CrossRef] [PubMed]

20. Liqiang, M.; Xiaocong, T.; Xu, X.; Liang, C.; Lin, X. Nanowire Electrodes for Electrochemical Energy Storage Devices. Chem. Rev. 2014, 114, 11828-11862.

21. Islam, M.S.; Fisher, C.A.J. Lithium and sodium battery cathode materials: Computational insights into voltage, diffusion and nanostructural properties. Chem. Soc. Rev. 2014, 43, 185-204. [CrossRef] [PubMed]

22. Roberts, A.D.; Li, X.; Zhang, H. Porous carbon spheres and monoliths: Morphology control, pore size tuning and their applications as Li-ion battery anode materials. Chem. Soc. Rev. 2014, 43, 4341-4356. [CrossRef] [PubMed]

23. Ding, D.; Li, X.; Lai, S.Y.; Gerdesb, K.; Liu, M. Enhancing SOFC cathode performance by surface modification through infiltration. Energy Environ. Sci. 2014, 7, 552-575. [CrossRef] 
24. Ding, X.; Yin, S.; An, K.; Luo, L.; Shi, N.; Qiang, Y.; Pasupathi, S.; Pollet, B.G.; Shen, P.K. FeN stabilized FeN@Pt core-shell nanostructures for oxygen reduction reaction. J. Mater. Chem. A 2015, 3, 4462-4469. [CrossRef]

25. Wang, Z.; Shemilt, J.; Xiao, P. Fabrication of ceramic composite coatings using electrophoretic deposition, reaction bonding and low temperature sintering. J. Eur. Ceram. Soc. 2002, 22, 183-189. [CrossRef]

26. Yang, Y.; Li, J.; Chen, D.; Zhao, J. A Facile Electrophoretic Deposition Route to the $\mathrm{Fe}_{3} \mathrm{O}_{4} / \mathrm{CNTs} / \mathrm{rGO}$ Composite Electrode as a Binder-Free Anode for Lithium Ion Battery. ACS Appl. Mater. Interfaces 2016, 8 , 26730-26739. [CrossRef] [PubMed]

27. Zhitomirsky, I. Electrophoretic hydroxyapatite coatings and fibers. Mater. Lett. 2000, 42, 262-271. [CrossRef]

28. Ishihara, T.; Sato, K.; Takita, Y. Electrophoretic Deposition of $\mathrm{Y}_{2} \mathrm{O}_{3}$-Stabilized $\mathrm{ZrO}_{2}$ Electrolyte Films in Solid Oxide Fuel Cells. J. Am. Ceram. Soc. 1996, 79, 913-919. [CrossRef]

29. Daryakenari, A.A.; Hosseini, D.; Ho, Y.L.; Saito, T.; Apostoluk, A.; Muller, C.R.; Delaunay, J.J. Single-Step Electrophoretic Deposition of Non-noble Metal Catalyst Layer with Low Onset Voltage for Ethanol Electro-oxidation. ACS Appl. Mater. Interfaces 2016, 8, 15975-15984. [CrossRef] [PubMed]

30. Kanamura, K.; Goto, A.; Rho, Y.O.; Umegaki, T. Electrophoretic fabrication of $\mathrm{LiCoO}_{2}$ positive electrodes for rechargeable lithium batteries. J. Power Sources 2001, 97-98, 294-297. [CrossRef]

31. Xia, X.; Tu, J.; Mai, Y.; Chen, R.; Wang, X.; Gu, C.; Zhao, X. Graphene Sheet/Porous NiO Hybrid Film for Supercapacitor Applications. Chem. Eur. J. 2011, 17, 10898-10905. [CrossRef] [PubMed]

32. Wu, M.S.; Lin, Y.P.; Lin, C.H.; Lee, J.T. Formation of nano-scaled crevices and spacers in NiO-attached graphene oxide nanosheets for supercapacitors. J. Mater. Chem. 2012, 22, 2442-2448. [CrossRef]

33. Sarkar, P.; Nicholson, P.S. Electrophoretic Deposition (EPD): Mechanisms, Kinetics, and Application to Ceramics. J. Am. Ceram. Soc. 1996, 79, 1987-2002. [CrossRef]

34. Besra, L.; Liu, M. A review on fundamentals and applications of electrophoretic deposition (EPD). Prog. Mater. Sci. 2007, 51, 1-61. [CrossRef]

35. Gani, M.S. Electrophoretic Deposition-A Review. Ind. Ceram. 1994, 14, 163-174.

36. Corni, I.; Ryan, M.P.; Bccaccini, A.R. Electrophoretic deposition: From traditional ceramics to nanotechnology. J. Eur. Ceram. Soc. 2008, 28, 1353-1367. [CrossRef]

37. Boccaccini, A.R.; Roether, J.A.; Thomas, B.J.C.; Shaffer, M.S.P.; Chavez, E.; Stoll, E. Electrophoretic deposition of carbon nanotubes. Carbon 2006, 44, 3149-3160. [CrossRef]

38. An, Q.; Rider, A.N.; Thostenson, E.T. Electrophoretic deposition of carbon nanotubes onto carbon-fiber fabric for production of carbon/epoxy composites with improved mechanical properties. Carbon 2012, 50, 4130-4143. [CrossRef]

39. Kanamura, K.; Hamagami, J. Innovation of novel functional material processing technique by using electrophoretic deposition process. Solid State Ion. 2004, 172, 303-308. [CrossRef]

40. Zhitomirsky, I. Cathodic electrodeposition of ceramic and organoceramic materials. Fundamental aspects. Adv. Colloid Interface Sci. 2002, 97, 279-317. [CrossRef]

41. Van der Biest, O.O.; Van der perre, L.J. Electrophoretic Deposition of Materials. Annu. Rev. Mater. Sci. 1999, 29, 327-352. [CrossRef]

42. Fukada, Y.; Nagarajan, N.; Mekky, W.; Bao, Y.; Kim, H.S.; Nicholson, P. Electrophoretic deposition-Mechanisms, myths and materials. J. Mater. Sci. 2004, 39, 787-801. [CrossRef]

43. Hamaker, H.C. Formation of a deposit by electrophoresis. Trans. Faraday Soc. 1940, 35, 279-287. [CrossRef]

44. Hamaker, H.C.; Verwey, E.J.W. Part II.-(C) Colloid stability. The role of the forces between the particles in electrodeposition and other phenomena. Trans. Faraday Soc. 1940, 36, 180-185. [CrossRef]

45. Hanaor, D.; Michelazzi, M.; Leonelli, C.; Sorrell, C.C. The effects of carboxylic acids on the aqueous dispersion and electrophoretic deposition of $\mathrm{ZrO}_{2}$. J. Eur. Ceram. Soc. 2012, 32, 235-244. [CrossRef]

46. Grillon, F.; Fayeulle, D.; Jeandin, M. Quantitative image analysis of electrophoretic coatings. J. Mater. Sci. Lett. 1992, 11, 272-275. [CrossRef]

47. Brown, D.R.; Salt, F.W. The mechanism of electrophoretic deposition. J. Appl. Chem. 1965, 15, 40-48. [CrossRef]

48. Koelmans, H. Suspensions in non-aqueous media. Philips Res. Rep. 1955, 10, 161-193.

49. Cannio, M.; Novak, S.; Besra, L.; Boccaccini, A.R. Electrophoretic Deposition. In Ceramics and Composites Processing Methods; Bansal, N.P., Boccaccini, A.R., Eds.; Bansal/Ceramics Composites Processing: New York, NY, USA, 2012. 
50. Ammam, M. Electrophoretic deposition under modulated electric fields: A review. RSC Adv. 2012, 2, 7633-7646. [CrossRef]

51. Velev, O.D.; Bhatt, K.H. On-chip micromanipulation and assembly of colloidal particles by electric fields. Soft Matter 2006, 2, 738-750. [CrossRef]

52. Kim, K.; Nakayama, Y.; Yamamoto, R. Direct Numerical Simulations of Electrophoresis of Charged Colloids. Phys. Rev. Lett. 2006, 96, 208302. [CrossRef] [PubMed]

53. Dickerson, J.H.; Boccaccini, A.F. Electrophoretic Deposition of Nanomaterials; Springer: New York, NY, USA, 2012; pp. 3-71.

54. Minor, M.; Linde, A.J.; Leeuwen, H.P.; Lyklema, J. Dynamic Aspects of Electrophoresis and Electroosmosis: A New Fast Method for Measuring Particle Mobilities. J. Colloid Interface Sci. 1997, 189, 370-375. [CrossRef]

55. Biesheuvel, P.M.; Verweij, H. Theory of Cast Formation in Electrophoretic Deposition. J. Am. Ceram. Soc. 1999, 82, 1451-1455. [CrossRef]

56. Ferrari, B.; Moreno, R. EPD kinetics: A review. J. Eur. Ceram. Soc. 2010, 30, 1069-1078. [CrossRef]

57. Zhang, Z.; Huang, Y.; Jiang, Z. Electrophoretic Deposition Forming of SiC-TZP Composites in a Nonaqueous Sol Media. J. Am. Ceram. Soc. 1994, 77, 1946-1949. [CrossRef]

58. Anné, G.; Vanmeensel, K.; Vleugels, J.; Van der Biest, O. Influence of the suspension composition on the electric field and deposition rate during electrophoretic deposition. Colloid Surf. A Phys. Eng. Asp. 2004, 245, 35-39. [CrossRef]

59. Ma, J.; Cheng, W. Electrophoretic Deposition of Lead Zirconate Titanate Ceramics. J. Am. Ceram. Soc. 2002, 85, 1735-1737. [CrossRef]

60. Anné, G.; Vanmeensel, K.; Vleugels, J.; Van der Biest, O. A Mathematical Description of the Kinetics of the Electrophoretic Deposition Process for $\mathrm{Al}_{2} \mathrm{O}_{3}$-Based Suspensions. J. Am. Ceram. Soc. 2005, 88, 2036-2039. [CrossRef]

61. Ferrari, B.; Moreno, R.; Cuesta, J. A resistivity model for electrophoretic deposition. Key Eng. Mater. 2006, 314, 175-180. [CrossRef]

62. Zarbov, M.; Schuster, I.; Gal-Or, L. Methodology for selection of charging agents for electrophoretic deposition of ceramic particles. J. Mater. Sci. 2004, 39, 813-817. [CrossRef]

63. Heavens, N. Electrophoretic deposition as a processing route for ceramics. In Advanced Ceramic Processing and Technology; Binner, G.P., Ed.; Noyes Publications: Park Ridge, NJ, USA, 1990; Volume 1, pp. $255-283$.

64. Ferrari, B.; Moreno, $\mathrm{R}$. The conductivity of aqueous $\mathrm{Al}_{2} \mathrm{O}_{3}$ slips for electrophoretic deposition. Mater. Lett. 1996, 28, 353-355. [CrossRef]

65. Li, Y.; Song, J.; Yang, J. A review on structure model and energy system design of lithium-ion battery in renewable energy vehicle. Renew. Sustain. Energ. Rev. 2014, 37, 627-633. [CrossRef]

66. Dunn, J.B.; Gaines, L.; Kelly, J.C.; James, C.; Gallagher, K.G. The significance of Li-ion batteries in electric vehicle life-cycle energy and emissions and recycling's role in its reduction. Energy Environ. Sci. 2015, 8, 158-168. [CrossRef]

67. Thackeray, M.M.; Wolverton, C.; Isaacs, E.D. Electrical energy storage for transportation-approaching the limits of, and going beyond, lithium-ion batteries. Energy Environ. Sci. 2012, 5, 7854-7863. [CrossRef]

68. Das, D.; Basu, R.N. Electrophoretic Deposition of Zirconia Thin Film on Nonconducting Substrate for Solid Oxide Fuel Cell Application. J. Am. Ceram. Soc. 2014, 97, 3452-3457. [CrossRef]

69. Hod, I.; Bury, W.; Karlin, D.M.; Deria, P.; Kung, C.W.; Katz, M.J.; So, M.; Klahr, B.; Jin, D.; Chung, Y.W.; et al. Directed growth of electroactive metal-organic framework thin films using electrophoretic deposition. Adv. Mater. 2014, 26, 6295-6300. [CrossRef] [PubMed]

70. Xu, J.J.; Wang, Z.L.; Xu, D.; Zhang, L.L.; Zhang, X.B. Tailoring deposition and morphology of discharge products towards high-rate and long-life lithium-oxygen batteries. Nat. Commun. 2013, 4, 3438. [CrossRef] [PubMed]

71. Ellis, B.L.; Lee, K.T.; Nazar, L.F. Positive Electrode Materials for Li-Ion and Li-Batteries. Chem. Mater. 2010, 22, 691-714. [CrossRef]

72. Pitchai, R.; Thavasi, V.; Mhaisalkar, S.G.; Ramakrishna, S. Nanostructured cathode materials: A key for better performance in Li-ion batteries. J. Mater. Chem. 2011, 21, 11040-11051. [CrossRef]

73. Whittingham, M.S. Lithium Batteries and Cathode Materials. Chem. Rev. 2004, 104, 4271-4301. [CrossRef] [PubMed] 
74. Kanamura, K.; Goto, A.; Hamagami, J.; Umegaki, T. Electrophoretic Fabrication of Positive Electrodes for Rechargeable Lithium Batteries. Electrochem. Solid-State Lett. 2000, 3, 259-262. [CrossRef]

75. Caballero, A.; Hernan, L.; Melero, M.; Morales, J.; Moreno, R.; Ferrari, N. LiNi ${ }_{0.5} \mathrm{Mn}_{1.5} \mathrm{O}_{4}$ thick-film electrodes prepared by electrophoretic deposition for use in high voltage lithium-ion batteries. J. Power Sources 2006, 158, 583-590. [CrossRef]

76. Ferrari, B.; Moreno, R.; Hernan, L.; Melero, M.; Morales, J.; Caballero, A. EPD of thick films for their application in lithium batteries. J. Eur. Ceram. Soc. 2007, 27, 3823-3827. [CrossRef]

77. Prasanna, L.; Subburaj, T.; Jo, Y.N.; Lee, C.W. Optimization of electrophoretic suspension to fabricate $\mathrm{Li}\left[\mathrm{Ni}_{1 / 3} \mathrm{Co}_{1 / 3} \mathrm{Mn}_{1 / 3}\right] \mathrm{O}_{2}$ based positive electrode for Li-ion batteries. Electrochim. Acta 2013, 95, 295-300. [CrossRef]

78. Park, J.H.; Lu, W.; Sastry, A.M. Erratum: Numerical Simulation of Stress Evolution in Lithium Manganese Dioxide Particles due to Coupled Phase Transition and Intercalation. J. Electrochem. Soc. 2011, 158, A201-A206. [CrossRef]

79. Peabody, C.; Arnold, C.B. The role of mechanically induced separator creep in lithium-ion battery capacity fade. J. Power Sources 2011, 196, 8147-8153. [CrossRef]

80. Hu, L.H.; Wu, F.Y.; Lin, C.T.; Khlobystov, A.N.; Li, L.J. Graphene-modified $\mathrm{LiFePO}_{4}$ cathode for lithium ion battery beyond theoretical capacity. Nat. Commun. 2013, 4, 1687-1692. [CrossRef] [PubMed]

81. Mak, K.F.; McGill, K.L.; Park, J.; McEuen, P.L. The valley Hall effect in $\mathrm{MoS}_{2}$ transistors. Science 2014, 344, 1489-1492. [CrossRef] [PubMed]

82. Nair, S.P.; Jyothsna, U.; Praveen, P.; Balakrishnan, A.; Subramanian, K.R.V.; Nair, S.V.; Sivakumar, N. Synthesis and Characterization of Electrophoretically Deposited Nanostructured $\mathrm{LiCoPO}_{4}$ for Rechargeable Lithium Ion Batteries. ISRN Nanotechnol. 2013, 2013, 653237.

83. Zhou, Y.N.; Xue, M.Z.; Fu, Z.W. Nanostructured thin film electrodes for lithium storage and all-solid-state thin-film lithium batteries. J. Power Sources 2013, 234, 310-332. [CrossRef]

84. Patil, A.; Patil, V.; Shin, D.W.; Choi, J.W.; Paik, D.S.; Yoon, S.J. Issue and challenges facing rechargeable thin film lithium batteries. Mater. Res. Bull. 2008, 43, 1913-1942. [CrossRef]

85. Dudney, N.J. Addition of a thin-film inorganic solid electrolite (Lipon) as a protective film in lithium batteries with a liquid electrolyte. J. Power Sources 2000, 89, 176-179. [CrossRef]

86. Dudney, N.J.; Jang, Y.I. Analysis of thin-film lithium batteries with cathodes of $50 \mathrm{~nm}$ to $4 \mu \mathrm{m}$ thick $\mathrm{LiCoO}_{2}$. J. Power Sources 2003, 119-121, 300-304. [CrossRef]

87. Dudney, N.J. Solid-state thin-film rechargeable batteries. Mater. Sci. Eng. B 2005, 116, 245-249. [CrossRef]

88. Quan, Z.; Iwase, K.; Sonoyama, N. Synthesis and electrochemical property of $\mathrm{LiCoO}_{2}$ thin films composed of nanosize compounds synthesized via nanosheet restacking method. J. Power Sources 2011, 196, 6762-6767. [CrossRef]

89. Mazor, H.; Golodnitsky, D.; Burstein, L.; Gladkich, A.; Peled, E. Electrophoretic deposition of lithium iron phosphate cathode for thin-film 3D-microbatteries. J. Power Sources 2012, 198, 264-272. [CrossRef]

90. Grijalva, H.; Inoue, N.; Boggabarapu, S.; Calvet, P. Amorphous and crystalline copper sulfides, CuS. J. Mater. Chem. 1996, 6, 1157-1160. [CrossRef]

91. Huang, Y.; Liu, H.; Lu, Y.C.; Hou, Y.; Li, Q. Electrophoretic lithium iron phosphate/reduced graphene oxide composite for lithium ion battery cathode application. J. Power Sources 2015, 284, 236-244. [CrossRef]

92. Yang, Y.; Chen, D.; Liu, B.; Zhao, J. Binder-Free Si Nanoparticle Electrode with 3D Porous Structure Prepared by Electrophoretic Deposition for Lithium-Ion Batteries. ACS Appl. Mater. Interfaces 2015, 7, 7497-7504. [CrossRef] [PubMed]

93. Kamat, P.V.; Thomas, K.G.; Barazzouk, S.; Girishcumar, G.; Vinodgopal, K.; Meisel, D. Self-Assembled Linear Bundles of Single Wall Carbon Nanotubes and Their Alignment and Deposition as a Film in a dc Field. J. Am. Chem. Soc. 2004, 126, 10757-10762. [CrossRef] [PubMed]

94. Zhu, Q.G.; Sujari, A.N.; Ghani, S.S. MWCNT Modified Composite Pencil Graphite Electrodes Fabricated by Direct Dripping and Electrophoretic Deposition Methods: A Comparison Study. J. Electrochem. Soc. 2013, 160, B23-B29. [CrossRef]

95. Ata, M.S.; Sun, Y.; Li, X.; Zhitomirsky, I. Electrophoretic deposition of graphene, carbon nanotubes and composites using aluminon as charging and film forming agent. Colloid Surf. A Physicochem. Eng. Asp. 2012, 398, 9-16. [CrossRef] 
96. Ui, K.; Minami, T.; Ishikawa, K.; Idemoto, Y.; Koura, N. Development of non-flammable lithium secondary battery with ambient-temperature molten salt electrolyte-Performance of binder-free carbon-negative electrode. J. Power Sources 2005, 146, 698-702. [CrossRef]

97. Chavez-Valdez, A.; Shaffer, M.S.P.; Boccaccini, A.R. Applications of Graphene Electrophoretic Deposition. A Review. J. Phys. Chem. B 2013, 117, 1502-1515. [CrossRef] [PubMed]

98. Lu, Y.; Zhang, D.; Wang, L.; Xu, M.; Song, J.; Goodenough, J.B. Electrochemical behavior of a graphite electrode prepared by anodic electrophoretic deposition. J. Electrochem. Soc. 2012, 159, A321-A324. [CrossRef]

99. Verma, P.; Maire, P.; Novak, P. A review of the features and analyses of the solid electrolyte interphase in Li-ion batteries. Electrochim. Acta 2010, 55, 6323-6932. [CrossRef]

100. Read, J.A.; Cresce, A.V.; Ervin, M.H.; Xu, K. Dual-graphite chemistry enabled by a high voltage electrolyte. Energy Environ. Sci. 2014, 7, 617-620. [CrossRef]

101. Wang, F.; Yi, J.; Wang, Y.; Wang, C.; Wang, J.; Xia, Y. Graphite Intercalation Compounds (GICs): A New Type of Promising Anode Material for Lithium-Ion Batteries. Adv. Energy Mater. 2014, 4, 1300600. [CrossRef]

102. Edström, K.; Herstedt, M.; Abraham, D.P. A new look at the solid electrolyte interphase on graphite anodes in Li-ion batteries. J. Power Sources 2006, 153, 380-384. [CrossRef]

103. Ushirogata, K.; Sodeyama, K.; Okuno, Y.; Tateyama, Y. Additive Effect on Reductive Decomposition and Binding of Carbonate-Based Solvent toward Solid Electrolyte Interphase Formation in Lithium-Ion Battery. J. Am. Chem. Soc. 2013, 135, 11967-11974. [CrossRef] [PubMed]

104. Xu, K.; Cresce, A. Interfacing electrolytes with electrodes in Li ion batteries. J. Mater. Chem. 2011, 21, 9849-9864. [CrossRef]

105. Nie, M.; Chalasani, D.; Abraham, D.P.; Chen, Y.; Bose, A.; Lucht, B.L. Lithium Ion Battery Graphite Solid Electrolyte Interphase Revealed by Microscopy and Spectroscopy. J. Phys. Chem. C 2013, 117, 1257-1267. [CrossRef]

106. Kang, S.H.; Abraham, D.P.; Xiao, A.; Lucht, B.L. Investigating the solid electrolyte interphase using binder-free graphite electrodes. J. Power Sources 2008, 175, 526-532. [CrossRef]

107. Xiao, A.; Yang, L.; Lucht, B.L.; Kang, S.H.; Abraham, D.P. Examining the Solid Electrolyte Interphase on Binder-Free Graphite Electrodes. J. Electrochem. Soc. 2009, 156, A318-A327. [CrossRef]

108. Nie, M.; Lucht, B.L. Role of Lithium Salt on Solid Electrolyte Interface (SEI) Formation and Structure in Lithium Ion Batteries. J. Electrochem. Soc. 2014, 161, A1001-A1006. [CrossRef]

109. Bolotin, K.I.; Sikes, K.J.; Hone, J.; Stormer, H.L.; Kim, P. Temperature-Dependent Transport in Suspended Graphene. Phys. Rev. Lett. 2008, 101, 096802. [CrossRef] [PubMed]

110. Liao, L.; Lin, Y.C.; Bao, M.Q.; Cheng, R.; Bai, J.W.; Liu, Y.A.; Qu, Y.Q.; Wang, K.L.; Huang, Y.; Duan, X.F. High speed graphene transistors with a self-aligned nanowire gate. Nature 2010, 467, 305-308. [CrossRef] [PubMed]

111. Balandin, A.A.; Ghosh, S.; Bao, W.Z.; Calizo, I.; Teweldebrhan, D.; Miao, F.; Lau, C.N. Superior Thermal Conductivity of Single-Layer Graphene. Nano Lett. 2008, 8, 902-907. [CrossRef] [PubMed]

112. Lee, C.; Wei, X.D.; Kysar, J.W.; Hone, J. Measurement of the elastic properties and intrinsic strength of monolayer graphene. Science 2008, 321, 385-388. [CrossRef] [PubMed]

113. Park, S.; Ruoff, R.S. Chemical methods for the production of graphenes. Nat. Nanotechnol. 2009, 4, $217-224$. [CrossRef] [PubMed]

114. Dreyer, D.R.; Park, S.; Bielawski, C.W.; Ruoff, R.S. The chemistry of graphene oxide. Chem. Soc. Rev. 2010, 39, 228-240. [CrossRef] [PubMed]

115. Lee, S.H.; Seo, S.D.; Park, K.S.; Shim, H.W.; Kim, E.W. Synthesis of graphene nanosheets by the electrolytic exfoliation of graphite and their direct assembly for lithium ion battery anodes. Mater. Chem. Phys. 2012, 135, 309-316. [CrossRef]

116. Seo, S.D.; Gwang, I.S.; Lee, S.H.; Shim, H.W.; Kim, D.W. 1D/2D carbon nanotube/graphene nanosheet composite anodes fabricated using electrophoretic assembly. Ceram. Int. 2012, 38, 3017-3021. [CrossRef]

117. Zhu, X.; Zhu, Y.; Murali, S.; Stoller, M.D.; Ruoff, R.S. Nanostructured Reduced Graphene Oxide $/ \mathrm{Fe}_{2} \mathrm{O}_{3}$ Composite As a High-Performance Anode Material for Lithium Ion Batteries. ACS Nano 2011, 5, 3333-3338. [CrossRef] [PubMed]

118. Zhou, W.; Zhu, J.; Cheng, C.; Liu, J.; Yang, H.; Cong, C.; Guan, C.; Jia, X.; Fan, H.J.; Yan, Q.; et al. A general strategy toward graphene@metal oxide core-shell nanostructures for high-performance lithium storage. Energy Environ. Sci. 2011, 4, 4954-4961. [CrossRef] 
119. Wang, D.; Yang, J.; Li, X.; Geng, D.; Li, R.; Cai, M.; Sham, T.K.; Sun, X. Layer by layer assembly of sandwiched graphene $/ \mathrm{SnO}_{2}$ nanorod/carbon nanostructures with ultrahigh lithium ion storage properties. Energy Environ. Sci. 2013, 6, 2900-2906. [CrossRef]

120. Kang, W.; Tang, Y.; Li, W.; Li, Z.; Yang, X.; Xu, J.; Lee, C.S. Porous $\mathrm{CuCo}_{2} \mathrm{O}_{4}$ nanocubes wrapped by reduced graphene oxide as high-performance lithium-ion battery anodes. Nanoscale 2014, 6, 6551-6556. [CrossRef] [PubMed]

121. Hu, T.; Sun, X.; Sun, H.; Yu, M.; Lu, F.; Liu, C.; Lian, J. Flexible free-standing graphene-TiO ${ }_{2}$ hybrid paper for use as lithium ion battery anode materials. Carbon 2013, 51, 322-326. [CrossRef]

122. Cai, D.; Yang, T.; Liu, B.; Wang, D.; Liu, Y.; Wang, L.; Li, Q.; Wang, T. A nanocomposite of tin dioxide octahedral nanocrystals exposed to high-energy facets anchored onto graphene sheets for high performance lithium-ion batteries. J. Mater. Chem. A 2014, 2, 13990-13995. [CrossRef]

123. Binotto, G.; Larcher, D.; Prakash, A.S.; Urbina, R.H.; Hegde, M.S. Synthesis, Characterization, and Li-Electrochemical Performance of Highly Porous $\mathrm{Co}_{3} \mathrm{O}_{4}$ Powders. Chem. Mater. 2007, 19, 3032-3040. [CrossRef]

124. Kang, B.W.; Ceder, G. Battery materials for ultrafast charging and discharging. Nature 2009, 458, $190-193$. [CrossRef] [PubMed]

125. Poizot, P.; Laruelle, S.; Grugeon, S.; Dupont, L. Nano-sized transition-metal oxides as negative-electrode materials for lithium-ion batteries. Nature 2000, 407, 496-499. [CrossRef] [PubMed]

126. Taberna, P.L.; Mitra, S.; Poizot, P.; Simon, P.; Tarascon, J.M. High rate capabilities $\mathrm{Fe}_{3} \mathrm{O}_{4}$-based $\mathrm{Cu}$ nano-architectured electrodes for lithium-ion battery applications. Nat. Mater. 2006, 5, 567-573. [CrossRef] [PubMed]

127. Sun, H.; Xin, G.; Hu, T.; Yu, M.; Shao, D.; Sun, X.; Lian, J. High-rate lithiation-induced reactivation of mesoporous hollow spheres for long-lived lithium-ion batteries. Nat. Commun. 2014, 5, 4526. [CrossRef] [PubMed]

128. Cabana, J.; Monconduit, L.; Larcher, D.; Palacín, M.R. Beyond intercalation-based Li-ion batteries: The state of the art and challenges of electrode materials reacting through conversion reactions. Adv. Mater. 2010, 22, E170-E192. [CrossRef] [PubMed]

129. Zhang, J.; Wang, K.; Xu, Q.; Zhou, Y.; Cheng, F.; Guo, S. Beyond yolk-shell nanoparticles: $\mathrm{Fe}_{3} \mathrm{O}_{4} @ \mathrm{Fe}_{3} \mathrm{C}$ core@shell nanoparticles as yolks and carbon nanospindles as shells for efficient lithium ion storage. ACS Nano 2015, 9, 3369-3376. [CrossRef] [PubMed]

130. Wang, J.; Yang, N.; Tang, H.; Dong, Z.; Jin, Q.; Yang, M.; Kisailus, D.; Zhao, H.; Tang, Z.; Wang, D. Accurate control of multishelled $\mathrm{Co}_{3} \mathrm{O}_{4}$ hollow microspheres as high-performance anode materials in lithium-ion batteries. Angew. Chem. 2013, 125, 6545-6548. [CrossRef]

131. Dillon, A.C.; Hahan, A.H.; Deshpande, R.; Parilla, P.A.; Jones, K.M.; Lee, S.H. Metal oxide nano-particles for improved electrochromic and lithium-ion battery technologies. Thin Solid Films 2008, 516, 794-797. [CrossRef]

132. Lee, S.H.; Deshpande, R.; Parilla, P.A.; Jones, K.M.; To, B.; Mahan, A.H.; Dillon, A.C. Crystalline $\mathrm{WO}_{3}$ Nanoparticles for Highly Improved Electrochromic Applications. Adv. Mater. 2006, 18, 763-766. [CrossRef]

133. Lee, S.H.; Deshpande, R.; Benhammou, D.; Parilla, P.A.; Mahan, A.H.; Dillon, A.C. Metal oxide nanoparticles for advanced energy applications. Thin Solid Films 2009, 517, 3591-3595. [CrossRef]

134. Wang, Y.; Cao, G. $\mathrm{Li}^{+}$-intercalation electrochemical/electrochromic properties of vanadium pentoxide films by sol electrophoretic deposition. Electrochim. Acta 2006, 51, 4865-4872. [CrossRef]

135. Suzuki, S.; Miyayama, M. Electrochemical Intercalation of Lithium into Thin Film of Stacked Tetratitanate Nanosheets Fabricated by Electrophoretic Deposition. J. Electrochem. Soc. 2013, 160, A293-A296. [CrossRef]

136. Suzuki, S.; Sakai, N.; Miyayama, M. Fabrication of Titanate Thin Film by Electrophoretic Deposition of Tetratitanate Nanosheets for Electrodes of Li-Ion Battery. Key Eng. Mater. 2009, 388, 37-40. [CrossRef]

137. Oltean, G.; Valvo, M.; Nyholm, L.; Edstrom, K. On the electrophoretic and sol-gel deposition of active materials on aluminium rod current collectors for three-dimensional Li-ion micro-batteries. Thin Solid Films 2014, 562, 63-69. [CrossRef]

138. Wu, M.S.; Lin, Y.P. Monodispersed macroporous architecture of nickel-oxide film as an anode material for thin-film lithium-ion batteries. Electrochim. Acta 2011, 56, 2068-2073. [CrossRef] 
139. Ha, D.H.; Islam, M.A.; Robinson, R.D. Binder-Free and Carbon-Free Nanoparticle Batteries: A Method for Nanoparticle Electrodes without Polymeric Binders or Carbon Black. Nano Lett. 2012, 12, 5122-5130. [CrossRef] [PubMed]

140. Kim, Y.J.; Lee, J.H.; Cho, S.G.; Kwon, Y.W.; In, I.S.; Lee, J.H.; You, N.H.; Reichmanis, E.; Ko, H.D.; Lee, K.T. Additive-Free Hollow-Structured $\mathrm{Co}_{3} \mathrm{O}_{4}$ Nanoparticle Li-Ion Battery: The Origins of Irreversible Capacity Loss. ACS Nano 2014, 8, 6701-6712. [CrossRef] [PubMed]

141. Reddy, A.L.M.; Shaijumon, M.M.; Gowda, S.R.; Ajayan, P.M. Coaxial $\mathrm{MnO}_{2}$ /carbon nanotube array electrodes for high-performance lithium batteries. Nano Lett. 2009, 9, 1002-1006. [CrossRef] [PubMed]

142. Huang, G.; Zhang, F.; Zhang, L.; Du, X.; Wang, J.; Wang, L. Hierarchical $\mathrm{NiFe}_{2} \mathrm{O}_{4} / \mathrm{Fe}_{2} \mathrm{O}_{3}$ nanotubes derived from metal organic frameworks for superior lithium ion battery anodes. J. Mater. Chem. A 2014, 2, 8048-8053. [CrossRef]

143. Luo, B.; Zhi, L. Design and construction of three dimensional graphene-based composites for lithium ion battery applications. Energy Environ. Sci. 2015, 8, 456-477. [CrossRef]

144. Wu, Z.S.; Zhou, G.; Yin, L.; Ren, W.; Li, F.; Cheng, H. Graphene/metal oxide composite electrode materials for energy storage. Nano Energy 2012, 1, 107-131. [CrossRef]

145. Klavetter, K.C.; Snider, J.L.; Souza, J.P.; Tu, H.; Cell, T.H.; Cho, J.H.; Ellison, C.J.; Heller, A.; Mullins, C.B. A free-standing, flexible lithium-ion anode formed from an air-dried slurry cast of high tap density $\mathrm{SnO}_{2}$, CMC polymer binder and Super-P Li. J. Mater. Chem. A 2014, 2, 14459-14467. [CrossRef]

146. Sun, J.; Zheng, G.; Lee, H.W.; Liu, N.; Wang, H.; Yao, H.; Yang, W.; Cui, Y. Formation of Stable Phosphorus-Carbon Bond for Enhanced Performance in Black Phosphorus Nanoparticle-Graphite Composite Battery Anodes. Nano Lett. 2014, 14, 4573-4580. [CrossRef] [PubMed]

147. Wu, H.; Chan, G.; Choi, J.W.; Ryu, I.; Yao, Y.; McDowell, M.T.; Lee, S.W.; Jackson, A.; Yang, Y.; Hu, L.; et al. Stable cycling of double-walled silicon nanotube battery anodes through solid-electrolyte interphase control. Nat. Nanotechnol. 2012, 7, 310-315. [CrossRef] [PubMed]

148. Ui, K.; Kawamura, S.; Kumagai, N. Fabrication of binder-free $\mathrm{SnO}_{2}$ nanoparticle electrode for lithium secondary batteries by electrophoretic deposition method. Electrochim. Acta 2012, 76, 383-388. [CrossRef]

149. Xiao, W.; Xia, H.; Fuh, J.Y.H.; Lu, L. Electrophoretic-deposited CNT/ $\mathrm{MnO}_{2}$ composites for high-power electrochemical energy storage/conversion applications. Phys. Scr. 2010, T139, 014008. [CrossRef]

150. Kim, J.C.; Hwang, I.S.; Seo, S.D.; Lee, G.H.; Shim, H.W.; Park, K.S.; Kim, D.W. Superior long-term cycling stability of $\mathrm{SnO} 2$ nanoparticle/multiwalled carbon nanotube heterostructured electrodes for Li-ion rechargeable batteries. Nanotechnology 2012, 23, 465402. [CrossRef] [PubMed]

151. Kim, J.C.; Hwnag, I.S.; Seo, S.D.; Kim, D.W. Nanocomposite Li-ion battery anodes consisting of multiwalled carbon nanotubes that anchor CoO nanoparticles. Mater. Lett. 2013, 104, 13-16. [CrossRef]

152. Rangasamy, B.; Hwnag, J.Y.; Choi, W.B. Multi layered Si-CuO quantum dots wrapped by graphene for high-performance anode material in lithium-ion battery. Carbon 2014, 77, 1065-1072. [CrossRef]

153. Wang, B.; Li, S.; Li, B.; Liu, J.; Yu, M. Facile and large-scale fabrication of hierarchical $\mathrm{ZnFe}_{2} \mathrm{O}_{4} /$ graphene hybrid films as advanced binder-free anodes for lithium-ion batteries. New J. Chem. 2015, 39, 1725-1733. [CrossRef]

154. Wang, B.; Li, S.; Liu, J.; Yu, M.; Li, B.; Wu, X. An efficient route to a hierarchical $\mathrm{CoFe}_{2} \mathrm{O}_{4} @$ graphene hybrid films with superior cycling stability and rate capability for lithium storage. Electrochim. Acta 2014, 146, 679-687. [CrossRef]

155. Menendez, R.; Alvarz, P.; Botas, C.; Nacimiento, F.; Alcantara, R.; Tirado, J.L.; Ortiz, G.F. Self-organized amorphous titania nanotubes with deposited graphene film like a new heterostructured electrode for lithium ion batteries. J. Power Sources 2014, 248, 886-893. [CrossRef]

156. Qin, J.; He, C.; Zhao, N.; Wang, Z.; Shi, C.; Liu, E.; Li, J. Graphene Networks Anchored with Sn@Graphene as Lithium Ion Battery Anode. ACS Nano 2014, 8, 1728-1738. [CrossRef] [PubMed]

157. Chang, J.; Huang, X.; Zhou, C.; Cui, S.; Hallac, P.B.; Jiang, J.; Gurley, P.T.; Chen, J. Multilayered Si nanoparticle/reduced graphene oxide hybrid as a high-performance lithium-ion battery anode. Adv. Mater. 2014, 26, 758-764. [CrossRef] [PubMed]

158. Sun, F.; Huang, K.; Qi, X.; Gao, T.; Liu, Y.; Zou, X.; Wei, X.; Zhong, J. A rationally designed composite of alternating strata of Si nanoparticles and graphene: A high-performance lithium-ion battery anode. Nanoscale 2013, 5, 8586-8592. [CrossRef] [PubMed] 
159. Wang, B.; Li, X.; Zhang, X.; Luo, B.; Jin, M.; Liang, M.; Dayeh, S.A.; Picraux, S.T.; Zhi, L. Adaptable silicon-carbon nanocables sandwiched between reduced graphene oxide sheets as lithium ion battery anodes. ACS Nano 2013, 7, 1437-1445. [CrossRef] [PubMed]

160. Wen, Y.; Zhu, Y.; Langrock, A.; Manivannan, A.; Ehrman, S.H.; Wang, C. Graphene-bonded and -encapsulated Si nanoparticles for lithium ion battery anodes. Small 2013, 9, 2810-2816. [CrossRef] [PubMed]

161. Hwang, I.S.; Kim, J.C.; Seo, S.D.; Lee, S.J.; Lee, J.H.; Kim, D.W. A binder-free Ge nanoparticle anode assembled on multiwalled carbon nanotube networks for Li-ion batteries. Chem. Commun. 2012, 48, 7061-7063. [CrossRef] [PubMed]

162. Seo, S.D.; Lee, G.H.; Lim, A.H.; Min, K.M.; Kim, J.C.; Shim, H.W.; Park, K.S.; Kim, D.W. Direct assembly of tin-MWCNT 3D-networked anode for rechargeable lithium ion batteries. RSC Adv. 2012, 2, 3315-3320. [CrossRef]

163. Bae, E.G.; Hwang, Y.H.; Pyo, M.H. Binder-free Sn/Graphene Nanocomposites Prepared by Electrophoretic Deposition for Anode Materials in Lithium Ion Batteries. Bull. Korean Chem. Soc. 2013, 34, 1199-1204. [CrossRef]

164. Nie, M.; Abraham, D.P.; Chen, Y.; Bose, A.; Lucht, B.L. Silicon Solid Electrolyte Interphase (SEI) of Lithium Ion Battery Characterized by Microscopy and Spectroscopy. J. Phys. Chem. C 2013, 117, 13403-13412. [CrossRef]

165. Zhang, W.M.; Wu, X.L.; Hu, J.S.; Guo, Y.G.; Wan, L.J. Carbon Coated $\mathrm{Fe}_{3} \mathrm{O}_{4}$ Nanospindles as a Superior Anode Material for Lithium-Ion Batteries. Adv. Funct. Mater. 2008, 18, 3941-3946. [CrossRef]

166. Jia, H.; Gao, P.; Yang, J.; Wang, J.; Nuli, Y.; Yang, Z. Novel Three-Dimensional Mesoporous Silicon for High Power Lithium-Ion Battery Anode Material. Adv. Energy Mater. 2011, 1, 1036-1039. [CrossRef]

167. Rolison, D.R.; Long, J.W.; Lytle, J.C.; Fischer, A.E.; Rhodes, C.P.; Mcevoy, T.M.; Bourg, M.E.; Lubers, A.M. Multifunctional 3D nanoarchitectures for energy storage and conversion. Chem. Soc. Rev. 2009, 38, $226-252$. [CrossRef] [PubMed]

168. Xu, J.; Wang, X.; Wang, X.; Chen, D.; Chen, X.; Li, D.; Shen, G. Three-dimensional structural engineering for energy-storage devices: From microscope to macroscope. ChemElectroChem 2014, 1, 975-1002. [CrossRef]

169. Jeun, J.H.; Kim, W.S.; Hong, S.H. Electrophoretic deposition of carbon nanoparticles on dendritic Sn foams fabricated by electrodeposition. Mater. Lett. 2013, 112, 109-112. [CrossRef]

170. Zhu, J.; Wang, D.; Cao, L.; Liu, T. Ultrafast preparation of three-dimensional porous tin-graphene composites with superior lithium ion storage. J. Mater. Chem. A 2014, 2, 12918-12923. [CrossRef]

171. Cohn, A.P.; Oakes, L.; Carter, R.; Chatterjee, S.; Westover, A.S.; Share, K.; Pint, C.L. Assessing the improved performance of freestanding, flexible graphene and carbon nanotube hybrid foams for lithium ion battery anodes. Nanoscale 2014, 6, 4669-4675. [CrossRef] [PubMed]

172. Nishikawa, K.; Dokko, K.; Kinoshita, K.; Woo, S.W.; Kanamura, K. Three-dimensionally ordered macroporous Ni-Sn anode for lithium batteries. J. Power Sources 2009, 189, 726-729. [CrossRef]

173. Carter, R.; Ozkes, L.; Cohn, A.P.; Holzgrafe, J.; Zarick, H.F.; Chatterjee, S.; Bardhan, R.; Pint, C.L. Solution Assembled Single-Walled Carbon Nanotube Foams: Superior Performance in Supercapacitors, Lithium-Ion, and Lithium-Air Batteries. J. Phys. Chem. C 2014, 118, 20137-20151. [CrossRef]

174. An, S.J.; Zhu, Y.; Lee, S.H.; Stoller, M.C.; Emilsson, T.; Park, S.J.; Velamakanni, A.; An, J.H.; Ruoff, R.S. Thin Film Fabrication and Simultaneous Anodic Reduction of Deposited Graphene Oxide Platelets by Electrophoretic Deposition. J. Phys. Chem. Lett. 2010, 1, 1259-1263. [CrossRef]

175. Deng, D.; Lee, J. Reversible Storage of Lithium in a Rambutan-Like Tin-Carbon Electrode. Angew. Chem. Int. Ed. 2009, 48, 1660-1663. [CrossRef] [PubMed]

176. Su, Y.; Li, S.; Wu, D.; Zhang, F.; Liang, H.; Gao, P.; Cheng, C.; Feng, X. Two-Dimensional Carbon-Coated Graphene/Metal Oxide Hybrids for Enhanced Lithium Storage. ACS Nano 2012, 6, 8349-8356. [CrossRef] [PubMed]

177. Hao, J.; Liu, X.; Li, N.; Liu, X.; Ma, X.; Zhang, Y.; Li, Y.; Zhao, J. Ionic liquid electrodeposition of 3D germanium-acetylene black-Ni foam nanocomposite electrodes for lithium-ion batteries. RSC Adv. 2014, 4, 60371-60375. [CrossRef]

178. Winter, M.; Brodd, R.J. What Are Batteries, Fuel Cells, and Supercapacitors? Chem. Rev. 2004, 104, 4245-4269. [CrossRef] [PubMed]

179. Zhang, L.L.; Zhao, X.S. Carbon-based materials as supercapacitor electrodes. Chem. Soc. Rev. 2009, 38, 2520-2531. [CrossRef] [PubMed] 
180. Miller, J.R.; Simon, P. Electrochemical Capacitors for Energy Management. Science 2008, 321, $651-652$. [CrossRef] [PubMed]

181. Zhang, L.L.; Zhao, X.; Stoller, M.D.; Zhu, Y.; Ji, H.; Murali, S.; Wu, Y.; Perales, S.; Clevenger, B.; Ruoff, R.S. Highly Conductive and Porous Activated Reduced Graphene Oxide Films for High-Power Supercapacitors. Nano Lett. 2012, 12, 1806-1812. [CrossRef] [PubMed]

182. Wang, M.; Duong, L.D.; Mai, N.T.; Kim, S.H.; Kim, Y.J.; Seo, H.W.; Kim, Y.C.; Jang, W.J.; Lee, Y.K.; Suhr, J.H.; Nam, J.D. All-Solid-State Reduced Graphene Oxide Supercapacitor with Large Volumetric Capacitance and Ultralong Stability Prepared by Electrophoretic Deposition Method. ACS Appl. Mater. Interfaces 2015, 7, 1348-1354. [CrossRef] [PubMed]

183. Dubal, D.P.; Ayyad, O.; Ruiz, V.; Romero, P. Hybrid energy storage: The merging of battery and supercapacitor chemistries. Chem. Soc. Rev. 2015, 44, 1777-1790. [CrossRef] [PubMed]

184. Nandhini, R.; Mini, P.A.; Avinash, B.; Nair, S.V.; Subramanian, K.R.V. Supercapacitor electrodes using nanoscale activated carbon from graphite by ball milling. Mater. Lett. 2012, 87, 165-168. [CrossRef]

185. Pech, D.; Brunet, M.; Durouo, H.; Guang, P.; Mochalin, V.; Gogotsi, Y.; Taberna, P.L.; Simon, P. Ultrahigh-power micrometer-sized supercapacitors based on onion-like carbon. Nat. Nanotechnol. 2010, 5 , 651-654. [CrossRef] [PubMed]

186. Huang, P.; Pech, D.; Lin, R.; Mcdonough, J.K.; Brunet, M.; Taberna, P.L.; Gogotsi, Y.; Simon, P. On-chip micro-supercapacitors for operation in a wide temperature range. Electrochem. Commun. 2013, 36, 53-56. [CrossRef]

187. In, H.J.; Kumar, S.; Horn, Y.S.; Barbastathis, G. Origami fabrication of nanostructured, three-dimensional devices: Electrochemical capacitors with carbon electrodes. Appl. Phys. Lett. 2006, 88, 0831041. [CrossRef]

188. Pech, D.; Brunet, M.; Taberna, P.; Simon, P.; Faber, N.; Mesnilgrente, F.; Conedera, V.; Durou, H. Elaboration of a Microstructured Inkjet-Printed Carbon Electrochemical Capacitor. J. Power Sources 2010, 195, 1266-1269. [CrossRef]

189. Shen, J.; Liu, A.; Tu, T.; Foo, G.; Yeo, C.; Chen-Park, M.B.; Jiang, R.; Chen, Y. How carboxylic groups improve the performance of single-walled carbon nanotube electrochemical capacitors? Energy Environ. Sci. 2011, 4, 4220-4229. [CrossRef]

190. Futaba, D.N.; Hata, K.; Yamada, T.; Hiraoka, T.; Hayamizu, Y.; Kakudate, Y.; Tanaike, O.; Hatori, H.; Yumura, M.; Iijima, S. Shape-engineerable and highly densely packed single-walled carbon nanotubes and their application as super-capacitor electrodes. Nat. Mater. 2006, 5, 987-994. [CrossRef] [PubMed]

191. Aboutalebi, S.H.; Chidembo, A.T.; Salari, M.; Konstantinov, K.; Wexler, D.; Liu, H.K.; Dou, S.X. Comparison of GO, GO/MWCNTs composite and MWCNTs as potential electrode materials for supercapacitors. Energy Environ. Sci. 2011, 4, 1855-1856. [CrossRef]

192. Bordjiba, T.; Mohamedi, M.; Dao, L.H. New Class of Carbon-Nanotube Aerogel Electrodes for Electrochemical Power Sources. Adv. Mater. 2008, 20, 815-819. [CrossRef]

193. Du, C.; Pan, N. High power density supercapacitor electrodes of carbon nanotube films by electrophoretic deposition. Nanotechnology 2006, 17, 5314-5318. [CrossRef]

194. Du, C.; Pan, N. Supercapacitors using carbon nanotubes films by electrophoretic deposition. J. Power Sources 2006, 160, 1487-1494. [CrossRef]

195. Moore, J.J.; Kang, J.H.; Wen, J.Z. Fabrication and characterization of single walled nanotube supercapacitor electrodes with uniform pores using electrophoretic deposition. Mater. Chem. Phys. 2012, 13, 68-73. [CrossRef]

196. Dinh, T.M.; Pech, D.; Brunet, M.; Achour, A. High resolution electrochemical micro-capacitors based on oxidized multi-walled carbon nanotubes. Phys. Conf. Ser. 2013, 476, 012106. [CrossRef]

197. Stoller, M.D.; Park, S.; Zhu, Y.; An, J.; Ruoff, R.S. Graphene-Based Ultracapacitors. Nano Lett. 2008, 8, 3498-3502. [CrossRef] [PubMed]

198. Lv, W.; Tang, D.M.; He, Y.B.; You, C.H.; Shi, Z.Q.; Chen, X.C.; Chen, C.M.; Hou, P.X.; Liu, C.; Yang, Q.H. Low-Temperature Exfoliated Graphenes: Vacuum-Promoted Exfoliation and Electrochemical Energy Storage. ACS Nano 2009, 3, 3730-3736. [CrossRef] [PubMed]

199. Zhu, Y.; Murali, S.; Stoller, M.D.; Ganesh, K.J.; Cai, W.; Ferreira, P.J.; Pirkle, A.; Wallace, R.M.; Cychosz, K.A.; Thommes, M.; et al. Carbon-Based Supercapacitors Produced by Activation of Graphene. Science 2011, 322, 1537-1541. [CrossRef] [PubMed] 
200. Wang, S.; Dryfe, R.A.W. Graphene oxide-assisted deposition of carbon nanotubes on carbon cloth as advanced binder-free electrodes for flexible supercapacitors. J. Mater. Chem. A 2013, 1, 5279-5283. [CrossRef]

201. Wang, M.; Oh, J.S.; Ghosh, T.; Hong, S.C.; Nam, G.Y.; Hwang, T.S.; Nam, J.D. An interleaved porous laminate composed of reduced graphene oxide sheets and carbon black spacers by in situ electrophoretic deposition. RSC Adv. 2014, 4, 3284-3292. [CrossRef]

202. Ye, S.; Feng, J.; Wu, P. Deposition of Three-Dimensional Graphene Aerogel on Nickel Foam as a Binder-Free Supercapacitor Electrode. ACS Appl. Mater. Interfaces 2013, 5, 7122-7129. [CrossRef] [PubMed]

203. Zhang, S.; Pan, N. Supercapacitor performance of crumpled and planar graphene materials produced by hydrogen gas reduction of graphene oxide. J. Mater. Chem. A 2013, 1, 7957-7962. [CrossRef]

204. Liu, Y.; Zhang, D.; Shang, Y.; Liu, T. A simple route to prepare free-standing graphene thin film for high-performance flexible electrode materials. RSC Adv. 2014, 4, 30422-30429. [CrossRef]

205. Iro, Z.S.; Subramani, C.; Dash, S.S. A Brief Review on Electrtode Materials for Supercapacitor. Int. J. Electrochem. Sci. 2016, 11, 10628-10643. [CrossRef]

206. Augustyn, V.; Simon, P.; Dunn, B. Pseudocapacitive oxide materials for high-rate electrochemical energy storage. Energy Environ. Sci. 2014, 7, 1597-1614. [CrossRef]

207. Jang, J.H.; Machida, K.; Kim, Y.; Naoi, K. Electrophoretic deposition (EPD) of hydrous ruthenium oxides with PTFE and their supercapacitor performances. Electrochim. Acta 2006, 52, 1733-1741. [CrossRef]

208. Chen, C.Y.; Lyu, Y.R.; Su, C.Y.; Lin, H.M.; Lin, C.K. Characterization of spray pyrolyzed manganese oxide powders deposited by electrophoretic deposition technique. Surf. Coat. Technol. 2007, 202, 1277-1281. [CrossRef]

209. Wang, S.C.; Chen, C.Y.; Chien, T.C.; Lee, P.Y.; Lin, C.K. Supercapacitive properties of spray pyrolyzed iron-added manganese oxide powders deposited by electrophoretic deposition technique. Thin Solid Films 2008, 517, 1234-1238. [CrossRef]

210. Zhitomirsky, J.L.I. Electrophoretic deposition of manganese oxide nanofibers. Mater. Chem. Phys. 2008, 112, 525-530.

211. Chen, C.Y.; Wang, S.C.; Lin, C.Y.; Chen, F.S.; Lin, C.K. Electrophoretically deposited manganese oxide coatings for supercapacitor application. Ceram. Int. 2009, 35, 3469-3474. [CrossRef]

212. Zheng, J.P.; Cygan, P.J.; Jow, T.R. Hydrous Ruthenium Oxide as an Electrode Material for Electrochemical Capacitors. J. Electrochem. Soc. 1995, 142, 2699-2703. [CrossRef]

213. Jang, J.H.; Kato, A.; Machida, K.; Naoi, K. Supercapacitor Performance of Hydrous Ruthenium Oxide Electrodes Prepared by Electrophoretic Deposition. J. Electrochem. Soc. 2006, 153, A321-A328. [CrossRef]

214. Ranjusha, R.; Nair, A.S.; Ramakrishna, S.; Anjali, P.; Sujith, K.; Subramanian, K.R.V.; Sivakumar, N.; Kim, T.N.; Shantikumarm, V.N.; Balakrishnan, A. Ultra fine $\mathrm{MnO}_{2}$ nanowire based high performance thin film rechargeable electrodes: Effect of surface morphology, electrolytes and concentrations. J. Mater. Chem. 2012, 22, 20465-20471. [CrossRef]

215. Santanagopalan, S.; Balram, A.; Meng, D.D. Scalable High-Power Redox Capacitors with Aligned Nanoforests of Crystalline $\mathrm{MnO}_{2}$ Nanorods by High Voltage Electrophoretic Deposition. ACS Nano 2013, 7, 2114-2125. [CrossRef] [PubMed]

216. Roshny, S.; Ranjusha, R.; Deepar, M.S.; Rejinold, N.S.; Jayakumar, R.; Nair, S.V.; Balakrishnan, $\mathrm{A} . \mathrm{MnO}_{2}$ nano/micro hybrids for supercapacitors: "Nano's Envy, Micro's pride". RSC Adv. 2014, 4, 15863-15869. [CrossRef]

217. Coustan, L.; Comte, A.L.; Brousse, T.; Favier, F. $\mathrm{MnO}_{2}$ as ink material for the fabrication of supercapacitor electrodes. Electrochim. Acta 2015, 152, 520-529. [CrossRef]

218. Wu, M.S.; Chan, D.S.; Lin, K.H.; Jow, J.J. A simple route to electrophoretic deposition of transition metal-coated nickel oxide films for electrochemical capacitors. Mater. Chem. Phys. 2011, 130, 1239-1245. [CrossRef]

219. Wu, M.S.; Huang, C.Y.; Lin, K.H. Electrophoretic deposition of nickel oxide electrode for high-rate electrochemical capacitors. J. Power Sources 2009, 186, 557-564. [CrossRef]

220. Paravannoor, A.; Ranjusha, R.; Asha, A.M.; Vani, R.; Kalluri, S.; Subramanian, K.R.V.; Sivakumar, N.; Kim, T.N.; Nair, S.V.; Balakrishnan, A. Chemical and structural stability of porous thin film NiO nanowire based electrodes for supercapacitors. Chem. Eng. J. 2013, 220, 360-366. [CrossRef]

221. Wu, M.S.; Huang, K.C. Enhanced electrochemical performance of nickel hydroxide electrode with monolayer hollow spheres composed of nanoflakes. Int. J. Hydrogen Energy 2011, 36, 13407-13413. [CrossRef] 
222. Amrutha, A.; Anjali, P.; Jickson, J.; Amruthalakshmi, V.; Anoop, S.S.; Shanticumar, N.V.; Avinash, B. 2D amorphous frameworks of $\mathrm{NiMoO}_{4}$ for supercapacitors: Defining the role of surface and bulk controlled diffusion processes. Appl. Surf. Sci. 2015, 326, 39-47.

223. Li, X.; Zhitomirsky, I. Electrodeposition of polypyrrolee-carbon nanotube composites for electrochemical supercapacitors. J. Power Sources 2013, 221, 49-56. [CrossRef]

224. Su, Y.; Zhitomirsky, I. Electrophoretic assembly of organic molecules and composites for electrochemical Supercapacitors. J. Colloid Surf. Sci. 2013, 392, 247-255. [CrossRef] [PubMed]

225. Shi, K.; Zhitomirsky, I. Polypyrrole nanofiber-carbon nanotube electrodes for supercapacitors with high mass loading obtained using an organic dye as a co-dispersant. J. Mater. Chem. A 2013, 1, 11614-11622. [CrossRef]

226. Su, Y.; Zhitomirsky, I. Asymmetric electrochemical supercapacitor, based on polypyrrole coated carbon nanotube electrodes. Appl. Energy 2015, 153, 48-55. [CrossRef]

227. Mini, P.A.; Balakrishnan, A.; Nair, S.V.; Subramanian, K.R.V. Highly super capacitive electrodes made of graphene/poly(pyrrole). Chem. Commun. 2011, 47, 5753-5755. [CrossRef] [PubMed]

228. Shi, K.; Zhitomirsky, I. Electrophoretic nanotechnology of graphene-carbon nanotube and graphene-polypyrrole nanofiber composites for electrochemical supercapacitors. J. Colloid Interface Sci. 2013, 407, 474-481. [CrossRef] [PubMed]

229. Liu, W.; Yan, X.; Chen, J.; Feng, Y.; Zue, Q. Novel and high-performance asymmetric micro-supercapacitors based on graphene quantum dots and polyaniline nanofibers. Nanoscale 2013, 5, 6053-6062. [CrossRef] [PubMed]

230. Tong, Z.; Yang, Y.; Wang, J.; Zhao, J.; Su, B.L.; Li, Y. Layered polyaniline/graphene film from sandwich-structured polyaniline/graphene/polyaniline nanosheets for high-performance pseudosupercapacitors. J. Mater. Chem. A 2014, 2, 4642-4651. [CrossRef]

231. Chen, C.Y.; Chien, T.C.; Chan, Y.C.; Lin, C.K.; Wang, S.C. Pseudocapacitive properties of carbon nanotube/manganese oxide electrode deposited by electrophoretic deposition. Diam. Relat. Mater. 2009, 18, 482-485. [CrossRef]

232. Wang, Y.; Zhitomirsky, I. Electrophoretic Deposition of Manganese Dioxide-Multiwalled Carbon Nanotube Composites for Electrochemical Supercapacitors. Langmuir 2009, 25, 9684-9689. [CrossRef] [PubMed]

233. Li, J.; Zhitomirsky, I. Electrophoretic deposition of manganese dioxide-carbon nanotube composites. J. Mater. Proc. Technol. 2009, 209, 3452-3459. [CrossRef]

234. Bordjiba, T.; Belanger, D. Development of new nanocomposite based on nanosized-manganese oxide and carbon nanotubes for high performance electrochemical capacitors. Electrochim. Acta 2010, 55, 3428-3433. [CrossRef]

235. Okamura, K.; Inoue, R.; Sebille, T.; Tomono, K.; Nakayuama, M. An Approach to Optimize the Composition of Supercapacitor Electrodes Consisting of Manganese-Molybdenum Mixed Oxide and Carbon Nanotubes. J. Electrochem. Soc. 2011, 158, A711-A717. [CrossRef]

236. Zhang, J.; Wang, Y.; Zang, J.; Xin, G.; Yuan, Y.; Qu, X. Electrophoretic deposition of $\mathrm{MnO}_{2}$-coated carbon nanotubes on a graphite sheet as a flexible electrode for supercapacitors. Carbon 2012, 50, 5196-5202. [CrossRef]

237. Su, Y.; Zhitomirsky, I. Electrophoretic Nanotechnology of Composite Electrodes for Electrochemical Supercapacitors. J. Phys. Chem. B 2013, 117, 1563-1570. [CrossRef] [PubMed]

238. Fang, H.; Zhang, S.; Wu, X.; Liu, W.; Wen, B.; Du, Z.; Jiang, T. Facile fabrication of multiwalled carbon nanotube/a-MnOOH coaxial nanocable films by electrophoretic deposition for supercapacitors. J. Power Sources 2013, 235, 95-104. [CrossRef]

239. Ranjusha, R.; Ramakrishna, S.; Nair, A.S.; Anjali, P.; Vineeth, S.; Sonia, T.S.; Sivakumar, N.; Subramanian, K.R.V.; Nair, S.V.; Balakrishnan, A. Fabrication and performance evaluation of button cell supercapacitors based on $\mathrm{MnO} 2$ nanowire/carbon nanobead electrodes. RSC Adv. 2013, 3, 17492-17499. [CrossRef]

240. Wang, Y.; Liu, Y.; Zhitomirsky, I. Surface modification of $\mathrm{MnO}_{2}$ and carbon nanotubes using organic dyes for nanotechnology of electrochemical supercapacitors. J. Mater. Chem. 2013, 1, 12519-12526. [CrossRef]

241. Liu, Y.; Ata, M.S.; Shi, K.; Zhu, G.Z.; Botton, G.A.; Zhitomirsky, I. Surface modification and cathodic electrophoretic deposition of ceramic materials and composites using celestine blue dye. RSC Adv. 2014, 4, 29652-29659. [CrossRef] 
242. Zhang, J.; Zang, J.; Huang, J.; Wang, Y.; Xin, G. Synthesis of an architectural electrode based on manganese oxide and carbon nanotubes for flexible supercapacitors. Mater. Lett. 2014, 126, 24-27. [CrossRef]

243. Wu, M.S.; Huang, C.Y.; Jow, J.J. Electrophoretic deposition of network-like carbon nanofiber as a conducting substrate for nanostructured nickel oxide electrode. Electrochem. Comm. 2009, 11, 779-782. [CrossRef]

244. Wu, M.S.; Huang, C.Y.; Lin, K.H. Facile Electrophoretic Deposition of Ni-Decorated Carbon Nanotube Film for Electrochemical Capacitors. Electrochem. Solid-State Lett. 2009, 12, A129-A131. [CrossRef]

245. Wu, M.S.; Lin, K.H. One-step Electrophoretic Deposition of Ni-Decorated Activated-Carbon Film as an Electrode Material for Supercapacitors. J. Phys. Chem. C 2010, 114, 6190-6196. [CrossRef]

246. Wu, M.S.; Zheng, Y.R.; Lin, G.W. Three-dimensional carbon nanotube networks with a supported nickel oxide nanonet for high-performance supercapacitors. Chem. Commun. 2014, 50, 8246-8248. [CrossRef] [PubMed]

247. Wu, M.S.; Hsu, W.H. Nickel nanoparticles embedded in partially graphitic porous carbon fabricated by direct carbonization of nickel-organic framework for high-performance supercapacitors. J. Power Sources 2015, 274, 1055-1062. [CrossRef]

248. Huq, M.M.; Hsieh, C.T.; Ho, C.Y. Preparation of carbon nanotube-activated carbon hybrid electrodes by electrophoretic deposition for supercapacitor applications. Diam. Relat. Mater. 2016, 62, 58-64. [CrossRef]

249. Wu, M.S.; Lin, C.J.; Ho, C.L. Multilayered architecture of graphene nanosheets and $\mathrm{MnO}_{2}$ nanowires as an electrode material for high-performance supercapacitors. Electrochim. Acta 2012, 81, 44-48. [CrossRef]

250. Wu, M.S.; Fu, Y.H. Tubular graphene nanoribbons with attached manganese oxide nanoparticles for use as electrodes in high-performance supercapacitors. Carbon 2013, 60, 236-245. [CrossRef]

251. Ghasemi, S.G.; Ojani, R.; Ausi, S. Bipotential deposition of nickel-cobalt hexacyanoferrate nanostructure on graphene coated stainless steel for supercapacitors. Int. J. Hydrogen Energy 2014, 39, 14918-14926. [CrossRef]

252. Ghasemi, S.; Hosseinzadeh, R.; Jafari, $\mathrm{M} . \mathrm{MnO}_{2}$ nanoparticles decorated on electrophoretically deposited graphene nanosheets for high performance supercapacitor. Int. J. Hydrogen Energy 2015, 39, 1037-1046. [CrossRef]

253. Xu, Y.; Li, J.; Huang, W. Porous Graphene Oxide Prepared on Nickel Foam by Electrophoretic Deposition and Thermal Reduction as High-Performance Supercapacitor Electrodes. Materials 2017, 10, 936.

254. Niu, Z.; Du, J.; Cao, X.; Sun, Y.; Zhou, W.; Hng, H.H.; Ma, J.; Chen, X.; Xie, S. Electrophoretic Build-Up of Alternately Multilayered Films and Micropatterns Based on Graphene Sheets and Nanoparticles and their Applications in Flexible Supercapacitors. Small 2012, 8, 3201-3208. [CrossRef] [PubMed]

255. Hung, C.J.; Lin, P.; Tseng, T.Y. Electrophoretic fabrication and pseudocapacitive properties of graphene/manganese oxide/carbon nanotube nanocomposites. J. Power Sources 2013, 243, 594-602. [CrossRef]

256. Zhang, H.; Zhang, X.; Zhang, D.; Sun, X.; Lin, H.; Wang, C.; Ma, Y. One-Step Electrophoretic Deposition of Reduced Graphene Oxide and $\mathrm{Ni}(\mathrm{OH})_{2}$ Composite Films for Controlled Syntheses Supercapacitor Electrodes. J. Phys. Chem. B 2012, 117, 1616-1627. [CrossRef] [PubMed]

257. Ormerod, R.M. Solid oxide fuel cells. Chem. Soc. Rev. 2003, 32, 17-28. [CrossRef] [PubMed]

258. Atkinson, A.; Barnett, S.; Gorte, R.J.; Irvine, J.T.S.; McEvoy, A.J.; Mogensen, M.; Singhal, S.C.; Vohs, J. Advanced anodes for high-temperature fuel cells. Nat. Mater. 2004, 3, 17-27. [CrossRef] [PubMed]

259. Sengodan, S.; Choi, S.; Jun, A.; Shin, T.H.; Ju, Y.W.; Jeong, H.Y.; Shin, J.Y.; Irvine, J.T.S.; Kim, G. Layered oxygen-deficient double perovskite as an efficient and stable anode for direct hydrocarbon solid oxide fuel cells. Nat. Mater. 2015, 14, 205-209. [CrossRef] [PubMed]

260. Soumya, M.S.; Binitha, G.; Praveen, P.; Subramanian, K.R.V.; Lee, Y.S. Electrochemical Performance of $\mathrm{PbO}_{2}$ and $\mathrm{PbO}_{2}-\mathrm{CNT}$ Composite Electrodes for Energy Storage Devices. J. Nanosci. Nanotechnol. 2015, 15, 703-708. [CrossRef] [PubMed]

261. Taub, S.; Williams, R.E.A.; Wang, X.; McComb, D.W.; Kilner, J.A.; Atkinson, A. The effects of transition metal oxide doping on the sintering of cerium gadolinium oxide. Acta Mater. 2014, 81, 128-140. [CrossRef]

262. Lee, J.G.; Park, J.H.; Shul, Y.G. Tailoring gadolinium-doped ceria-based solid oxide fuel cells to achieve 2 $\mathrm{W} \cdot \mathrm{cm}^{-2}$ at $550{ }^{\circ} \mathrm{C}$. Nat. Commun. 2014, 5, 4045-4055. [CrossRef] [PubMed]

263. Ishihara, T.; Shimise, K.; Kudo, T.; Nishiguchi, H.; Akbay, T.; Takita, Y. Preparation of Yttria-Stabilized Zirconia Thin Films on Strontium-Doped $\mathrm{LaMnO}_{3}$ Cathode Substrates via Electrophoretic Deposition for Solid Oxide Fuel Cells. J. Am. Ceram. Soc. 2000, 83, 1921-1927. [CrossRef] 
264. Besra, L.; Compson, C.; Liu, M. Electrophoretic Deposition of YSZ Particles on Non-Conducting Porous NiO-YSZ Substrates for Solid Oxide Fuel Cell Applications. J. Am. Ceram. Soc. 2006, 89, 3003-3009. [CrossRef]

265. Ishihara, T.; Sato, K.; Mizuhara, Y.; Takita, Y. Preparation of Yttria-Stabilized Zirconia Films for Solid Oxide Fuel Cells by Electrophoretic Deposition Method. Chem. Lett. 1992, 21, 943-946. [CrossRef]

266. Will, J.; Hruschka, M.K.M.; Gubler, L.; Gauckler, L.J. Electrophoretic deposition of zirconia on porous anodic substrates. J. Am. Ceram. Soc. 2001, 84, 328-332. [CrossRef]

267. Besra, L.; Compson, C.; Liu, M. Electrophoretic deposition on non-conducting substrates: The case of YSZ film on NiO-YSZ composite substrates for solid oxide fuel cell application. J. Power Sources 2007, 173, 130-136. [CrossRef]

268. Basu, R.N.; Randall, C.A.; Mayo, M.J. Fabrication of Dense Zirconia Electrolyte Films for Tubular Solid Oxide Fuel Cells by Electrophoretic Deposition. J. Am. Ceram. Soc. 2001, 84, 33-40. [CrossRef]

269. Hosomi, T.; Matsuda, M.; Miyake, M. Electrophoretic deposition for fabrication of YSZ electrolyte film on non-conducting porous NiO-YSZ composite substrate for intermediate temperature SOFC. J. Eur. Ceram. Soc. 2007, 27, 173-178. [CrossRef]

270. Ji, C.; Lan, W.; Xiao, P. Fabrication of Yttria-Stabilized Zirconia Coatings Using Electrophoretic Deposition: Packing Mechanism During Deposition. J. Am. Ceram. Soc. 2008, 91, 1102-1109. [CrossRef]

271. Majhi, S.M.; Behura, S.K.; Bhattacharjee, S.; Singh, B.P.; Chongdar, T.K.; Gokhale, N.M.; Besra, L. Anode supported solid oxide fuel cells (SOFC) by electrophoretic deposition. Int. J. Hydrogen Energy 2011, 36, 14930-14935. [CrossRef]

272. Ji, L.; Lu, Z.; Huang, X.; Liu, Z.; Chen, K.; Sha, X.; Li, G.; Su, W. Preparation of YSZ film by EPD and its application in SOFCs. J. Alloys Compd. 2006, 424, 299-303. [CrossRef]

273. Chen, F.; Liu, M. Preparation of yttria-stabilized zirconia (YSZ) films on $\mathrm{La}_{0.85} \mathrm{Sr}_{0.15} \mathrm{MnO}_{3}$ (LSM) and LSM \pm YSZ substrates using an electrophoretic deposition (EPD) process. J. Eur. Ceram. Soc. 2001, 424, 127-134. [CrossRef]

274. Aruna, S.T.; Rajam, K.S. A study on the electrophoretic deposition of 8 YSZ coating using mixture of acetone and ethanol solvents. Mater. Chem. Phys. 2008, 111, 131-136. [CrossRef]

275. Talebi, T.; Haji, M.; Raissi, B.; Maghsoudipour, A. YSZ electrolyte coating on NiO-YSZ composite by electrophoretic deposition for solid oxide fuel cells (SOFCs). Int. J. Hydrogen Energy 2010, 35, 9455-9459. [CrossRef]

276. Zou, Y.; Zhou, W.; Sunarso, J.; Liang, F.; Shao, Z. Electrophoretic deposition of YSZ thin-film electrolyte for SOFCs utilizing electrostatic-steric stabilized suspensions obtained via high energy ball milling. Int. J. Hydrogen Energy 2011, 36, 9195-9204. [CrossRef]

277. Negishi, H.; Tamaji, K.; Sakai, N.; Horita, T.; Yanagishita, H.; Yokokawa, H. Electrophoretic deposition of YSZ powders for solid oxie fuel cells. J. Mater. Sci. 2004, 39, 833-838. [CrossRef]

278. Negishi, H.; Yamaji, K.; Imura, T.; Kitamoto, D.; Ikegami, T.; Yanagishita, H. Electrophoretic Deposition Mechanism of YSZ/n-Propanol Suspension. J. Electrochem. Soc. 2005, 152, J16-J23. [CrossRef]

279. Garcia, P.; Ferrari, B.; Moreno, R.; Gerencia, A.J.S.; Colomer, M.T. YSZ/Ni-YSZ semi-cells shaped by electrophoretic deposition. J. Eur. Ceram. Soc. 2007, 27, 4241-4244. [CrossRef]

280. Negishi, H.; Sakai, N.; Yamaji, K.; Horita, T.; Yokokawa, H. Application of Electrophoretic Deposition Technique to Solid Oxide Fuel Cells. J. Electrochem. Soc. 2000, 147, 1682-1687. [CrossRef]

281. Cherng, J.S.; Sau, J.R.; Chung, C.C. Aqueous electrophoretic deposition of YSZ electrolyte layers for solid oxide fuel cells. J. Solid-State Electrochem. 2008, 12, 925-933. [CrossRef]

282. Zhitomirsky, I.; Petric, A. Electrophoretic deposition of ceramic materials for fuel cell applications. J. Eur. Ceram. Soc. 2000, 20, 2055-2061. [CrossRef]

283. Zhitomirsky, I.; Petric, A. Electrophoretic deposition of electrolyte materials for solid oxide fuel cells. J. Mater. Sci. 2004, 39, 825-831. [CrossRef]

284. Matsuda, M.; Ohara, O.; Murata, K.; Ohara, S.; Fukui, T.; Miyake, M. Electrophoretic Fabrication and Cell Performance of Dense Sr- and $\mathrm{Mg}$-Doped $\mathrm{LaGaO}_{3}$-Based Electrolyte Films. Electrochem. Solid-State Lett. 2003, 6, A140-A143. [CrossRef]

285. Santillan, M.J.; Carneire, A.; Quarnata, N.; Boccaccini, A.R. Electrophoretic deposition of $\mathrm{La}_{0.6} \mathrm{Sr}_{0.4} \mathrm{Co}_{0.8} \mathrm{Fe}_{0.2} \mathrm{O}_{3-\delta}$ cathodes on $\mathrm{Ce}_{0.9} \mathrm{Gd}_{0.1} \mathrm{O}_{1.95}$ substrates for intermediate temperature solid oxide fuel cell (IT-SOFC). J. Eur. Ceram. Soc. 2009, 29, 1125-1132. [CrossRef] 
286. Bozza, F.; Polini, R.; Traversa, E. Electrophoretic Deposition of Dense Sr- and Mg-Doped $\mathrm{LaGaO}_{3}$ Electrolyte Films on Porous La-Doped Ceria for Intermediate Temperature Solid Oxide Fuel Cells. Fuel Cells 2008, 5, 344-350. [CrossRef]

287. Bozza, F.; Polini, R.; Traversa, E. High performance anode-supported intermediate temperature solid oxide fuel cells (IT-SOFCs) with $\mathrm{La}_{0.8} \mathrm{Sr}_{0.2} \mathrm{Ga}_{0.8} \mathrm{Mg}_{0.2} \mathrm{O}_{3-\delta}$ electrolyte films prepared by electrophoretic deposition. Electrochem. Commun. 2009, 11, 1680-1683. [CrossRef]

288. Bozza, F.; Polini, R.; Traversa, E. Electrophoretic Deposition of Dense $\mathrm{La}_{0.8} \mathrm{Sr}_{0.2} \mathrm{Ga}_{0.8} \mathrm{Mg}_{0.115} \mathrm{Co}_{0.085} \mathrm{O}_{3-\delta}$ Electrolyte Films from Single-Phase Powders for Intermediate Temperature Solid Oxide Fuel Cells. J. Am. Ceram. Soc. 2009, 92, 1999-2004. [CrossRef]

289. Besra, L.; Zha, S.; Liu, M. Preparation of NiO-YSZ/YSZ bi-layers for solid oxide fuel cells by electrophoretic deposition. J. Power Sources 2006, 160, 207-214. [CrossRef]

290. Matsuda, M.; Hosomi, T.; Murata, K.; Fukui, T.; Miyake, M. Fabrication of bilayered YSZ/SDC electrolyte film by electrophoretic deposition for reduced-temperature operating anode-supported SOFC. J. Power Sources 2007, 165, 102-107. [CrossRef]

291. Itagaki, Y.; Watanabe, S.; Yamaji, T.; Asamoto, M.; Yahiro, H.; Sadaoka, Y. Electrophoretic deposition of bi-layered LSM/LSM-YSZ cathodes for solid oxide fuel cell. J. Power Sources 2012, 214, 153-158. [CrossRef]

292. Cheng, M.Y.; Shiau, C.Y.; Lin, P.H.; Chang, J.C. Anode-supported solid oxide fuel cell with electrophoretic deposition-derived electrolyte operated under single-chamber conditions and a methane-air mixture. J. Solid-State Electrochem. 2011, 15, 773-779. [CrossRef]

293. Zunic, M.; Chevallier, L.; Deganello, F.; Epifanio, A.D.; Licoccia, S.; Bartolomeo, E.D.; Traversa, E. Electrophoretic deposition of dense $\mathrm{BaCe}_{0.9} \mathrm{Y}_{0.1} \mathrm{O}_{3-\mathrm{x}}$ electrolyte thick-films on Ni-based anodes for intermediate temperature solid oxide fuel cells. J. Power Sources 2009, 190, 417-422. [CrossRef]

294. Zunic, M.; Chevallier, L.; Deganello, F.; Epifanio, A.D.; Licoccia, S.; Traversa, E. Anode Supported Protonic Solid Oxide Fuel Cells Fabricated Using Electrophoretic Deposition. Fuel Cells 2011, 11, 165-171. [CrossRef]

295. Cherng, J.S.; Ho, M.Y.; Yeh, T.H.; Chen, W.H. Anode-supported micro-tubular SOFCs made by aqueous electrophoretic deposition. Ceram. Int. 2012, 38S, S447-S480. [CrossRef]

296. Cherng, J.S.; Wu, C.C.; Chen, W.H.; Yeh, T.H. Microstructure and performance of micro-tubular solid oxide fuel cells made by aqueous electrophoretic deposition. Ceram. Int. 2013, 39, S601-S604. [CrossRef]

297. Cherng, J.S.; Wu, C.C.; Yu, R.A.; Yeh, T.H. Anode morphology and performance of micro-tubular solid oxide fuel cells made by aqueous electrophoretic deposition. J. Power Sources 2013, 232, 353-356. [CrossRef]

298. Droushiotis, N.; Hankin, A.; Rozain, C.; Kelsall, G.H. Phase Inversion and Electrophoretic Deposition Processes for Fabrication of Micro-Tubular Hollow Fiber SOFCs. J. Electrochem. Soc. 2014, 161, F271-F279. [CrossRef]

299. Zhang, H.; Zhan, Z.; Liu, X. Electrophoretic deposition of $(\mathrm{Mn}, \mathrm{Co})_{3} \mathrm{O}_{4}$ spinel coating for solid oxide fuel cell interconnects. J. Power Sources 2011, 196, 8041-8047. [CrossRef]

300. Smeacetto, F.; Miranda, A.D.; Polo, S.C.; Molin, S.; Boccaccini, D.; Salvo, M.; Boccaccini, A.R. Electrophoretic deposition of $\mathrm{Mn}_{1.5} \mathrm{Co}_{1.5} \mathrm{O}_{4}$ on metallic interconnect and interaction with glass-ceramic sealant for solid oxide fuel cells application. J. Power Sources 2015, 280, 379-386. [CrossRef]

301. Zhang, Y.; Javed, A.; Zhou, M.; Liang, S.; Xiao, P. Fabrication of Mn-Co Spinel Coatings on Crofer 22 APU Stainless Steel by Electrophoretic Deposition for Interconnect Applications in Solid Oxide Fuel Cells. Int. J. Appl. Ceram. Technol. 2014, 11, 332-341. [CrossRef]

302. Debe, M.K. Electrocatalyst approaches and challenges for automotive fuel cells. Nature 2012, 486, 43-51. [CrossRef] [PubMed]

303. Hong, W.T.; Risch, M.; Stoerzinger, K.A.; Grimaud, A.; Suntivich, J.; Shao-Horn, Y. Toward the rational design of non-precious transition metal oxides for oxygen electrocatalysis. Energy Environ. Sci. 2015, 8, 1404-1427. [CrossRef]

304. Winther-Jensen, B.; MacFarlane, D.R. New generation, metal-free electrocatalysts for fuel cells, solar cells and water splitting. Energy Environ. Sci. 2011, 4, 2790-2798. [CrossRef]

305. Zhao, X.; Yin, M.; Ma, L.; Liang, L.; Liu, C.; Liao, J.; Lu, T.; Xing, W. Recent advances in catalysts for direct methanol fuel cells. Energy Environ. Sci. 2011, 4, 2736-2753. [CrossRef]

306. Edwards, P.P.; Kuznetsov, V.L.; David, W.I.F.; Brandon, N.P. Hydrogen and fuel cells: Towards a sustainable energy future. Energy Policy 2008, 36, 4356-4362. [CrossRef] 
307. Walter, M.G.; Warren, E.L.; McKone, J.R.; Boettcher, S.W.; Mi, Q.; Santori, E.; Lewis, N.S. Solar Water Splitting Cells. Chem. Rev. 2010, 110, 6446-6473. [CrossRef] [PubMed]

308. Hayashi, K.; Furuya, N. Preparation of Gas Diffusion Electrodes by Electrophoretic Deposition. J. Electrochem. Soc. 2004, 151, A354-A357. [CrossRef]

309. Morikawa, H.; Tsuihiji, N.; Mitsui, T.; Kanamyra, K. Preparation of Membrane Electrode Assembly for Fuel Cell by Using Electrophoretic Deposition Process. J. Electrochem. Soc. 2004, 151, A1733-A1737. [CrossRef]

310. Girishkumar, G.; Rettker, M.; Underhile, R.; Binz, D.; Vinodgopal, K.; McGinn, R.; Kamat, P. Single-Wall Carbon Nanotube-Based Proton Exchange Membrane Assembly for Hydrogen Fuel Cells. Langmuir 2005, 21, 8487-8494. [CrossRef] [PubMed]

311. Louh, R.F.; Chang, A.C.C.; Chen, V.; Wong, D. Design of electrophoretically deposited microporous layer/catalysts layer composite structure for power generation of fuel cells. Int. J. Hydrogen Energy 2008, 33, 5199-5204. [CrossRef]

312. Seger, B.; Kongkanand, A.; Vinodgopal, K.; Kamat, P.V. Platinum dispersed on silica nanoparticle as electrocatalyst for PEM fuel cell. J. Electroanal. Chem. 2008, 621, 198-204. [CrossRef]

313. Jeng, K.T.; Huang, W.H.; Hsu, N.Y. Application of low-voltage electrophoretic deposition to fabrication of direct methanol fuel cell electrode composite catalyst layer. Mater. Chem. Phys. 2009, 113, 574-578. [CrossRef]

314. Felix, C.; Jao, T.C.; Pasupathi, S.; Pollet, B.G. Optimisation of electrophoretic deposition parameters for gas diffusion electrodes in high temperature polymer electrolyte membrane fuel cells. J. Power Sources 2013, 243, 40-47. [CrossRef]

315. Huo, W.; Zhou, Y.; He, H.; Sun, F.; Zou, Z.; Yang, H. Rapid, simple and low cost fabrication of a microfluidic direct methanol fuel cell based on polydimethylsiloxane. Microsyst. Technol. 2014, 20, 493-498. [CrossRef]

316. Felix, C.; Jao, T.C.; Pasupathi, S.; Linkov, V.M.; Pollet, B.G. Fabrication of gas diffusion electrodes via electrophoretic deposition for high temperature polymer electrolyte membrane fuel cells. J. Power Sources 2014, 258, 238-245. [CrossRef]

317. Yu, Y.T.; Song, J.C.; Kim, J.H.; Kim, Y.S.; Lee, H.G. Nano-architecture platinum catalyst layer prepared by electrophoresis deposition for PEM fuel cells. J. Solid-State Electrochem. 2012, 16, 1377-1381. [CrossRef]

318. Adilbish, G.; Kim, J.W.; Lee, H.G.; Yu, Y.T. Effect of the deposition time on the electrocatalytic activity of $\mathrm{Pt} / \mathrm{C}$ catalyst electrodes prepared by pulsed electrophoresis deposition method. Int. J. Hydrogen Energy 2013, 38, 3606-3613. [CrossRef]

319. Zheng, J.S.; Wang, M.X.; Zhang, X.S.; Wu, Y.X.; Li, P.; Zhou, X.G.; Yuan, W.K. Platinum/carbon nanofiber nanocomposite synthesized by electrophoretic deposition as electrocatalyst for oxygen reduction. J. Power Sources 2008, 175, 211-216. [CrossRef]

320. Qin, Y.H.; Yang, H.H.; Zhang, X.S.; Li, P.; Zhou, X.G.; Niu, L.; Yuan, W.K. Electrophoretic deposition of network-like carbon nanofibers as a palladium catalyst support for ethanol oxidation in alkaline media. Carbon 2010, 48, 3323-3329. [CrossRef]

321. Seger, B.; Kamat, P.V. Electrocatalytically Active Graphene-Platinum Nanocomposites. Role of 2-D Carbon Support in PEM Fuel Cells. J. Phys. Chem. C 2009, 113, 7990-7995. [CrossRef]

322. Liu, S.; Wang, J.; Zeng, J.; Ou, J.; Li, Z.; Liu, X.; Yang, S. “Green” electrochemical synthesis of Pt/graphene sheet nanocomposite film and its electrocatalytic property. J. Power Sources 2010, 195, 4628-4633. [CrossRef]

323. Chartarrayawadee, W.; Moulton, S.E.; Li, D.; Too, C.O.; Wallace, G.G. Novel composite graphene/platinum electro-catalytic electrodes prepared by electrophoretic deposition from colloidal solutions. Electrochim. Acta 2012, 60, 213-223. [CrossRef]

324. Vinodgopal, K.; Haria, M.; Meisel, D.; Kamat, P. Fullerene-Based Carbon Nanostructures for Methanol Oxidation. Nano Lett. 2004, 4, 415-418. [CrossRef]

325. Girishkumar, G.; Viodgopal, K.; Kamat, P.V. Carbon Nanostructures in Portable Fuel Cells: Single-Walled Carbon Nanotube Electrodes for Methanol Oxidation and Oxygen Reduction. J. Phys. Chem. B 2004, 108, 19960-19966. [CrossRef]

326. Gewirth, A.A.; Thorum, M.S. Electroreduction of Dioxygen for Fuel-Cell Applications: Materials and Challenges. Inorg. Chem. 2010, 49, 3557-3566. [CrossRef] [PubMed]

327. Chen, Z.W.; Higgins, D.; Yu, A.P.; Zhang, L.; Zhang, J.J. A review on non-precious metal electrocatalysts for PEM fuel cells. Energy Environ. Sci. 2011, 4, 3167-3192. [CrossRef] 
328. Yang, S.; Feng, X.; Wang, X.; Muellen, K. Graphene-Based Carbon Nitride Nanosheets as Efficient Metal-Free Electrocatalysts for Oxygen Reduction Reactions. Angew. Chem. Int. Ed. 2011, 50, 5339-5343. [CrossRef] [PubMed]

329. Chi, B.; Li, J.; Yang, X.; Lin, H.; Wang, N. Electrophoretic deposition of $\mathrm{ZnCo}_{2} \mathrm{O}_{4}$ spinel and its electrocatalytic properties for oxygen evolution reaction. Electrochim. Acta 2005, 50, 2059-2064. [CrossRef]

330. Fayette, M.; Nelson, A.; Robinson, R.D. Electrophoretic deposition improves catalytic performance of $\mathrm{Co}_{3} \mathrm{O}_{4}$ nanoparticles for oxygen reduction/oxygen evolution reactions. J. Mater. Chem. A 2015, 3, 4274-4283. [CrossRef]

331. Suryanto, B.H.; Lu, X.; Zhao, C. Layer-by-layer assembly of transparent amorphous $\mathrm{Co}_{3} \mathrm{O}_{4}$ nanoparticles/graphene composite electrodes for sustained oxygen evolution reaction. J. Mater. Chem. A 2013, 1, 12726-12731. [CrossRef]

332. Neirinck, B.; Biest, O.V.D.; Vleugels, J. A Current Opinion on Electrophoretic Deposition in Pulsed and Alternating Fields. J. Phys. Chem. B 2013, 117, 1516-1526. [CrossRef] [PubMed]

333. Kaprans, K.; Bajars, G.; Kucinskis, G.; Dorondo, A.; Mateuss, J.; Gabrusenoks, J.; Kleperis, J.; Lusis, A. Electrophoretic Nanocrystalline Graphene Film Electrode for Lithium Ion Battery. Mater. Sci. Eng. 2015, 77, 012042. [CrossRef]

334. Kotobuki, M. Preparation of Composite $\mathrm{Li}_{4} \mathrm{Ti}_{5} \mathrm{O}_{12}$ Electrode for Lithium Rechargeable Batteries by Electrophoretic Deposition. J. Funct. Mater. Res. 2013, 1, 1-5. [CrossRef]

335. Wu, M.S.; Ou, Y.H.; Lin, Y. Electrodeposition of iron oxide nanorods on carbon nanofiber scaffolds as an anode material for lithium-ion batteries. Electrochim. Acta 2010, 55, 3240-3244. [CrossRef]

336. Cabanas-Pola, S.; Gonzalezb, Z.; Sanchez-Herenciab, F.J.; Ferrarib, B.; Caballeroc, A.; Hernánc, L.; Morales, J. Cyclability of binder-free $\beta-\mathrm{Ni}(\mathrm{OH})_{2}$ anodes shaped by EPD for Li-ion batteries. J. Eur. Ceram. Soc. 2015, 35, 573-584. [CrossRef]

337. Park, S.H.; Lee, W.J. Hierarchically mesoporous carbon nanofiber $/ \mathrm{Mn}_{3} \mathrm{O}_{4}$ coaxial nanocables as anodes in lithium ion batteries. J. Power Sources 2015, 281, 301-309. [CrossRef]

338. Park, S.H.; Lee, W.J. Coaxial carbon nanofiber/NiO core-shell nanocables as anodes for lithium ion batteries. RSC Adv. 2015, 5, 23548-23555. [CrossRef]

339. Park, S.H.; Lee, W.J. Hierarchically mesoporous flower-like cobalt oxide/carbon nanofiber composites with shell-core structure as anodes for lithium ion batteries. Carbon 2015, 89, 197-207. [CrossRef]

340. Hao, J.; Li, N.; Ma, X.; Liu, X.; Liu, X.; Li, Y.; Xu, H.; Zhao, J. Ionic liquid electrodeposition of germanium/carbon nanotube composite anode material for lithium ion batteries. Mater. Lett. 2015, 144, 50-53. [CrossRef]

341. Yang, Y.; Li, J.; Chen, D.; Fu, T.; Sung, D.; Zhao, J. Binder-Free Carbon-Coated Silicon-Reduced Graphene Oxide Nanocomposite Electrode Prepared by Electrophoretic Deposition as a High-Performance Anode for Lithium-Ion Batteries. ChemElectroChem 2016, 3, 757-763. [CrossRef]

342. Dinh, T.M.; Armstrong, K.; Guay, D.; Pech, D. High-resolution on-chip supercapacitors with ultra-high scan rate ability. J. Mater. Chem. A 2014, 2, 7170-7174. [CrossRef]

343. Santhanagopalan, S.; Teng, F.; Meng, D.D. High-Voltage Electrophoretic Deposition for Vertically Aligned Forests of One-Dimensional Nanoparticles. Langmuir 2011, 27, 561-569. [CrossRef] [PubMed]

344. Talib, E.; Azam, M.A. An extensive study on carbon nanomaterials electrode from electrophoretic deposition technique for energy storage device. J. Mater. Res. 2016, 31, 1972-1982. [CrossRef]

345. Novoselov, K.S.; Geim, A.K.; Morozov, S.V.; Jiang, D.; Zhang, Y.; Dubonos, S.V.; Grigorieva, I.V.; Firsov, A.A. Electric Field Effect in Atomically Thin Carbon Films. Science 2004, 306, 666-669. [CrossRef] [PubMed]

346. Chen, Y.; Zhang, X.; Yu, P.; Ma, Y. Electrophoretic deposition of graphene nanosheets on nickel foams for electrochemical capacitors. J. Power Sources 2010, 195, 3031-3035. [CrossRef]

347. Dou, Y.Y.; Luo, M.; Liang, S.; Zhang, X.L.; Ding, X.Y.; Liang, B. Flexible free-standing graphene-like film electrode for supercapacitors by electrophoretic deposition and electrochemical reduction. Trans. Nonferrous Met. Soc. 2014, 24, 1425-1433. [CrossRef]

348. Wang, S.; Pei, B.; Zhao, X.; Dryfe, R.A.W. Highly porous graphene on carbon cloth as advanced electrodes for flexible all-solid-state supercapacitors. Nano Energy 2013, 2, 530-536. [CrossRef]

349. Boccaccini, A.R.; Dickerson, J.H.; Ferrari, B.; Biest, O.V.; Uchikoshi, T. Nickel Oxide/Nickel Foam Composite as Supercapacitor Electrode via Electrophoretic Deposition. Key Eng. Mater. 2015, 254, 58-64. 
350. Lake, J.R.; Cheng, A.; Selverston, S.; Tanaka, Z.; Joehne, J.; Meyyappan, M.; Chen, B. Graphene metal oxide composite supercapacitor electrodes. J. Vac. Sci. Technol. B 2012, 30, 03D118. [CrossRef]

351. Sugimoto, W.; Yokoshima, K.; Ohuchi, K.; Murakami, Y.; Takasu, Y. Fabrication of Thin-Film, Flexible, and Transparent Electrodes Composed of Ruthenic Acid Nanosheets by Electrophoretic Deposition and Application to Electrochemical Capacitors. J. Electrochem. Soc. 2006, 153, A255-A260. [CrossRef]

352. Li, J.; Zhitomirsky, I. Cathodic electrophoretic deposition of manganese dioxide films. Colloids Surf. A Physicochem. Eng. Asp. 2009, 348, 248-253. [CrossRef]

353. Ammam, M.; Fransaer, J. Ionic Liquid-Heteropolyacid: Synthesis, Characterization, and Supercapacitor Study of Films Deposited by Electrophoresis. J. Electrochem. Soc. 2011, 158, A14-A21. [CrossRef]

354. Hung, C.J.; Lin, P.; Tseng, T.Y. High energy density asymmetric pseudocapacitors fabricated by graphene/carbon nanotube $/ \mathrm{MnO}_{2}$ plus carbon nanotubes nanocomposites electrode. J. Power Sources 2014, 259, 145-153. [CrossRef]

355. Ghasemi, S.; Hosseini, S.R.; Sen, P. Preparation of graphene/nickel-iron hexacyanoferrate coordination polymer nanocomposite for electrochemical energy storage. Electrochim. Acta 2015, 160, 337-346. [CrossRef]

356. Kong, S.; Cheng, K.; Ouyang, T.; Gao, Y.; Ye, K.; Wang, G. Facile electrodepositing processed of $\mathrm{RuO}_{2}$-graphene nanosheets-CNT composites as a binder-free electrode for electrochemical supercapacitors. Electrochim. Acta 2017, 246, 433-442. [CrossRef]

357. Liu, C.; Yu, Z.; Neff, D.; Zhamu, A.; Jang, B.Z. Graphene-Based Supercapacitor with an Ultrahigh Energy Density. Nano Lett. 2010, 10, 4863-4868. [CrossRef] [PubMed]

358. Yu, D.; Dai, L. Self-Assembled Graphene/Carbon Nanotube Hybrid Films for Supercapacitors. J. Phys. Chem. Lett. 2010, 1, 467-470. [CrossRef]

359. Grunbaum, N.; Dessemond, L.; Fouletier, J.; Prado, F.; Caneiro, A. Electrode reaction of $\mathrm{Sr}_{1-\mathrm{x}} \mathrm{La}_{\mathrm{x}} \mathrm{Co}_{0.8} \mathrm{Fe}_{0.2} \mathrm{O}_{3-\delta}$ with $\mathrm{x}=0.1$ and 0.6 on $\mathrm{Ce}_{0.9} \mathrm{Gd}_{0.1} \mathrm{O}_{1.95}$ at $600 \leq \mathrm{T} \leq 800{ }^{\circ} \mathrm{C}$. Solid State Ion. 2006, 177, 907-913. [CrossRef]

(C) 2018 by the authors. Licensee MDPI, Basel, Switzerland. This article is an open access article distributed under the terms and conditions of the Creative Commons Attribution (CC BY) license (http:/ / creativecommons.org/licenses/by/4.0/). 